San Jose State University

SJSU ScholarWorks

Master's Theses

Master's Theses and Graduate Research

1995

\title{
Batch distillation simulation using the quasi-state column approximation
}

Keith A. Freidman

San Jose State University

Follow this and additional works at: https://scholarworks.sjsu.edu/etd_theses

\section{Recommended Citation}

Freidman, Keith A., "Batch distillation simulation using the quasi-state column approximation" (1995). Master's Theses. 1141.

DOI: https://doi.org/10.31979/etd.6hzp-ns5b

https://scholarworks.sjsu.edu/etd_theses/1141

This Thesis is brought to you for free and open access by the Master's Theses and Graduate Research at SJSU ScholarWorks. It has been accepted for inclusion in Master's Theses by an authorized administrator of SJSU ScholarWorks. For more information, please contact scholarworks@sjsu.edu. 


\section{INFORMATION TO USERS}

This manuscript has been reproduced from the microfilm master. UMI films the text directly from the original or copy submitted. Thus, some thesis and dissertation copies are in typewriter face, while others may be from any type of computer printer.

The quality of this reproduction is dependent upon the quality of the copy submitted. Broken or indistinct print, colored or poor quality illustrations and photographs, print bleedthrough, substandard margins, and improper alignment can adversely affect reproduction.

In the unlikely. event that the author did not send UMI a complete manuscript and there are missing pages, these will be noted. Also, if unauthorized copyright material had to be removed, a note will indicate the deletion.

Oversize materials (e.g., maps, drawings, charts) are reproduced by sectioning the original, beginning at the upper left-hand corner and contimuing from left to right in equal sections with small overlaps. Each original is also photographed in one exposure and is included in reduced form at the back of the book.

Photographs included in the original manuscript have been reproduced xerographically in this copy. Higher quality $6^{n} \times 9^{n}$ black and white photographic prints are available for any photographs or illustrations appearing in this copy for an additional charge. Contact UMI directly to order.

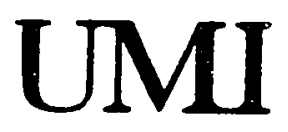

A Bell \& Howell information Company

300 North Zeeb Road. Ann Afbor. MI 48106-1346 USA

313:761-4700 800:521-0600 



\title{
BATCH DISTILLATION SIMULATION USING \\ THE QUASI-STEADY-STATE COLUMN APPROXIMATION
}

\author{
A Thesis \\ Presented to \\ The Faculty of the Department of Chemical Engineering \\ San Jose State University \\ In Partial Fulfillment \\ of the Requirements for the Degree \\ Master of Science
}

by

Keith A. Friedman

December 1995 
UMI Number: 1377232

UMI Microform 1377232

Copyright 1996, by UMI Company. All rights reserved. This microform edition is protected against unauthorized copying under Title 17, United states Code.

\section{UMI \\ 300 North Zeeb Road \\ Ann Arbor, MI 48103}


(C) 1995

Keith A. Friedman

ALL RIGHTS RESERVED 
Approved for the

Department of Chemical Engineering

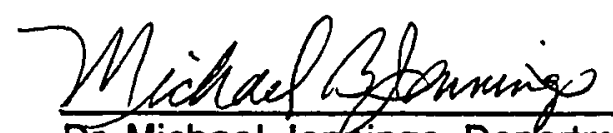

Dr. Michael Jenthings, Department Chair and Research Advisor

Robut R. Rumic

Dr. Robert Romig, Professor

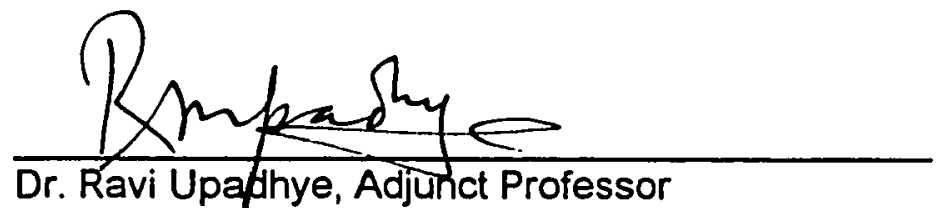

Dr. Ravi Upadahye, Adjunct Professor

Approved for the University

$\frac{\text { Derenc Nr. tanfore }}{7}$ 


\begin{abstract}
BATCH DISTILLATION SIMULATION USING

THE QUASI-STEADY-STATE COLUMN APPROXIMATION

by Keith $A$. Friedman
\end{abstract}

Since the 1960's, batch distillation column design has been aided by computer solution of rigorous fully-dynamic process models. Recently, researchers have substantially increased the speed of batch distillation simulation through the use of the quasi-steady-state column approximation (QSSCA) approach. This approximation says that the transient behavior of the column can be neglected relative to transients in the boiler, when the material holdup in the column is much smaller than that in the boiler.

Despite its advantages and successes, batch distillation simulation using the QSSCA approach is not readily available to working chemical engineers using common flowsheet simulators. Therefore, the QSSCA approach to batch distillation simulation was implemented and investigated on a prototypical process simulator, ASPEN PLUS. The implementation is presented and illustrated with examples. It was tested it on published case studies of batch distillation. The results compare favorably with experimental data and other simulations. 


\section{ACKNOWLEDGMENTS}

- San Jose State University professors Mike Jennings, Robert Romig and Ravi Upadhye provided support and advice. The SJSU Chemical Engineering department provided an outstanding educational environment.

- Aspen Technology provided a student-version of ASPEN Plus and technical assistance.

- Other investigators' published work guided mine, particularly that of Galindez and Fredenslund, Domenech and Enjalbert, and Diwekar and Madhavan.

- Friends encouraged and assisted, particularly Robert and Blanche Friedman, Connie Yokum, John Stillian and Ruth Siegel.

- Dionex Corporation provided tuition reimbursement, and access to literature searching and computers, after-hours.

- Alameda Instruments, especially Dan Hugens, Robert Shinagawa and Scott Amundson, provided financial support and experimental data. (Alameda Instruments is now part of Athens Corp.)

- Almost twenty years later, I can still remember how much fun I had writing my first programs in professor Donald Hanson's distillation class at U.C. Berkeley. 


\section{TABLE OF CONTENTS}

1 Introduction 1

1.1. Batch Distillation Review 1

1.2 Simulation of Batch Distillation 4

1.3 Research Objective and Hypotheses 8

1.4 Additional Advantages of this Effort 9

2 Literature Review 11

2.1 Rayleigh Equation for a Simple Batch Still 11

2.2 Early Models of Batch Rectification 13

$\begin{array}{ll}2.3 & \text { Investigations of Hold-up Effects } \\ 2.4 & 15\end{array}$

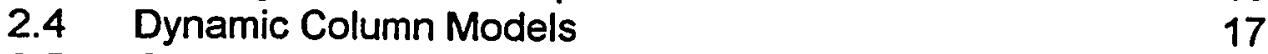

2.5 Quasi-Steady-State Column Models 20

3 Methods Development 23

3.1 Simulating Batch Processes with Steady-State Models 23

3.2 Implementing this Batch Simulation Approach 34

3.3 Numerical Integration with a Flowsheet Simulator 41

4 Tests, Results and Discussion 46

4.1 Description of the Tests 46

4.2 Results and Discussion 53

5 Conclusions on Hypotheses 65

Appendix A: Example of Simulator Output 69

$\begin{array}{ll}\text { Appendix B: Collection of Simulations } & 138\end{array}$

$\begin{array}{ll}\text { References } & 156\end{array}$ 


\section{CHAPTER 1. INTRODUCTION}

Since the 1960's, computers have aided the design of batch distillation columns by solving rigorous, fully dynamic (RFD) process models. Recently, researchers have substantially increased the speed of batch distillation simulations with the quasi-steady-state column approximation (QSSCA) approach. This thesis pursues this research by investigating a particularly advantageous implementation of the QSSCA approach.

This chapter introduces and outlines this work. To justify the effort, the first section describes the importance of batch distillation and the need for process simulation. The second section surveys modern methods of batch distillation simulation, including the RFD and QSSCA approaches. This survey reveals an important direction for extension of the state-of-the-art: implementation of the QSSCA approach on a general-purpose process simulator (GPPS). This is the objective of this thesis. The third section presents the primary research objective and corresponding hypotheses associated with this investigation. Besides investigating a simulation approach, this work has other implicit benefits that are described in the fourth section of this chapter.

\subsection{Batch Distillation Review}

Dictionaries (Lapedes, 1978; Mish, 1983) define distillation as a process of applying heat and boiling a liquid mixture, and then condensing the vapor to progressively separate the mixture components by differences in their volatilities. 
Distillation is also known as fractionation or rectification, and distillation columns are also called towers or stills. Distillation can be continuous, with continuous feed to a column whose conditions are steady-state. Alternatively, it can be discontinuous, with a batch of feed loaded into the boiler at the beginning and column conditions changing as distillation proceeds.

Continuous or discontinuous, distillation is a superior separation process. In his book Separation Processes, C. Judson King (1971) states:

"Distillation is an energy-separating-agent equilibration process, and hence is desirable from an energy consumption viewpoint when staging is required. Distillation involves no solid phases, and hence enjoys an advantage relative to crystallization, which is another energy-separating-agent equilibration process. No contaminating mass-separating-agent is added in distillation, and it is easily staged within a single vessel. Because of this favorable combination of factors, it is no accident that distillation is the most frequently used separation process in practice, at least for large-scale operations. In fact, a sound approach to the selection of appropriate separation processes is to begin by asking 'Why not distillation?"

While continuous distillation dominates in large-scale operations, batch distillation has economical and operational advantages in many small-scale applications. Diwekar and Madhavan (1991c) state: "Batch distillation is preferable to continuous distillation where small quantities of high technology (and/or) high value-added chemicals and biochemicals are to be separated. The batch unit requires less capital for separating relatively pure components." Luyben (1988) echoes: "Even though batch distillation typically consumes more energy than continuous distillation, it provides more flexibility and involves less capital investment. Since energy costs are not too significant in small-volume, high- 
value products, batch distillation is often attractive for this class of products. ${ }^{n}$ AlTuwaim and Luyben (1991) explain: "...a single column can handle any number of components. To achieve the same results using a continuous distillation system, NC-1 columns would typically be required for a system of NC components." They continue: "Batch distillation columns play an important role in batch processes." Galindez and Fredenslund (1988b) explain:

"Batch distillation may be preferable to continuous distillation where relatively small quantities of material are to be separated at irregularly scheduled periods. The most outstanding attribute of batch distillation is its flexibility. Little change is required when switching from one mixture to another. Reflux ratio and throughput can be varied easily. No balance of feed and drawoff need be maintained. In situations where the composition of the feed may change frequently or where different mixtures must be handled, the versatility of the batch distillation unit is excellent."

One can envision a plant producing specialty chemicals where a few batch stills separate the products of many different batch reactors. Such a plant would enjoy these economical and operational advantages.

These advantages have placed batch distillation in many important applications. "Batch distillation is one of the most widely used separation processes in the manufacture of specialty chemicals. Specialty chemicals represent about $15 \%$ of worldwide chemicals production, with approximately $\$ 150$ billion produced annually" (Sundaram and Evans, 1993). Hard liquor is a commodity chemical produced by batch distillation. Recovery of acids in semiconductor processing is an example of batch distillation used for recycling wastes (Davison, 1992; SF Examiner, 1990). 


\subsection{Simulation of Batch Distillation}

Batch distillation is an important process; however, it is not a simple one. Luyben (1988) and Al-Tuwaim and Luyben (1991) state:

"The batch distillation process is characterized by unsteady-state conditions. This means that the compositions are functions of time. A large number of design and operating parameters must be optimized in order to design and operate the column: the number of trays, the size of the initial charge to the still pot, and the reflux ratio as a function of time (during product withdrawal periods and during the slop-cut periods)."

Because the process is so complex, optimal design and operation require analysis, not just experience. Sundaram and Evans (1993) state:

"In contrast to continuous distillation, until recently there have been few computer tools available for computer simulation and optimization of batch distillation. Batch distillations are performed based on trial and error experience, and the operation can be far from the economical optimum. There is a real need for systematic methodologies for the design and operation of batch separations."

Process simulation entails three basic steps: 1) formulating a mathematical model of a physical process, 2) specifying process conditions as inputs to the model, and 3) solving the model to see how the process behaves. Using the Hagen-Poiseuille equation with a specified pressure drop to calculate flowrate through a pipe is a simple process simulation (Bird, et al., 1960). Writing a FORTRAN program, specifying feed and pressure, and calculating the products of an adiabatic flash is a more involved process simulation. Calculating the compositions and states of streams in a process plant using a general purpose flowsheet simulator is an example of large-scale process simulation. 
Simulation is fundamental to engineering practice, because it predicts process behavior. The ASPEN PLUS Manual (1987) describes the benefits of process simulation:

"During process design, once the decision has been made to build a new plant or to modernize an existing plant, ASPEN PLUS models may be used to study trade-offs, to investigate off-design operation, and to investigate the flexibility of the plant to handle a range of feedstocks. Simulation studies during process design can avoid costly mistakes before committing to plant hardware. Process engineers can use a simulation model to optimize the design of their process by making a series of case studies to ensure that the plant will work properly under a wide range of operating conditions.

For an existing plant, an ASPEN PLUS model can serve as a powerful tool for plant engineers to improve plant operations, to improve yield and throughput, and to reduce energy use. The model can be used to determine changes in operating conditions needed to accommodate changes in feedstocks, changes in product requirements, and changes in environmental conditions. The model can guide plant operations to reduce costs and improve productivity. Finally, the modeling can be used to study possible plant modifications for 'debottlenecking' or for revamping the plant to incorporate technology advances such as an improved catalyst, a new solvent to a new process unit."

Both process simulation and pilot-scale experiments can supply the information necessary for process design or optimization. Experiments are frequently expensive, time-consuming, and are often impossible in operating plants. Process simulation is indispensable to engineering practice, for situations where experiment is impracticable.

\subsubsection{Batch Distillation Simulation with Rigorous Fully Dynamic (RFD) Models}

Current batch distillation simulations use the rigorous, fully dynamic or quasi-steady-state column approximation methods. The RFD approach entails deriving the set of differential and algebraic equations that describe the process 
and solving the system numerically. This set of equations includes: 1)material and energy balances, 2) vapor-liquid equilibria, 3) mass and heat transfer relations and 4) fluid dynamics equations. This approach has been successful for batch distillation simulation in numerous applications (see Chapter 2).

RFD is a successful, but complex technique for batch distillation simulation. According to Seider (1984):

"(The programs) require lengthy operation of large computers ... The equations may be difficult to integrate rapidly and accurately because they may constitute a so-called stiff system as considered by Gear (1971). When such systems are integrated by simple explicit methods, the time step cannot be too large or small, or the solution will suffer from instability or truncation-error."

The fully dynamic approach buys rigor for speed, which is a reasonable exchange, especially when closely analyzing one column under one set of conditions. Engineers often need to solve their models tens or hundreds of times when optimizing column design or operating conditions or when evaluating a control strategy, and then the calculation time takes its toll. Diwekar (1991a) states: "Another major issue in batch process design or synthesis is operational flexibility, which gives rise to a large number of alternative evaluations. Use of rigorous models becomes prohibitively expensive because of large computational efforts involved and extensive data and memory requirements." This burden drives some to forsake the rigorous model approach for faster methods such as the quasi-steady-state column approximation approach. 


\subsubsection{Quasi-Steady-State Column Approximation (QSSCA) Models}

The QSSCA approach speeds calculations by exploiting the stiffness of the system. L.M. Rose (1985) explains:

"... the system of differential equations (has) two regions for the time constants. The hold-up equations (describing column trays) have time constants in seconds and the (equations describing) boiler contents (have time constants) in hours. An established technique for treating systems with two ranges of time constants is to assume that the set with the small time constant so quickly approaches equilibrium that during a large time step appropriate for the large time constant system, the variables associated with the smaller time constant remains constant. Hence, ... the column calculation reverts to the same set of equations as for continuous distillation."

This approach inherently can run much faster than an RFD simulation because it eliminates most of the differential equations, and the ones that remain have longer time constants, appropriate for the boiler. In addition, the QSSCA approach can take advantage of specialized programs for solving continuous distillation problems. These programs are much faster and more stable than the general prograrns for solving systems of ordinary differential equations used in the RFD approach.

The QSSCA approach has simulated batch distillation in many applications (see Chapter 2). Though fast and popular, the steady column approach has drawbacks, because it forgoes dynamic description of the column and therefore relinquishes information on the time to start-up or respond to changes. Holdup has some effects on separation and thus can affect accuracy of simulation, in some cases. These are reasons to do preliminary work with the speed of the steady approach and finally check the simulation with the accuracy of the fully 
dynamic approach.

Despite its advantages and successes, batch distillation simulation using the QSSCA approach is not easily available to working chemical engineers who use common flowsheet simulators. The major American process simulation packages use RFD-based simulations, such as BATCHFRAC in ASPEN PLUS (Boston et al., 1981). A comprehensive literature search found that simulation using the QSSCA is in only one flowsheet simulator, SIMBAD, by academics in Argentina (Chiotti and Scenna, 1989). Publications on the QSSCA-based simulations describe its results in detail, but they are sketchy about the procedures. The papers review the principles, but this generally is not sufficient to instruct a chemical engineer on construction of his or her own simulation program. Thus, there is an unmet need for an easy procedure for implementing batch distillation simulation using the QSSCA in a widely available flowsheet simulator.

\subsection{Research Objective and Hypotheses}

This research has an objective to develop and investigate a straight-forward implementation of the quasi-steady-state column approximation approach to batch distillation simulation on a commercial modular process simulator.

To achieve this objective, the following hypotheses are evaluated:

1) A batch distillation simulation based on the QSSCA approach can be implemented on a prototypical, commercial, modular process simulator.

2) Results from this simulator are comparable with the results of published simulations using the QSSCA approach. 
3) A general paradigm can be illustrated to facilitate implementation of this simulation technique.

Terms in the hypotheses are defined as follows:

Batch distillation simulation based on the QSSCA approach is the prediction of distillate or tops and raffinate or bottoms composition and volume during the process.

The quasi-steady-state column approximation states that transitory behavior of the column is so brief that it can be neglected relative to longer transients in the boiler, because material holdup in the rectification column is negligible compared with the holdup in the boiler.

Implementation means developing the model using the primary commands available in the simulation language without writing specific modules in a lower-level programming language, such as FORTRAN.

ASPEN PLUS is a prototypical, commercial flowsheet simulator, because it is one of the major, commercial simulators widely available in the United States. Comparison with other results is comparison of the course of distillate and boiler composition and volume predicted by this simulation with published values from experiments and other simulations.

\subsection{Additional Advantages of this Effort}

Besides meeting these needs, other advantages accrue from integrating batch distillation simulation using the QSSCA approach into a general-purpose process simulator (GPPS). Integration transparently incorporates batch distilla- 
tion results into simulation of a complete process. It gives the batch distillation simulator access to the continuous distillation routines and physical property models and databases in the GPPS. These modules are some of the best available, and they are continuously maintained and improved by the GPPS vendor. Availability of batch distillation simulation by both QSSCA and RFD approaches on one GPPS allows quick calculations by QSSCA to optimize preliminary design, and more rigorous calculations by RFD to check final design.

Besides creating a design tool, this investigation suggests the parameters that are important in the implementation of the approach and their effects on the calculations. Significant parameters may include: 1) step-size for integrating composition change in the boiler, 2) model for the steady-state distillation column, and 3) details of programming on the process simulator. The implementation procedure and the identification of important parameters are generally applicable principles that apply to other GPPS's besides ASPEN PLUS.

This approach probably is widely applicable, but it surely is not universal. Therefore, in each new application, the user must independently assess the accuracy of its predictions before using it for design. 


\section{CHAPTER 2. LITERATURE REVIEW}

This review traces the history of batch distillation simulation, based on a general literature search and specific reviews by Seader (1984), Diwekar and Madhavan (1991c), Sundaram and Evans (1993) and others. It also compares the primary, current simulation techniques: the fully dynamic and quasi-steadystate approaches.

\subsection{Rayleigh Equation for a Simple Batch Still}

Mathematical modeling of batch distillation began with the analysis of a simple batch still: a boiler directly connected to a condenser. The first publication was Lord Rayleigh's 1902 paper "On the Distillation of Binary Mixtures." "Young (1922), Rosanoff (and coworkers) (1914), Lewis (1909), Lewis and Robinson (1922), and Peters (1923) all discussed the theory of...simple distillation," according to Rose and Welshans (1940a).

Lord Rayleigh's analysis applies to multicomponent as well as binary mixtures. This simple yet rigorous treatment begins with overall and component material balances on the boiling liquid. In the following equations, $V$ and $L$ are the mols of vapor and liquid, and $x$ and $y$ are the instantaneous vapor and liquid mol fractions, respectively. The overall balance states: the increment of vapor (dV) equals the decrement of remaining liquid in the still (dL).

$$
\mathrm{dV}=-\mathrm{dL}
$$


The component balance states: the increase of a component in the vapor ( $y \mathrm{dV})$ equals the decrease of that component in the liquid $(d(L x))$. This equals the component's mole fraction times the moles of liquid decrement (xdL) added to the decrease in the component's mole fraction multiplied by the moles of liquid remaining (Ldx).

$$
y d V=-d(L x)=-(x d L+L d x)
$$

Combining and rearranging these differential balances to eliminate $d V$ yields:

$$
\begin{aligned}
& -y d L=-(x d L+L d x) \\
& (x-y) d L=-L d x \\
& \frac{-d L}{L}=\frac{d x}{(x-y)} \\
& \int_{L 0}^{L} \frac{-d L}{L}=\ln \left(\frac{L 0}{L}\right)=\int_{x_{0}}^{x} \frac{d x}{(x-y)}
\end{aligned}
$$

The last equation can be integrated from the beginning of distillation at time zero, when $L$ is $L_{0}, x$ is $x_{0}$ and $y$ is $y_{0}$, to some later time. Integration of the left-handside results in a logarithmic relationship, $\ln \left(L_{0} / L\right)$. The right-hand-side, $\int d x /(x-y)$, can be integrated with a vapor-liquid equilibrium function, assuming well-mixed vapor and liquid phases and specified pressure. Integration always can be performed numerically or graphically. For mixtures with constant relative volatility's, simplified analytical expressions can be found for the integrals (Seader, 1988). This integral equation relates liquid and vapor compositions to liquid boil-up. 
The integrated energy balance relates boil-up to the known heat rate to the still. Integrating liquid boil-up with the equilibrium vapor composition finds the accumulated distillate composition.

\subsection{Early Models of Batch Rectification}

The simple batch still has limited utility because it consists only one separation stage. Finer separation requires a rectifying column that includes numerous stages on top of the boiler. Mathematical modeling of batch rectification began in the late 1930's and 1940's, when investigators developed design methods for stills operating with either 1) substantially total reflux, 2) varying reflux and constant distillate composition, or 3) constant reflux and varying distillate composition. By 1940, Rose derived "a general expression for the calculation of such batch distillation curves (composition of distillate cuts plotted against percentage of charge distilled), and the calculations for certain limiting cases of distillation under substantially total reflux," according to Smoker and Rose (1940). In 1940, Rose and Welshans used Fenske's total reflux equation to find the relationship between boiler and distillate composition and investigated the effects of relative volatility and number of plates on the sharpness of separation. In 1937, Bogart developed a design method for a batch rectification producing constant overhead composition by increasing the reflux ratio. Figure 2-1 illustrates this operation on a McCabe-Thiele (1925) $x-y$ diagram with an equilibrium curve, a 45-degree or total reflux line and several operating lines (Seader, 1984). 
Figure 2-1. McCabe-Thiele Diagrams for Batch Distillation
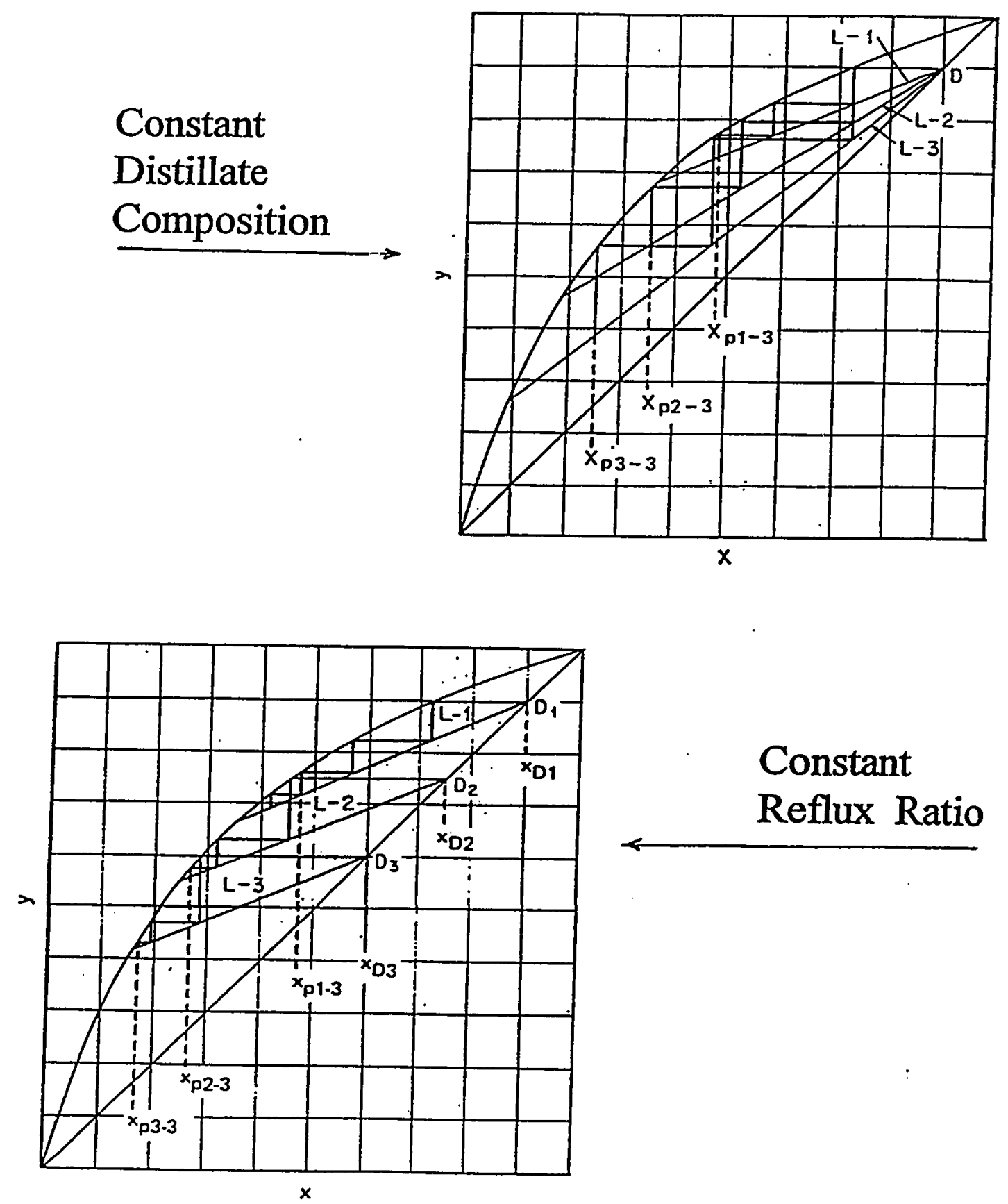
Perry's Handbook (1984) describes the basis of the McCabe-Thiele diagram. The operating line slope is the ratio of liquid to vapor flows. This slope increases during distillation and generates a family of operating lines. The operating lines all intersect the 45-degree line at the constant overhead composition. From this intersection, the column's theoretical plates are stepped-off between the operating line and the equilibrium curve to find the boiler composition. In 1940, Smoker and Rose modeled batch rectification with (finite) constant reflux ratio, and therefore changing distillate composition. Their method uses a McCabe Thiele diagram to find the relationship between boiler and distillate composition for integration of the Rayleigh equation. Their $x-y$ diagram, Figure 2-1, also has an equilibrium curve, a 45-degree line and several operating lines (Seader, 1984). The operating line slope is the constant liquid-to-vapor flow ratio. The intersection of the operating and 45-degree lines is the distillate composition, which becomes increasingly concentrated with the less volatile component as distillation proceeds, generating a family of operating lines. From the distillate intersection, the column's theoretical plates are stepped-off between the operating line and the equilibrium curve to find the boiler composition.

\subsection{Investigations of Hold-up Effects}

McCabe-Thiele graphical methods are only exact for an ideal binary system with equimolal overflow in an adiabatic column with negligible holdup and uniform pressure. Column holdup is the inventory of liquid and vapor in the trays 
or packing and condenser. In 1940, Rose and Welshans extended their model of batch distillation with substantially total reflux to include holdup. They found "that the size of the intermediate (slop) cut for maximum sharpness of separation (of a binary mixture) varies in an approximately linear fashion (increasing) with the holdup..." In 1941, Colburn and Stearns developed a theoretical and experimental basis for explaining the first two effects of holdup: provision of capacity or "inertia" in the column and depletion of lighter components from the charge in the boiler (Seader, 1988). "As both these effects occur at the same time and change in importance during the course of distillation, it is difficult, without rigorous calculations, to predict whether the overall effect of hold-up will be favorable or detrimental; it is equally difficult to estimate the magnitude of the holdup effect," according to Seader (1984).

This uncertainty, and the uncertainty encountered in applying McCabeThiele graphical methods approximately to systems violating their assumptions, encouraged over-design of batch distillation columns, that is, using too many stages or too much reflux. Elimination of these uncertainties motivated development of rigorous batch distillation models. Between 1950 and 1953, Rose, Johnson and Williams studied holdup effects experimentally and theoretically. They developed differential material balances, and solved them by plate-to-plate calculations, either by hand or on early IBM computers. In 1951, Pigford, Tepe and Garrahan predicted the effects of holdup by modeling a batch still with seven 
theoretical stages on a mechanical analog computer. They found "a general tendency for the size of the intermediate fraction (slop cut) to increase with increasing holdup,...(except) in the case of certain easy separations...(where) the size of the intermediate cut decreases at first and then increases with increasing holdup."

\subsection{Dynamic Column Models including Energy and Material Balance}

Rigorous mathematical models of batch distillation involve differential equations for overall and component material balance and energy balance in the boiler, column and condenser. In 1960, Huckaba and Danly simulated binary batch distillation with a computer program, performing mass and energy balances on trays with constant mass holdup, and validated their simulation with experimental data. In 1963, Meadows modeled multicomponent batch distillation, including mass, energy and volume balances on trays with constant volume holdup. In 1967, Barb and Holland modeled all phases of batch column operation, including startup and different product periods. Distefano extended Meadows' model in 1968, and successfully simulated several commercial batch distillation columns. "The Distefano model is the most cited rigorous model for batch distillation and most of the studies and simulation models that have appeared since 1968, e.g., Boston et al. (1981), are based on this model," according to Diwekar (1991a).

Batch distillation models are available in several commercial, general-pur- 
pose process simulators. CHEMCAD by Chemstations has "BATCH" for batch distillation simulation. PRO/II by Simulation Sciences has "BATCHSIM" which uses Distefano's model. ASPEN PLUS by Aspen Technology has "BATCHFRAC" which also uses Distefano's model. BATCHFRAC incorporates the specification flexibility found in continuous column simulators, according to Seader (1984):

"(BATCHFRAC) divides the batch distillation process into a sequence of operation steps. At the beginning of each step, the reboiler may receive an additional charge, distillate or sidestream receivers may be dumped, and a feed reservoir may be refilled. Specifications for an operation step include feed, sidestream withdrawal, and tray heat-transfer rates. In addition any two of the following five variables must be specified: reflux ratio, distillate rate, boil-up rate, condenser duty, and reboiler duty. Finally, column configuration and operating conditions (number of stages, holdups, tray pressures,...) can be changed at the beginning of each operation step. An operation step is terminated when a specified criterion, selected from the following list, is reached: a time duration; a component purity in the reboiler, distillate, or distillate accumulator; an amount of material in the reboiler or distillate accumulator; or a reboiler or condenser temperature."

In recent publications, researchers reported modeling batch distillation together with chemical reaction, packed columns and optimization of operating strategy. Ruby (1978), Egly (1979) and their coworkers, and Cuille and Reklaitis (1986) extended Meadows' model to account for liquid-phase chemical reactions. Reuter and colleagues (1989) used their approach to simulate esterification in a batch reaction driven to completion by distillation. In all the studies noted above, researchers derived their models for batch distillation in plate columns. Aly (1987, 1990a,b), Jahromi (1982), Domenech and their coworkers derived models 
for packed columns and found that axial dispersion is significant, but radial dispersion is negligible. In the late 1980's and the 1990's, some researchers saw their batch distillation models not as ends in themselves, but as tools for investigating the optimization of batch still design and operation. Luyben (1988) and Farhat and coworkers (1990) studied the effect of fixed and variable reflux ratio on the quantity of product produced, and Quintero-Marmol and Luyben (1990) and Mujtaba and Macchietto (1988) investigated slop-cut recycling strategies and found approaches that are significant improvements over simply adding the slop cut to the next batch. Diwekar and Madhavan (1991a,b,c) developed a short-cut method for preliminary design and analysis of batch columns. Diwekar and her associates $(1987,1989,1992)$ used this method to solve optimal design, operation and control problems.

The algebraic and ordinary differential equations in a rigorous batch distillation model constitute an initial value problem. It is generally impossible to solve these models analytically, because the equation set is very large, and the thermodynamic functions generally are nonlinear. Since the application of large digital computers to chemical engineering in the 1960s, numerical solutions have been developed; Meadows (1963) used finite differences, and Distefano $(1968 a, b)$ compared 11 methods. Their programs required "lengthy operation of large computers," because "the equations may be difficult to integrate rapidly and accurately because they may constitute a so-called stiff system as considered by 
Gear (1971)," according to Seader (1984). Boston (1978) invented an "insideout" algorithm, "...a robust and efficient method which could cope with the stiff nonlinear equations produced by the integration formula," according to Sundaram and Evans (1993). Others turned to stable implicit methods; for example, Gallun and Holland (1982) used an improved Gear method, Holland and Liapis (1983) and Reuter and coworkers (1989) used two-point implicit methods, Aly and colleagues (1987, 1990a,b) used a Galerkin-type finite element method, and Hitch and Rousseau (1988) used a relaxation method, which they described as slow but stable. Seeming to ignore the stiffness problem, Al-Tuwaim (1991), Luyben $(1988,1990)$ and Quintero-Marmol $(1990,1992)$ worked together and used a modified Euler method, but they frequently neglected energy balances and avoided nonlinear thermodynamics.

\subsection{Quasi Steady-State Column Models}

The fully dynamic approach obtains stability and rigor at the cost of speed. This is a reasonable exchange, especially when closely analyzing one column under one set of conditions. However, an engineer may solve a model tens or hundreds of times when optimizing column design or evaluating an operating strategy, and then the calculation time takes its toll. This burden drove Diwekar to replace the rigorous model approach with short-cut methods that approximate the column as a whole. Luyben grossly simplified his model to speed calculations, and others took the quasi-steady-state column approximation (QSSCA) 
approach.

The QSSCA approach speeds calculations by exploiting the stiffness of the system. Rose (1985) explains it, with reference to the relaxation method, but his discussion is generally applicable:

"(The) relaxation method is not a very quick way of achieving convergence in (a system of equations describing) a column, and this problem is magnified when it is coupled with the boiler mass balance equations. The resulting system is a system of differential equations with two regions for the time constants. The hold-up equations (describing column trays) have time constants in seconds and the (equations describing) boiler contents (have time constants) in hours. It is well known that such equations are difficult to integrate numerically (they are stiff), and the (time) step length must be very small and computer times correspondingly large.

The situation is intensified when packing is used for the column internals, because here the holdup is a thin film on the packing, and the boiler may contain 10 tons of liquid! The less important the holdup ... the more difficult ... the calculation to predict its effect, because the system of differential equations becomes stiffer!

Unfortunately, this approach does not help to solve our batch design problem of choosing a degree of detail commensurate with the equipment costs. Our systems of equations can be solved, but computer time hundreds of times longer than the time for steady state distillation is obtained, and design costs are inappropriate to the size of equipment being designed.

An established technique for treating systems with two ranges of time constants is to assume that the set with the small time constant so quickly approaches equilibrium that during a large time step appropriate for the large time constant system, the variables associated with the smaller time constant remain constant. Hence, Equation 5.12 (the component material balances on column trays) has a zero right-hand-side (accumulation terms), and the column calculation reverts to the same set of equations as for continuous distillation."

In several recent publications, researchers have used the QSSCA approach to simulate batch distillation. Rose $(1979,1985)$ used it as the basis of 
his simulator BATCH. According to Logsdon et al. (1990), "The no-holdup simulation model has been used by Diwekar et al. (1989) and Domenech and Enjalbert (1981) for screening purposes in preliminary design." Bernot and colleagues $(1990,1991)$ used QSSCA to investigate azeotropic batch distillation, and Farhat and collaborators (1990) used it to study optimization of multifraction batch distillation. Quintero-Marmol and Luyben $(1990,1992)$ compared simulations by RFD and QSSCA, and found the results similar. Nad and Spiegel (1987) compared the QSSCA and RFD approaches, and found QSSCA 20 times faster, according to Galindez and Fredenslund (1988b). Galindez and Fredenslund combined QSSCA with an existing continuous column simulator to take advantages of the highly developed algorithms (UNIDIST and UNIFAC) in it. Chiotti and Scenna (1989) incorporated QSSCA batch distillation simulation into SIMBAD, his general purposes modular process simulator.

Though fast and popular, QSSCA has drawbacks. It absolutely drops dynamic description of the column, and thus relinquishes information on the time to reach steady state or respond to changes. Holdup has some effects on separation, and in some cases this can affect the accuracy of simulation. These are reasons to do preliminary work with the speed of QSSCA and finally check it with the accuracy of the fully dynamic approach. 


\section{CHAPTER 3. METHODS DEVELOPMENT}

\subsection{Simulating Batch Processes with Steady-State Models}

Batch process simulators that use a series of continuous process models rely on the following premise: at any instant, a batch process with material in the batch tank produces the same product as the same process running continuously with the same material as feed. Diwekar and Madhavan (1991c) state the premise as follows: "This (short-cut) method is based on the reasonable approximation that the batch distillation column can be considered as a continuous distillation column with changing feed. In other words, the bottom product of one time step forms the feed of the next time step." This premise is a basis for this modeling effort, and it is substantiated based on material and energy balances and equilibrium thermodynamics.

In the premise, the phrase "at any instant" means during an interval of time so short that the amount of product withdrawn from the batch process is small compared to the size of the batch tank. Alternatively, a small product increment could replace the short time interval. The phrases "a batch process" and "the same process running continuously" mean that the batch and continuous processes have the same process flow diagram, equipment design, heat input, etc. The phrases "material in the batch tank" and "the same material as feed" mean that the feed composition, state and quantity per unit time in the model con- 
tinuous process equals the composition, state and quantity of material in the batch process over the time interval being simulated. The phrase "produces the same product" means that the quantity, composition and state of product are the same in both processes, and this is the claim of the premise.

Material balance sets a necessary condition for equality of products from batch and steady processes: over the differential time interval being modeled, the feed to the steady process must equal the quantity and composition of the initial inventory in the batch process. This is demonstrated by the following overall and component material balance equations (input $=$ output + accumulation). They specifically apply to binary distillation, operating steady-state and batch-wise in the single-stage columns shown in Figure 3-0. Similar balances can be written for multicomponent distillation in multistage columns. Their symbols are defined in Figure 3-0 and below.

Steady State

Batch

$\underline{\text { Reboiler }}$

$$
\begin{array}{ll}
F+L_{1}=B+V_{0}+0 & 0+L_{1}=B+V_{0}+\frac{d A_{0}}{d t} \\
F z+L_{1} x_{1}=B x_{0}+V_{0} y_{0}+0 & 0+L_{1} x_{1}=B x_{0}+V_{0} y_{0}+\frac{d A_{0} x_{0}}{d t}
\end{array}
$$



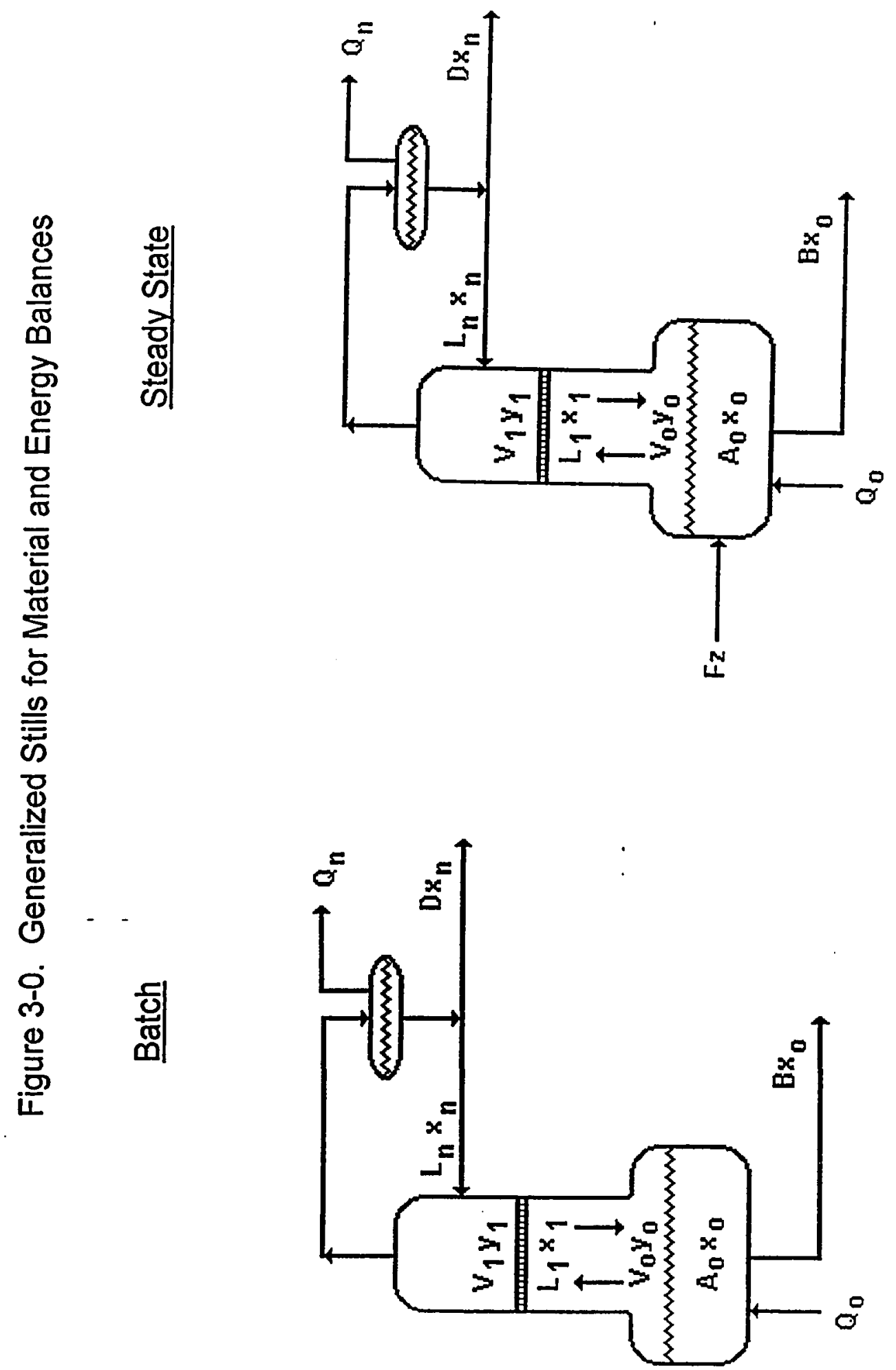
Steady State

Batch

\section{Column Stage}

$$
\begin{array}{ll}
V_{0}+L_{n}=V_{1}+L_{1}+0 & V_{0}+L_{n}=V_{1}+L_{1}+\frac{d A_{1}}{d t} \\
V_{0} y_{0}+L_{n} x_{n}=V_{1} y_{1}+L_{1} x_{1}+0 & V_{0} y_{0}+L_{n} x_{n}=V_{1} y_{1}+L_{1} x_{1}+\frac{d A_{1} x_{1}}{d t}
\end{array}
$$

\section{Condenser}

$$
\begin{array}{ll}
V_{1}=D+L_{n}+0 & V_{1}=D+L_{n}+\frac{d A_{n}}{d t} \\
V_{1} y_{1}=D x_{n}+L_{n} x_{n}+0 & \because \\
V_{1} y_{1}=D x_{n}+L_{n} x_{n}+\frac{d A_{n} x_{n}}{d t}
\end{array}
$$

Adding the balances gives:

$$
\begin{array}{ll}
F=B+D & 0=B+D+\frac{d A_{0}}{d t}+\frac{d A_{1}}{d t}+\frac{d A_{n}}{d t} \\
F z=B x_{0}+D x_{n} & 0=B x_{0}++D x_{n}+\frac{d A_{0} x_{0}}{d t}+\frac{d A_{1} x_{1}}{d t}+\frac{d A_{n} x_{n}}{d t}
\end{array}
$$

Applying the QSSCA, which says that $d A_{0} / d t$ is much larger than $\left(d A_{1} / d t+\right.$ $\left.d A_{n} / d t\right)$ because $A_{0}$ is much larger than $\left(A_{1}+A_{n}\right)$, and rearranging, gives:

$$
\begin{array}{ll}
F=B+D & -\frac{d A_{0}}{d t}=B+D \\
F z=B x_{0}+D x_{n} & -\frac{d A_{0} x_{0}}{d t}=B x_{0}++D x_{n}
\end{array}
$$

Concluding: If steady state $F=-\frac{d A_{0}}{d t}$ batch, 
then, steady state $(B+D)=(B+D)$ batch.

Likewise: If steady state $F z=-\frac{d A_{0} x_{0}}{d t}$ batch, then, steady state $\left(B x_{0}+D x_{n}\right)=\left(B x_{0}+D x_{n}\right)$ batch.

where, F, D, B, L, V Feed, Distillate, Bottoms, Liquid, Vapor flowrates A Vapor and Liquid Accumulation

$z, y, x \quad$ Mol fractions of a component in $F, V$ or $D, L$ or $B$

$0,1, n \quad$ Subscripts denoting Reboiler, Column, Condenser

The feed to the steady process must equal the whole charge to the batch process, not just the quantity distilled, because the program empties the batch still after each step and uses the bottoms as the charge for the next step. These are necessary, though not sufficient, conditions for process equivalence.

The material balances above and the energy balance below apply exactly to differential time intervals and differential fluid elements. The quasi-steadystate column approximation says that they also apply approximately to short time steps. It says that, over a small change in batch still concentrations, the material and energy streams of the batch system are approximated by those of a continuous system. In other words, batch distillation is a quasi-static process. The stage-wise equilibrium approximation says that the balances also apply to all the material on a separation stage. That is, the vapor and liquid phases on each stage are well-mixed and equilibrated at any instant. In other words, the re- 
sponse to perturbations away from well-mixed equilibrium is rapid relative to other time lags in the system. This approximation is used to calculate concentrations and other state variables without involving irreversible thermodynamics and transport phenomena. It is common in both batch and continuous process modeling, and it is corrected on the flowsheet simulator by using a stage efficiency parameter.

Energy balance sets another necessary condition for products of batch and steady processes to be equal: the sum of feed enthalpy and heat into the steady process must equal the sum of inventory enthalpy and heat into the batch process over the differential of time being modeled. Two processes meet this condition if the composition, state and temperature of feed to the continuous process equal the composition, state and temperature of inventory in the batch process, and the heat into the two processes is equal. The following energy balance equations demonstrate this. Again, they apply to the steady and batch distillation columns in Figure 3-0.

Steady State

Batch

Reboiler

$F H_{F}+L_{1} H_{L 1}+Q_{0}=B H_{L O}+V_{0} H_{V O}+0$

$$
Q_{0}+L_{1} H_{L 1}=B H_{L O}+V_{0} H_{V O}+\frac{d A_{0} H_{M O}}{d t}
$$


Steady State

Batch

\section{Column Stage}

$V_{0} H_{V 0}+L_{n} H_{L n}=L_{1} H_{L 1}+V_{1} H_{V 1}+0$

$$
V_{0} H_{V 0}+L_{n} H_{L n}=L_{1} H_{L 1}+V_{1} H_{V 1}+\frac{d A_{1} H_{M 1}}{d t}
$$

\section{Condenser}

$V_{1} H_{V 1}+Q_{n}=L_{n} H_{L n}+D H_{L n}+0$

$$
V_{1} H_{V 1}+Q_{n}=L_{n} H_{L n}+D H_{L n}+\frac{d A_{1} H_{M n}}{d t}
$$

Adding the balances gives:

$\mathrm{FH}_{\mathrm{F}}+\mathrm{Q}_{0}+\mathrm{Q}_{\mathrm{n}}=\mathrm{BH}_{\mathrm{LO}}+\mathrm{DH}_{\mathrm{Ln}}$

$$
Q_{0}+Q_{n}=B H_{L O}+D H_{L n}+\frac{d A_{0} H_{M 0}}{d t}+\frac{d A_{1} H_{M 1}}{d t}+\frac{d A_{1} H_{M n}}{d t}
$$

Applying the QSSCA, which says that $d A_{0} H_{M O} / d t$ is much larger than $\left(d A_{1}\right.$

$\left.H_{M 1} / d t+d A_{n} H_{M n} / d t\right)$ because $A_{0}$ is much larger than $\left(A_{1}+A_{n}\right)$, and rearranging, gives:

$F H_{F}+Q_{0}+Q_{n}=B H_{L 0}+D H_{L n}$

$$
-\frac{d A_{0} H_{M 0}}{d t}+Q_{0}+Q_{n}=B H_{L 0}+D H_{L n}
$$

Concluding: If steady state $\left(F H_{F}+Q_{0}+Q_{n}\right)=\left(-\frac{d A_{0} H_{M O}}{d t}+Q_{0}+Q_{n}\right)$ batch, then, steady state $\left(\mathrm{BH}_{L 0}+\mathrm{DH}_{L n}\right)=\left(B \mathrm{BH}_{\mathrm{LO}}+\mathrm{DH}_{\mathrm{Ln}}\right)$ batch. 
where, $\mathrm{H}$

Molar enthalpy (a state function of composition, temperature, pressure.)

\section{F,L,V,M Subscripts denoting Feed, Liquid, Vapor, Mixed}

Meeting the energy balance condition ensures top and bottom products having the same state and temperature in the two processes, given that they have the same flowrates and compositions for material balance reasons.

Material and energy balances involve the extensive properties of materials in processes, and they set some of the conditions for process equivalence.

Equilibrium thermodynamics sets other, complementary conditions on the intensive properties. The same equations determine equilibrium in steady and batch processes.

Steady State

Batch

Reboiler

$$
\begin{array}{ll}
y_{0} / x_{0}=K_{0}=K\left(T_{0}, P_{0}, x_{0}\right) & y_{0} / x_{0}=K_{0}=K\left(T_{0}, P_{0}, x_{0}\right) \\
H_{L O}=H_{L O}\left(T_{0}, P_{0}, x_{0}\right) & H_{L O}=H_{L O}\left(T_{0}, P_{0}, x_{0}\right) \\
H_{V O}=H_{L O}\left(T_{0}, P_{0}, y_{0}\right) & H_{V O}=H_{L O}\left(T_{0}, P_{0}, y_{0}\right) \\
H_{M O}=\left(A_{L O} H_{L O}+A_{V O} H_{V O}\right) /\left(A_{L O}+A_{V O}\right)
\end{array}
$$

$$
H_{M O}=\left(A_{L O} H_{L O}+A_{V O} H_{V O}\right) /\left(A_{L O}+A_{V O}\right)
$$


Steady State

Batch

\section{Column Stage}

$$
\begin{array}{ll}
y_{1} / x_{1}=K_{1}=K\left(T_{1}, P_{1}, x_{1}\right) & y_{1} / x_{1}=K_{1}=K\left(T_{1}, P_{1}, x_{1}\right) \\
H_{L 1}=H_{L 1}\left(T_{1}, P_{1}, x_{1}\right) & H_{L 1}=H_{L 1}\left(T_{1}, P_{1}, x_{1}\right) \\
H_{V 1}=H_{L 1}\left(T_{1}, P_{1}, y_{1}\right) & H_{V 1}=H_{L 1}\left(T_{1}, P_{1}, y_{1}\right) \\
H_{M 1}=\left(A_{L 1} H_{L 1}+A_{V 1} H_{V_{1}}\right) /\left(A_{L 1}+A_{V 1}\right)
\end{array}
$$

$$
H_{M 1}=\left(A_{L 1} H_{L 1}+A_{V 1} H_{V 1}\right) /\left(A_{L 1}+A_{V 1}\right)
$$

\section{Condenser}

$$
\begin{array}{ll}
y_{n} / x_{n}=K_{n}=K\left(T_{n}, P_{n}, x_{n}\right) & y_{n} / x_{n}=K_{n}=K\left(T_{n}, P_{n}, x_{n}\right) \\
H_{L n}=H_{L n}\left(T_{n}, P_{n}, x_{n}\right) & H_{L n}=H_{L n}\left(T_{n}, P_{n}, x_{n}\right) \\
H_{V_{n}}=H_{L n}\left(T_{n}, P_{n}, y_{n}\right) & H_{V_{n}}=H_{L n}\left(T_{n}, P_{n}, y_{n}\right) \\
H_{M n}=\left(A_{L n} H_{L n}+A_{V n} H_{V n}\right) /\left(A_{L n}+A_{V n}\right)
\end{array}
$$

$$
H_{M n}=\left(A_{L n} H_{L n}+A_{V n} H_{V n}\right) /\left(A_{L n}+A_{V n}\right)
$$

where, $\mathrm{K} \quad$ Vapor/Liquid Equilibrium Constant

T Temperature

P Pressure

The equilibrium conditions are the same in the steady and batch processes; the following thought experiment elucidates this.

Two identical portions of material, $\mathrm{Fz}$ are fed to a steady process and made the inventory of a batch process. The two mechanically identical processes are a binary vapor/liquid equilibrium, so Phases $=2$ and Components $=2$. Gibbs' Phase Rule states that Degrees of Freedom = 2 - Phases + Com- 
ponents. If two state variables, say temperature and pressure, are specified the same in both cases, the two remaining degrees of freedom are taken and the two systems are completely determined. Then before product removal, the same material is under the same thermodynamic conditions in the two systems, so both systems come to the same equilibrium.

This result really is not surprising. There is no difference, thermodynamically, between a continuous process where $\mathrm{F} \mathrm{mol} / \mathrm{min}$ of feed of some composition are heated at $Q$ Joules/min at pressure $P$ atm and products $D$ and $B$ are discharged to holding tanks, and a batch process where $F$ mols of feed of the same composition are heated with $Q$ Joules at pressure $P$ atm for one minute and products $D$ and $B$ are unloaded from the batch tank. The same starting material receives the same energy under the same conditions of thermodynamic state variables, therefore the products are the same, if both processes reach equilibrium and the phases separate well. The difference between the continuous and batch processes is their path, not their endpoints, and only endpoints matter in equilibrium. Thus, equilibrium thermodynamics sets another necessary condition for process equivalence: a number of state variables, equal in number to the degrees of freedom, must be set the same in both the batch and steady process.

Figure 3-1 illustrates these principles on McCabe-Thiele diagrams for a batch distillation and a continuous distillation simulating it. The batch tank and the continuous feed have the same composition and quantity of material, so the operating line endpoint is the same on both diagrams. Since the heat 


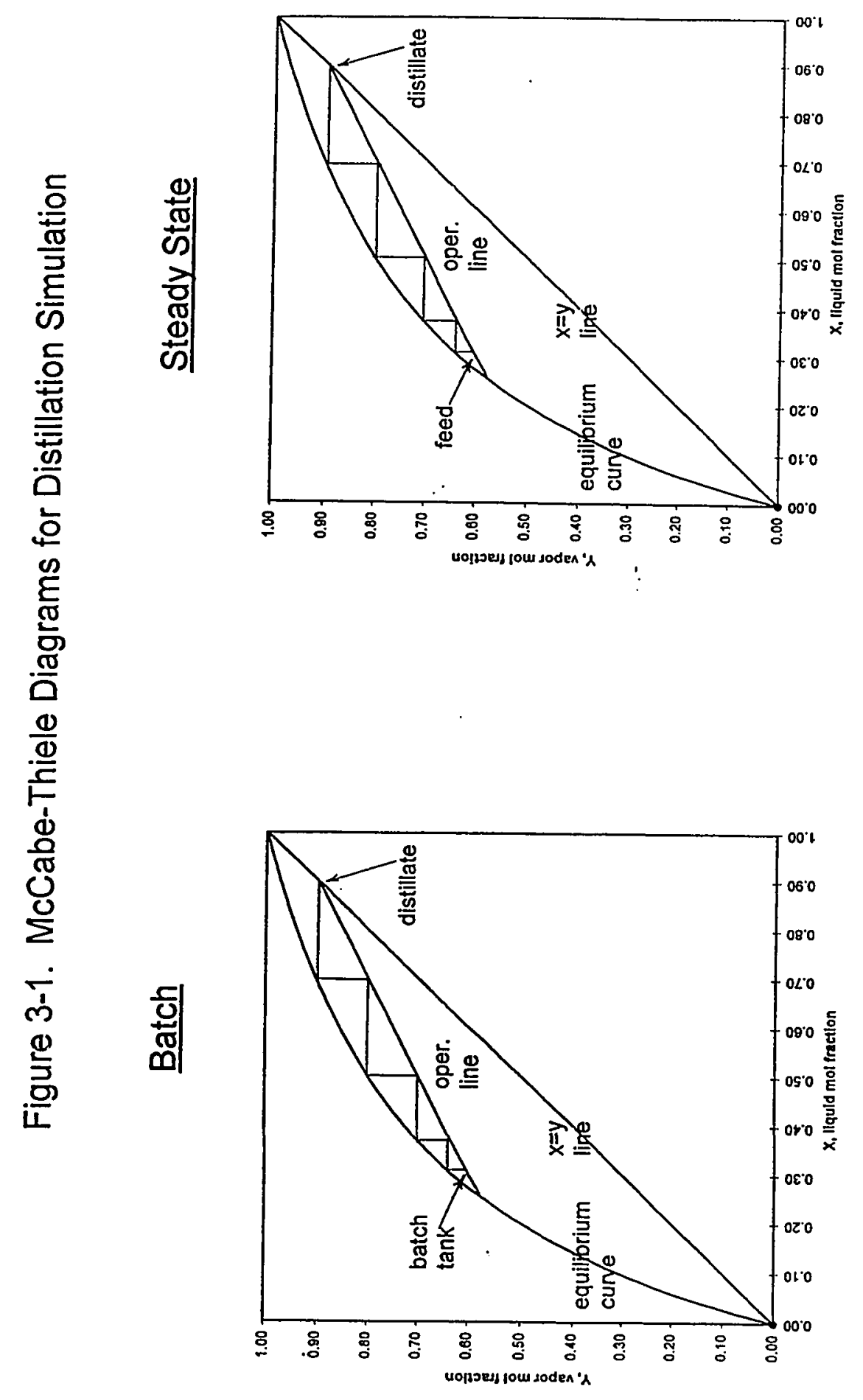


rates and equipment design are the same, the vapor/liquid ratio is the same in both columns and the operating line has the same slope on both diagrams. With the same end point and slope, the operating line is the same on both diagrams. Since the processes are the same, both diagrams only have an operating line for rectification. The columns operate at the same thermodynamic state on the same material, so the equilibrium curve is the same. The $x=y$ line is the same on both diagrams, and it represents the streams crossing in the total condenser on top of both columns. Thus, all of the guide lines are the same on both diagrams. When the same number of stages are stepped off on both diagrams, they predict the same distillate, confirming the simulation. The diagrams in Figure 3-1 represent one step-of-integration in the simulation of the process. As the distillation proceeds the boiler composition changes and new operating lines represent the process, as shown on Figure 2-1. Each operating line is another step in the integration of the process. The more rapidly the operating line changes, the finer the steps-of-integration.

\subsection{Implementing this Batch Simulation Approach in a GPPS}

Having established that a steady process model can simulate a step in a batch process, the next step is to use this premise in a computer program to simulate batch distillation. This program must perform two interacting tasks: 1) column simulation to find product composition from boiler composition, that is, $y=$ $y(x)$, and 2) integration or differential equation solution to relate final distillate 
product to the initial still charge, that is, $\int d(L x)=\int d(V y)$. This section describes the programming for column simulation from the top-down: the programming environment, the thermodynamics model, the column simulator, and the simulation of column holdup. To help concretize this general discussion of principles, Exhibits 4-1, 4-2, 4-3 and Appendix A show example programs. The programs' specifics apply to test cases described in the next chapter.

Galindez and Fredenslund (1988b) and Chiotti and Scenna (1989) used preprogrammed subroutines for solving steady-state columns in their batch distillation simulations. Writing original software to model continuous rectification really is not necessary as a number of proven software packages are available. Among the best steady column simulators available are those in general-purpose process simulators such as ASPEN PLUS, Process, ChemCad, etc. Since they all have fine rigorous distillation models, the programmer can choose among them on peripheral considerations: cost, ease of use, etc. On these bases, ASPEN PLUS was chosen for this study.

Working within the general-purpose flowsheet simulator, the programmer must choose a model for thermodynamics-physical properties. It should represent the chemical system without using excessive computer time, considering the other approximations in the model. Since a goal of this work is to compare results this QSSCA model of batch distillation to similar simulations in the literature, UNIFAC/Redlich-Kwong, a properties model closely matching those used in the 
published work, was chosen.

There are three choices for the distillation column model: 1) a column built of primitive unit operations like flashes, reactors and heat exchangers, 2) a rigorous, stage-by-stage column solver, or 3 ) a short-cut column solver. The sequence-of-flashes approach was tried and abandoned, because convergence would have required extensive FORTRAN programming, contrary the hypothesis of implementation using the primary commands available in the simulation language.

Distillation column solvers are specialists at solving convergence problems. Two basic types of analysis are available in distillation column solvers, rigorous or short-cut. Obviously, rigorous stage-by-stage calculations are more accurate than short-cut calculations that treat the column as a single entity. Rigorous solvers usually also accommodate a wider range of more detailed design specifications than short-cut solvers. However, short-cut solvers involve far fewer calculations and hence are much faster than rigorous solvers. The choice between rigorous and short-cut solvers is a choice between accuracy and speed. The recommended compromise is an extension of the advice for using RFD and QSSCA. Use QSSCA with short-cut models for preliminary design scouting, then use QSSCA with rigorous columns to optimize, and finally use RFD simulation to check the final design. In this study, programs were written with both rigorous and short-cut solvers. 
If material and thermal holdups in the column are negligible, the specifications and conditions of steady and batch columns are the same, but if there are holdups, the specifications and conditions are inherently different. In continuous distillation, the material holdups on the trays and in the boiler and condenser are established during startup, and they are not taken from the feed during operation. Continuous process models, which only simulate operation after startup, can ignore material and thermal holdup. In batch processes, the batch charge must produce "products" in addition to the distillate and raffinate: the holdups. As the batch distillation proceeds, the holdups combine their material with the vapor and liquid rising and falling onto a stage, and as their compositions change, they act as sources and sinks of material, something that does not happen in steady-state processing. While steady and batch distillation are inherently different when there are holdups, the view of holdups as feed and product from each stage is the basis of a conception of a continuous column that can model to a batch column.

To model material and associated thermal holdups in batch distillation, the model must account for two considerations: carrying holdups from step-to-step and starting up the column. Galindez and Fredenslund's work (1988b) provides a way to simulate holdups by treating them as stage products from the previous step-of-integration that feed the next step-of-integration. They represent a tray's holdup as a stage product, a sidestream from the column tray, which comes from 
stage $\mathrm{j}$ of the column at step $\mathrm{k}-1$ of the integration, to stage $\mathrm{j}$ of the column at step $k$ of the integration, and passes onto stage $j$ of the column at step $k+1$ of the integration. Figure 3-2 compares their model which accounts for holdup in the column, with a simpler model that neglects holdup. The holdups pass from one integretion step to the next, and thus stay in the column. Their quantities are constant until the end of the process, but their composition changes to reflect the changing composition on the trays.

To simulate the startup of such a column and establish the holdups, the model initially runs with total reflux, just as in real life. The program specifications divide the feed charge among the boiler and the holdups on the trays, all at the initial charge composition. The column then runs with total internal reflux. Each stage produces a product equal in quantity to its holdup feed, but with its composition reflecting the separation occurring in the column. This composition is fed to the corresponding tray in the column in the next step-of-integration, also operating with total internal reflux. Total reflux continues until the composition of holdups stabilizes, and then distillate production begins while holdup input and output continues. Figure 3-3 shows an example of this stabilization. This approach simulates a condensate accumulator as a stage with a larger holdup. To simulate complete distillation of the charge, the column draws on the boiler contents and holdups for top product, until the column is dry.

Without holdups, simulating a startup phase is not necessary. There is no 
Figure 3-2 A Chain of Columns Integrating Batch Distillation

Neglecting Holdup

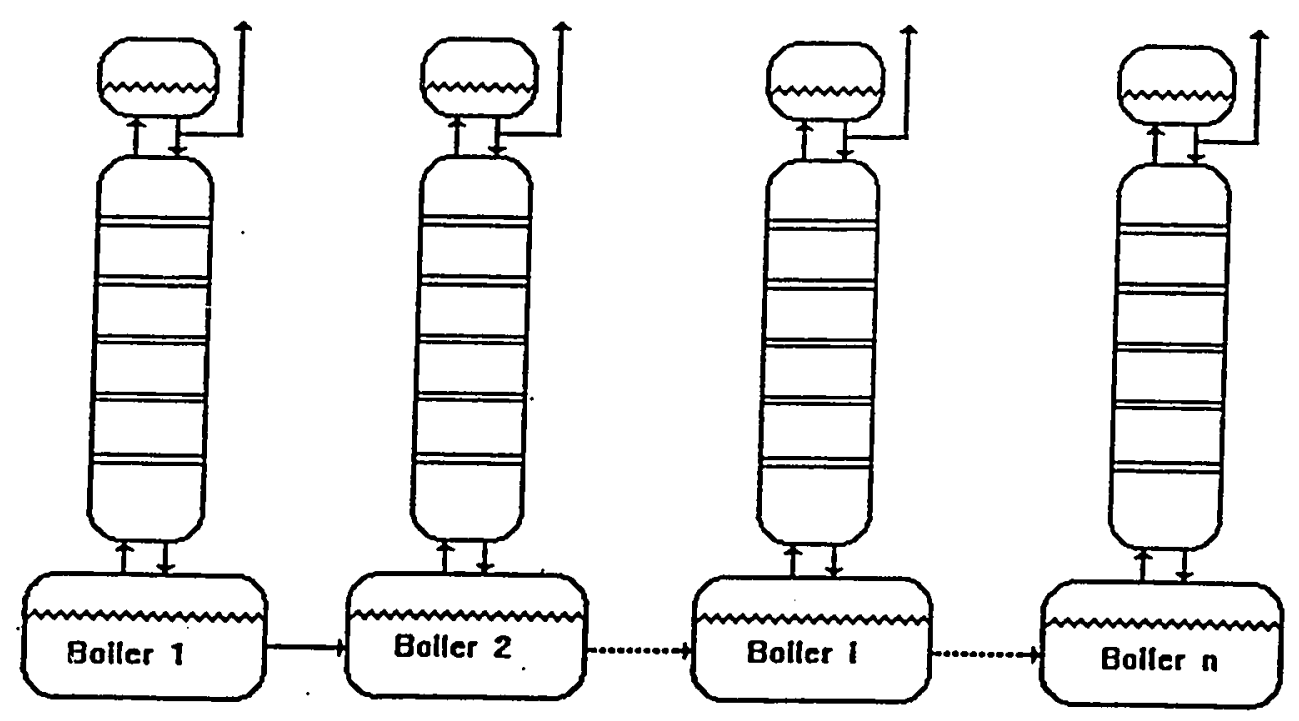

Accounting for Holdup

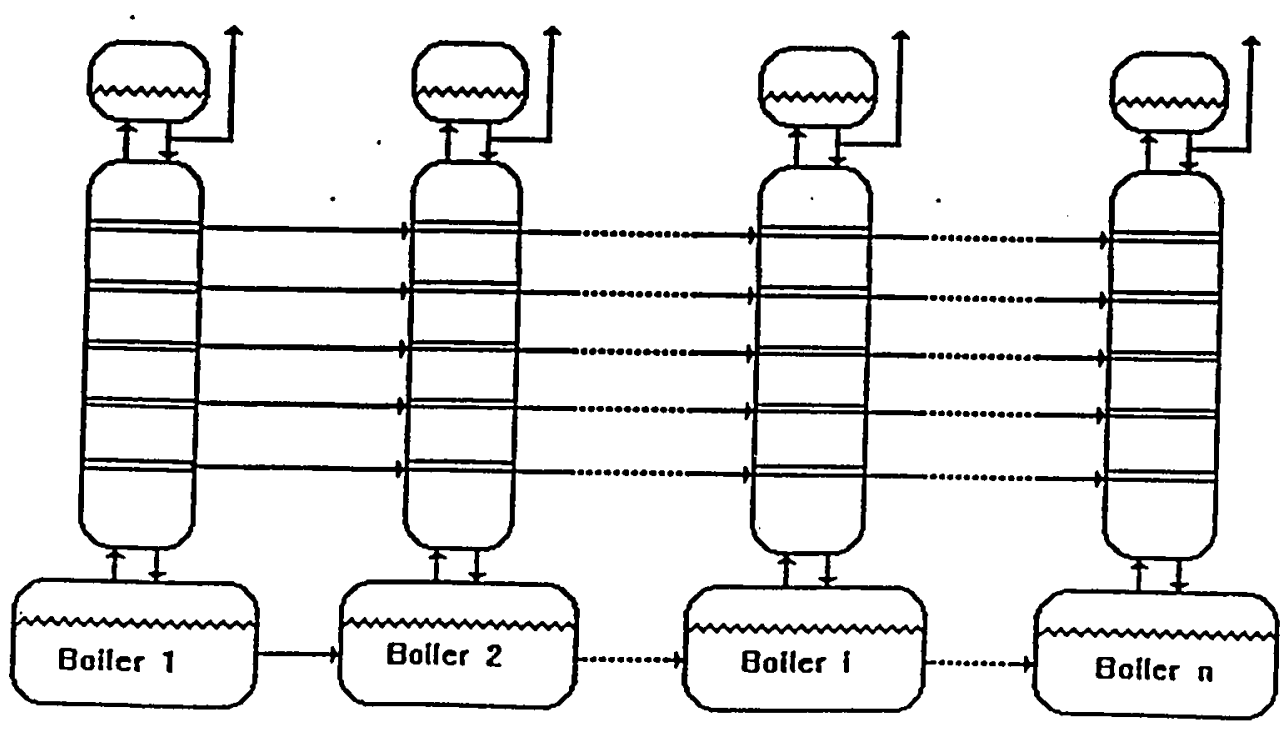




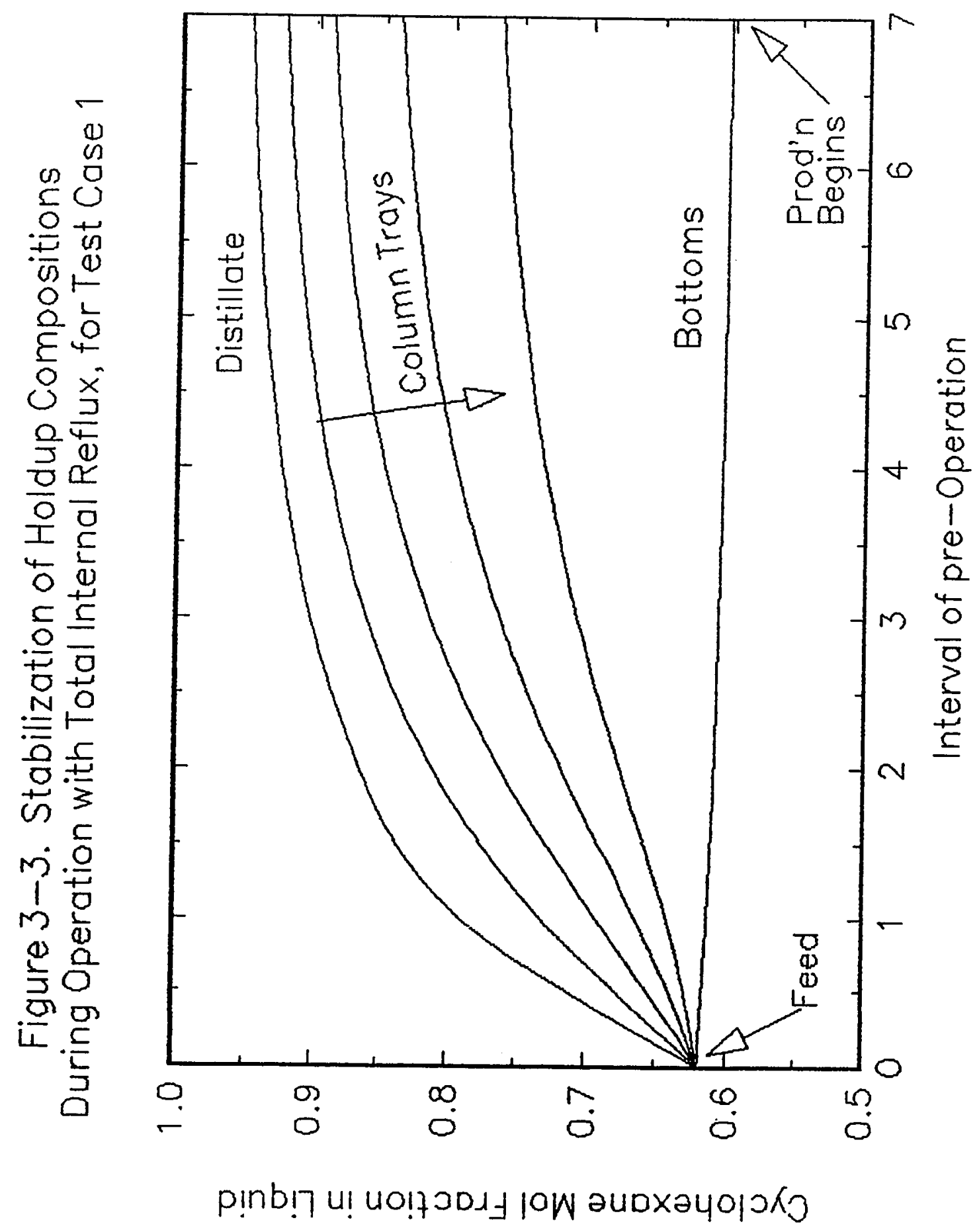


inertia in a column without holdups, since the column starts each step empty. Programs in this study simulated columns with and without holdups.

\subsection{Performing Numerical Integration with a Flowsheet Simulator}

Given: 1) the premise that a steady process model can simulate the instantaneous operation of a batch process, and 2) a means of evaluating the function, top product composition and flowrate as a function of bottom charge and heat rate, attention now turns to implementing its integration. Integration finds the function $y=y(P)$, where $y$ is the product composition and $P$ is the amount of product. Integration is necessary, because while distillate composition can be found from boiler composition, only the initial boiler composition is known and the process must be stepwise integrated to find the compositions at later times. The program integrates increments of product, and finds the residue composition as a function of them: $\int d(L x)=\int d(V y)$, as in the Rayleigh equation. This algorithm involves three issues: 1) evaluating and integrating the function in a general purpose process simulator (GPPS), 2) controlling stepsize, and 3) determining convergence.

This is the procedure for integration in a GPPS. The program feeds the initial charge and heat to a steady distillation modeling the batch still. It solves the column equations to predict the product compositions. These product flows and compositions for the initial instant of batch distillation are used to approximately predict the product over the first short interval, delta $t$, of the process. 
Alternatively, the interval could be delta $\mathrm{P}$, a small amount of product, and the corresponding time interval could be calculated from energy balance and heat rate. The simulator calculates the charge remaining from the feed and product by material balance. This residue is the charge for the next interval of batch distillation and the feed for the next steady column simulating that batch distillation. What has just been described is a simple Euler integration of batch distillation: solving the differential equation by taking and integrating steps using the initial value of the slope in each interval. In this study, programs used this integration method.

The integration is easy, if tedious, to program in ASPEN PLUS. It is a chain of rectification columns, as shown in Figure 3-2. Each step of integration is a column, with its distillate going out of the flowsheet as a product and its bottoms feeding the column at the next step of integration. The program specifies the distillate flowrate, for example, and the raffinate flowrate decreases as the charge distills. The GPPS gives the results: distillate and raffinate compositions and flowrates, temperatures and heat rates for each column in the chain and hence for each step of integration. Appendix A contains an example of simulator output.

The program repeats the whole integration with smaller stepsizes until the result, distillate composition versus quantity distilled, is stable within a specified tolerance, that is, the integration has converged. Figure 3-4 shows an example 


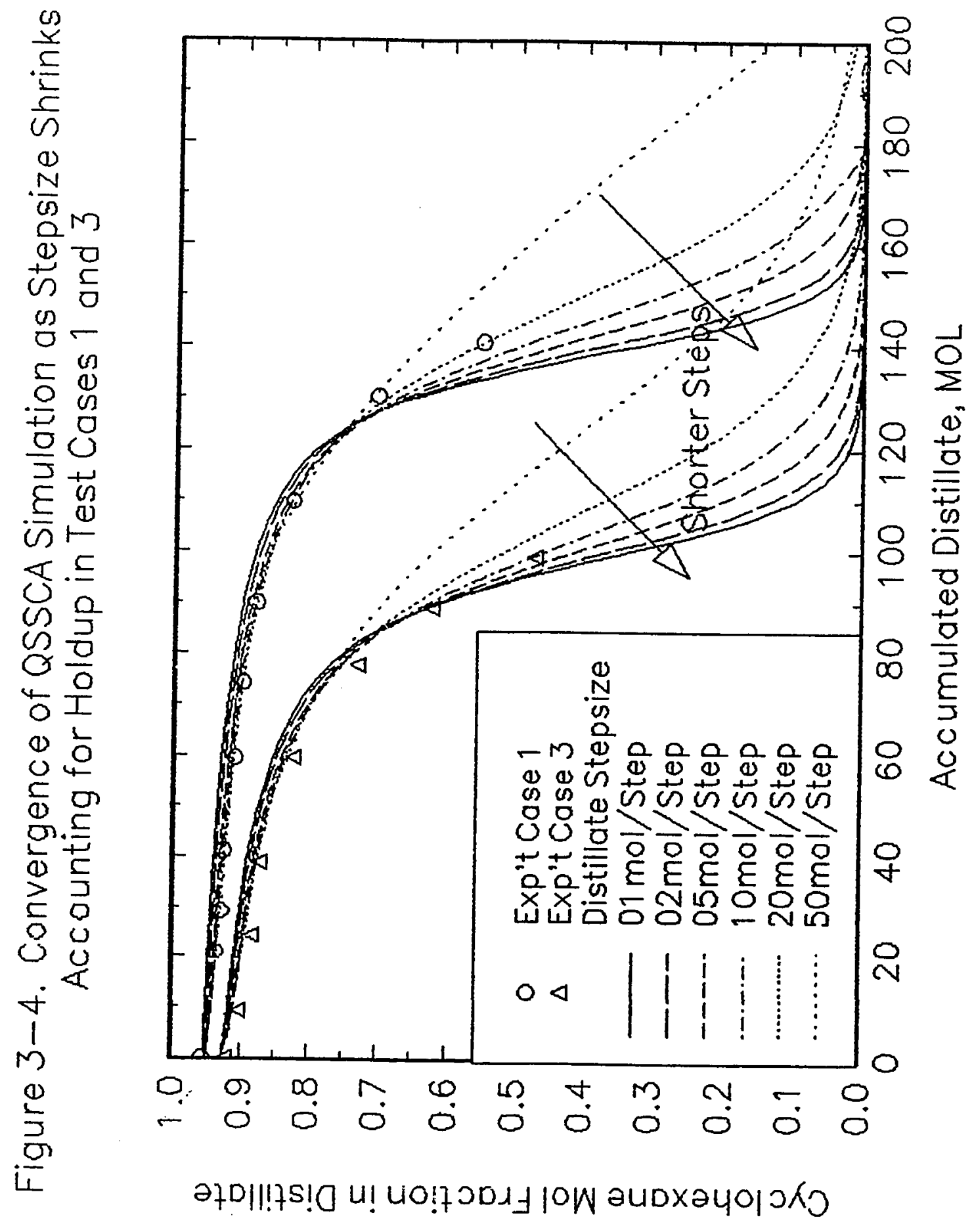


of this convergence. Since this is a first-order integration method, the difference between the results of one iteration and the ultimate converged solution decreases by a factor on the order of one half each time the stepsize halves (Riggs, 1988). Programming successive iterations with decreasing stepsizes requires human intervention, because process simulators currently cannot automatically change flowsheet arrangements (number of columns, connections, etc.), only process parameters (flowrates, temperatures, etc.). The programmer rewrites the flowsheet with, say, double the number of columns and half the stepsize and reruns the job. The rewriting and rerunning continue until the simulation converges. When the jobs are generated using a text editor, this is not nearly as tedious as it sounds.

Programs in this study were run with fixed-quantity stepsizes equaling $25 \%, 10 \%, 5 \%, 2.5 \%, 1 \%$ and $0.5 \%$ of the initial charge. This gave the visual demonstration of convergence in Figures 3-4 and 4-8. Examining these results suggests a more sophisticated algorithm for controlling integration stepsize. Distillate and raffinate compositions change slowly at the beginning, when the quantity of charge is large compared to the amount of distillate. These compositions change rapidly at the end, when distillate quantities become substantial fractions of the remaining charge. A stepsize small enough to accurately capture the end of the distillation curve wastes computer time in the beginning of distillation. To use computer time simulation. The engineer decides what sections of 
the curve are important. For efficiently, stepsize should decrease during distillation. One way to do this is to make the distillate some fraction of the remaining charge at each step. The fractional approach needs a cut-off point, say $10 \%$ of original charge remaining or a crossover to a fixed quantity stepsize, because the simulation could go on forever, distilling the same percentage of the remaining charge.

A less visual and more mathematical convergence criterion could be some percentage variation in the accumulated product composition for the first quantity of distillate as the stepsize halves. Another criterion is convergence of amount distilled with some set purity. The convergence criterion derives from the purpose of the simulation. For example, the very end of the curve, which needs the smallest stepsize, probably does not need very close characterization, as the products and slop cuts have already distilled, and the bottom product simply is unloaded from the still pot. The program could separate the distillation into several separate problems. It could calculate each stage of the process with stepsize, convergence criteria and cutoff point appropriate for it. The approach is very flexible. 


\section{CHAPTER 4. TESTS, RESULTS and DISCUSSION}

\subsection{Description of the Tests}

This chapter describes tests of the quasi-steady-state column approximation (QSSCA) approach in a specific application. The work of Domenech and Enjalbert $(1974 a, b)$ provides the information for the test cases, operating conditions and distillation curves. Table 4-1 lists their operating conditions, and Figure 4-1 shows their experimental and simulation results. They did a series of experiments to test the validity of their own rigorous fully dynamic (RFD) model. Domenech and Enjalbert batch distilled four mixtures of cyclohexane and toluene, a nonideal system. They used a pilot-scale column, and their experiments distilled about half the original charge. Several other investigators have tested their models against Domenech and Enjalbert's experiments. This gives an opportunity to compare this model with other models, and with experiments.

Table 4-1. Operating Conditions for Test Cases

Initial Charge to Still

Quantity

Components Cyclohexane (light)

\& Toluene

Composition Variable (see below)
Distillation Column

Physical Stages 4 Sieve Trays

Stage Efficiency $75 \%$

Holdup

Condenser

Reflux Ratio

Pressure

Case Number

Reflux Ratio

Cyclohexane Charge 0.62

2

0.55
$2.5 \mathrm{~mol}$ (on each tray and in the cond'r)

Total Variable (see below) $1 \mathrm{~atm}$ 


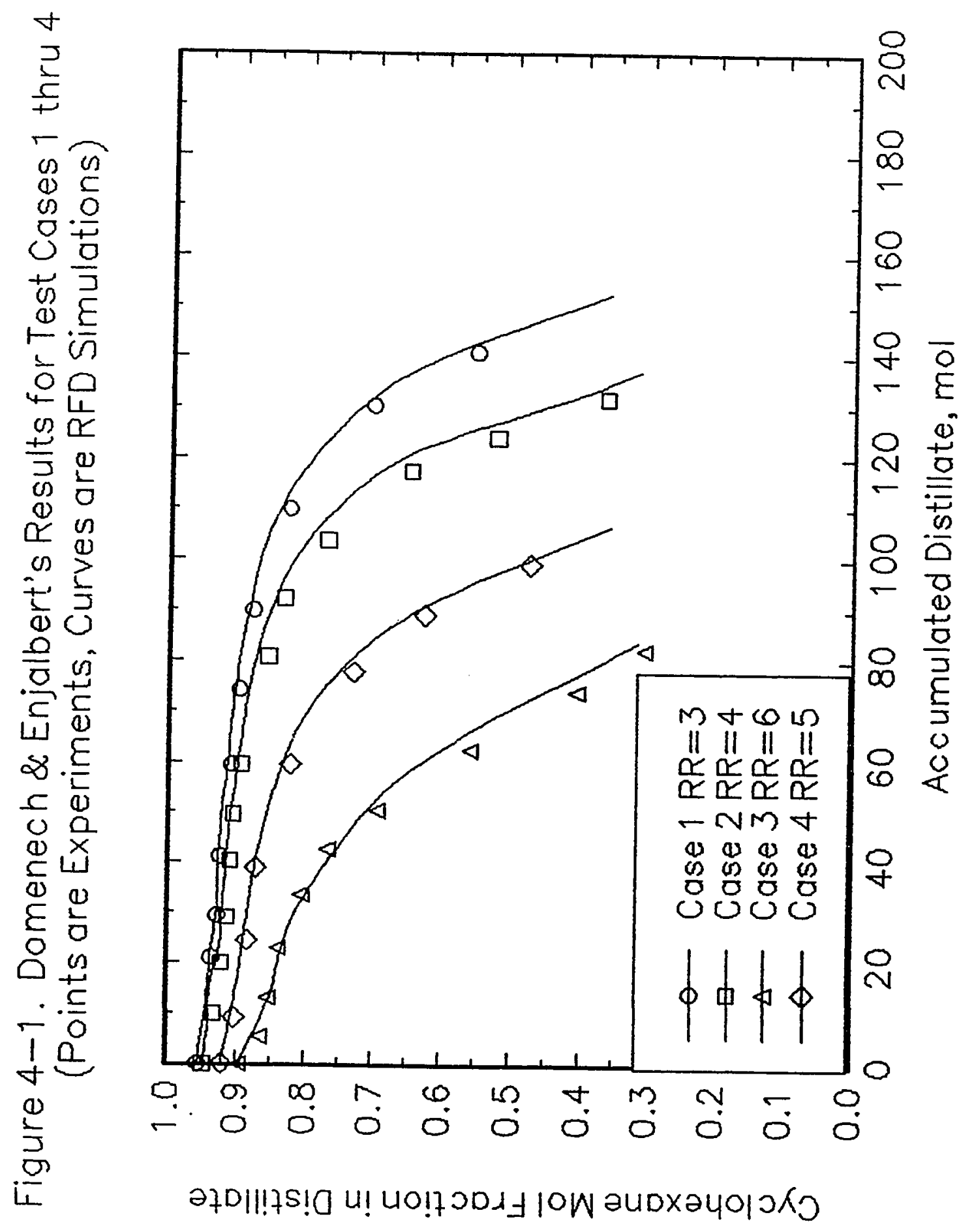


Exhibits 4-1, 4-2 and 4-3 and Appendix A are examples of the three-dimensional matrix of ASPEN PLUS programs written to cover the range of process models, step-sizes and process conditions. The programs display the three types of column models. Exhibit 4-2 and Appendix A show rigorous column calculations and accounting for liquid holdup on the trays. Because it accounts for holdup, the program in Exhibit 4-2 also includes simulation of column startup. The example program in Exhibit 4-1 also shows rigorous stage-by-stage calculations, but it neglects holdup. Exhibit 4-3 shows the Edmister overall column calculation. The program exhibits include columns simulating each step of distillation, and each program shows a different step-size. Exhibit 4-2 has 200 columns to simulate the $200 \mathrm{~mol}$ distillation in $1 \mathrm{~mol}$ steps, Exhibit 4-1 and Appendix A have four columns for 50 mol steps and Exhibit $4-3$ has 20 columns for 10 mol product increments. Exhibit 4-2 includes seven columns producing no product overhead, to simulate convergence of the holdup compositions during startup. Each example implements the process conditions of one of Domenech and Enjalbert's tests. Exhibit 4-2 and Appendix A have specifications for Case 1, Exhibit 4-1 has Case 2, and Exhibit 4-3 has Case 4: Comments in the programs identify the specifications. The Methods Development Chapter discusses the principles behind the programs, including the startup simulation and interconnection between columns. 


\section{Exhibit 4-1. Program for QSSCA Simulation of Batch Distillation, Neglecting Holdup}

TITLE "Batch Distillation Sim'n w/ QSSCA, Rigor Col Calc'n w/ No Holdup, 50mol/Step" DESCRIPTION " Design \& Operating Conditions for Domenech \& Enjalbert's [D9,D11] Case 2"

IN-UNITS MET ;metric

OUT-UNITS MET

COMPONENTS C6H12 CYCLOHEXANE C6H12/ C7H8 TOLUENE C7H8

DATABANKS ASPENPCD ; ASPEN PLUS Component Data Bank

PROP-SOURCES ASPENPCD

PROPERTIES SYSOP7 ; UNIFAC/Redlich-Kwong

\section{FLOWSHEET}

; a free-standing column distilling $0.1 \mathrm{~mol}$ to find composition of initial distillate BLOCK OODSTL IN=00FEED OUT=00TOPS 00BTMS

; chain of columns to integrate batch distillation in $50 \mathrm{~mol}$ distillate steps

BLOCK 50DSTL IN=FEED OUT=50TOPS 50BTMS

BLOCK 100DSTL IN=50BTMS OUT=100TOPS 100BTMS

BLOCK 150DSTL IN=100BTMS OUT=150TOPS 150BTMS

BLOCK 199DSTL IN=150BTMS OUT=199TOPS 199BTMS

; distill 199 of 200 mols, to avoid errors when boiler runs dry

; feed streams are initial charges to batch boilers

STREAM OOFEED PRES $=1$ [ATM] VFRAC $=0$ NPHASE $=2$ MOLE-FLOW $=0.200[\mathrm{KMOLHR}]$

MOLE-FRAC $\mathrm{C} 6 \mathrm{H} 12 \mathrm{0.55} / \mathrm{C} 7 \mathrm{H} 80.45$; feed to column calc'ing initial distillate

STREAM FEED PRES $=1$ [ATM] VFRAC $=0$ NPHASE $=2$ MOLE-FLOW $=0.200[\mathrm{KMOLHR]}$

MOLE-FRAC $\mathrm{C} 6 \mathrm{H} 120.55 / \mathrm{C} 7 \mathrm{H} 80.45$; feed to chain of columns integrating batch ; atmospheric pressure and bubble-point temperature, D\&E Case 2 compositions

typical examples of unit operations blocks

BLOCK OODSTL RADFRAC ; column calc'ing initial distillate

PARAM NSTAGE=6 EFF=MURPHREE

FEEDS OOFEED 6 ON-STAGE

PRODUCTS OOTOPS $1 /$ OOBTMS 6

P-SPEC 1 1[ATM]

COL-SPECS MOLE-RDV $=0$ MOLE-RR=4 MOLE-D=0.0001[KMOL/HR]

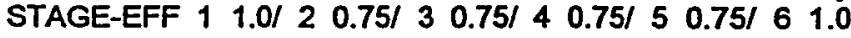

; chain of columns integrating batch

BLOCK 50DSTL RADFRAC ; rigorous fractionation calculation

PARAM NSTAGE=6 EFF=MURPHREE ; 6 stages=cond' +4 trays + boiler

FEEDS FEED 6 ON-STAGE ; charge to boiler=tray \#6

PRODUCTS 5OTOPS $1 / 50 B T M S 6$; TOPS=distillate product from tray \#1, ; BTMS=boiler's remaining charge passed to the next column

P-SPEC 1 1[ATM] ; operating pressure

COL-SPECS MOLE-RDV=0 MOLE-RR=4 MOLE-D=0.050[KMOLHR]

; total condenser $\Rightarrow$ distillate vap/liq $=0$, molar reflux ratio $=4$, distillate $=50 \mathrm{~mol} / \mathrm{hr}=\mathrm{stepsize}$

STAGE-EFF 1 1.0/ $20.75 / 30.75 / 40.75 / 50.75 / 61.0$; Murphree efficiencies

$*$

BLOCK 199DSTL RADFRAC ;last column in chain 


\section{Exhibit 4-2. Program for QSSCA Simulation of Batch Distillation, Accounting for Holdup}

TITLE "Batch Distillation Sim'n w/ QSSCA, Rigor Col Calc'n w/ 2.5mol/tray Holdup, 1mol/Step" DESCRIPTION " Design \& Operating Conditions for Domenech \& Enjalbert's [D9,D11] Case 1"

COMPONENTS C6H12 CYCLOHEXANE C6H12/ C7H8 TOLUENE C7H8

DATABANKS ASPENPCD ; ASPEN PLUS Component Data Bank

PROP-SOURCES ASPENPCD

PROPERTIES SYSOP7 ; UNIFAC/Redlich-Kwong

FLOWSHEET ; chain of columns to startup and integrate batch distillation

; startup columns=OADSTL thru OFDSTL and O0ODSTL, total internal reflux

BLOCK OADSTL IN=0AFEED1 OAFEED2 OAFEED3 OAFEED4 OAFEED5 OAFEED6 \& OUT=0APROD1 OAPROD2 OAPROD3 OAPROD4 OAPROD5 OAPROD6

BLOCK OBDSTL IN=0APROD1 OAPROD2 OAPROD3 OAPROD4 OAPROD5 OAPROD6 \& OUT=0BPROD1 OBPROD2 OBPROD3 OBPROD4 OBPROD5 OBPROD6

; sidestreams=0APROD1, OAPROD2,...,OAPROD5, OAPROD6, from condenser, top tray,

; ...,bottom tray and boiler, respectively, are holdups passed from column to column.

*

BLOCK O0ODSTL IN=0FPROD1 OFPROD2 OFPROD3 OFPROD4 OFPROD5 OFPROD6 \& OUT=000PROD1 000PROD2 O00PROD3 000PROD4 000PROD5 000PROD6

; production columns=001DSTL thru 200DSTL, producing $1 \mathrm{~mol} / \mathrm{col}$ distillate

BLOCK 001DSTL IN=000PROD1 000PROD2 000PROD3 000PROD4 000PROD5 000PROD6 \& OUT=001PROD1 001PROD2 001PROD3 001PROD4 001PROD5 001PROD6

BLOCK 001SPLT IN=001PROD1 OUT=002FEED1 Z001TOPS

BLOCK 002DSTL IN=002FEED1 001PROD2 001PROD3 001PROD4 001PROD5 001PROD6 \& OUT=002PROD1 002PROD2 002PROD3 002PROD4 002PROD5 002PROD6

BLOCK 002SPLT IN=002PROD1 OUT=003FEED1 Z002TOPS

*

BLOCK 200DSTL IN=200FEED1 199PROD2 199PROD3 199PROD4 199PROD5 199PROD6 \& OUT=200PROD1 200PROD2 200PROD3 200PROD4 200PROD5 200PROD6

BLOCK 200SPLT IN=200PROD1 OUT=201FEED1 200TOPS

; feed streams=initial holdups fed to cond'r and trays $=0.0025[\mathrm{kmol}]$,

; and remainder charged to boiler $=200-12.5=0.01875[\mathrm{kmol}]$.

; atmospheric pressure, bubble-point temperature, D\&E Case 1 compositions

STREAM OAFEED1 PRES=1[ATM] VFRAC=0 NPHASE=2 MOLE-FLOW=0.00250[KMOLHR] MOLE-FRAC $\mathrm{C} 6 \mathrm{H} 12$ 0.62/ $\mathrm{C} 7 \mathrm{H} 80.38$

STREAM OAFEED2 PRES=1[ATM] VFRAC=0 NPHASE=2 MOLE-FLOW=0.00250[KMOLHR] MOLE-FRAC $\mathrm{C} 6 \mathrm{H} 12$ 0.62/ $\mathrm{C} 7 \mathrm{H} 80.38$

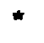

STREAM OAFEED6 PRES=1[ATM] VFRAC=0 NPHASE=2 MOLE-FLOW=0.1876[KMOL/HR] MOLE-FRAC C6H12 0.62/ C7H8 0.38 


\title{
Exhibit 4-2. Program for QSSCA Simulation of Batch Distillation, Accounting for Holdup (continued)
}

\author{
; typical examples of unit operations blocks \\ : startup columns=0ADSTL thru OFDSTL and 000DSTL, total internal reflux \\ BLOCK OADSTL RADFRAC ; rigorous fractionation calculationn \\ PARAM NSTAGE=6 EFF=MURPHREE ; 6 stages=cond' +4 trays + boiler \\ ; holdup feeds to condenser and trays, and charge to boiler \\ FEEDS OAFEED1 1 ON-STAGE/ \& ; condenser (top of column) \\ OAFEED2 2 ON-STAGEI \& ; ist tray \\ OAFEED3 3 ON-STAGE/ \& ; 2nd tray \\ OAFEED4 4 ON-STAGE/ \& :3rd tray \\ OAFEED5 5 ON-STAGEI \& ; 4 th tray \\ OAFEED6 6 ON-STAGE ; boiler (btm of column) \\ : liquid holdup products from condenser, trays and boiler \\ PRODUCTS OAPROD1 $1 / \&$; cond'rs phase $=1$ \& flow=.0025 set in COL-SPECS \\ OAPROD2 2 PHASE=L MOLE-FLOW=0.0025[KMOLHR] \& \\ OAPROD3 3 PHASE $=L$ MOLE-FLOW $=0.0025[\mathrm{KMOL} / \mathrm{HR}] / \&$ \\ OAPROD4 4 PHASE $=L$ MOLE-FLOW $=0.0025[\mathrm{KMOL} / \mathrm{HR}] / \&$ \\ OAPROD5 5 PHASE=L MOLE-FLOW=0.0025[KMOL/HR]/ \& \\ OAPROD 6 ; boiler's holdup is its charge to the next column \\ P-SPEC 1 1[ATM] ; operating pressure \\ COL-SPECS MOLE-RDV $=0$ MOLE-RR $=3$ MOLE-D=0.0025[KMOL/HR] \\ ; total condenser $\Rightarrow$ distillate vap/liq $=0$, molar reflux ratio $=3$, \\ ; distillate $=0.0025[\mathrm{kmol} / \mathrm{col}]=$ condenser's holdup product \\ STAGE-EFF 1 1.0/ $20.75 / 30.75 / 40.75 / 50.75 / 61.0$; Murphree efficiencies \\ ; production columns=001DSTL thru 200DSTL, producing 1[mol/hr-col] distillate \\ BLOCK 001DSTL RADFRAC ; typical production column \\ PARAM NSTAGE $=6$ EFF=MURPHREE \\ FEEDS OOOPROD 11 ON-STAGEI \& \\ OOOPROD2 2 ON-STAGEI \& \\ OOOPROD3 3 ON-STAGEI \& \\ OOOPROD4 4 ON-STAGEI \& \\ OOOPROD5 5 ON-STAGEI \& \\ OOOPROD6 6 ON-STAGE \\ PRODUCTS 001PROD1 1/ \& \\ 001PROD2 2 PHASE=L MOLE-FLOW=0.0025[KMOL/HR]/ \& \\ 001PROD3 3 PHASE $=L$ MOLE-FLOW $=0.0025$ [KMOL/HR] \& \\ 001PROD4 4 PHASE=L MOLE-FLOW=0.0025[KMOL/HR]/ \& \\ 001PROD5 5 PHASE $=$ L MOLE-FLOW $=0.0025[\mathrm{KMOL} / \mathrm{HR}] / \&$ \\ D01PROD6 6 \\ P.SPEC 1 1[ATM] \\ COL-SPECS MOLE-RDV=0 MOLE-RR=3 MOLE-D=0.0035[KMOL/HR] \\ · STAGE-EFF $11.0 / 20.75 / 30.75 / 40.75 / 50.75 / 61.0$ \\ BLOCK 001SPLT FSPLIT \\ MOLE-FLOW 002FEED1 0.0025[KMOLHR] \\ ; 001PROD1 $=0.0035[\mathrm{kmol} / \mathrm{col}]=$ distillate, is split between \\ ; 002FEED1 $=0.0025[\mathrm{kmol} / \mathrm{col}]=$ cond'r holdup to next column, and \\ ; Z001TOPS $=0.0010[\mathrm{kmol} / \mathrm{col}]=$ product
}




\section{Exhibit 4-3. Program for QSSCA Simimulation of Batch Distillation, Shortcut Column Calculation}

TITLE "Batch Distillation Sim'n w/ QSSCA, Shortcut Col Calc'n w/ No Holdup, 10mol/Step" DESCRIPTION " Design \& Operating Conditions for Domenech \& Enjalbert's [D9,D11] Case 4"

IN-UNITS MET ;metric

OUT-UNITS MET

COMPONENTS C6H12 CYCLOHEXANE C6H12/ C7H8 TOLUENE C7H8

DATABANKS ASPENPCD ; ASPEN PLUS Component Data Bank

PROP-SOURCES ASPENPCD

PROPERTIES SYSOP7 ; UNIFAC/Redlich-Kwong

FLOWSHEET ; chain of columns to integrate batch distillation in $10 \mathrm{~mol}$ distillate steps

$\begin{array}{ll}\text { BLOCK 000DSTL IN=FEED } & \text { OUT=Z000TOPS 000BTMS } \\ \text { BLOCK 010DSTL IN=000BTMS } & \begin{array}{l}\text { OUT=Z010TOPS 010BTMS } \\ \text { OUT=Z020TOPS 020BTMS } \\ \text { BLOCK 020DSTL IN=010BTMS }\end{array} \\ \star & \\ \text { BLOCK 190DSTL IN=180BTMS } & \text { OUT=Z190TOPS 190BTMS } \\ \text { BLOCK 200DSTL IN=190BTMS } & \text { OUT=Z200TOPS 200BTMS }\end{array}$

; shortcut columns have one feed and two outputs: TOPS=distillate product

; and BTMS=remaining charge fed to next column

; feed stream is initial charges to first batch boiler

STREAM FEED PRES=1[ATM] VFRAC=0 NPHASE=2 MOLE-

FLOW $=0.200[K M O L A R]$

MOLE-FRAC C6H12 0.30/ $\mathrm{C7H} 80.70$; for RR=5

; atmospheric pressure and bubble-point temperature, D\&E Case 4 compositions

;ypical examples of unit operations blocks

BLOCK 000DSTL DISTL ; first column distills $0.002 \mathrm{~mol}$ to find initial distillate composition PARAM NSTAGE $=5$ FEED-LOC $=5$ RR=5 D:F=0.00001 \& : distill/feed $=.002 \mathrm{~mol} / 200 \mathrm{~mol}$

COND-TYPE $=$ TOTAL PTOP=1[ATM] PBOT=1[ATM]

BLOCK 010DSTL DISTL ; edmister shortcut column calculation

PARAM NSTAGE $=5$ FEED-LOC $=5$ RR=5 $D: F=0.05 \&$

COND-TYPE=TOTAL PTOP=1[ATM] PBOT=1[ATM]

; column has 5 stages (incl. boiler) plus total cond'r, feed to stage $5=b$ tm=boiler

; reflux ratio $=5$, distillate $/$ feed $=0.05=10 \mathrm{~mol} / 200 \mathrm{~mol}$, $1 \mathrm{~atm}$ oper. pressure

BLOCK 0200STL DISTL

PARAM NSTAGE=5 FEED-LOC=5 RR=5 $D: F=0.05263$ \& ;

distill/feed $=10 \mathrm{~mol} / 190 \mathrm{~mol}$

COND-TYPE=TOTAL PTOP=1[ATM] PBOT=1[ATM]

*

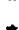

BLOCK 190DSTL DISTL

PARAM NSTAGE=5 FEED-LOC=5 RR=5 D:F=0.5 \& ; distill/feed $=10 \mathrm{~mol} / 20 \mathrm{~mol}$ COND-TYPE=TOTAL PTOP=1[ATM] PBOT=1[ATM]

BLOCK 200DSTL DISTL ; last col distills 9.9999 of $10 \mathrm{~mol}$ remaining, to avoid error PARAM NSTAGE $=5$ FEED-LOC $=5$ RR=5 $D: F=0.99999$ \&

COND-TYPE $=$ TOTAL PTOP=1[ATM] PBOT $=1$ [ATM] 


\subsection{Results and Discussion}

All the simulations ran with no errors. In some simulations, all of the light component went overhead before the boiler was empty. When this occurred, ASPEN PLUS issued warnings objecting to continuing distillation with only one component. This warning did not indicate a real problem. All the results were rational: mol fractions between 0 and 1, flowrates positive, etc. ASPEN PLUS's calculations of its unit operations models, mostly distillation columns all converged. The runs were stable. As simulation and process parameters changed, the results changed in reasonable ways, not showing excessive sensitivity or blowing-up.

Running these ASPEN PLUS programs to simulate the test cases generated voluminous output. Distillation curve data were extracted from the output. Some are shown in this chapter and Chapter 3, and all are collected in Appendix B. Appendix A contains a short example of ASPEN PLUS output.

Besides being "computer correct," the results make "chemical engineering sense." All unit operations and overall flowsheets are in material and energy balance (Appendix A). The more volatile component, cyclohexane, distills above the less volatile, toluene. Figure 4-2 shows that the light component concentration increases, and the heavy component concentration decreases along the column from boiler to condenser, throughout the distillation. Following the distillate composition over time in Figure 4-3, all simulations show a plateau of cyclohexane, which falls off as it distills away and toluene begins distilling. The 


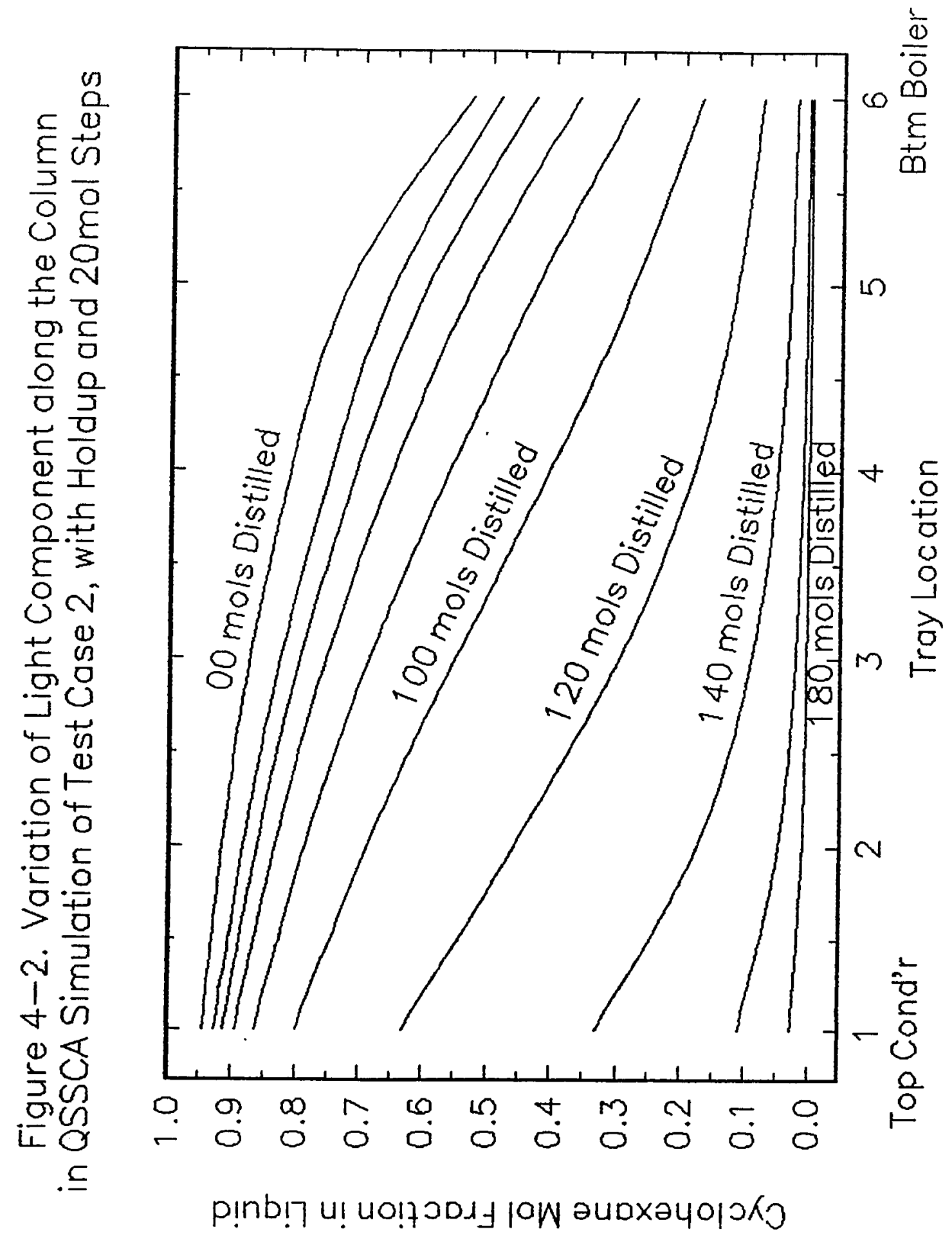




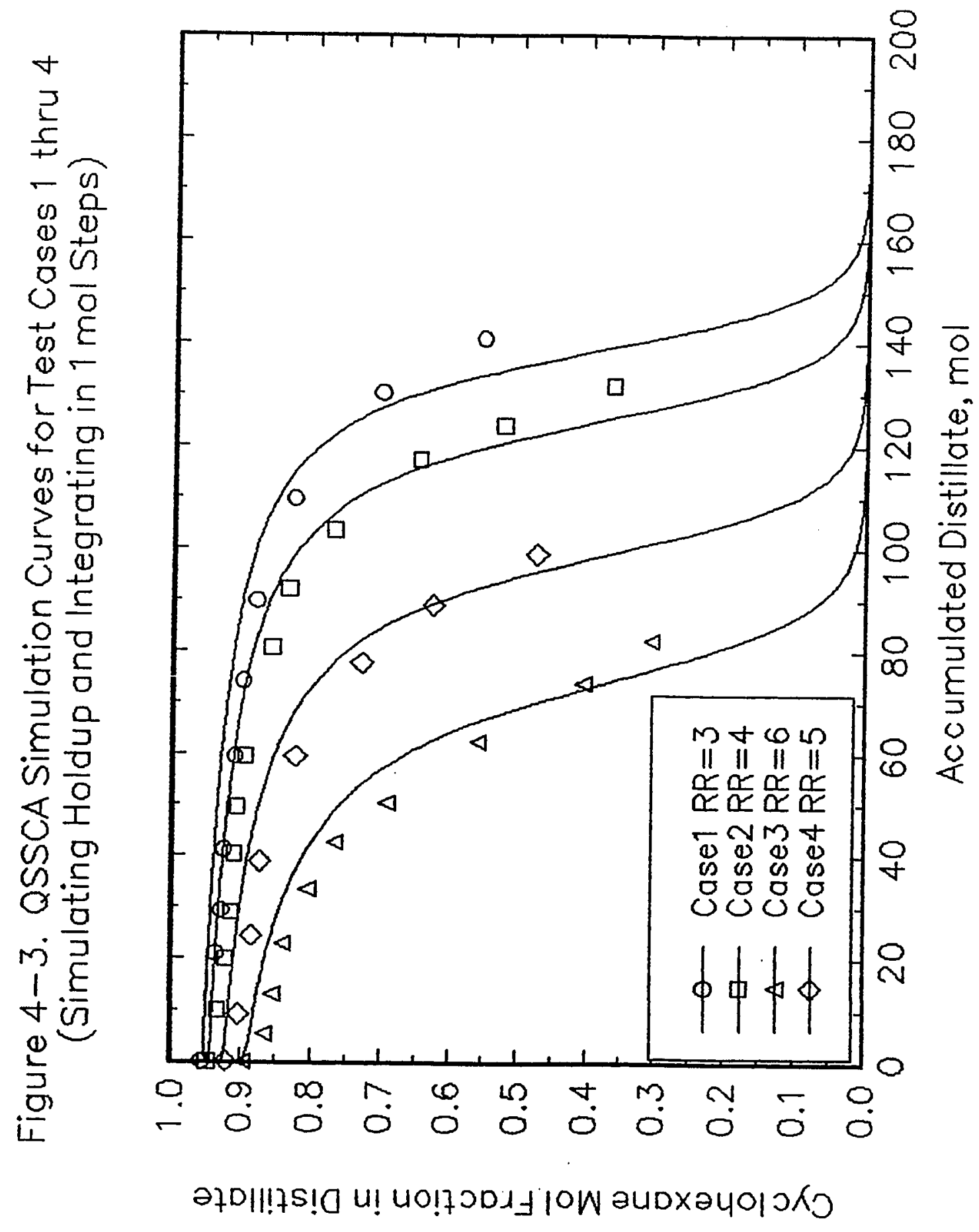


simulations respond to changes in process conditions as distillations normally do. When the initial charge to the boiler is richer in the light component, the first distillate is richer in it too. Comparing Cases 1 and 2 with Cases 3 and 4 in Figure 4-3 shows this. When the reflux ratio is higher, the break in the distillation curve after the light plateau is sharper. Comparing Case 3 with Case 4 demonstrates this. These comparisons are not as clear-cut as one might wish, because the boiler charge and the reflux ratio vary simultaneously in these tests.

Figures 4-4 and 4-5 compare published simulations and simulations from this study against experimental data. Domenech and Enjalbert's model uses a fully dynamic approach. Its predictions are in excellent accord with their experimental results. Galindez and Fredenslund's (1988b) model uses QSSCA. Its predictions capture the shapes of the distillation curves, and predict the distillate accumulations when the curves break. However, its distillate cyclohexane predictions are a bit too high during the first part of distillation, before the break. This study's simulation, using a similar model, gives similar results. In Cases 1 and 2, its predictions follow the cyclohexane plateaus well, and simulate the curves' breaks almost as well as Galindez and Fredenslund's model. In Cases 3 and 4, its predictions follow the plateaus more closely than Galindez and Fredenslund's model; after the break both models give equally good, though not identical, predictions of the curves. Both this simulation and Galindez and Fredenslund's simulation predict the cyclohexane plateau too high. This could be due to many factors, including inexact correspondence between the physical 


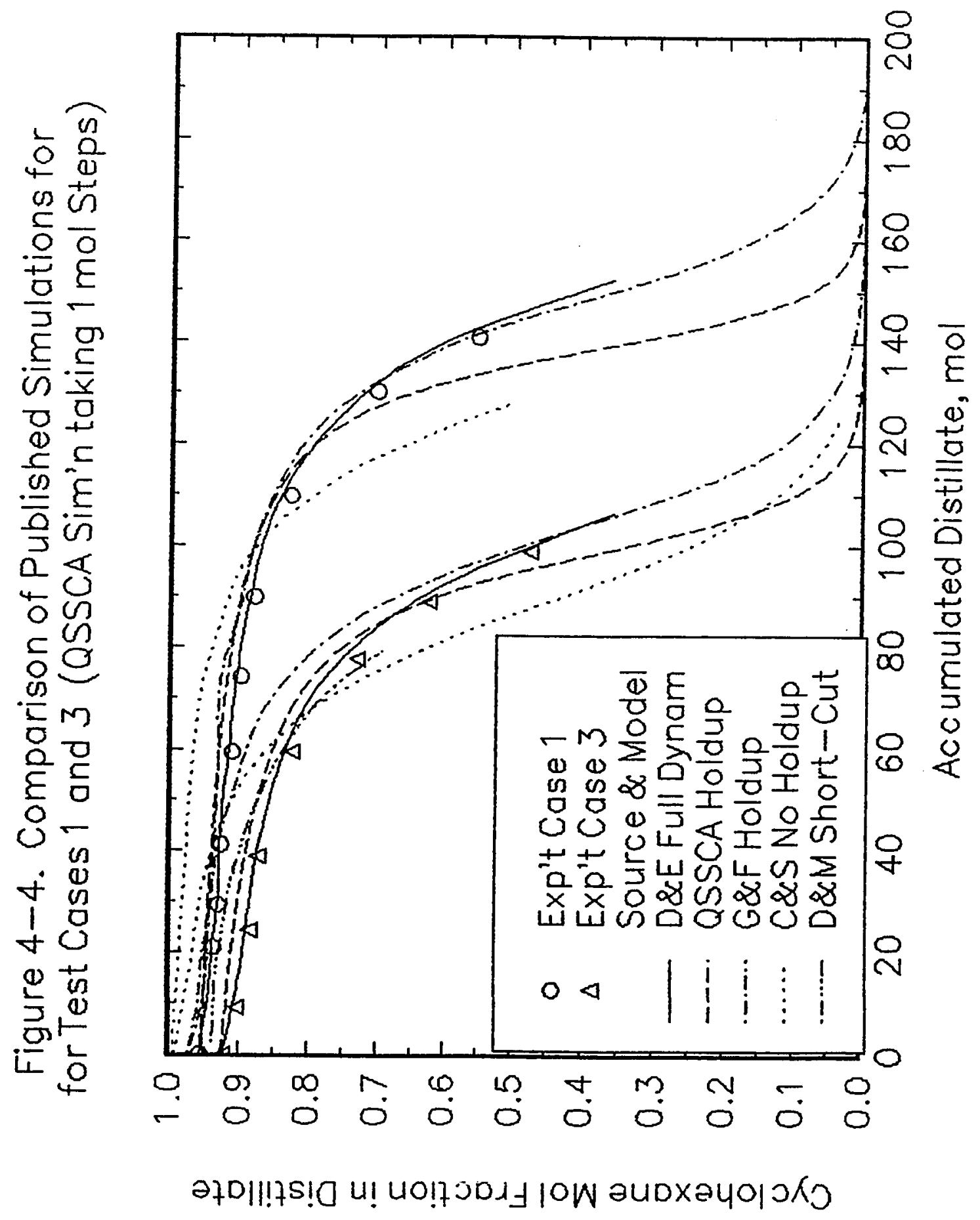




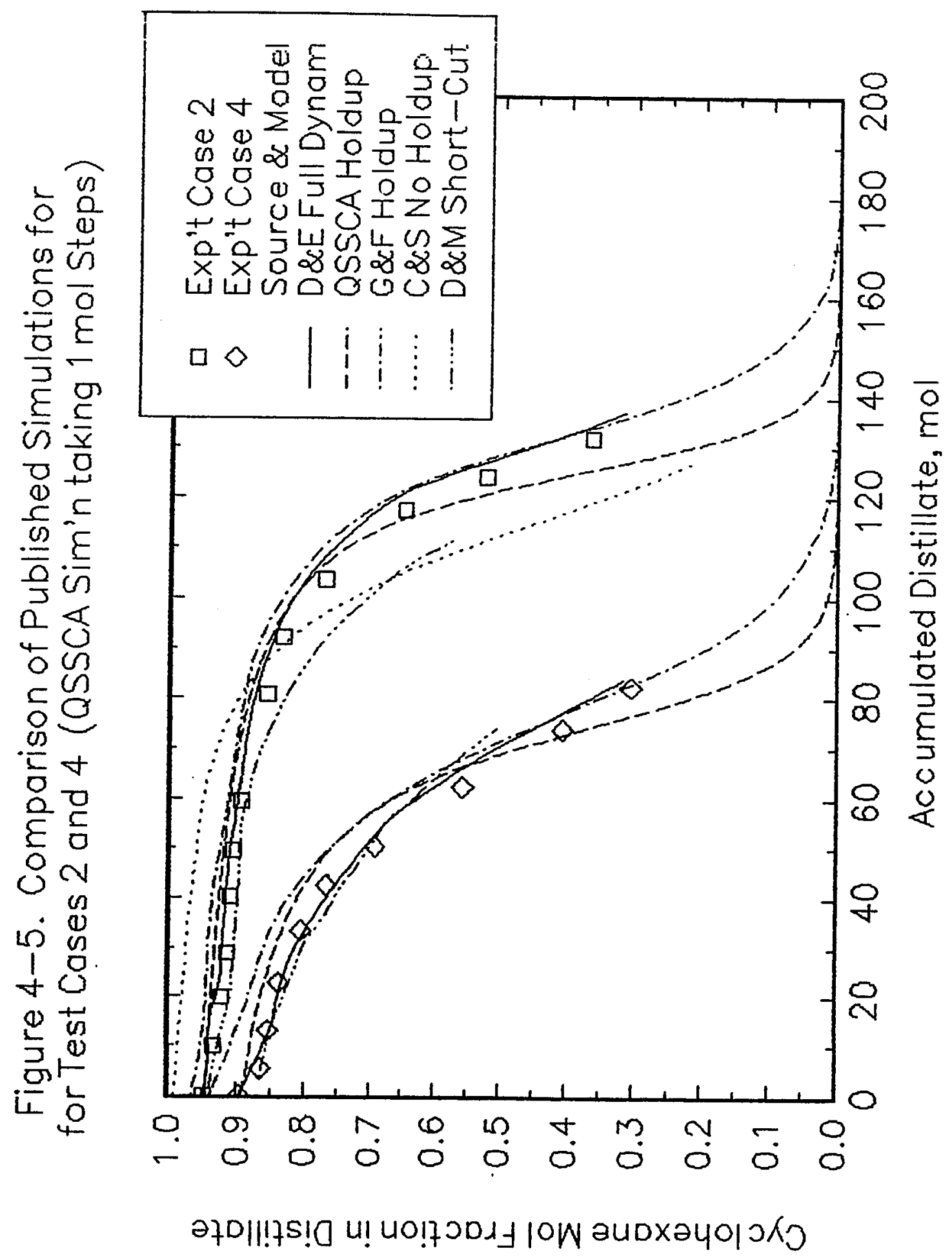


properties model and the actual chemical system. In both simulations, the overprediction of the plateau increases as reflux ratio increases; this is most clearly seen by comparing Cases 1 and 3, with reflux ratios of 3 and 6, in Figure 4-4. This trend could be the result of using a constant stage efficiency of $75 \%$. The efficiency could decrease as vapor and liquid flowrates increases with the reflux ratio. Decreasing efficiency would degrade separation and lower the cyclohexane plateau.

Chiotti and Scenna's (1989) model also uses QSSCA, but, unlike Galindez and Fredenslund's, it neglects holdup. The agreement of their model's predictions with experimental results is poorer than that of Domenech and Enjalbert's or Galindez and Fredenslund's models. During the first part of the distillation, it predicts distillate cyclohexane values that are far too high. With material balance, these high values cause it to predict the break in the distillation curve far too early. This is true in Cases $1,2,3$; they did not publish predictions for Case 4. Diwekar and Madhavan's (1991c) model uses QSSCA with a short-cut column calculation; other models employ plate-to-plate column calculations. The accuracy of its predictions varies in Cases 2, 3 and 4; they did not report on Case 1. In Case 2, it predicts the early distillate quite well, but it predicts the break from the plateau too early. It predicts the plateau too high in Case 3. In Case 4, its predictions follow the experimental points closely. Overall, this study's model compares quite favorably with those in the literature. 
These results suggest that simplifying the model degrades the accuracy of its predictions. The correlation of complexity and accuracy in the literature is only a correlation. The literature contains different models by different investigators, so factors besides complexity may be at work. Published accounts lack sufficient detail to identify and control for these factors. In the work reported here, these extraneous factors are under control, and examining the complexity and accuracy relationship should be possible. Figures $4-6$ and 4-7 compare converged simulations by the three column models. The simplest model, which uses short-cut column calculations, gives the poorest predictions. However, the most complex model, which does plate-to-plate column calculations and accounts for holdup, does no better than the simpler model, which calculates plate-to-plate but neglects holdup. Thus, this study's results are ambiguous on the complexity and accuracy relationship, probably because holdup can be neglected in these cases.

Publications generally report only the final converged results of a model. They seldom report on convergence behavior. This work retains that information and discusses it. Figures 3-3 and 4-8 show the behavior of the simulations as distillate step-size decreases. As step-size decreases from 50 to 20 to ... to 2 to $1 \mathrm{~mol}$ out of a $200 \mathrm{~mol}$ batch, the simulations show no signs of instability. At all points along their lengths, the difference between successive distillation curves decreases as step-size decreases, and they converge toward a final result. Aside from small differences, the three column models show similar be- 


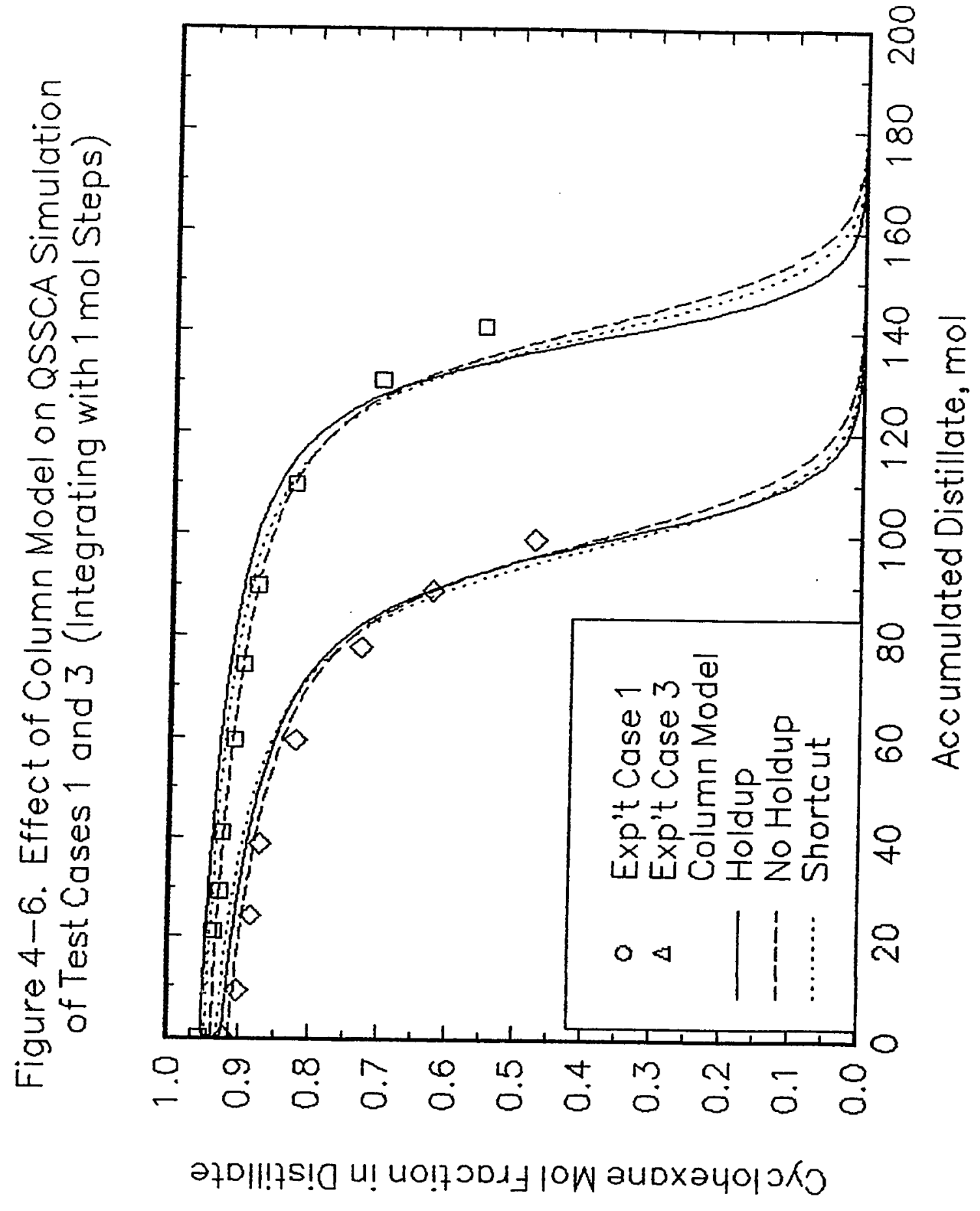




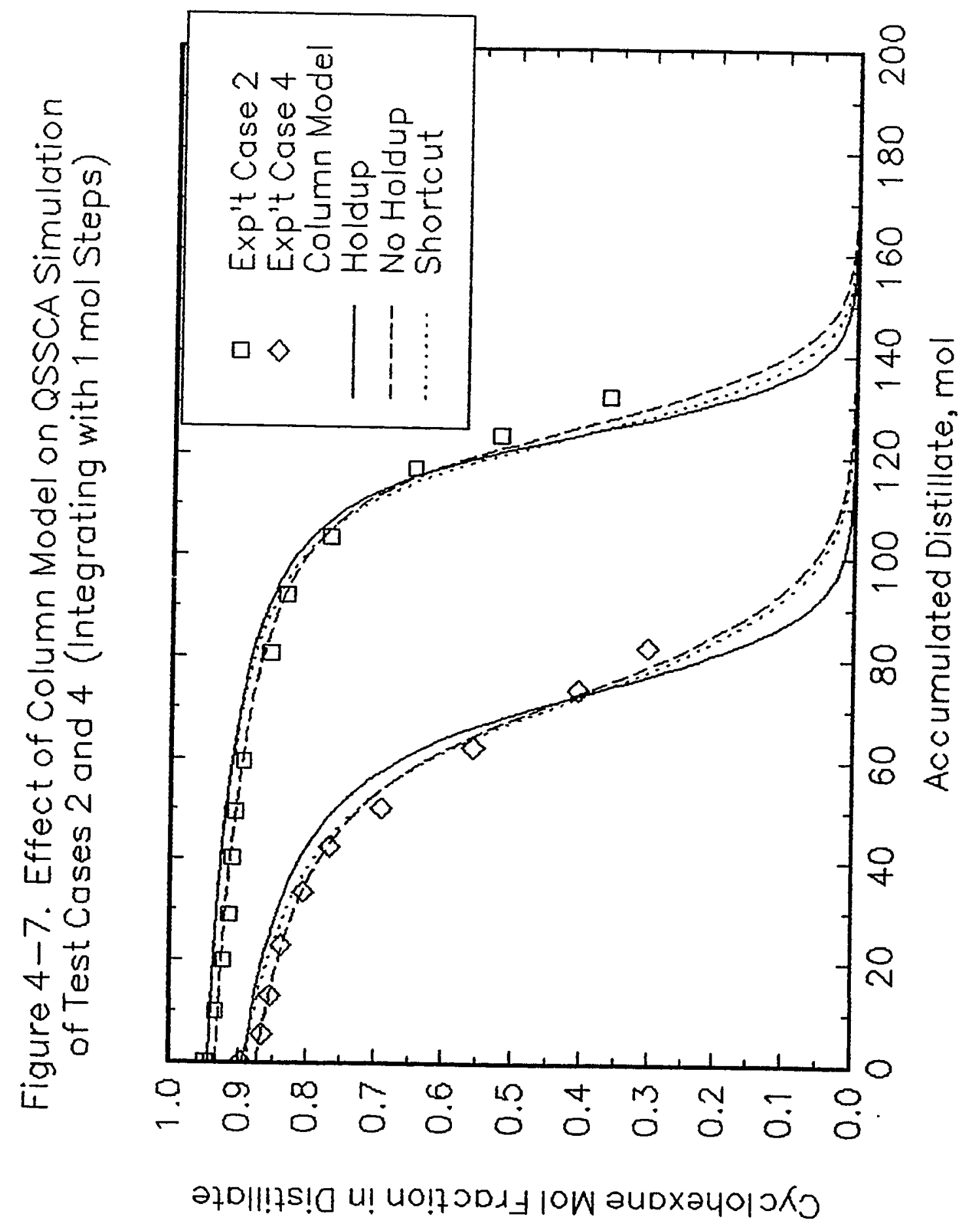

62. 


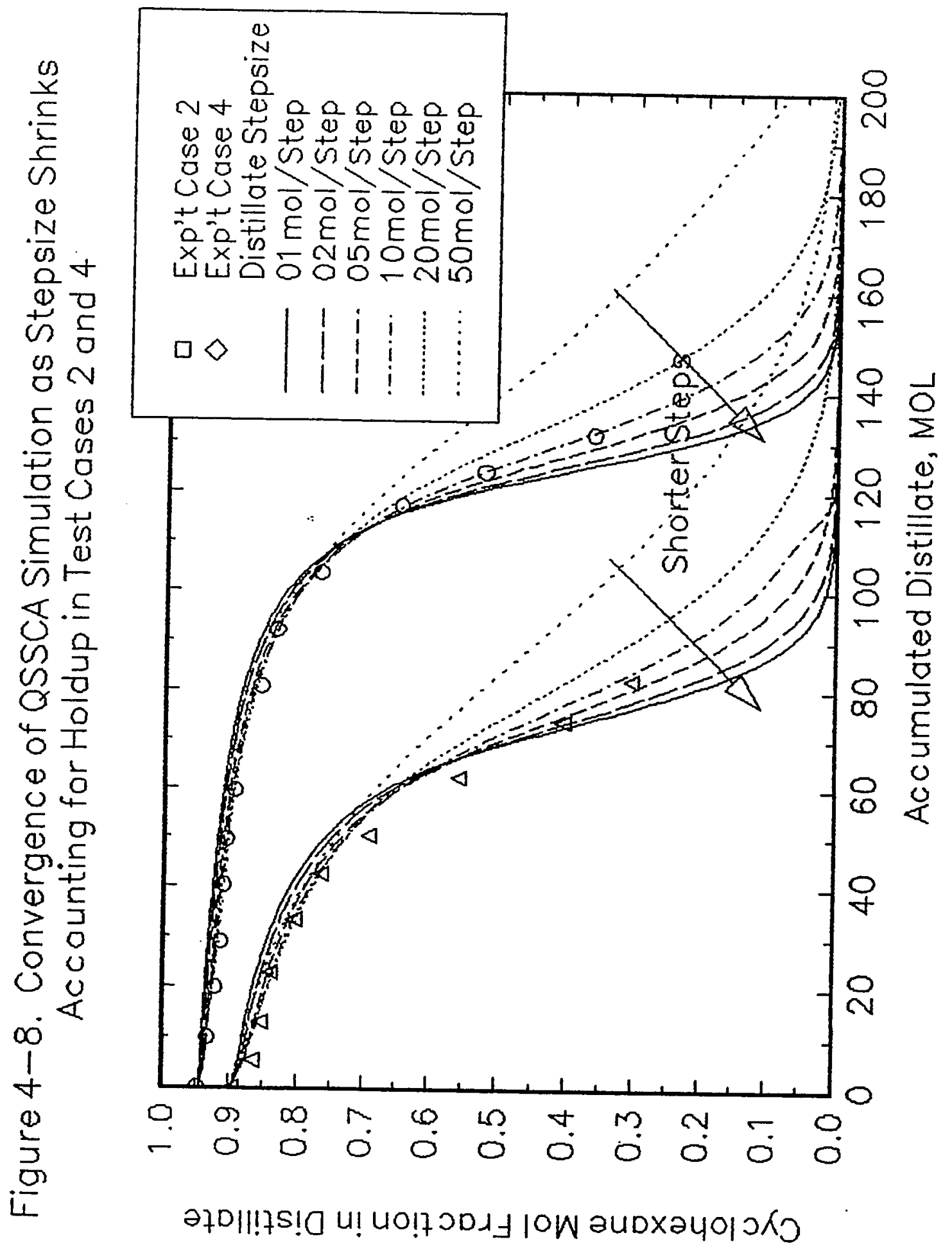


havior in all four cases. As the curves converge, they do not always converge to their best agreement with the experimental results. During the light component plateau before the break, the No Holdup and Short-Cut simulations converge down to better agreement with the experimental points. The Holdup simulation converges slightly upward and away from the experiment during this period, though its shape improves. After the break, all the simulation curves drop below Domenech and Enjalbert's last few points as they converge. The break sharpens as the step-size decreases. 


\section{CHAPTER 5. CONCLUSIONS ON HYPOTHESES}

Chapter 1 states the motivations for this investigation: the importance of batch distillation, the necessity for process simulation in batch column design, and the shortcomings of existing simulation software. It finds "an unmet need for an easy procedure for implementing batch distillation simulation using the quasisteady-state column approximation (QSSCA) in a widely available flowsheet simulator." This finding leads to the research objective: "to develop and investigate a straightforward implementation of the quasi-steady-state column approximation approach to batch distillation simulation on a commercial modular process simulator." To achieve this objective, this study investigated three hypotheses. This section will summarize the conclusions of this investigation.

The first and third hypotheses are:

"A batch distillation simulation based on the QSSCA approach can be implemented on a prototypical, commercial, modular process simulator."

"A general paradigm can be illustrated to facilitate implementation of this simulation technique."

The Methods Development and Results Chapters demonstrate the truth of these hypotheses. Chapter 3 justifies the QSSCA approach with a discussion of how a steady-state model can simulate a batch process over a short interval. Step 1 in Exhibit 5-1 summarizes general principles for creating a steady column model simulating a batch distillation column. Using this facility for simulating intervals of 
batch distillation, Chapter 3 describes how to integrate these intervals to predict the distillate and raffinate compositions and volumes during distillation. This involves a chain of columns, one for each step-of-integration, where the bottoms and holdups of one column are the feeds to the next. The numerical integration is converged by adding columns to the chain, to decrease the size of the intervals, until the results are not changing by more than a specified tolerance. The simulation is programmed first with short-cut column calculations and neglecting column holdup and then with rigorous column calculations, neglecting and accounting for holdup. The results are compared to determine if there is a significant difference which justifies the more rigorous approach. Table 5-1 summarizes the procedure above. Development of general criteria determining which processes need the rigorous approach and which can use short-cut calculations is beyond the scope of this study. This determination can be done on a case-bycase basis by engineers using this procedure.

These principles have been applied before, for example the freestanding programs of Galindez and Fredenslund (1988b), and Diwekar and Madhavan (1991c). This study extends this work, applying this approach within the environment of a general purpose process simulator (GPPS). Chapters 3 and 4 describe how to apply these principles to translate Domenech and Enjalbert's description of batch distillation experiments $(1974 a, b)$ into a model in ASPEN PLUS. Domenech and Enjalbert's batch column is not atypical, and the ASPEN PLUS program uses only the primary commands available in the simulation language, 
no tricks or custom FORTRAN modules. Therefore the paradigm should be quite general, and allow simulation of many batch columns for which a GPPS can provide a steady column model. However widely applicable, this approach surely will not be universal. Therefore, in each new application, the user must independently assess the accuracy of its predictions before using them for design.

The second hypothesis is "Results from this simulator are comparable with the results of published simulations using the QSSCA approach." In Chapter 4 and Appendices $A$ and $B$, the test results demonstrate the success of this simulator. It runs correctly, according to both mathematical and chemical engineering criteria, and it closely approximates experimental batch distillation curves. Its performance is better than that of Chiotti and Scenna's (1989), and Diwekar and Madhavan's (1991c) simple QSSCA simulations, and comparable to Galindez and Fredenslund's sophisticated QSSCA simulation (1988b). However, it is not as accurate as the rigorous fully dynamic (RFD) simulation of Domenech and Enjalbert $(1974 a, b)$. This performance leads to the recommendation to use QSSCA with short-cut models for preliminary design scouting, use QSSCA with rigorous columns to optimize, and use RFD simulation to check the final design and investigate process control. All of this can be done in the same process simulator environment, using the techniques developed in this thesis. 


\section{Exhibit 5-1. Procedure for Simulating Batch Distillation with a Steady Column in a General Purpose Process Simulator}

1) Formulate a steady column model of the batch column according to the principles developed in Chapter 3.

a) Over the time interval being modeled, the feed to the steady process must equal the quantity and composition of the initial inventory in the batch process. For example, $100 \mathrm{~kg} / \mathrm{hour}$ feed to a steady process to model batch processing of $100 \mathrm{~kg}$ for one hour.

b) The heat and distillate production rates in the steady and batch processes should be equal.

c) The steady and batch processes should have the same column design (number of stages, stage efficiency, operating pressure, etc.).

d) Holdups in the batch column should be simulated as stage feeds and products in the steady column model as described by Galindez and Fredenslund.

e) Holdups should be established in the steady column by simulating operation with total internal reflux before distillate production begins.

2) Program the flowsheet simulator for the steady column model.

3) Run the simulation and correct the inevitable programming errors.

4) Divide the batch distillation into intervals and add a steady column model for each interval to integrate the simulation over the whole process

5) Run the integrating simulation. Check the results with chemical engineering logic to be sure that they are reasonable. Compare the results with experiments, if possible.

6) Decrease the interval size and re-run the simulation until it has converged.

7) Use short-cut column calculations and neglect column holdup in the simulation procedure described above.

8) Use rigorous column calculations, neglecting and accounting for column holdup in the simulation.

9) Compare the three results to determine if there is a significant difference which justifies the more rigorous approach. 


\section{APPENDIX A. EXAMPLE OF SIMULATOR OUTPUT}

This example was generated by running the program 50D3RHU.INP in ASPEN PLUS by the command: "ASPEN 50D3RHU.INP 50D3RHU." After the run, ASPEN PLUS's history and report files were combined into an output file with the command: "GENOUT 50D3RHU." 


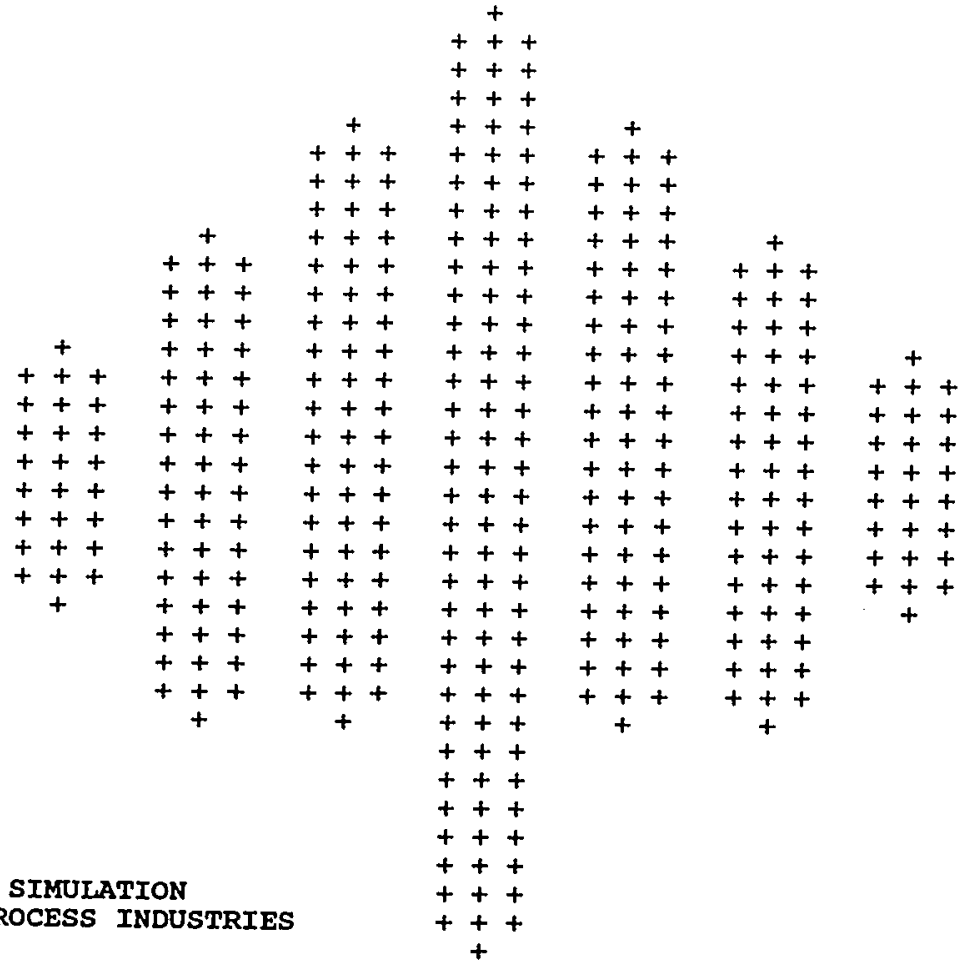

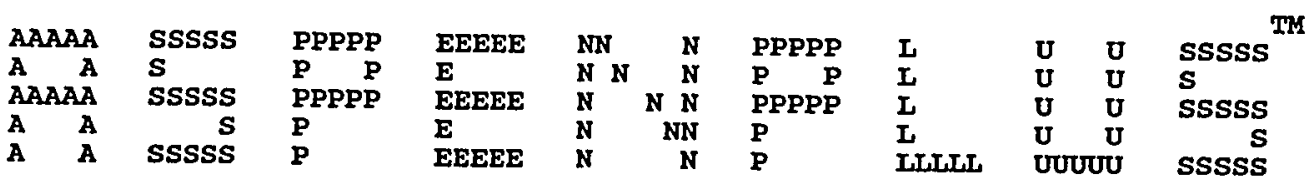

ASPEN PLUS IS A TRADEMARK OF ASPEN TECHNOLOGY, INC.

251 VASSAR STREET

CAMBRIDGE, MASSACHUSETTS 02139 617-497-9010

VERSION: DOS-386

RELEASE: 8.4-1

INSTALLATION: sjsu-utv

HOTLINE :

U.S.A. 617-497-9010

EUROPE 31-70-3541051

JANUARY 4, 1993

MONDAY

8:31:00 A.M.

ASPEN PLUS (TM) IS A PROPRIETARY PRODUCT OF ASPEN TECHNOLOGY, INC. (ASPENTECH), CAMBRIDGE, MASSACHUSETTS, AND MAY BE USED ONLY UNDER AGREEMENT WITH ASPENTECH OR THROUGH NETWORK SERVICES LICENSED BY ASPENTECH. ASPEN PLUS(TM) IS A TRADEMARK OF ASPENTECH. THE ASPEN I PLUS COMPUTER SOFTWARE SYSTEM IS USED FOR FLOWSHEET SIMULATION. 


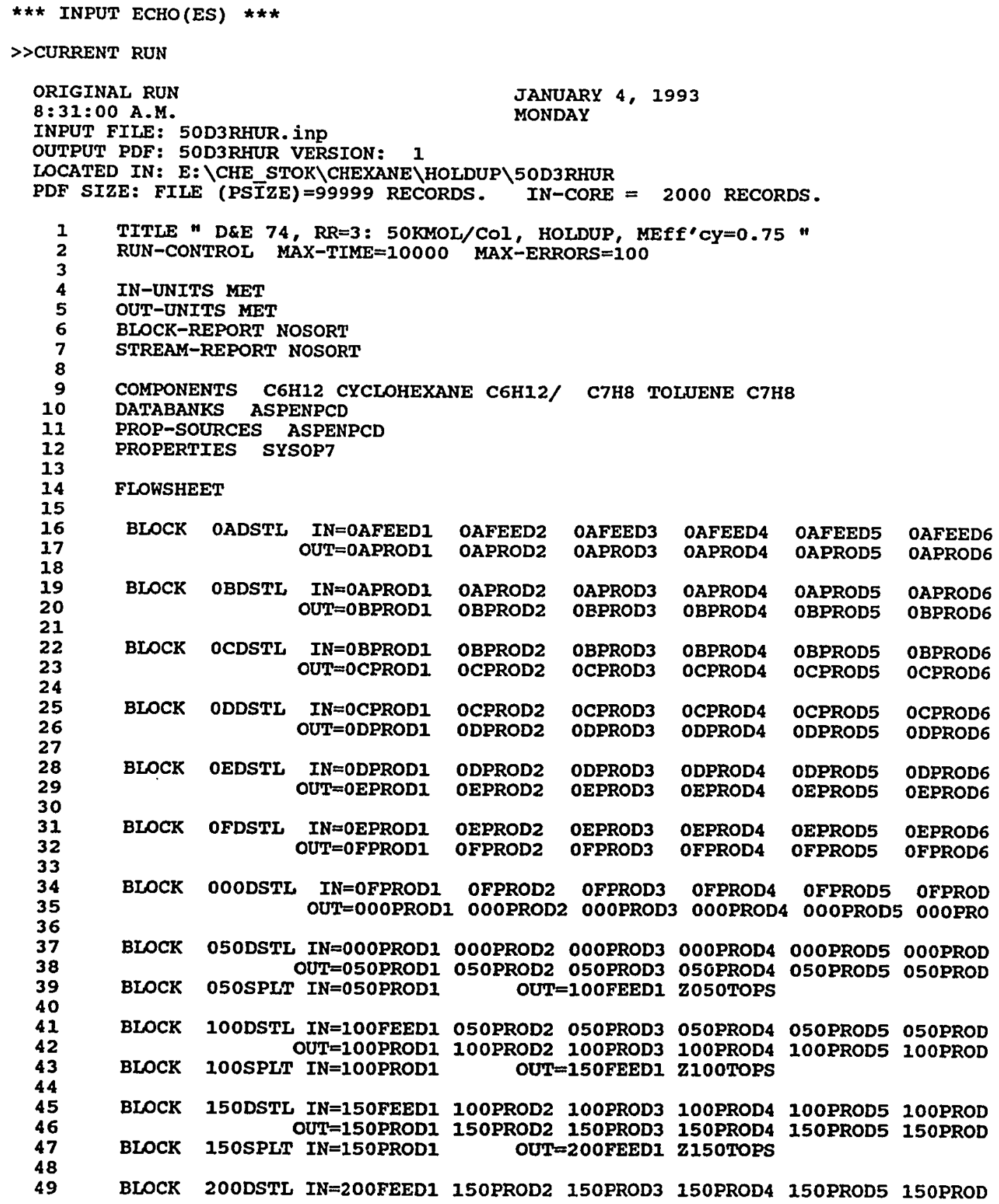

BLOCK DOODSTL IN=OFPROD1 OFPROD2 OFPROD3 OFPROD4 OFPROD5 OFPROD OUT=OOOPROD1 OOOPROD2 OOOPROD3 OOOPROD4 OOOPROD5 OOOPRO

BLOCK O5ODSTL IN=0OOPROD1 OOOPROD2 OOOPROD3 OOOPROD4 OOOPROD5 OOOPROD BLOCK OUT=05OPROD1 O5OPROD2 O5OPROD3 O5OPROD4 O5OPROD5 O5OPROD

BLOCK 200DSTL IN=200FEED1 150PROD2 150PROD3 150PROD4 150PROD5 150PROD 


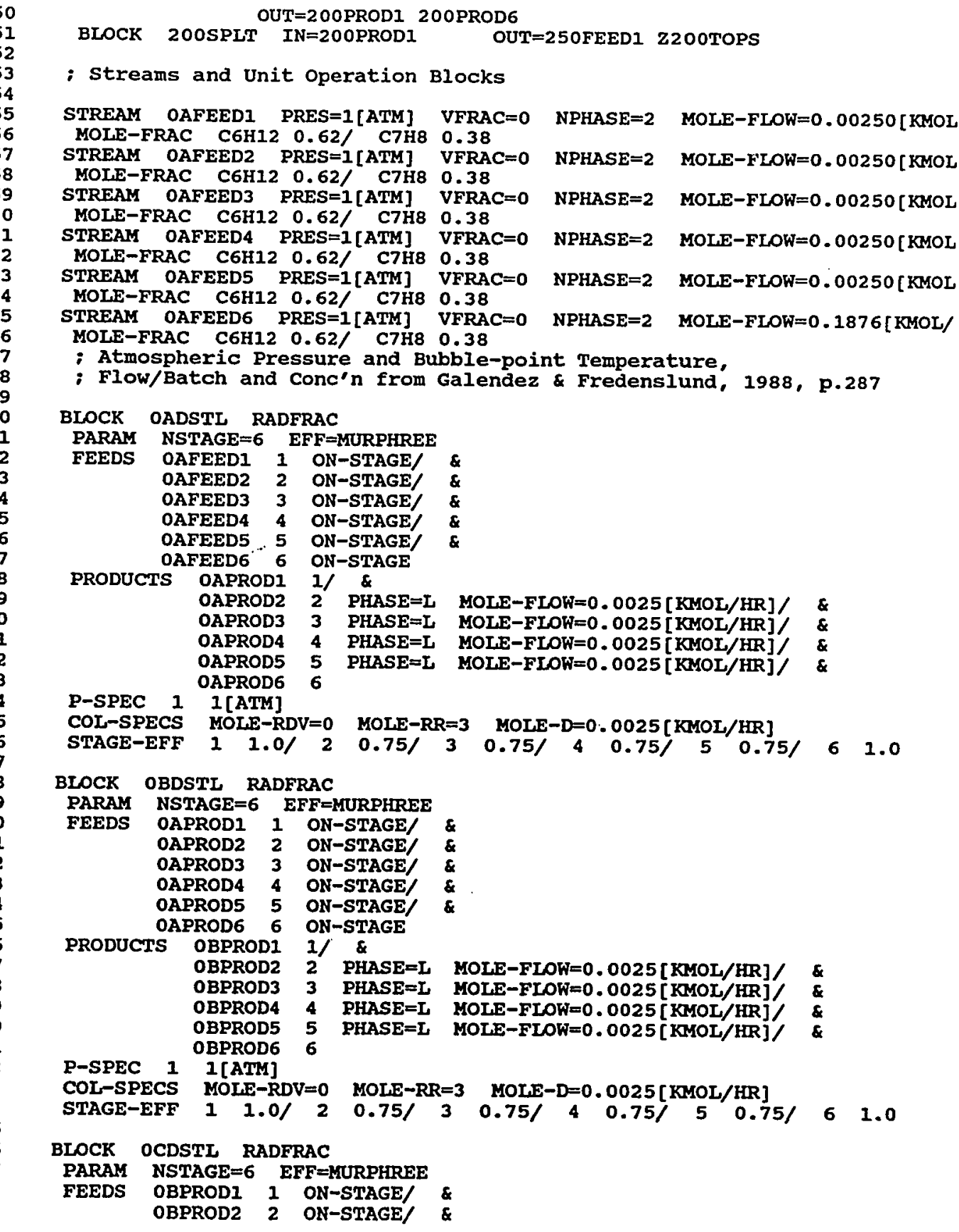




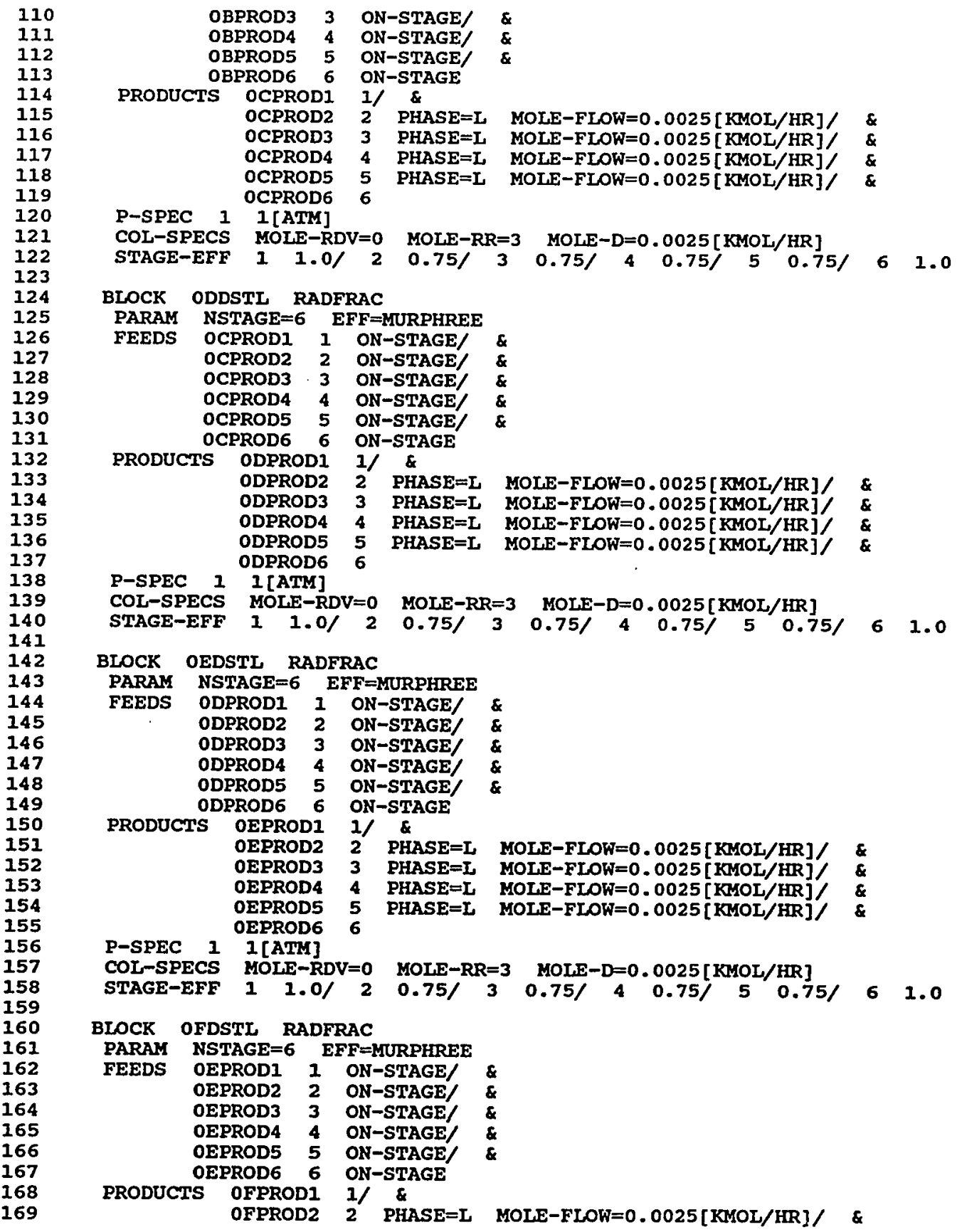




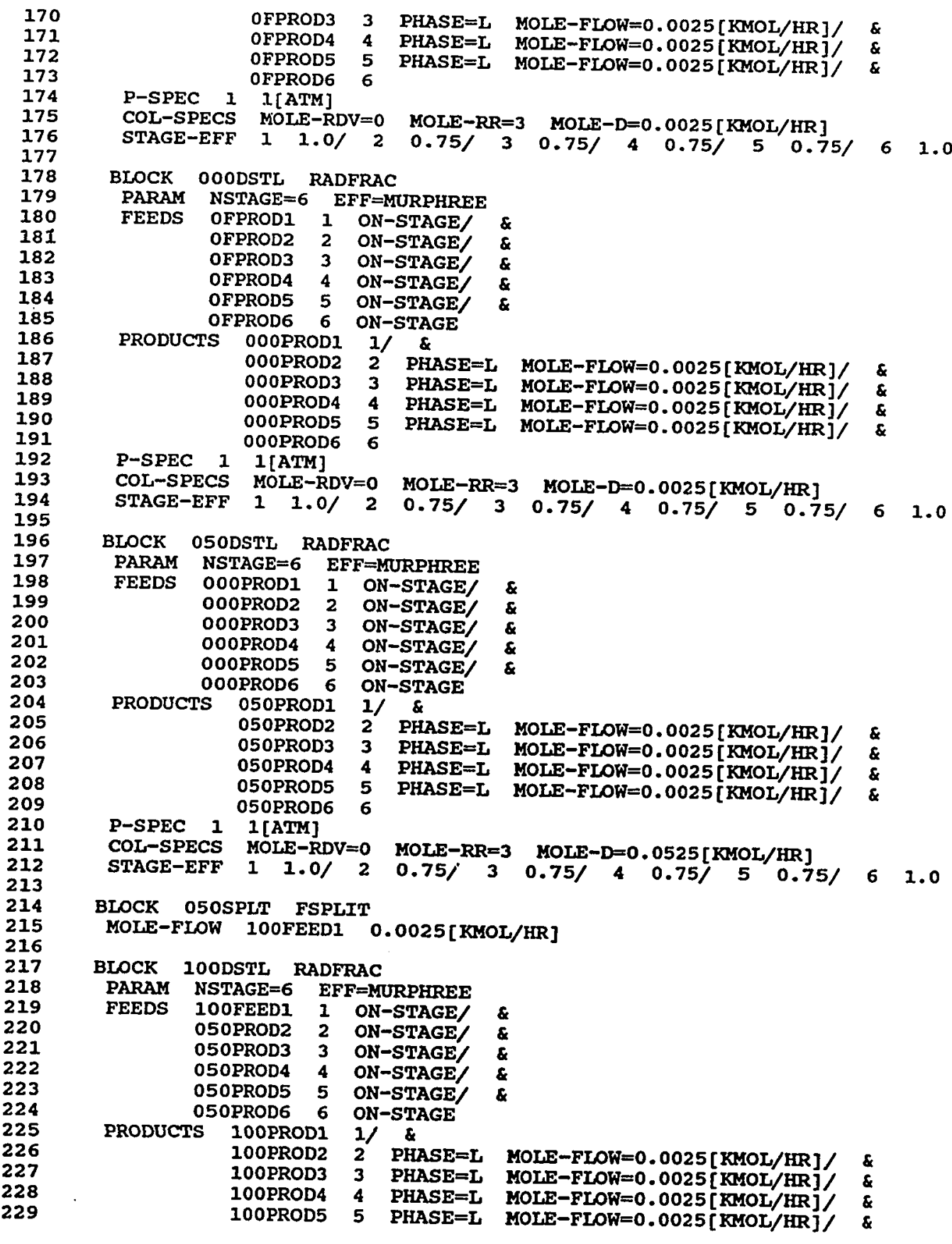




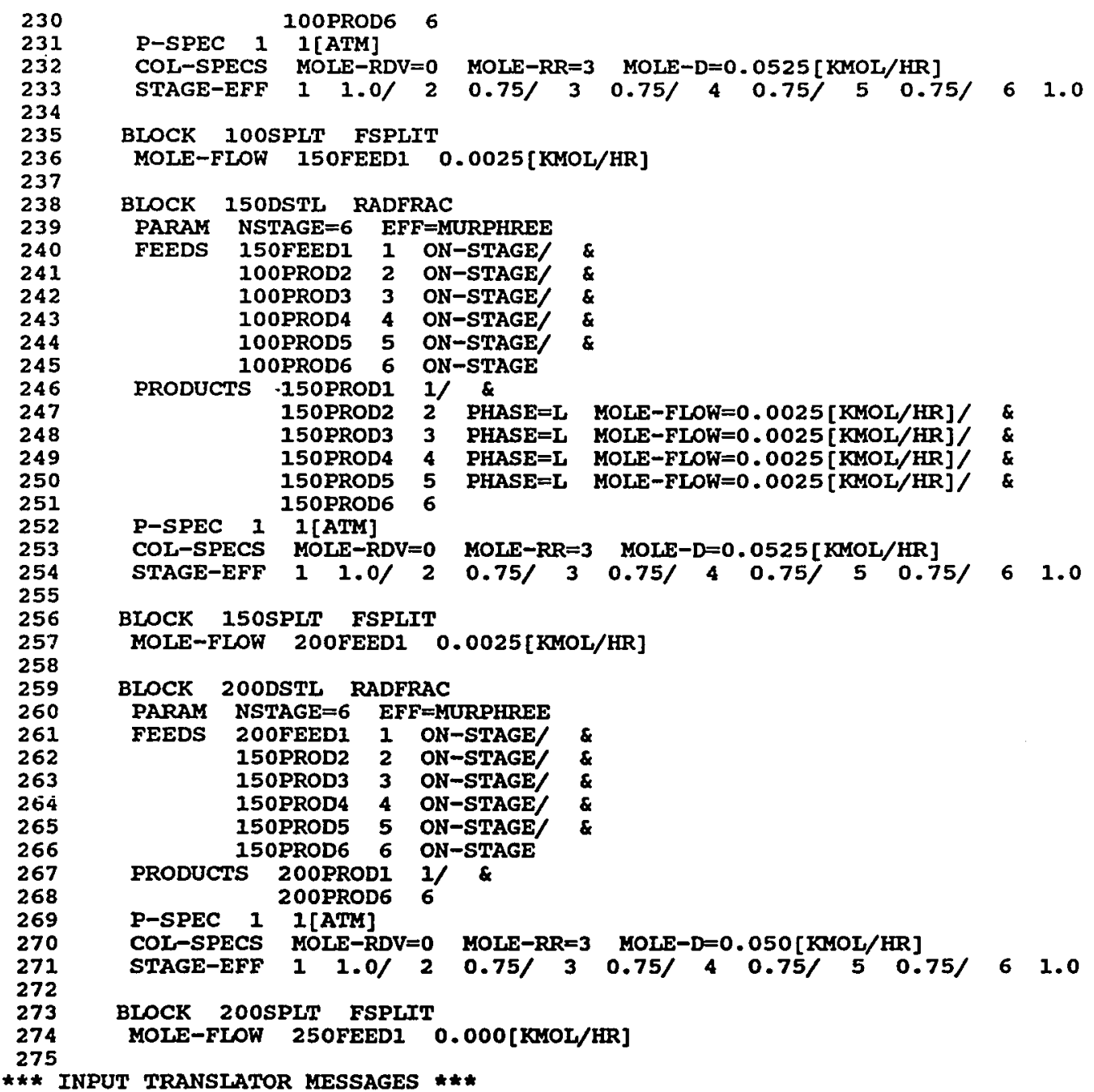

THIS VERSION OF ASPEN PLUS LICENSED TO SAN JOSE STATE UNIVERSITY

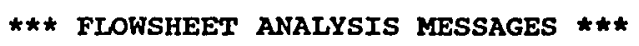

FLOWSHEET CONNECTIVITY BY STREAMS

$\begin{array}{llllll}\text { STREAM } & \text { SOURCE } & \text { DEST } & \text { STREAY } & \text { SOURCE } & \text { DEST } \\ \text { OAFEED6 } & - & \text { OADSTL } & \text { OAFEED5 } & - & \text { OADSTL } \\ \text { OAFEED4 } & - & \text { OADSTL } & \text { OAFEED3 } & - & \text { OADSTL } \\ \text { OAFEED2 } & -- & \text { OADSTL } & \text { OAFEED1 } & - & \text { OADSTL } \\ \text { OAPROD1 } & \text { OADSTL } & \text { OBDSTL } & \text { OAPROD2 } & \text { OADSTL } & \text { OBDSTL }\end{array}$




\begin{tabular}{|c|c|c|c|c|c|}
\hline OAPROD3 & OADSTL & OBDSTL & OAPROD4 & OADSTL & OBDSTL \\
\hline OAPROD5 & OADSTL & OBDSTL & OAPROD6 & OADSTL & OBDSTL \\
\hline OBPROD1 & OBDSTL & OCDSTL & OBPROD2 & OBDSTL & OCDSTL \\
\hline OBPROD3 & OBDSTL & OCDSTL & OBPROD4 & OBDSTL & OCDSTI \\
\hline OBPROD5 & OBDSTL & OCDSTL & OBPROD6 & OBDSTL & OCDSTL \\
\hline OCPROD1 & OCDSTL & ODDSTL & OCPROD2 & OCDSTL & ODDSTL \\
\hline OCPROD3 & OCDSTL & ODDSTL & OCPROD4 & OCDSTL & ODDSTI \\
\hline OCPROD5 & OCDSTL & ODDSTL & OCPROD6 & OCDSTL & ODDSTL \\
\hline ODPROD1 & ODDSTL & OEDSTL & ODPROD2 & ODDSTL & OEDSTL \\
\hline ODPROD3 & ODDSTL & OEDSTL & ODPROD4 & ODDSTL & OEDSTL \\
\hline ODPROD5 & ODDSTL & OEDSTL & ODPROD6 & ODDSTL & OEDSTL \\
\hline OEPROD1 & OEDSTL & OFDSTL & OEPROD2 & OEDSTL & OFDSTL \\
\hline OEPROD3 & OEDSTL & OFDSTL & OEPROD4 & OEDSTL & OFDSTL \\
\hline OEPROD5 & OEDSTL & OFDSTL & OEPROD6 & OEDSTL & OFDSTL \\
\hline OEPRODI & OFDSTL & OOODSTL & OFPROD2 & OFDSTL & OOODSTL \\
\hline OFPROD3 & OFDSTL & OOODSTL & OFPROD4 & OFDSTL & OOODSTL \\
\hline OFPROD5 & OFDSTL & OOODSTI & OFPROD6 & OFDSTL & OOODSTL \\
\hline OOORRODI & OOODSTL & O50DSTI & OOOPROD2 & OOODSTI & 050DSTL \\
\hline O0OPROD3 & OOODSTL & O50DSTI & OOOPROD4 & OOODSTL & 050DSTL \\
\hline OOOPROD5 & OOODSTI & O5ODSTL & OOOPROD6 & OOODSTL & 050DSTL \\
\hline $\begin{array}{l}\text { 050PROD1 } \\
050 \text { PROD3 }\end{array}$ & $\begin{array}{l}\text { 050DSTL } \\
\text { 050DSTL }\end{array}$ & 050SPIT & $\begin{array}{l}\text { 050PROD2 } \\
\text { 050PROD4 }\end{array}$ & $\begin{array}{l}\text { 050DSTL } \\
\text { 050DSTL }\end{array}$ & $\begin{array}{l}\text { 100DSTL } \\
\text { 100DSTI }\end{array}$ \\
\hline 05OPROD5 & O50DSTL & IOODSTL & O5OPROD6 & O5ODSTL & 10ODSTL \\
\hline 100FEEDI & 050SPLT & 10ODSTL & zo50TOPS & O5OSPLT & --ー \\
\hline 100PROD1 & 100DSTI & 100SPLT & 100PROD2 & 10ODSTL & 150DSTL \\
\hline 100PROD3 & 100DSTL & 150DSTL & 100PROD4 & 100DSTI & 150DSTL \\
\hline 100PROD5 & 100DSTL & 150DSTL & 100PROD6 & 100DSTL & 150DSTL \\
\hline 150FEED1 & 100SPLT & 150DSTL & Z100TOPS & 100SPIT & - \\
\hline 150PROD1 & 150DSTL & 150SPLT & 150PROD2 & 150DSTL & 200DSTI \\
\hline 150PROD3 & 150DSTL & 200DSTL & 150PROD4 & 150DSTL & 200DSTL \\
\hline 150PROD5 & 150DSTL & 200DSTL & 150PROD6 & 150DSTL & 200DSTL \\
\hline 200FEED1 & 15OSPLI & 200DSTL & Z150TOPS & 150SPLT & -ー-ー \\
\hline 200RROD1 & 200DSTI & 200SPIT & 200PROD6 & 200DSTL & --- \\
\hline 250FEED1 & 200SPLT & $-\infty$ & z200TOPS & 200SPLT & 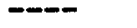 \\
\hline
\end{tabular}

FLOWSHEET CONNECTIVITY BY BLOCKS

\begin{tabular}{|c|c|c|c|}
\hline BLOCK & INLETS & & \\
\hline OADSTL & $\begin{array}{l}\text { OAFEED1 } \\
\text { OAFEED4 }\end{array}$ & $\begin{array}{l}\text { OAFEED2 } 0 \\
\text { OAFEED5 }\end{array}$ & $\begin{array}{l}\text { OAFEED3 } \\
\text { OAFEED6 }\end{array}$ \\
\hline OBDSTL & OAPRODI & OAPROD2 & OAPROD3 \\
\hline & OAPROD4 & OAPROD5 0 & OAPROD6 \\
\hline OCDSTI & OBPRODI & OBPROD2 & $\begin{array}{l}\text { OBPROD3 } \\
\text { ORPROD6 }\end{array}$ \\
\hline ODDSTL & OCPROD1 & OCPROD2 O & OCPROD3 \\
\hline OEDSTL & $\begin{array}{l}\text { ODPROD1 } \\
\text { ODPROD4 }\end{array}$ & $\begin{array}{l}\text { ODPROD2 } \\
\text { ODPROD5 }\end{array}$ & $\begin{array}{l}\text { ODPROD3 } \\
\text { ODPROD6 }\end{array}$ \\
\hline OFDSTL & $\begin{array}{l}\text { OEPROD1 } \\
\text { OEPROD4 }\end{array}$ & $\begin{array}{ll}\text { OEPROD2 } & 0 \\
\text { OEPROD5 } & 0\end{array}$ & $\begin{array}{l}\text { OEPROD3 } \\
\text { OEPROD6 }\end{array}$ \\
\hline OOODSTL & $\begin{array}{l}\text { OFPROD1 } \\
\text { OFPROD4 }\end{array}$ & $\begin{array}{ll}\text { OFPROD2 } & 0 \\
\text { OFPROD5 } & 0\end{array}$ & $\begin{array}{l}\text { OFPROD3 } \\
\text { OFPROD6 }\end{array}$ \\
\hline 050DSTL & $\begin{array}{l}\text { OOOPROD1 } \\
\text { OOOPROD4 }\end{array}$ & $\begin{array}{l}\text { OOOPROD2 } \\
\text { O0OPROD5 }\end{array}$ & $\begin{array}{ll}2 & \text { OOOPROD3 } \\
5 & \text { O0OPROD6 }\end{array}$ \\
\hline 050 & 050PROD1 & & \\
\hline & $\begin{array}{l}\text { 100FEED1 } \\
\text { 050PROD4 }\end{array}$ & $\begin{array}{l}\text { O50RROD2 } \\
\text { O5ORROD5 }\end{array}$ & $\begin{array}{cl}22 & \text { O5OPROD3 } \\
55 & \text { O5OPROD6 }\end{array}$ \\
\hline $\begin{array}{l}\text { 100SPLT } \\
\text { 150DSTL }\end{array}$ & $\begin{array}{l}\text { 100PROD1 } \\
\text { 150FEED1 } \\
\text { 100PROD4 }\end{array}$ & $\begin{array}{l}\text { 100PROD2 } \\
100 \text { PROD5 }\end{array}$ & $\begin{array}{ll}2 & 100 \text { PROD3 } \\
5 & 100 \text { PROD6 }\end{array}$ \\
\hline
\end{tabular}

OUTLETS

OAPROD1 OAPROD2 OAPROD3 OAPROD4 OAPROD5 OAPROD6 OBPROD1 OBPROD2 OBPROD3 OBPROD4 OBPROD5 OBPROD6 OCPROD1 OCPROD2 OCPROD3 OCPROD4 OCPROD5 OCPROD6 ODPROD1 ODPROD2 ODPROD3 ODPROD4 ODPROD5 ODPROD6 OEPROD1 OEPROD2 OEPROD3 OEPROD4 OEPROD5 OEPROD6 OFPROD1 OFPROD2 OFPROD3 OFPROD4 OFPROD5 OFPROD6 OOOPROD1 OOOPROD2 OOOPROD3 OOOPROD4 OOOPROD5 OOOPROD6 05OPROD1 050PROD2 050PROD3 O5OPROD4 O5OPROD5 O5OPROD6 IOOFEEDI 2050TOPS

100PROD1 100RROD2 100PROD3 100PROD4 100PROD5 100PROD6 15OFEEDI Z1OOTOPS

I5OPRODI 150RROD2 150PROD3 150PROD4 150PROD5 15OPROD6 


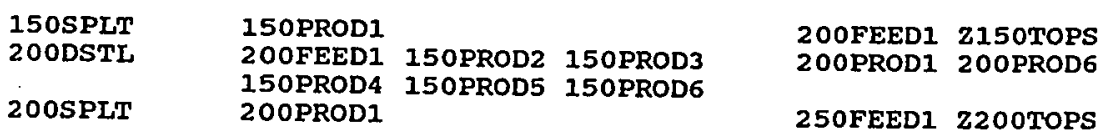

COMPUTATION ORDER FOR THE FLOWSHEET IS:

OADSTL OBDSTL OCDSTL ODDSTL OEDSTL OFDSTL OOODSTL O5ODSTL O5OSPLT IOODSTL

100SPLT 150DSTL 150SPLT 200DSTL 200SPLT

MODULE apmod IS USED; CREATION DATE 07/31/91 10:15:30:25

LOCATED IN : E: \AP84A \Xeq \apmod

NO ERRORS OR WARNINGS GENERATED

SIMULATION PROGRAM MAY BE EXECUTED

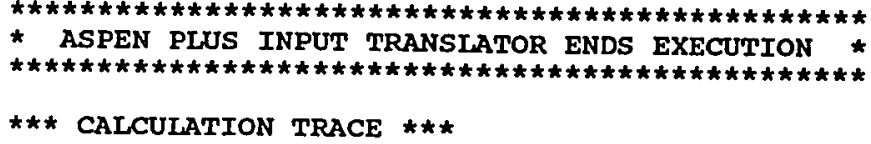

D\&E 74, RR=3: 5OKMOL/COL, HOLDUP, MEFF'CY=0.75

SIMULATION CALCULATIONS BEGIN

ENTHALPY CALCULATION FOR INLET STREAM OAFEEDI OF BLOCK OADSTL

KODE $=3$ NTRIAL $=4 T=360.6 \quad P=0.1013 \mathrm{~T}+06 \mathrm{~V}=0.0000 \mathrm{E}+00$

ENTHALPY CALCULATION FOR INLET STREAM OAFEED2 OF BLOCK OADSTL

KODE $=3$ NTRIAL $=4 T=360.6 \quad P=0.1013 E+06 \quad V=0.0000 E+00$

ENTHALPY CALCULATION FOR INLET STREAM OAFEED3 OF BLOCK OADSTI,

KODE $=3$ NTRIAL $=4 T=360.6 \cdot \quad P=0.1013 \mathrm{E}+06 \mathrm{~V}=0.0000 \mathrm{E}+00$

ENTHALPY CALCULATION FOR INLET STREAK OAFEED4 OF BLOCK OADSTL,

KODE $=3$ NTRIAL $=4 T=360.6 \quad P=0.1013 E+06 \quad V=0.0000 E+00$

ENTHALPY CALCULATION FOR INLET STREAM OAFEED5 OF BLOCK OADSTI

KODE $=3$ NTRIAL $=4 \mathrm{~T}=360.6 \quad \mathrm{P}=0.1013 \mathrm{E}+06 \mathrm{~V}=0.0000 \mathrm{E}+00$

ENTHLLPY CALCULATION FOR INLET STREAM OAFEED6 OF BLOCK OADSTL

KODE $=3$ NTRIAL $=4 T=360.6 \quad P=0.1013 E+06 \quad V=0.0000 E+00$

UOS BLOCK OADSTI MODEL: RADFRAC

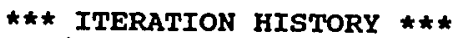

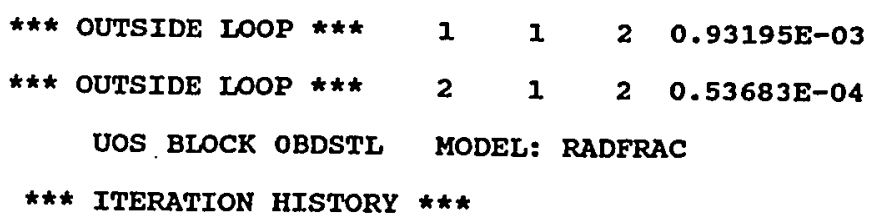




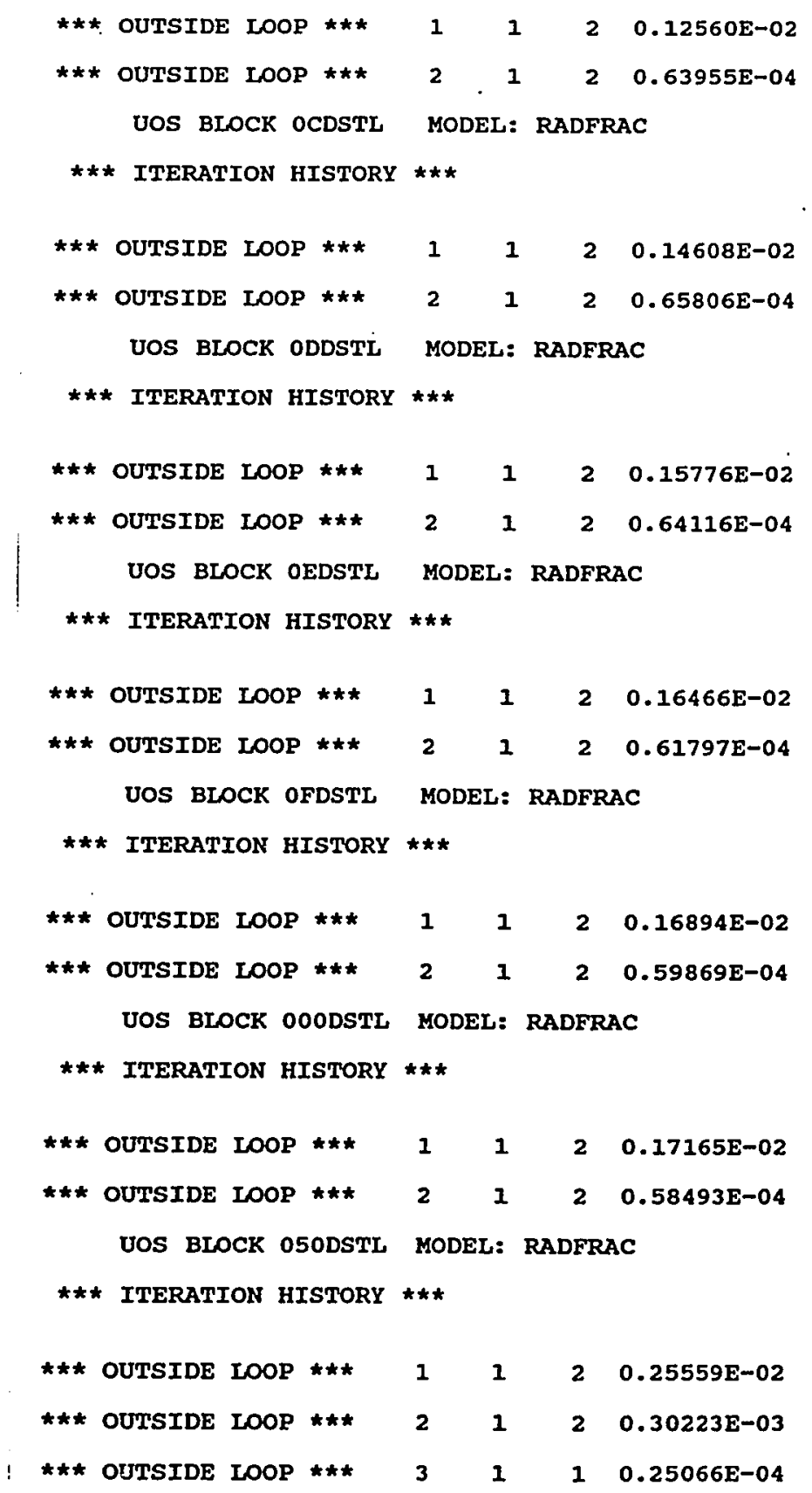




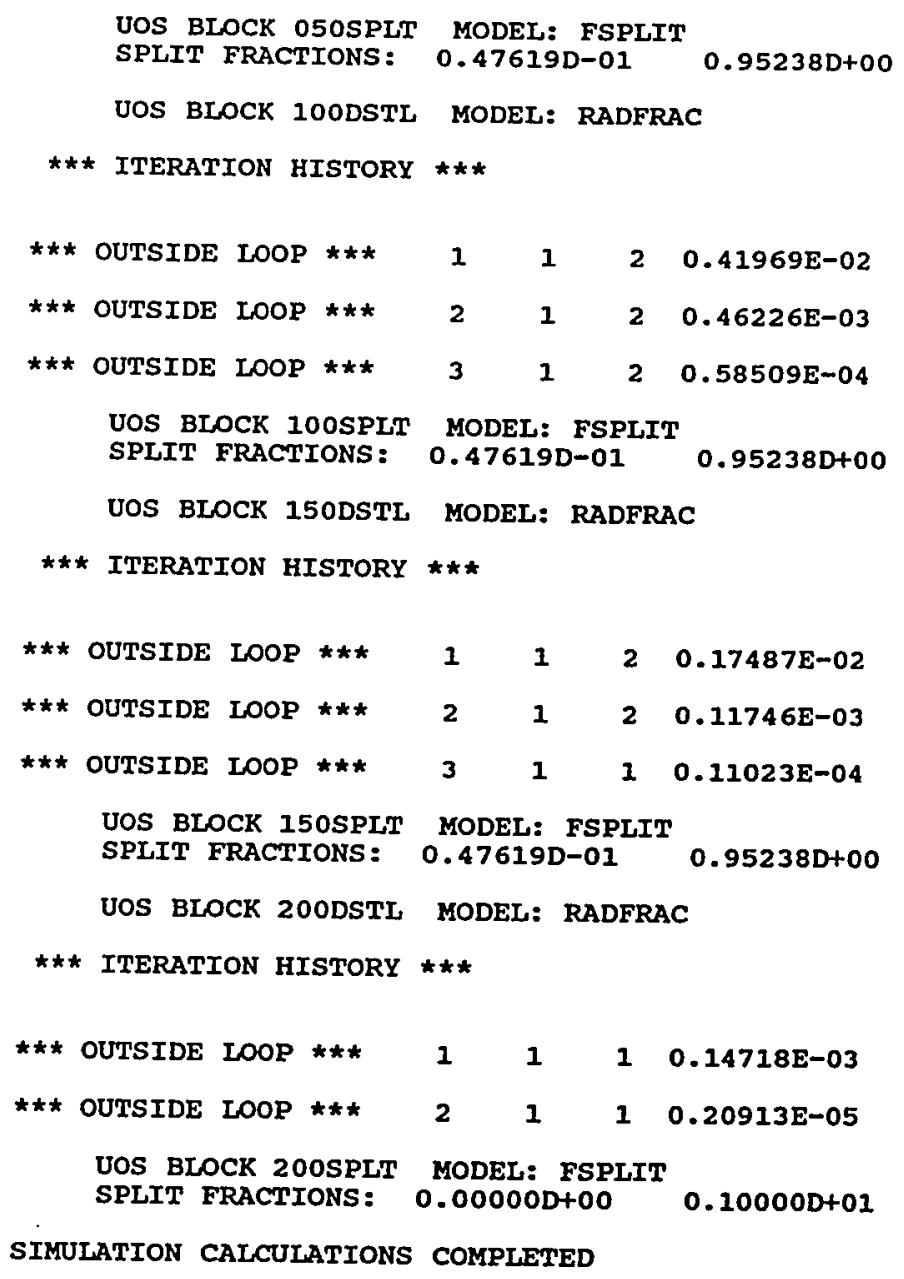




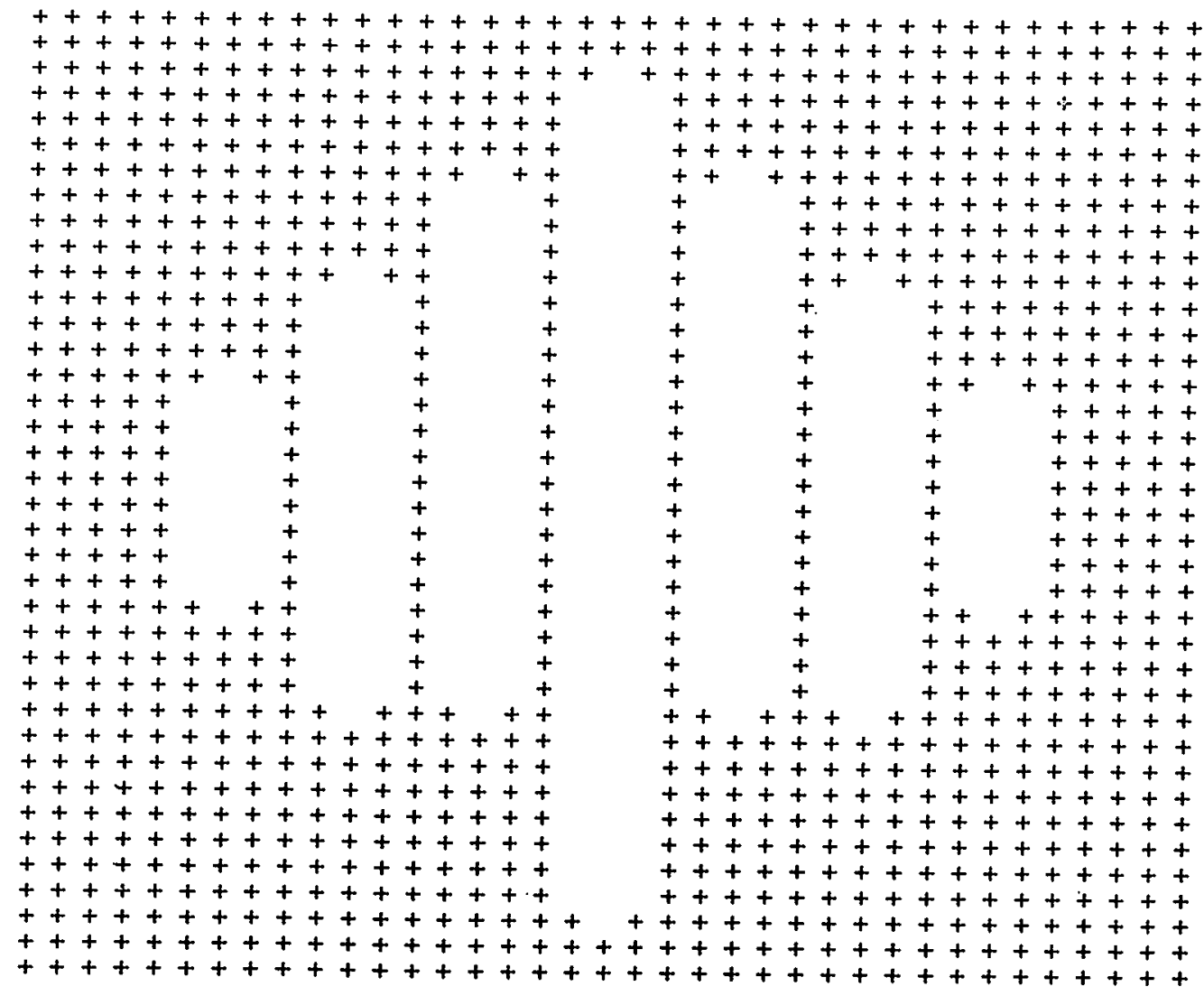

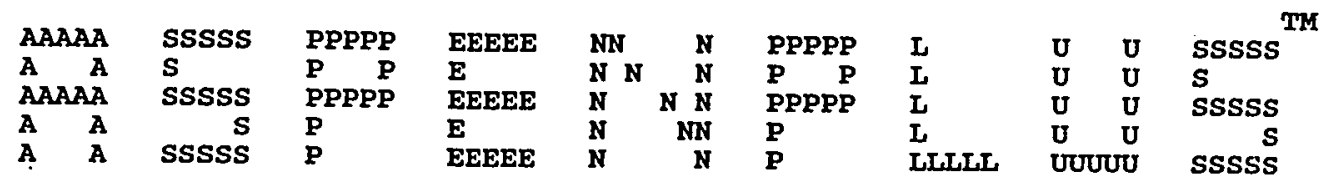

ASPEN PLUS IS A TRADEMARK OF ASPEN TECHNOLOGY, INC.

251 VASSAR STREET

CAMBRIDGE, MASSACHUSETTS 02139 617-497-9010

VERSION: DOS -386

RELEASE: $8.4-1$

INSTALLATION: sjsu-utv
HOTLINE:

U.S.A. 617-497-9010

EUROPE 31-70-3541051

JANUARY 4, 1993

MONDAY

$8: 34: 35$ A.M. 
ASPEN PLUS VER: DOS-386 REL: 8.4-1 INST: sjsu-utv 01/04/93 PAGE I D\&E 74, RR=3: 50KMOL/COL, HOLDUP, MEFF'CY=0.75

ASPEN PLUS (TM) IS A PROPRIETARY PRODUCT OF ASPEN TECHNOLOGY, INC. (ASPENTECH), CAMBRIDGE, MASSACHUSETTS, AND MAY BE USED ONLY UNDER AGREEMENT WITH ASPENTECH OR THROUGH NETWORK SERVICES LICENSED BY ASPENTECH. ASPEN PLUS (TM) IS A TRADEMARK OF ASPENTECH. THE ASPEN PLUS COMPUTER SOFTWARE SYSTEM IS USED FOR FLOWSHEET SIMULATION.

TABLE OF CONTENTS

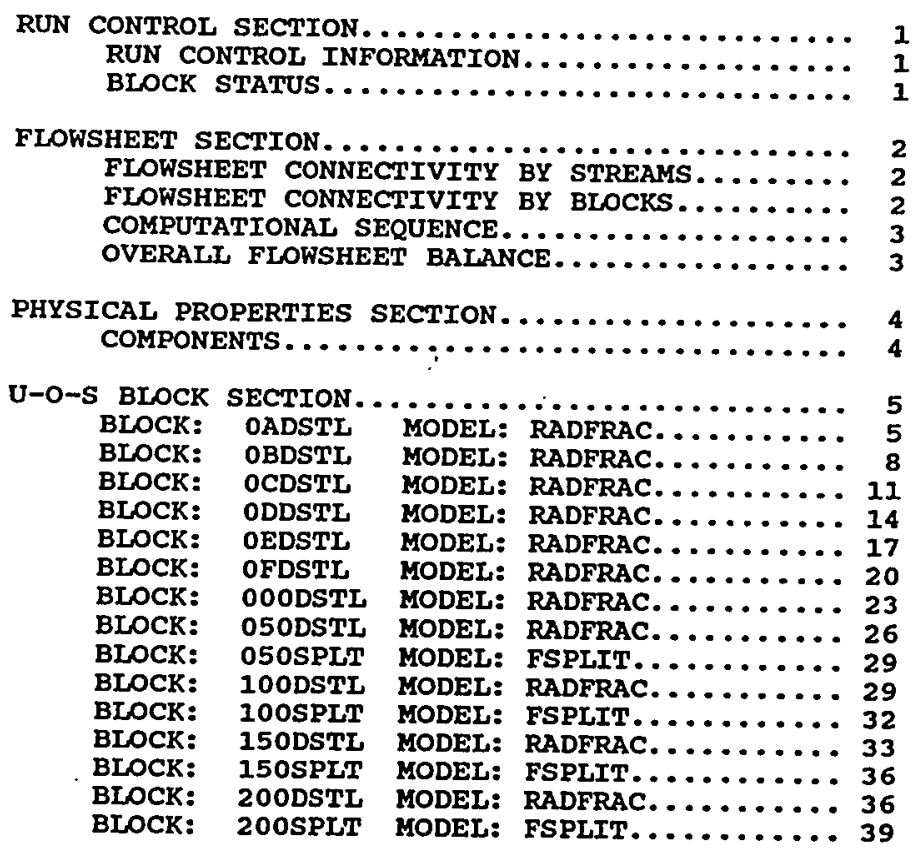


ASPEN PIUS VER: DOS-386 REL: 8.4-1 INST: sjSu-utV 01/04/93 PAGE II $D \& E$ 74, $R R=3$ : 5OKMOL/COL, HOLDUP, MEFF'CY $=0.75$

TABLE OF CONTENTS

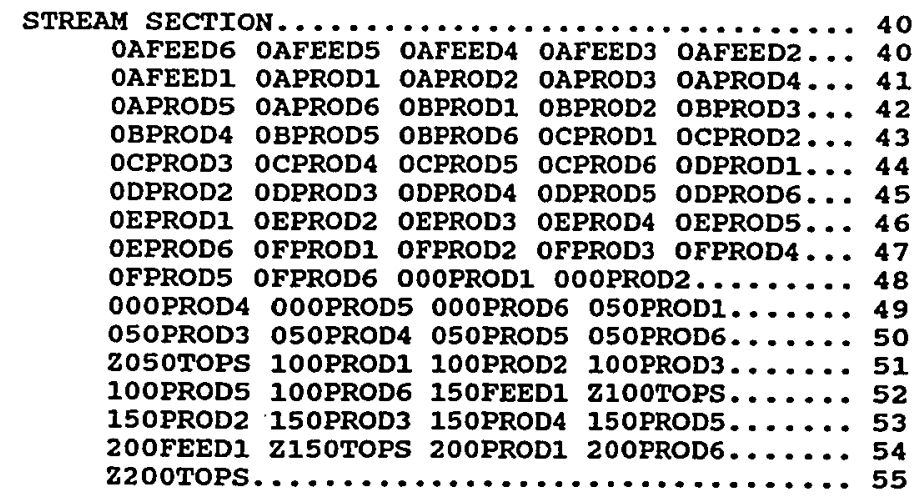




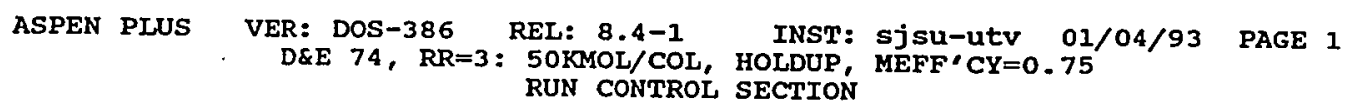

RUN CONTROL INFORMATION

THIS VERSION OF ASPEN PLUS LICENSED TO SAN JOSE STATE UNIVERSITY TYPE OF RUN: NEW

INPUT FILE NAME: 5OD3RHUR.inp

OUTPUT PROBLEM DATA FILE NAME: 5OD3RHUR VERSION NO. 1 IOCATED IN:

E: \CHE_STOK\CHEXANE \HOLDUP \5OD3RHUR

PDF SIZE USED FOR INPUT TRANSLATION:

NUMBER OF FILE RECORDS (PSIZE) $=99999$

NUMBER OF IN-CORE RECORDS $=2000$

PSIZE NEEDED FOR SIMULATION $=2000$

CALLING PROGRAM NAME:

LOCATED IN:

apmod

E: $\backslash A P B 4 A \backslash$ xeq $\backslash$ apmod

SIMULATION REQUESTED FOR ENTIRE FLOWSHEET

BLOCK STATUS

$\star$

* ALL UNIT OPERATION BLOCKS FERE COMPLETED NORMALIY

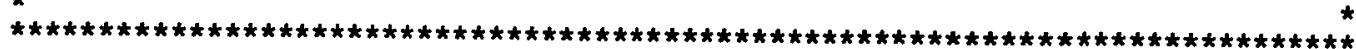


FLOWSHEET CONNECTIVITY BY STREAMS

\begin{tabular}{|c|c|c|c|c|c|}
\hline STREAM & SOURCE & DEST & STREAM & SOURCE & DEST \\
\hline OAFEED6 & - & OADSTL & OAFEED5 & --- & OADSTL \\
\hline OAFEED4 & 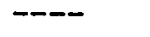 & OADSTL & OAFEED3 & -ーー- & OADSTI \\
\hline OAFEED2 & --- & OADSTL & OAFEEDI & --ー- & OADSTL \\
\hline OAPRODI & OADSTL & OBDSTL & OAPROD2 & OADSTL & OBDSTL \\
\hline OAPROD3 & OADSTL & OBDSTL & OAPROD4 & OADSTL & OBDSTL \\
\hline OAPRODS & OADSTL & OBDSTL & OAPROD6 & OADSTL & OBDSTI \\
\hline OBPRODI & OBDSTL & OCDSTL & OBPROD2 & OBDSTL & OCDSTI \\
\hline OBPROD3 & OBDSTL & OCDSTL & OBPROD4 & OBDSTL & OCDSTL \\
\hline OBPROD5 & OBDSTL & OCDSTL & OBPROD6 & OBDSTL & OCDSTL \\
\hline OCPRODI. & OCDSTI & ODDSTL & OCPROD2 & OCDSTL & ODDSTL \\
\hline OCPROD3 & OCDSTL & ODDSTL & OCPROD4 & OCDSTL & ODDSTL \\
\hline OCPROD5 & OCDSTL & ODDSTL & OCPROD6 & OCDSTL & ODDSTL \\
\hline ODPROD1 & ODDSTL & OEDSTI & ODPROD2 & ODDSTI & OEDSTL \\
\hline ODPROD3 & ODDSTL & OEDSTL & ODPROD4 & ODDSTL & OEDSTL \\
\hline ODPROD5 & ODDSTL & OEDSTL & ODPROD6 & ODDSTL & OEDSTL \\
\hline OEPRODI & OEDSTL & OFDSTL & OEPROD2 & OEDSTL & OFDSTL \\
\hline OEPROD3 & OEDSTL & OFDSTL & OEPROD4 & OEDSTL & OFDSTL \\
\hline OEPRODS & OEDSTL & OFDSTL & OEPROD6 & OEDSTL & OFDSTL \\
\hline OFPROD1 & OFDSTL & OOODSTL & OFPROD2 & OFDSTL & OOODSTL \\
\hline OFPROD3 & OFDSTL & OOODSTL & OFPROD4 & OFDSTL & OOODSTL \\
\hline OFPROD5 & OFDSTL & OOODSTL & OFPROD6 & OFDSTL & OOODSTL \\
\hline 000PROD1 & OOODSTL & O5ODSTL & 000PROD2 & OOODSTL & 050DSTL \\
\hline OOOPROD3 & OOODSTL & O50DSTL & OOORROD4 & OOODSTI & 050DSTL \\
\hline OOOPROD5 & OOODSTL & O50DSTL & OOORROD6 & OOODSTL & 050DSTL \\
\hline C5OPROD1 & O5ODSTI & O5OSPLT & O50PROD2 & 050DSTL & 100DSTL \\
\hline 050PROD3 & 050DSTL & 100DSTI & O50PROD4 & O5ODSTL & 100DSTL \\
\hline 050RROD5 & 050DSTI & 100DSTI & O5OPROD6 & 050DSTL & IOODSTL \\
\hline 100FEED1 & 050SPLT & 100DSTL & z050TOPS & 050SPLT & --- \\
\hline I0OPROD1 & 100DSTL & 100SPLT & 100PROD2 & 100DSTL & 150DSTI \\
\hline 100PROD3 & 100DSTL & 150DSTL & 100PROD4 & 100DSTL & 15ODSTL \\
\hline 100PROD5 & 100DSTL & 150DSTL & 100PROD6 & 100DSTI & 150DSTL \\
\hline 150FEEDI & I0OSPLT & 150DSTL & Z100TORS & 100SPLT & - \\
\hline 150PROD1 & 150DSTL & 150SPIT & 150PROD2 & 150DSTL & 200DSTL \\
\hline 150PROD3 & 150DSTL & 200DSTL & 150PROD4 & 150DSTL & 200DSTL \\
\hline 150PRODS & 250DSTI & 200DSTL & 150PROD6 & 150DSTL & 200DSTL \\
\hline 200FEEDI & 150SPET & 200DSTL & z150TOPS & 150SPIT & $-\infty$ \\
\hline $\begin{array}{l}\text { 200PROD1 } \\
250 F E E D 1\end{array}$ & $\begin{array}{l}\text { 200DSTL } \\
\text { 200SPLT }\end{array}$ & 200SPLT & $\begin{array}{l}\text { 200PROD6 } \\
\text { 2200TOPS }\end{array}$ & $\begin{array}{l}\text { 200DSTL } \\
\text { 200SPIT }\end{array}$ & -- \\
\hline$+\infty$ & 20002012 & & & 200SPLT & - \\
\hline
\end{tabular}

FLOWSHEET CONNECTIVITY BY BLOCKS

BLOCK INLETS

OADSTL OAFEED1 OAFEED2 OAFEED3

OBDSTL OAFEED4 OAFEED5 OAFEED6

OAPROD1 OAPROD2 OAPROD3

$\begin{array}{lll} & \text { OAPROD4 OAPROD5 OAPROD6 } \\ \text { OCDSTL } & \text { OBPROD1 OBPROD2 OBPROD3 }\end{array}$

OBPROD4 OBPROD5 OBPROD6

ODDSTL OCPROD1 OCPROD2 OCPROD3

OEDSTL OCPROD4 OCPROD5 OCPROD6
OUTLETS

OAPROD1 OAPROD2 OAPROD3

OAPROD4 OAPROD5 OAPROD6

OBPROD1 OBPROD2 OBPROD3

OBPROD4 OBPROD5 OBPROD6

OCPROD1 OCPROD2 OCPROD3

OCPROD4 OCPROD5 OCPROD6

ODPROD1 ODPROD2 ODPROD3

ODPROD4 ODPROD5 ODPROD6

OEPROD1 OEPROD2 OEPROD3 

ASPEN PLUS VER: DOS-386 REL: 8.4-1, INST: sjsu-utV 01/04/93 PAGE 3
D\&E 74, RR=3: 50KMOL/COL, HOLDUP, MEFF'CY=0.75 FLOWSHEET SECTION

FLOWSHEET CONNECTIVITY BX BLOCKS (CONTINUED)

\begin{tabular}{|c|c|c|c|}
\hline \multirow[b]{2}{*}{ OFDSTL } & ODPROD4 & \multicolumn{2}{|c|}{ ODPROD5 ODPROD6 } \\
\hline & OEPRODI & OEPROD2 0 & ERROD3 \\
\hline OOODSTL & $\begin{array}{l}\text { OEPROD4 } \\
\text { OFPRODI } \\
\text { OFPROD4 }\end{array}$ & $\begin{array}{ll}\text { OEPROD5 } & 0 \\
\text { OFPROD2 } & \end{array}$ & $\begin{array}{l}\text { EPROD6 } \\
\text { FPROD3 }\end{array}$ \\
\hline 050DSTL & $\begin{array}{l}\text { OOOPROD1 } \\
\text { OOOPROD4 }\end{array}$ & OOOPROD2 & $\begin{array}{l}\text { OOOPROD } 3 \\
\text { OOOPROD6 }\end{array}$ \\
\hline 05OSPLT & 050PROD1 & & \\
\hline $100 D$ & $\begin{array}{l}\text { 100FEED } 1 \\
\text { 050PROD4 } \\
100 \text { PROD } 1\end{array}$ & $\begin{array}{l}\text { 050PROD2 } \\
\text { O50PROD5 }\end{array}$ & $\begin{array}{l}\text { 050PROD3 } \\
\text { 050PROD6 }\end{array}$ \\
\hline 150DSTI & $\begin{array}{l}\text { 100PROD1 } \\
\text { 150FEED1 } \\
\text { I0OPROD4 }\end{array}$ & $\begin{array}{l}\text { 100PROD2 } \\
\text { 100PROD5 }\end{array}$ & $\begin{array}{l}\text { 100PROD3 } \\
\text { 100PROD }\end{array}$ \\
\hline $\begin{array}{l}\text { 150SPLT } \\
\text { 200DSTL }\end{array}$ & 150PROD1 & & \\
\hline $00 \mathrm{OSP}$ & $\begin{array}{l}200 \text { FEED1 } \\
150 \text { PROD } 4 \\
200 P R O D 1\end{array}$ & $\begin{array}{l}\text { 150PROD2 } \\
\text { 150PROD5 }\end{array}$ & $\begin{array}{l}\text { 150PROD3 } \\
\text { 150PROD } 6\end{array}$ \\
\hline
\end{tabular}

\begin{tabular}{|c|c|c|}
\hline $\begin{array}{l}\text { OEPROD4 } \\
\text { OFPROD1 } \\
\text { OFPROD4 }\end{array}$ & $\begin{array}{ll}\text { OEPROD5 } & 0 \\
\text { OFPROD2 } & 0 \\
\text { OFPROD5 }\end{array}$ & $\begin{array}{l}\text { EPROD6 } \\
\text { FPROD3 } \\
\text { FPROD6 }\end{array}$ \\
\hline OOOPRODI & OOOPROD2 & OOOPROD3 \\
\hline 000PROD4 & OOOPROD5 & OOOPROD6 \\
\hline O5OPRODI & 050PROD2 & O5OPROD3 \\
\hline $\begin{array}{l}\text { 050PROD4 } \\
\text { 100FEEDI }\end{array}$ & $\begin{array}{l}\text { O50PROD5 } \\
\text { Z050TOPS }\end{array}$ & ROD 6 \\
\hline 100PRODI & 100PROD2 & 100PROD3 \\
\hline OPROD4 & 100PROD5 & 100PROD6 \\
\hline OFEED1 & Z100TOPS & \\
\hline 150PROD1 & 150RROD2 & 150PROD3 \\
\hline 150PROD4 & 150PROD5 & 150PROD \\
\hline 200PRODI & $\begin{array}{l}2150 T O P S \\
200 P R O D 6\end{array}$ & \\
\hline OFE & Z & \\
\hline
\end{tabular}

COMPUTATIONAL SEQUENCE

SEQUENCE USED WAS:

OADSTL OBDSTL OCDSTL ODDSTL OEDSTL OFDSTL OOODSTL 05ODSTL 050SPLT

10ODSTL 10OSPLT 150DSTL 150SPLT 200DSTL 200SPLT

OVERALL FLOWSHEET BALANCE

OVERAIT ELOWSHEET BALANCE

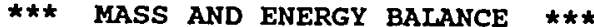

$\begin{array}{lccr}\text { CONVENTIONAL COMPONENTS } & \text { (KMOL/HR ) } & \text { OUT } & \text { RELATIVE DIFF } \\ \text { C6HI2 } & 0.124062 & 0.124062 & -0.251883 E-10 \\ \text { C7HB } & 0.760380 \mathrm{E}-01 & 0.760380 \mathrm{E}-01 & -0.365799 \mathrm{E}-08 \\ \text { TOTAL BALANCE } & & & \\ \text { MOLE (KMOL/HR ) } & 0.200100 & 0.200100 & -0.140565 \mathrm{E}-08 \\ \text { MASS (KG/HR ) } & 17.4475 & 17.4475 & -0.148397 \mathrm{E}-08 \\ \text { ENTHALPY (CAL/SEC ) } & -1081.71 & -1078.70 & -0.278363 \mathrm{E}-02\end{array}$


ASPEN PLUS VER: DOS-386 REL: 8.4-1 INST: sjsu-utV 01/04/93 PAGE 4 D\&E 74, RR=3: 50KMOL/COL, HOLDUP, MEFF' $C Y=0.75$ PHYSICAL PROPERTIES SECTION

COMPONENTS

ID TYPE FORMULA

C6H12 C $\quad$ C6H12-1

C7H8
C7H8
NAME OR ALIAS
CYCLOHEXANE

TOLUENE
REPORT NAME

C6H12

C7H8 
ASPEN PLUS VER: DOS-386 REL: 8.4-1 INST: sjsu-utV 01/04/93 PAGE 5 D\&E 74, RR=3: 5OKMOL/COL, HOLDUP, MEFF'CY=0.75

U-O-S BLOCK SECTION

\begin{tabular}{crll} 
BLOCK: & \multicolumn{2}{c}{ OADSTL } & MODEL: RADFRAC \\
\hline INLETS & OAFEEDI & STAGE & 1 \\
& OAFEED2 & STAGE & 2 \\
& OAFEED3 & STAGE & 3 \\
& OAFEED4 & STAGE & 4 \\
& OAFEED5 & STAGE & 5 \\
OUTLETS & OAFEED6 & STAGE & 6 \\
& OAPROD1 & STAGE & 1 \\
& OAPROD2 & STAGE & 2 \\
& OAPROD3 & STAGE & 3 \\
& OAPROD4 & STAGE & 4 \\
& OAPROD5 & STAGE & 5 \\
& OAPROD6 & STAGE & 6
\end{tabular}

PROPERTY OPTION SET: SYSOP7 UNIFAC / REDLICH-KWONG

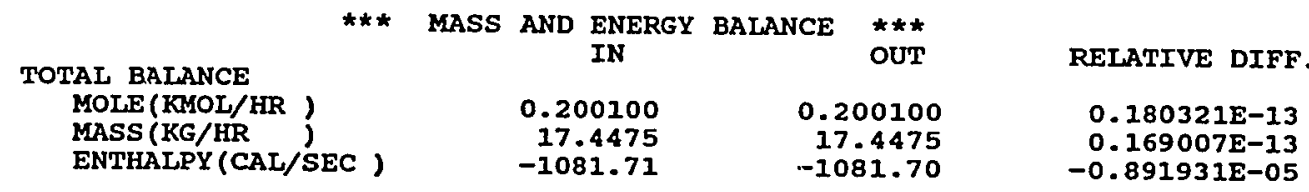

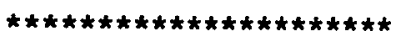

$\star \star \star \star$ INPUT DATA $\star \star \star \star *$

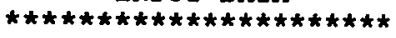

**** INPUT PARAMETERS

NUMBER OF STAGES

ALGORITHM OPTION

ABSORBER OPTION

INITIALIZATION OPTION

HYDRAULIC PARAMETER CALCULATIONS

INSIDE LOOP CONVERGENCE METHOD

MAXIMUM NO. OF OUTSIDE LOOP ITERATIONS

MAXIMUM NO. OF INSIDE LOOP ITERATIONS

MAXIMUM NUMBER OF FLASH ITERATIONS

FLASH TOLERANCE

OUTSIDE IOOP CONVERGENCE TOLERANCE
6

STANDARD
NO
STANDARD
NO
NEWTON
25
10
50
0.000100000
0.000100000




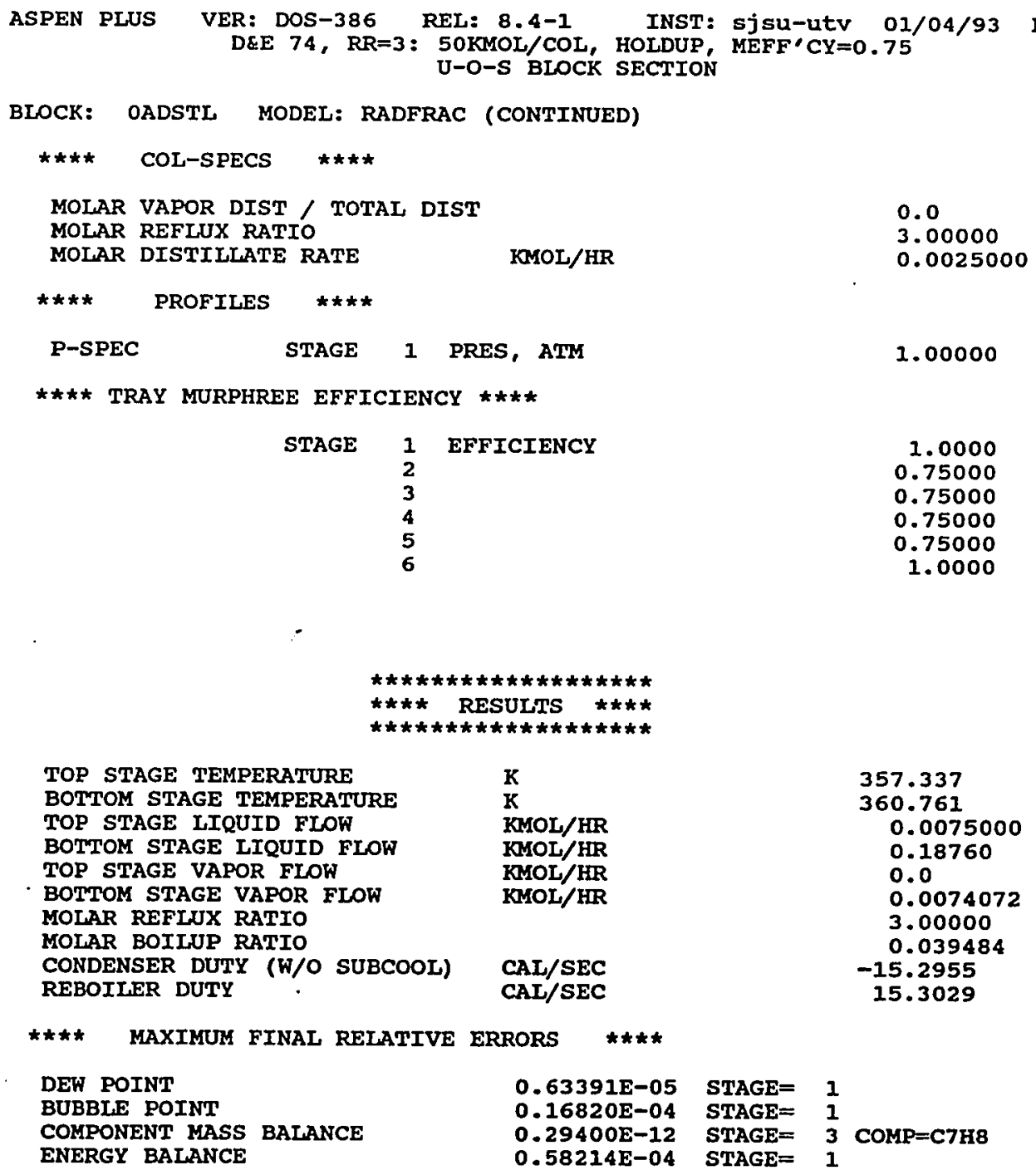




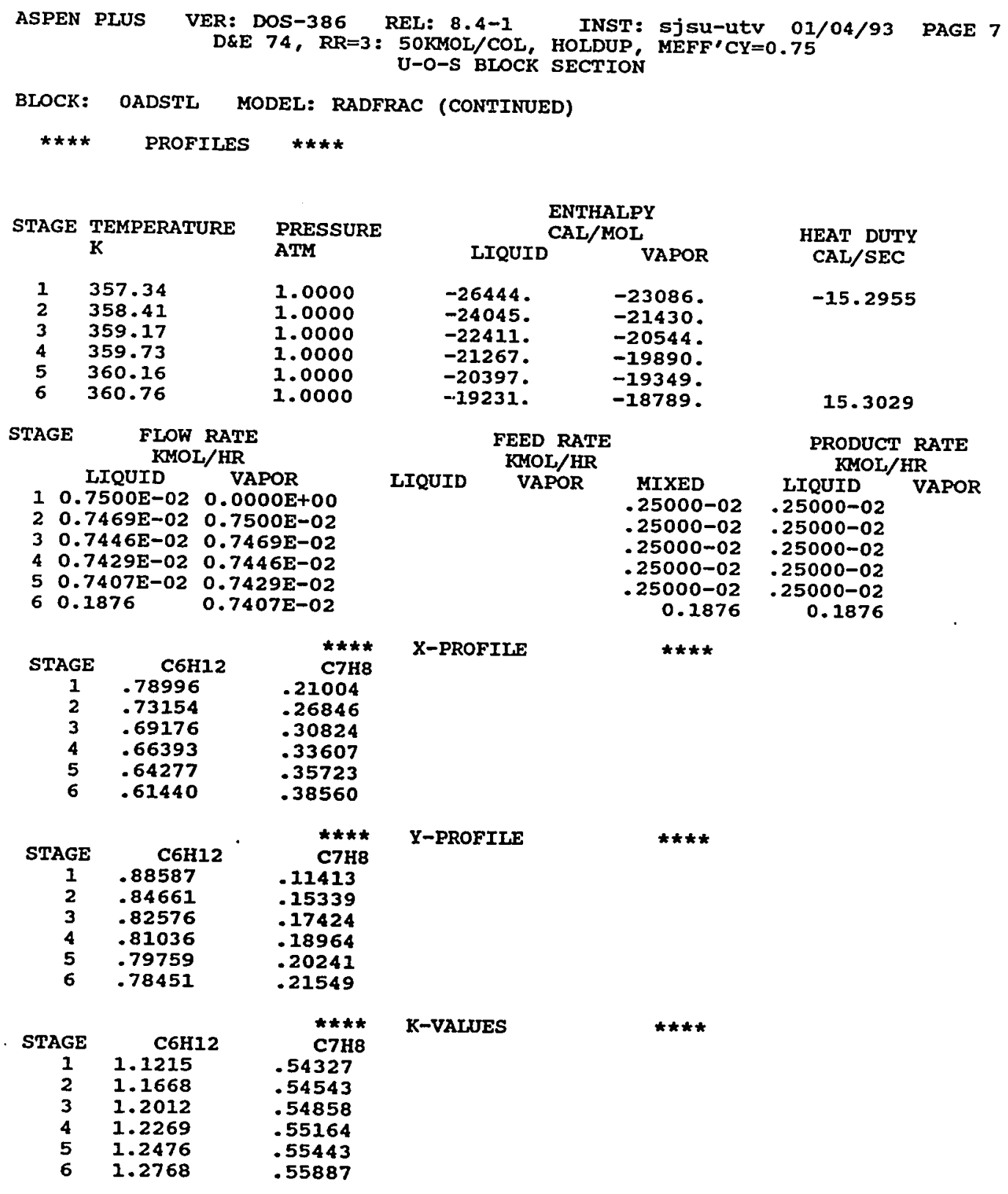




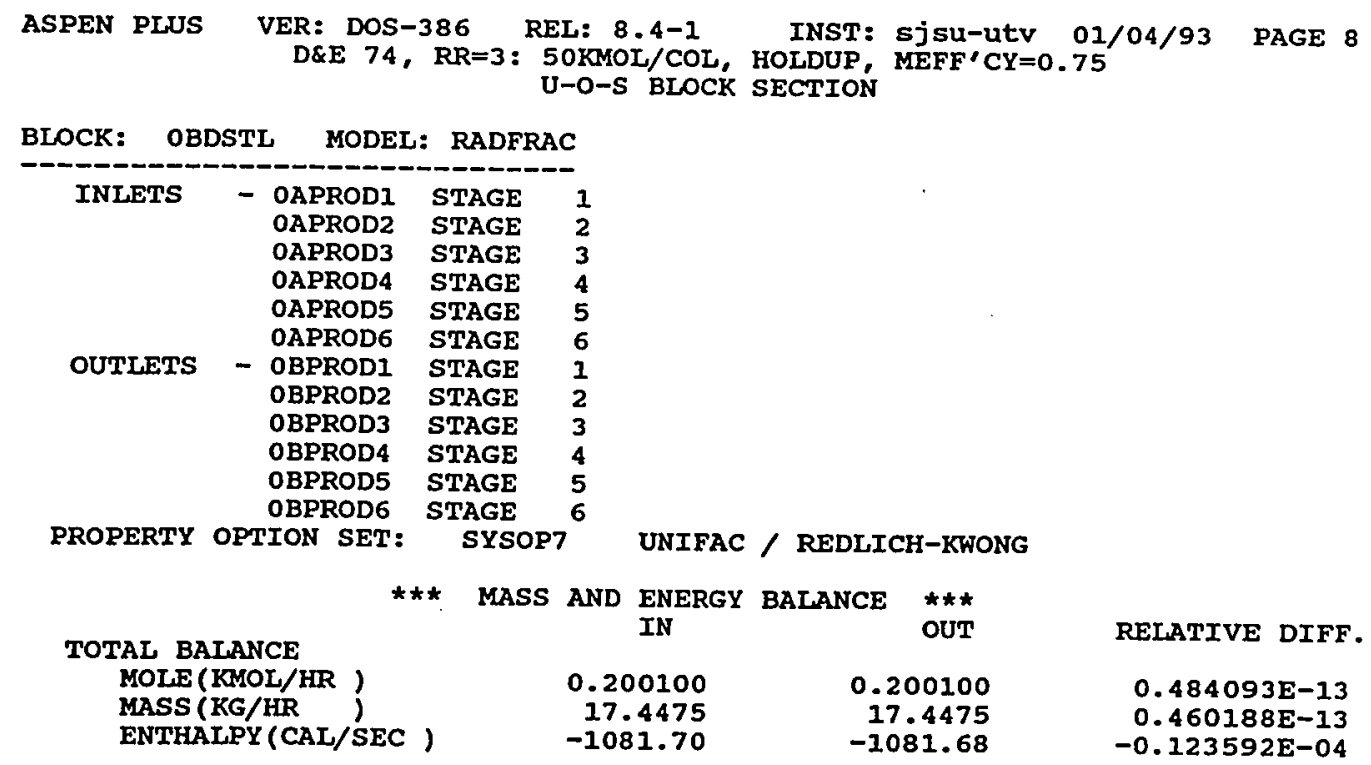

NUMBER OF STAGES

ALGORITHM OPTION

ABSORBER OPTION

INITIALIZATION OPTION

HYDRAULIC PARAMETER CALCULATIONS

INSIDE LOOP CONVERGENCE METHOD

MAXIMUM NO. OF OUTSIDE LOOP ITERATIONS

MAXIMUM NO. OF INSIDE LOOP ITERATIONS

MAXIMUM NUMBER OF FLASH ITERATIONS

FLASH TOLERANCE

OUTSIDE LOOP CONVERGENCE TOLERANCE

STANDARD
NO
STANDARD
NO
NEWTON
25
10
50
0.000100000
0.000100000




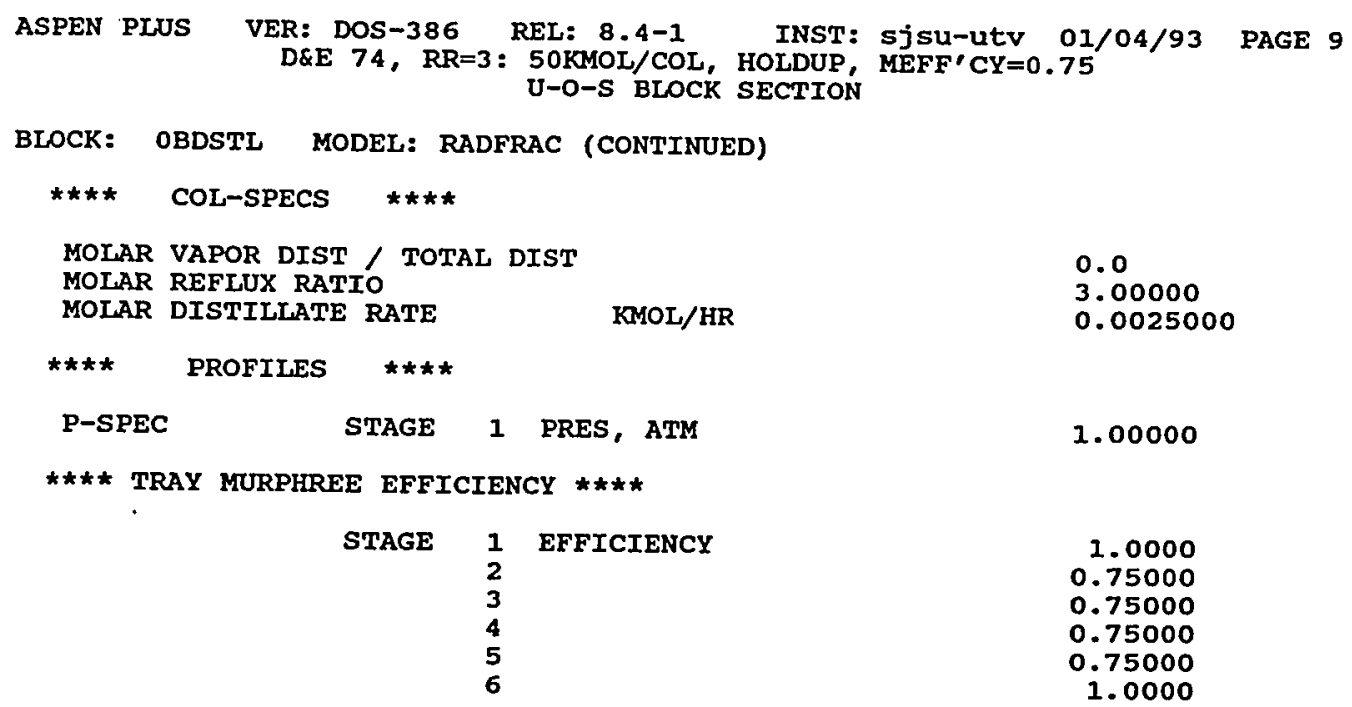

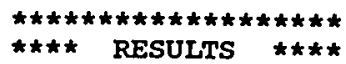

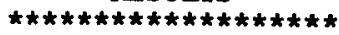

TOP STAGE TEMPERATURE BOTTOM STAGE TEMPERATURE TOP STAGE IIQUID FLOW BOTTOM STAGE LIQUID FLOW TOP STAGE VAPOR FLOW BOTTOM STAGE VAPOR FLOW MOLAR REFLUX RATIO MOIAR BOILUP RATIO CONDENSER DUTY ( $W / O$ SUBCOOL) REBOILER DUTY

$\mathbf{K}$ KMOL/HR KMOL/HR

KMOL/HR KMOL/HR

CAL/SEC

CAL/SEC
356.063

360.850

0.0075000

0.18760

0.0

0.0073475

3.00000

0.039166

$-15.1748$

15.1857

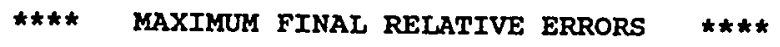

DEW POINT

BUBBLE POINT

COMPONENT MASS BALANCE

$0.35867 \mathrm{E}-05$

$0.14053 E-04$

STAGE $=5$
STAGE $=5$

ENERGY BALANCE

$0.49621 \mathrm{E}-04$

STAGE $=3$ COMP $=\mathrm{C} 7 \mathrm{H} 8$

STAGE $=1$ 


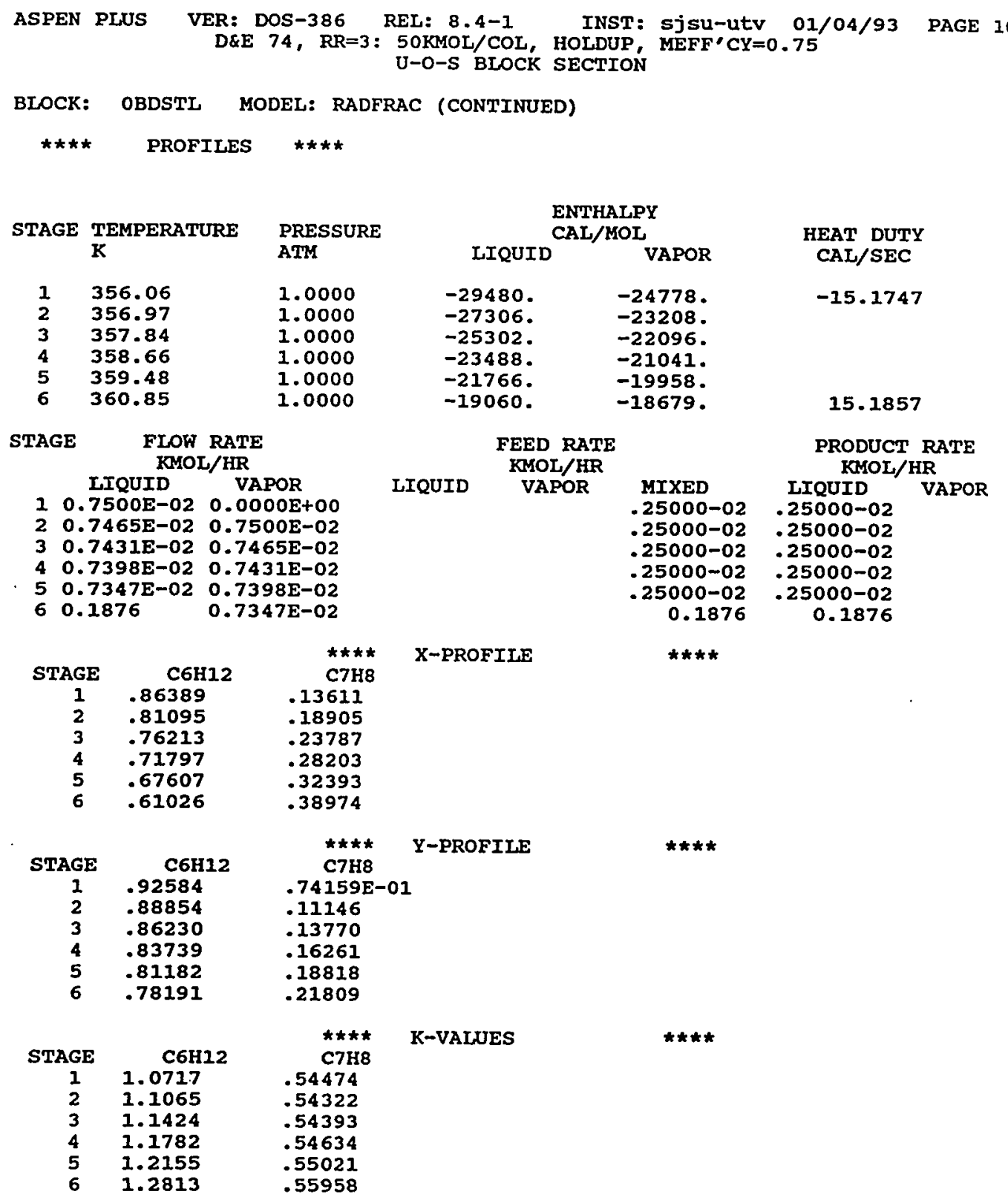




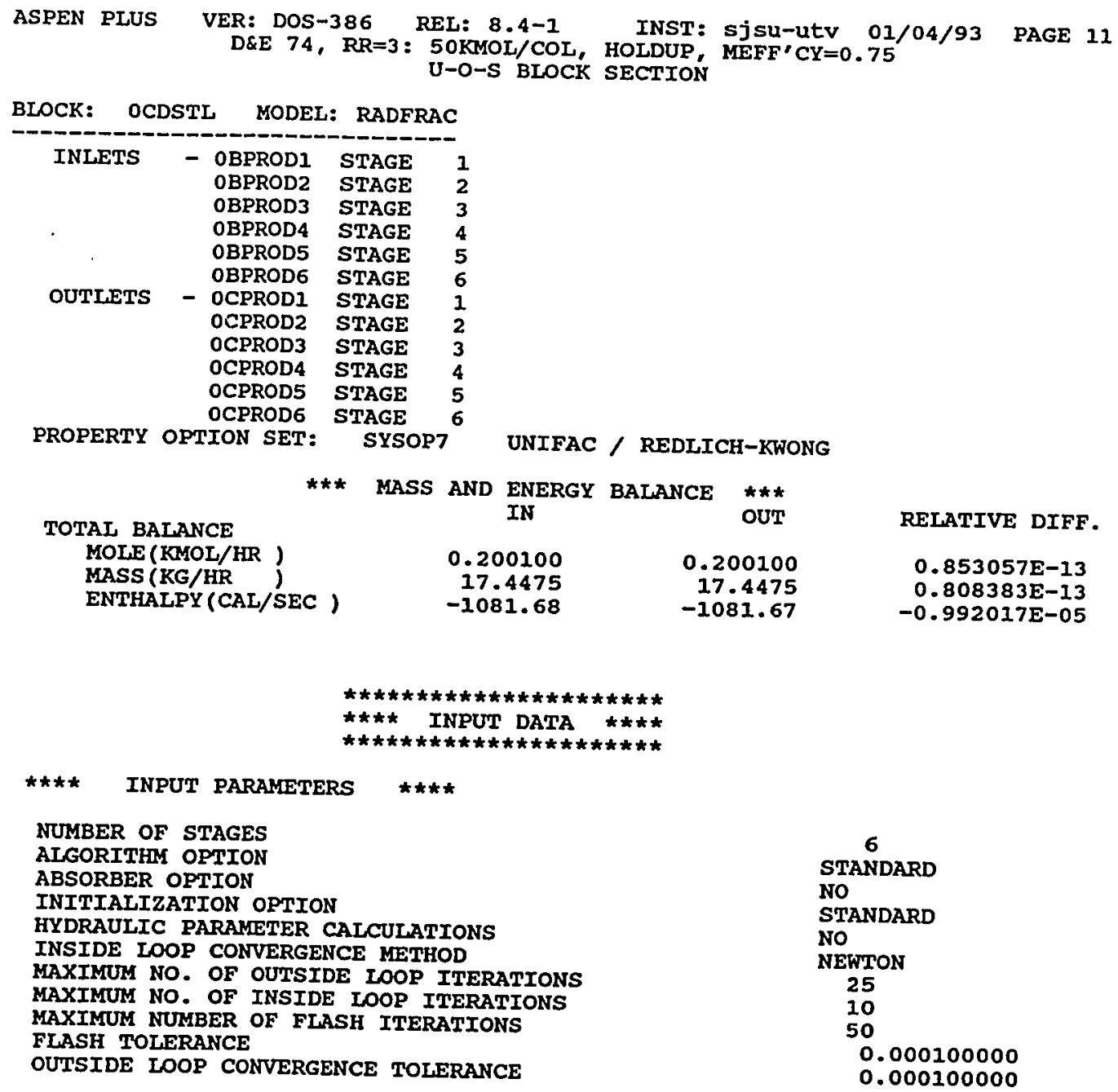




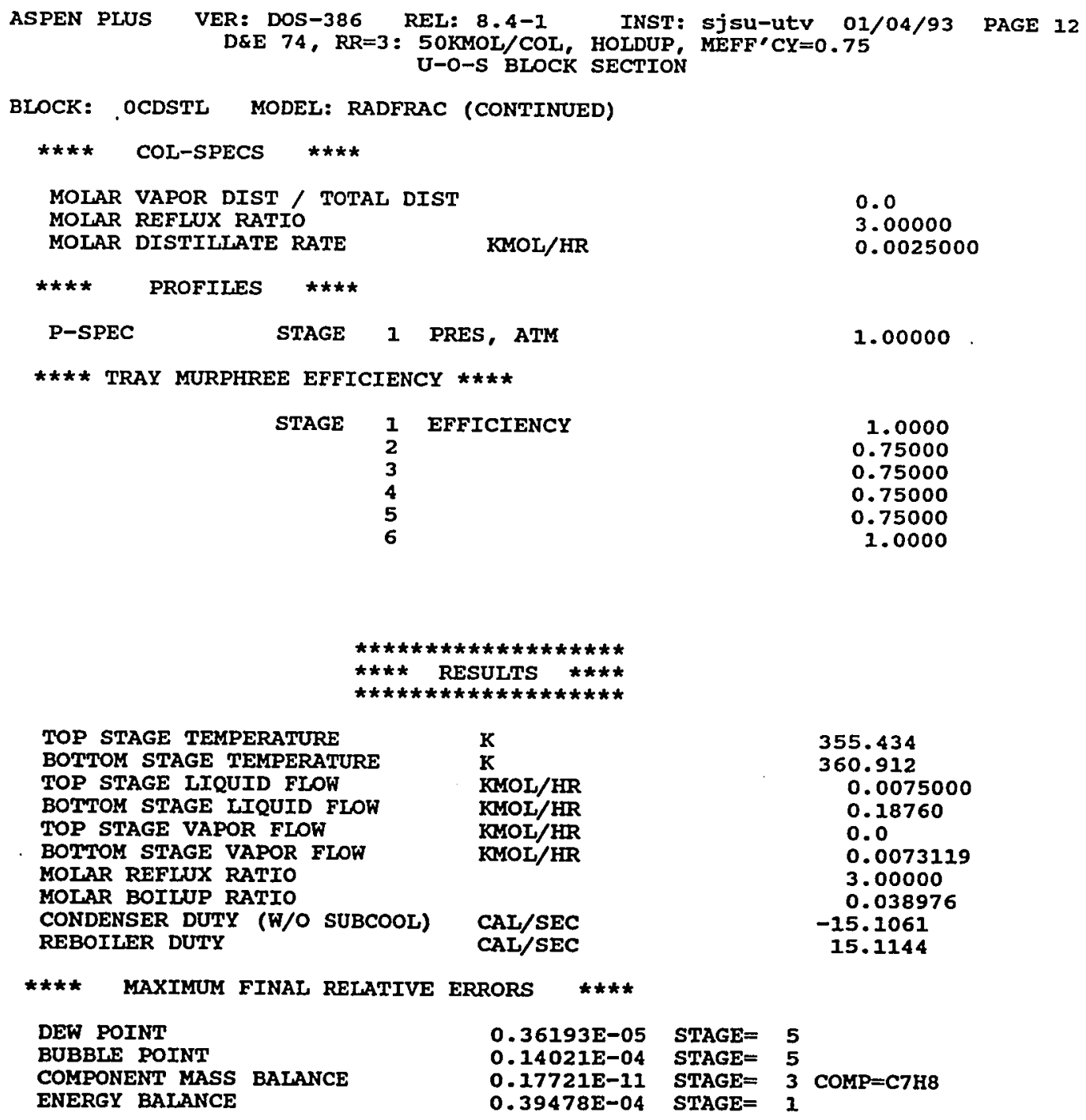




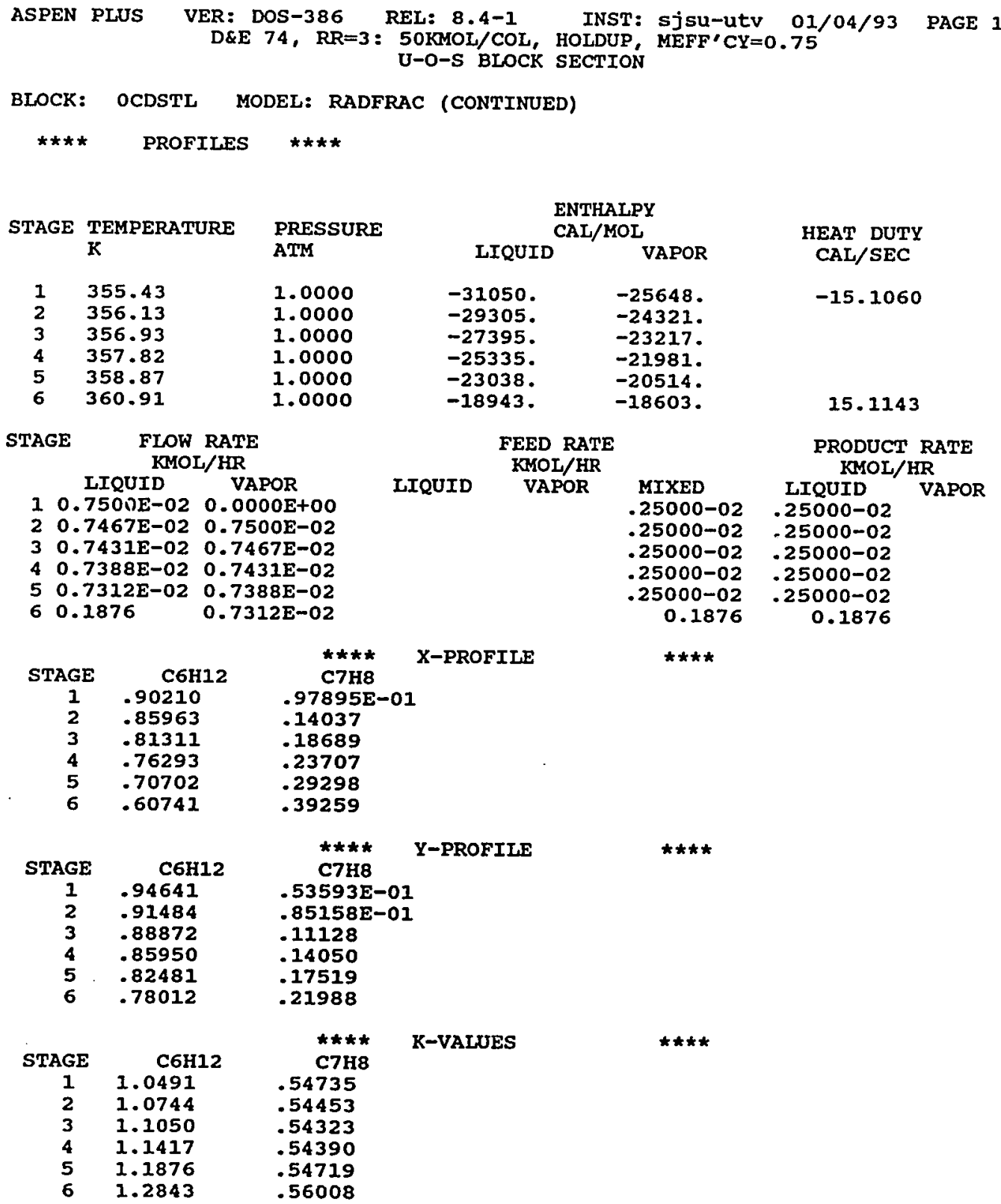




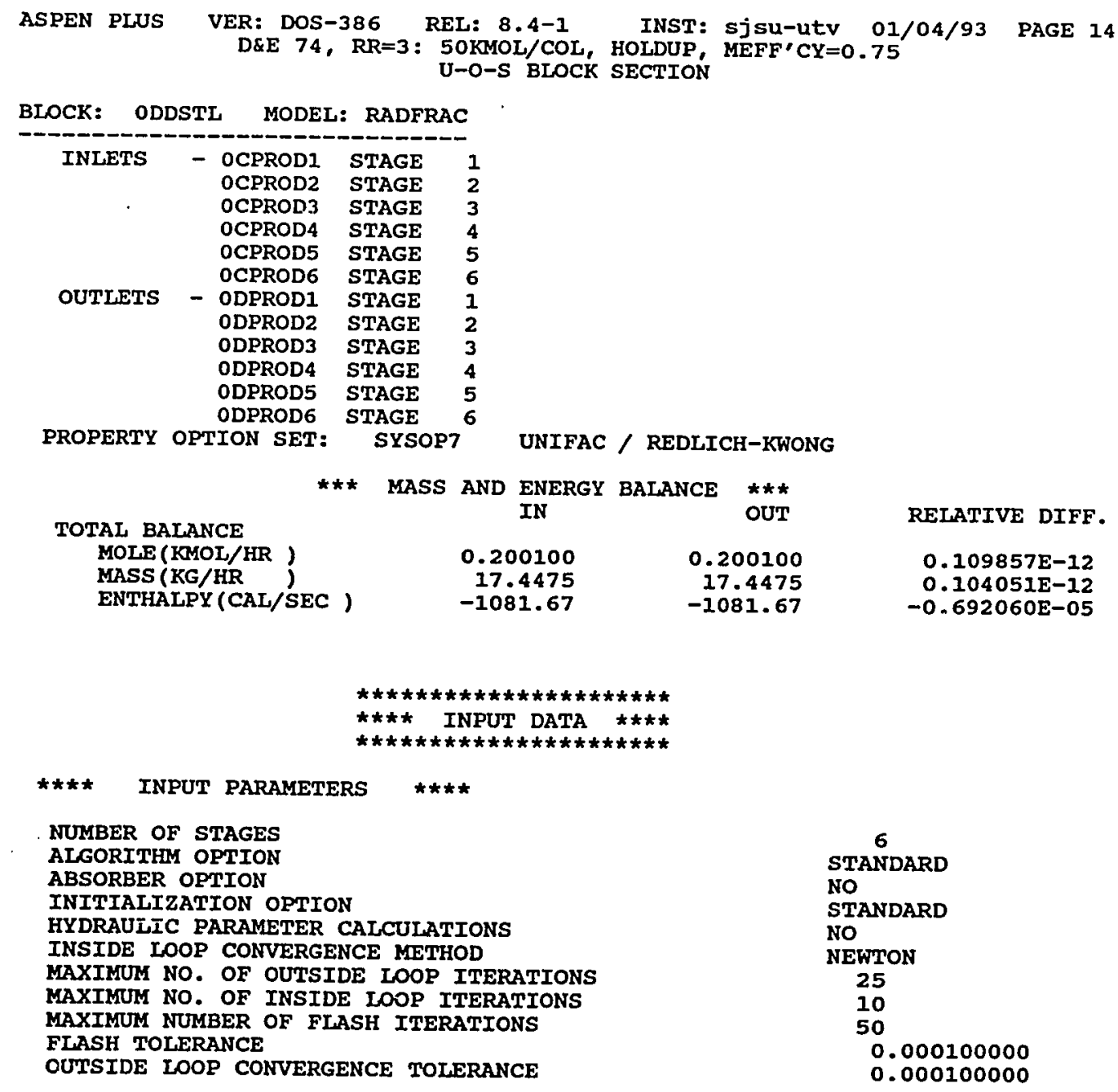




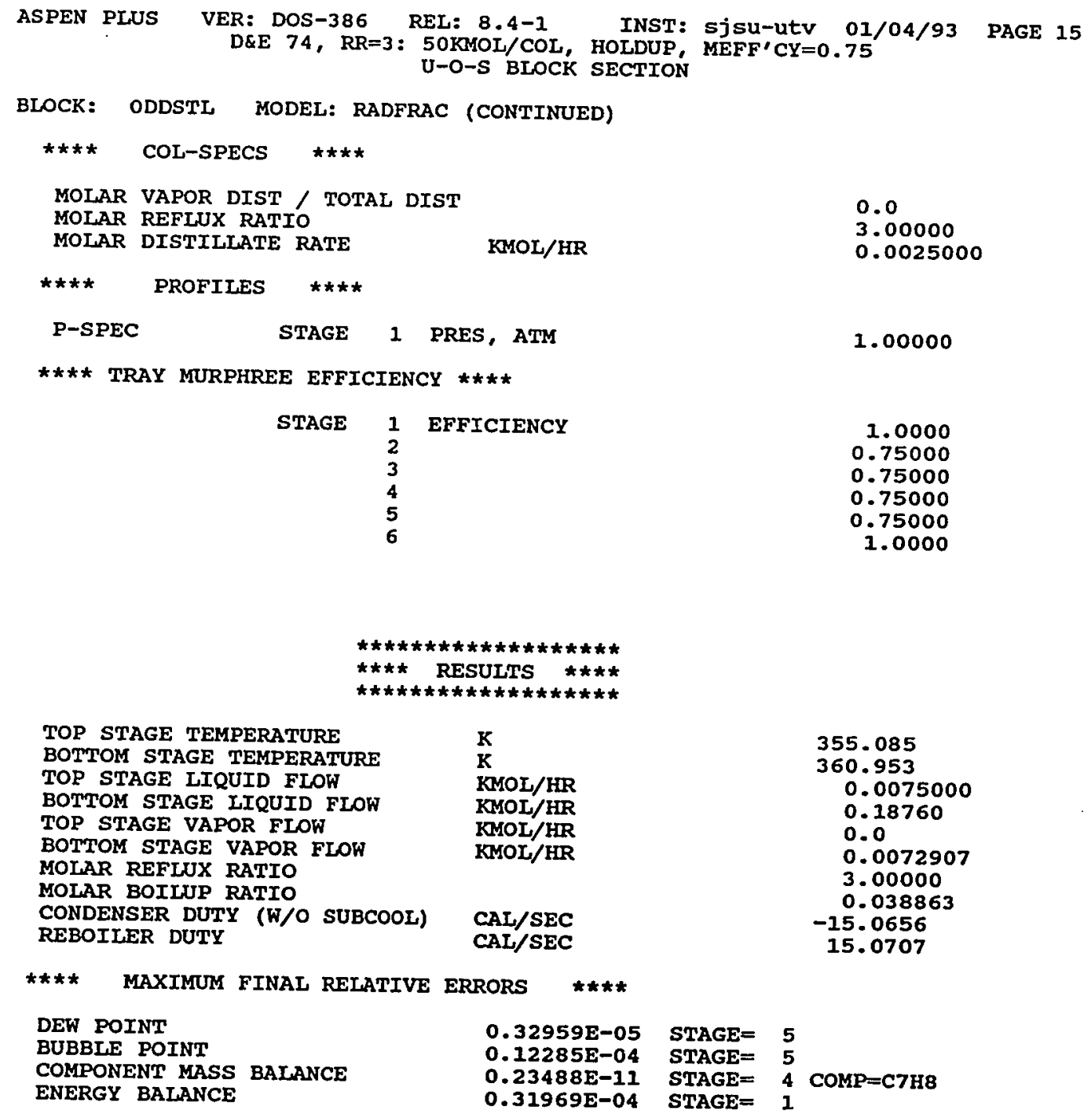


ASPEN PLUS VER: DOS-386 REL: 8.4-1 INST: sjsu-utV 01/04/93 PAGE 16 D\&E 74, RR=3: 50KMOL/COL, HOLDUP, MEFF'CY=0.75 U-O-S BLOCK SECTION

BLOCK: ODDSTL MODEL: RADFRAC (CONTINUED)

\begin{tabular}{|c|c|c|}
\hline$\star \star \star \star$ & PROFILES & $\star \star \star \star \star$ \\
\hline TAGE & $\begin{array}{l}\text { TEMPERATURE } \\
\mathrm{K}\end{array}$ & $\begin{array}{l}\text { PRESSURE } \\
\text { ATM }\end{array}$ \\
\hline $\begin{array}{l}1 \\
2 \\
3 \\
4 \\
5 \\
6\end{array}$ & $\begin{array}{l}355.08 \\
355.65 \\
356.35 \\
357.25 \\
358.42 \\
360.95\end{array}$ & $\begin{array}{l}1.0000 \\
1.0000 \\
1.0000 \\
1.0000 \\
1.0000 \\
1.0000\end{array}$ \\
\hline
\end{tabular}

\begin{tabular}{ccc}
\multicolumn{2}{c}{$\begin{array}{c}\text { ENTHALPY } \\
\text { CAL/MOL }\end{array}$} & $\begin{array}{c}\text { HEAT DUTY } \\
\text { CAL/SEC }\end{array}$ \\
LIQUID & VAPOR & -15.0656 \\
-31942. & -26144. & \\
-30515. & -25008. & \\
-28772. & -23958. & \\
-26653. & -22646. & \\
-24013. & -20933. & 15.0706 \\
-18866. & -18553. &
\end{tabular}

STAGE FLOW RATE IMOL/HR LIQUID VAPOR

$10.7500 E-02 \quad 0.0000 \mathrm{E}+00$

$20.7471 \mathrm{E}-02 \quad 0.7500 \mathrm{E}-02$

$30.7433 E-02 \quad 0.7471 E-02$

$40.7385 \mathrm{E}-02 \quad 0.7433 \mathrm{E}-02$

$50.7291 E-02 \quad 0.7385 E-02$

$60.1876 \quad 0.7291 E-02$

FEED RATE

KMOL/HR

PRODUCT RATE KMOL/HR

IIOUID

$.25000-02$

$.25000-02$

$.25000-02$

25000-02

$.25000-02$

0.1876

VAPOR

.25000-02

$.25000-02$

. 25000-02

.25000-02

0.1876

\begin{tabular}{ccr} 
STAGE & \multicolumn{1}{c}{ C6H12 } & $\begin{array}{c}\star \star \star \\
\text { C7H } \\
1\end{array}$ \\
2 & .92385 & .76152 \\
3 & .88908 & .11092 \\
4 & .79665 & .15335 \\
5 & .73074 & .20496 \\
6 & .60554 & .26926 \\
& & .39446
\end{tabular}

STAGE C6H12 $\quad$ C7* 12 Y-PROFILE

\begin{tabular}{ccc} 
STAGE & \multicolumn{1}{c}{$\begin{array}{c}\star \star 6 * 12 \\
1\end{array}$} & $\begin{array}{c}\text { C7H8 } \\
1\end{array}$ \\
\hline 2 & .95815 & $.41846 \mathrm{E}-01$ \\
3 & .90621 & $.68904 \mathrm{E}-01$ \\
4 & .87514 & $.93789 \mathrm{E}-01$ \\
5 & .83460 & .12486 \\
6 & .77894 & .16540 \\
& & .22106
\end{tabular}

STAGE C6H12 12 C7H8

$\begin{array}{ccc}\text { TAGE } & \text { C6H12 } & \text { C7H8 } \\ 1 & 1.0371 & .54940 \\ 2 & 1.0566 & .54632 \\ 3 & 1.0826 & .54398 \\ 4 & 1.1178 & .54322 \\ 5 & 1.1675 & .54546 \\ 6 & 1.2864 & .56042\end{array}$




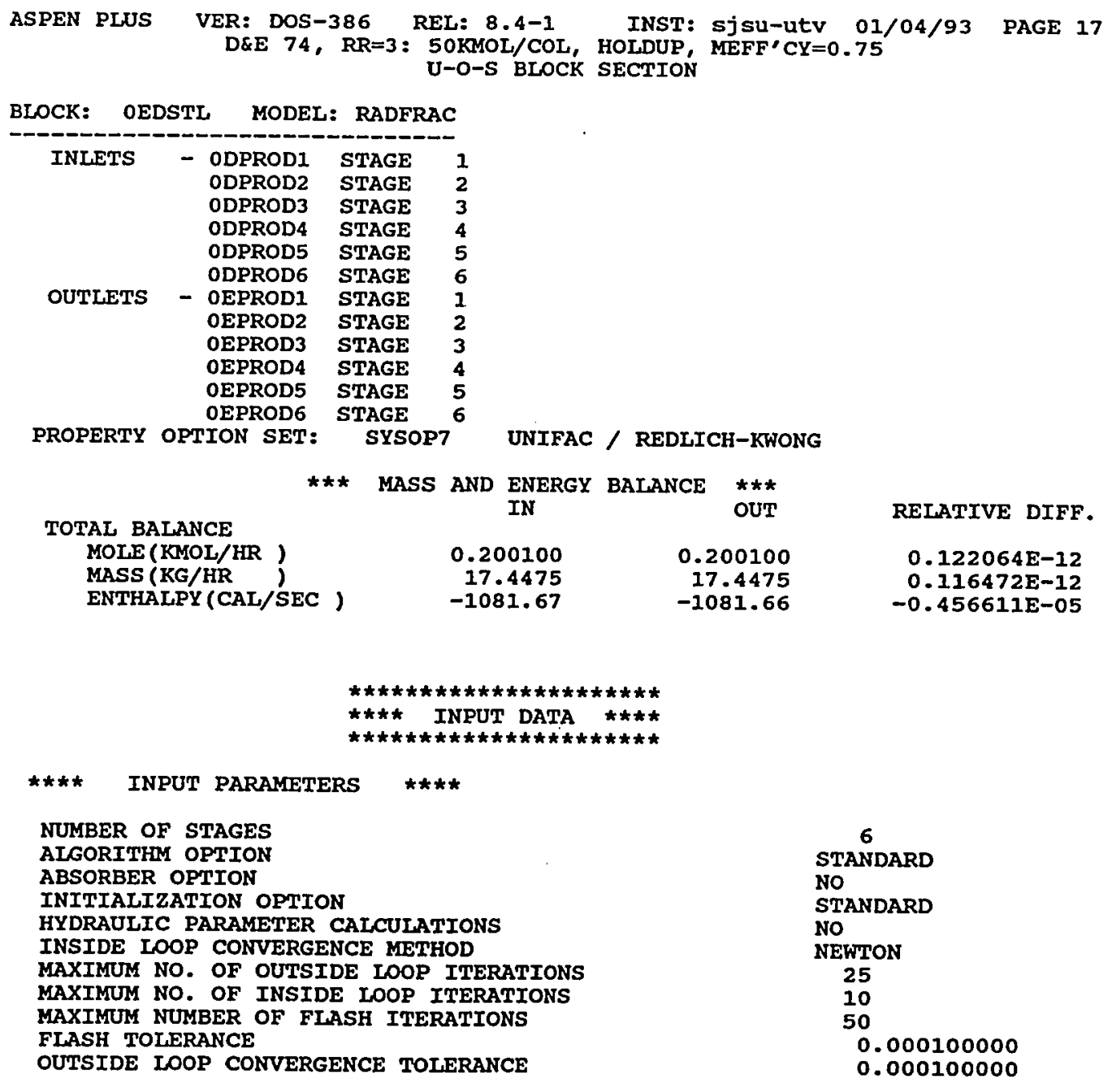




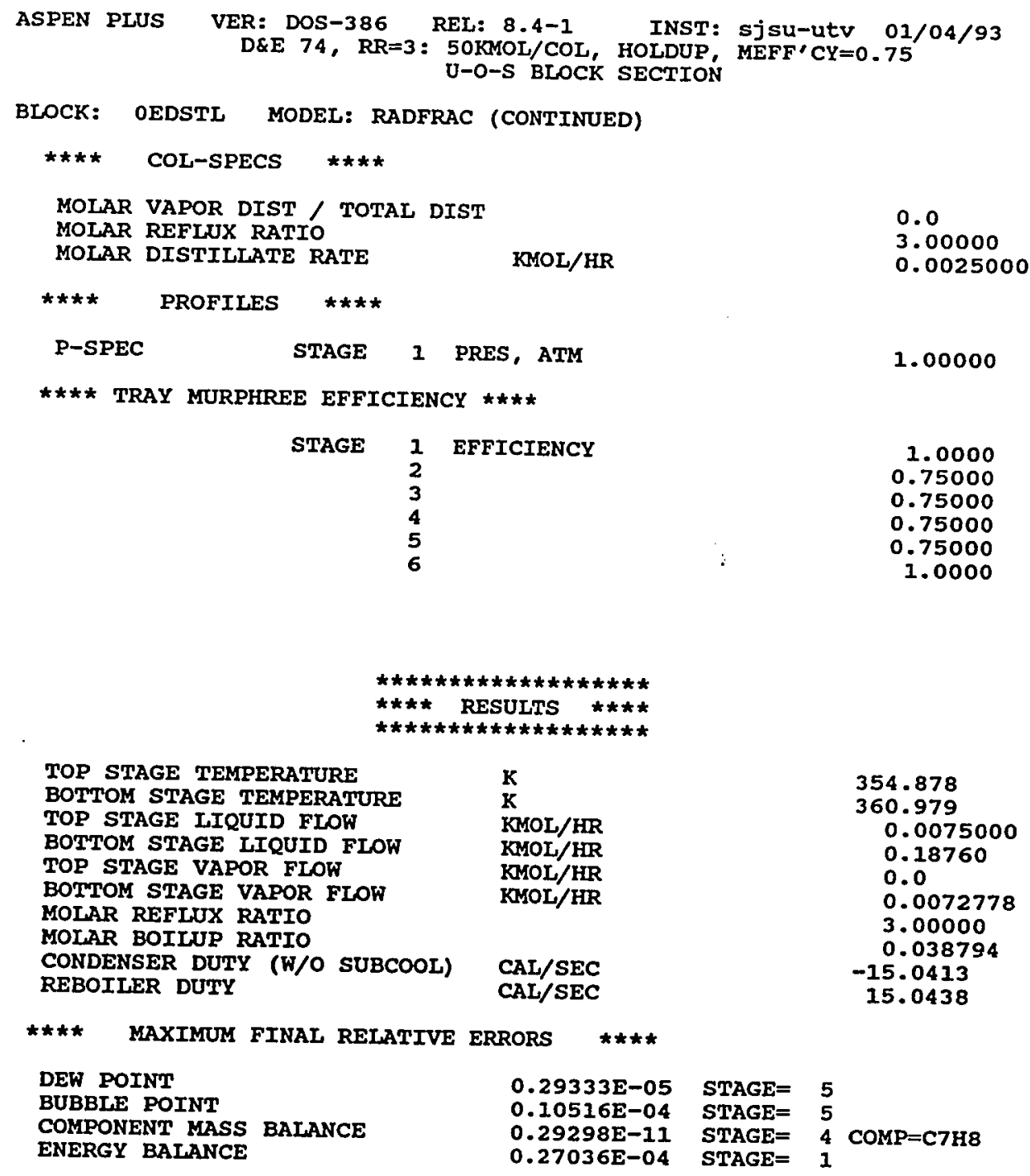


ASPEN PLUS VER: DOS-386 REL: 8.4-1 INST: sjsu-utv 01/04/93 PAGE 19 $D \& E$ 74, $R R=3$ : 5OKMOL/COL, HOLDUP, MEFF' $C Y=0.75$

U-O-S BLOCK SECTION

BLOCK: OEDSTL MODEL: RADFRAC (CONTINUED)

$\star \star \star \star \quad$ PROFILES $\star \star \star \star \star *$

\begin{tabular}{|c|c|c|c|c|c|}
\hline \multirow{2}{*}{ STAGE } & \multirow{2}{*}{$\begin{array}{l}\text { TEMPERATURE } \\
\mathrm{K}\end{array}$} & PRE & \multicolumn{2}{|c|}{$\begin{array}{l}\text { ENTHALPY } \\
\text { CAL/MOL }\end{array}$} & \multirow{2}{*}{$\begin{array}{l}\text { HEAT DUTY } \\
\text { CAL/SEC }\end{array}$} \\
\hline & & ATM & LIQUID & VAPOR & \\
\hline $\begin{array}{l}1 \\
2 \\
3 \\
4 \\
5 \\
6\end{array}$ & $\begin{array}{l}354.88 \\
355.35 \\
356.00 \\
356.87 \\
358.11 \\
360.98\end{array}$ & $\begin{array}{l}1.0000 \\
1.0000 \\
1.0000 \\
1.0000 \\
1.0000 \\
1.0000\end{array}$ & $\begin{array}{l}-32476 \\
-31253 \\
-29647 \\
-27530 \\
-24690 \\
-18817\end{array}$ & $\begin{array}{l}-26442 \\
-25433 \\
-24431 \\
-23086 \\
-21221 \\
-18521\end{array}$ & -15.0413 \\
\hline
\end{tabular}

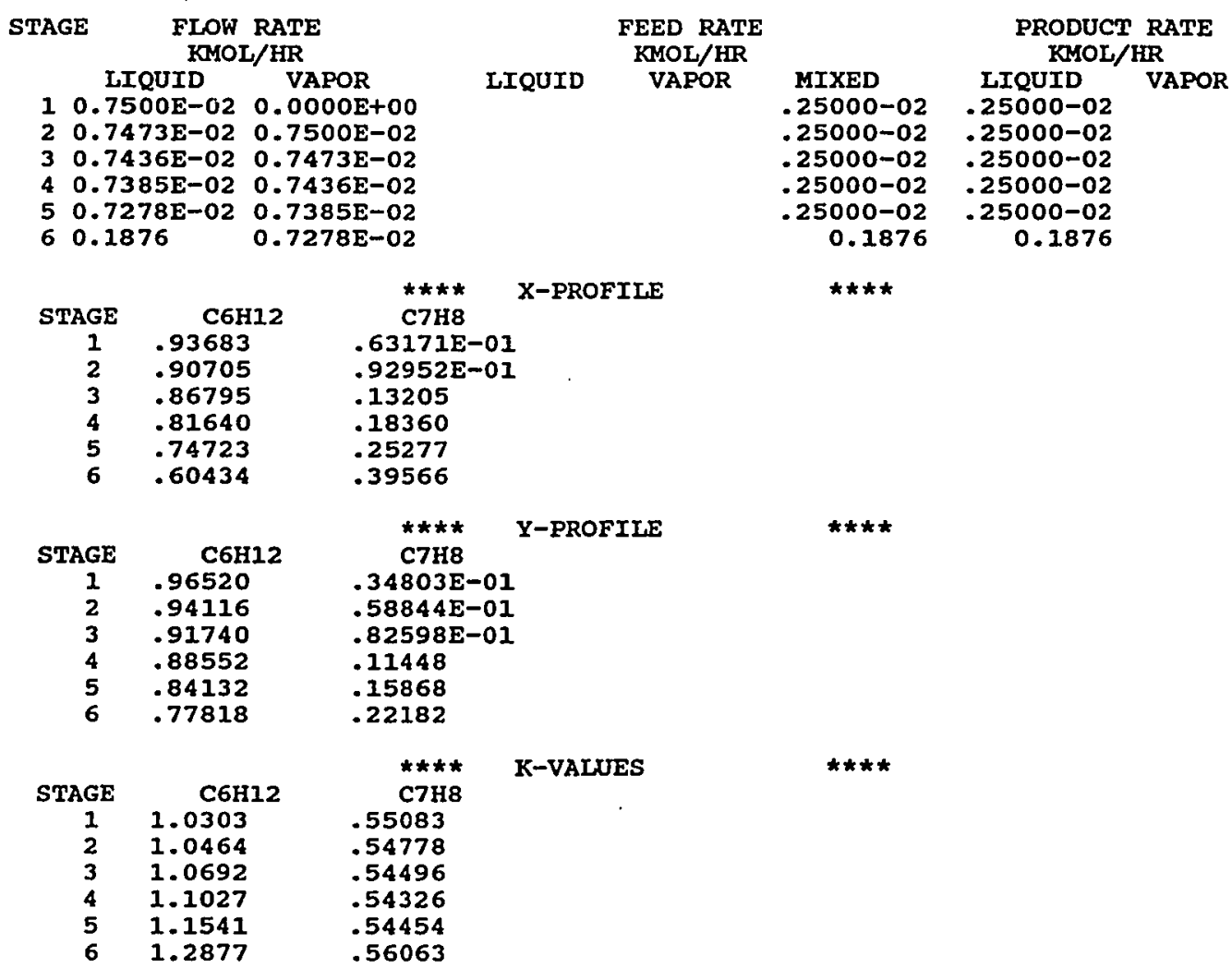




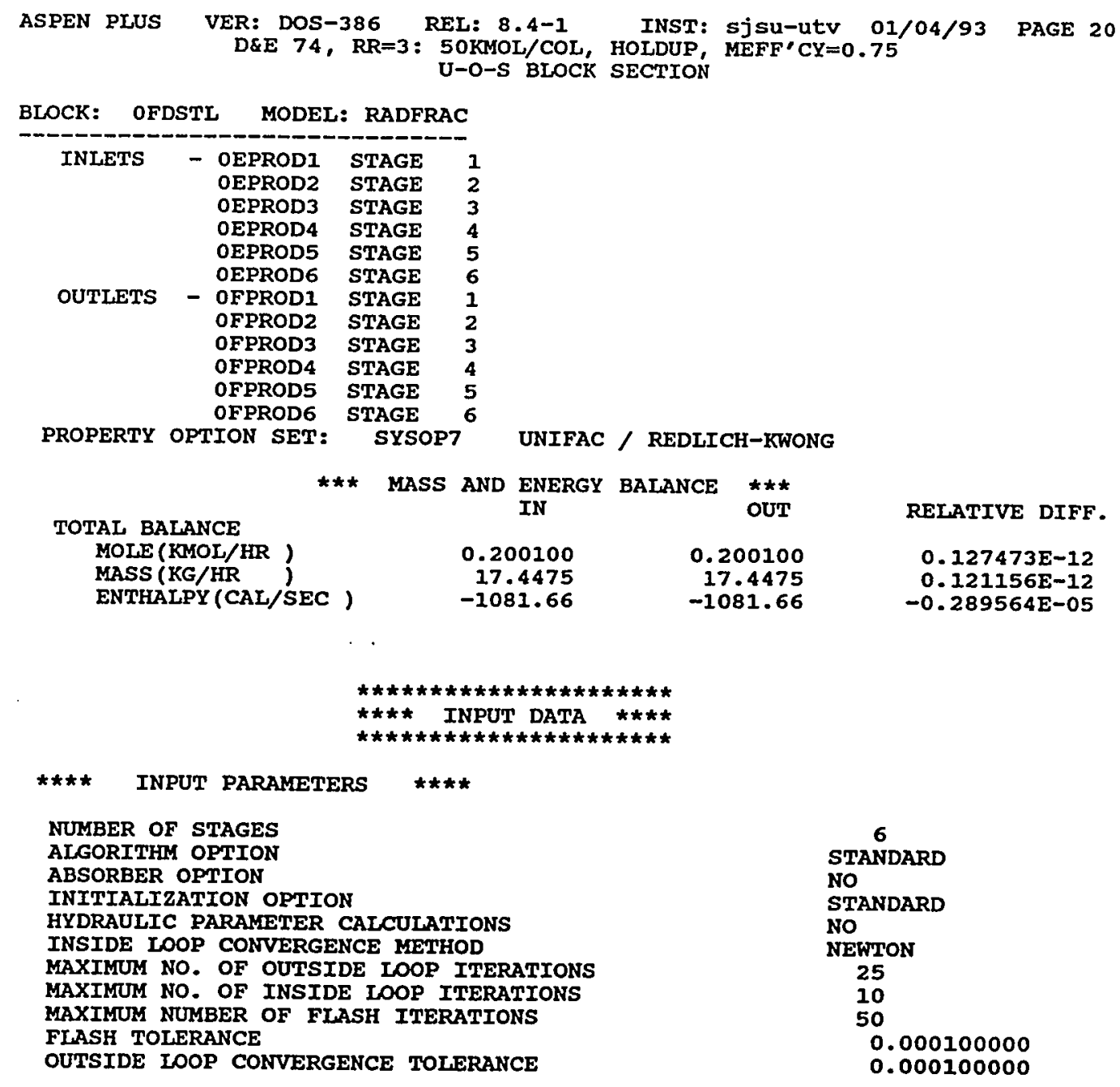




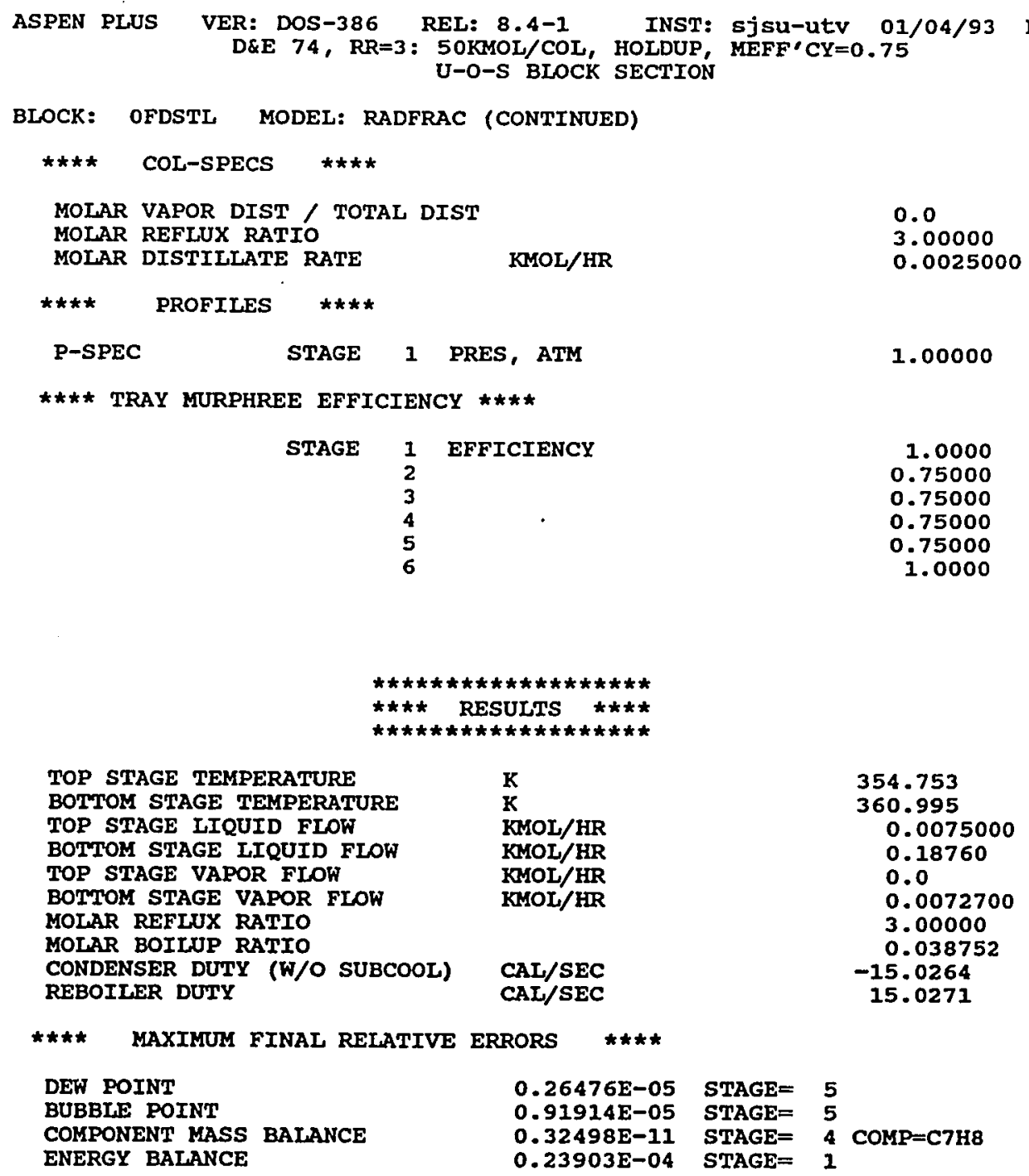




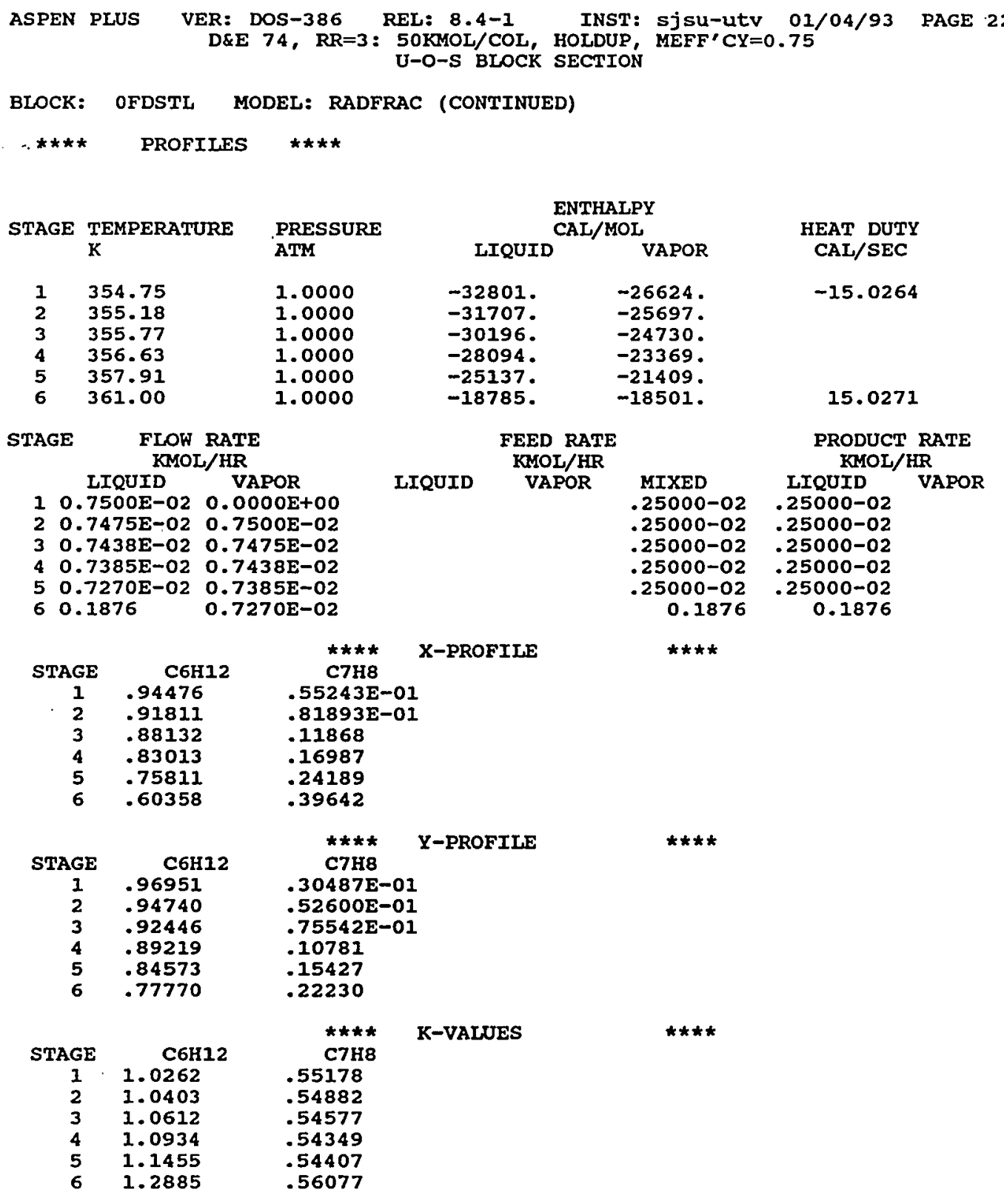


ASPEN PLUS VER: DOS-386 REL: 8.4-1 INST: sjsu-utv 01/04/93 PAGE 23 D\&E 74, $R R=3$ : 50KMOL/COL, HOLDUP, MEFF' $C Y=0.75$

U-O-S BLOCK SECTION

BLOCK: OOODSTL MODEL: RADFRAC

$\begin{array}{crll}\text { INLETS } & \text { OFPROD1 } & \text { STAGE } & 1 \\ & \text { OFPROD2 } & \text { STAGE } & 2 \\ & \text { OFPROD3 } & \text { STAGE } & 3 \\ & \text { OFPROD4 } & \text { STAGE } & 4 \\ & \text { OFPROD5 } & \text { STAGE } & 5 \\ \text { OUTLETS } & \text { OFPROD6 } & \text { STAGE } & 6 \\ & \text { OOOPROD1 } & \text { STAGE } & 1 \\ & \text { OOOPROD2 } & \text { STAGE } & 2 \\ & \text { OOOPROD3 } & \text { STAGE } & 3 \\ & \text { OOOPROD4 } & \text { STAGE } & 4 \\ & \text { OOOPROD5 } & \text { STAGE } & 5 \\ \text { PROPERTY OPTION SET: } & \text { OOOPROD6 } & \text { STAGE } & 6 \\ \text { OPSOP7 }\end{array}$

UNIFAC / REDLICH-KWONG

$\star * *$ MASS AND ENERgY BALANCE

IN

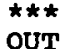

TOTAL BAIANCE

$\begin{array}{lrr}\text { MOLE (KMOL/HR ) } & 0.200100 & 0.200100 \\ \text { MASS (KG/HR } & 17.4475 & 17.4475\end{array}$

MASS (KG/HR )

$-1081.66$

17.4475

$-1081.66$

RELATIVE DIFF.

$0.129692 \mathrm{E}-12$

$0.123395 \mathrm{E}-12$

$-0.182147 \mathrm{E}-05$

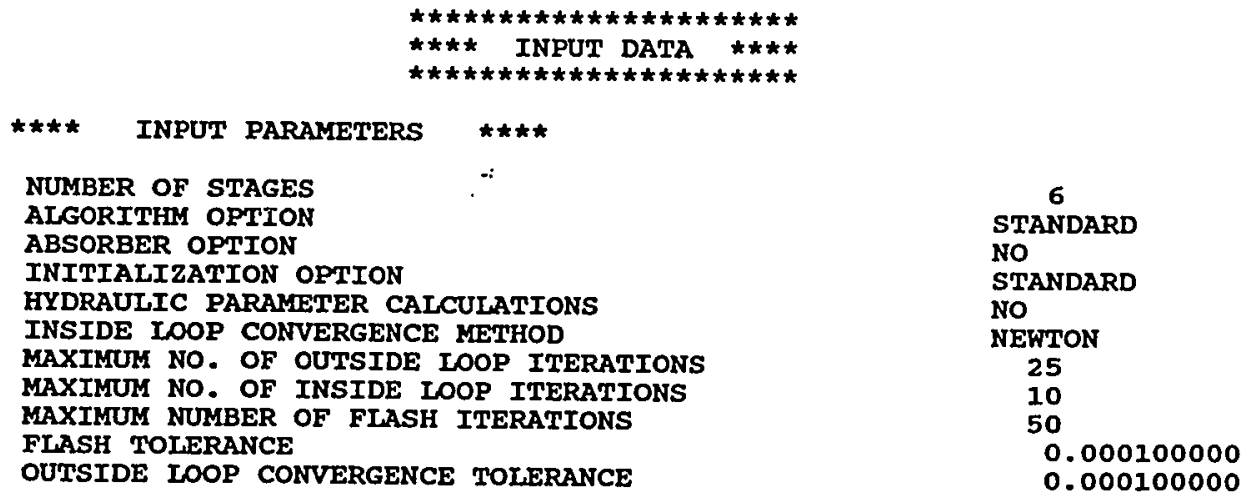




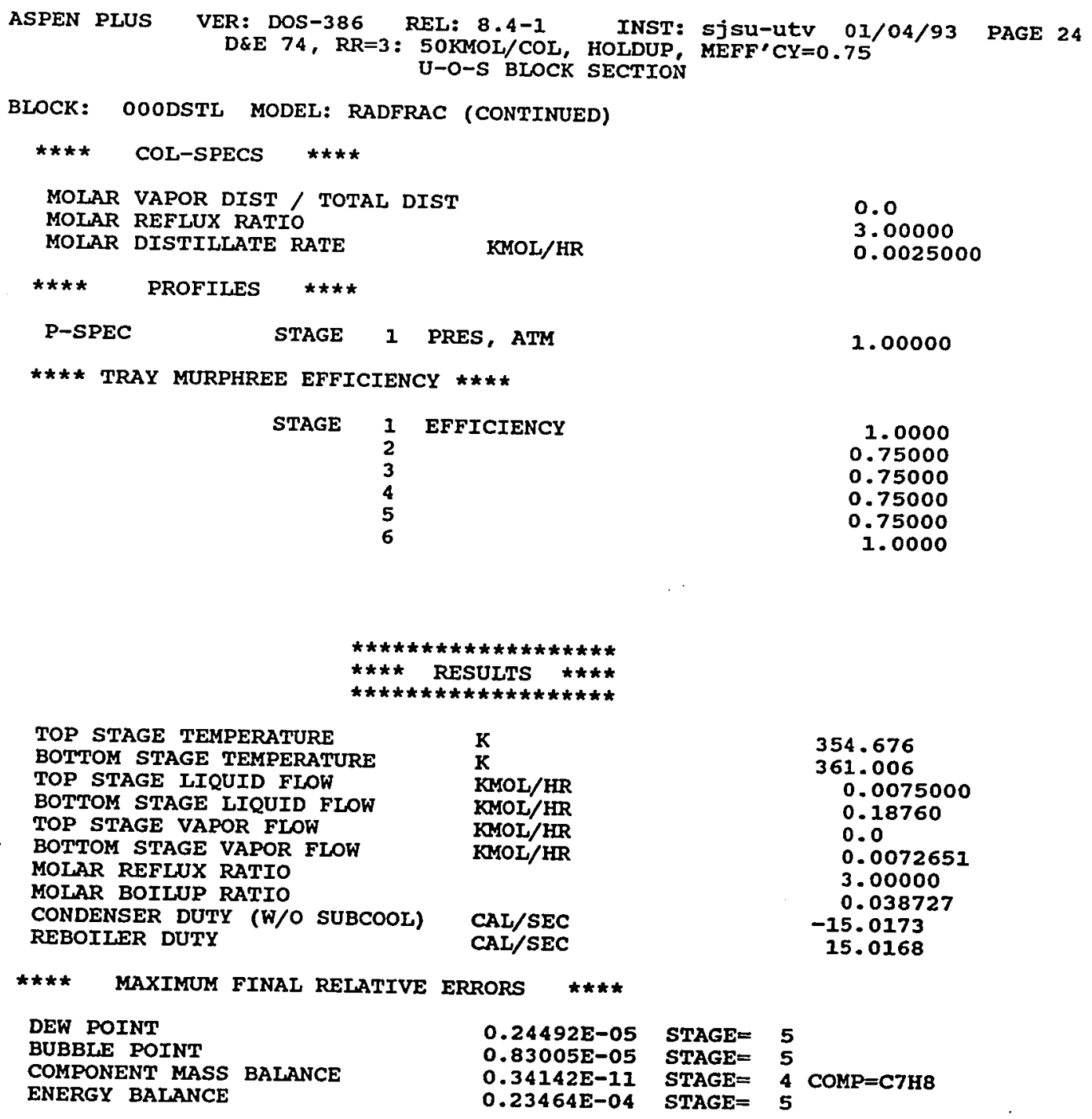

TOP STAGE TEMPFRATURE BOTTOM STAGE TEMPERATUR TOP STAGE VAPOR FIOW $0.23464 \mathrm{E}-04$
STAGE= STAGE $=5$

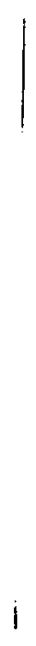

i 


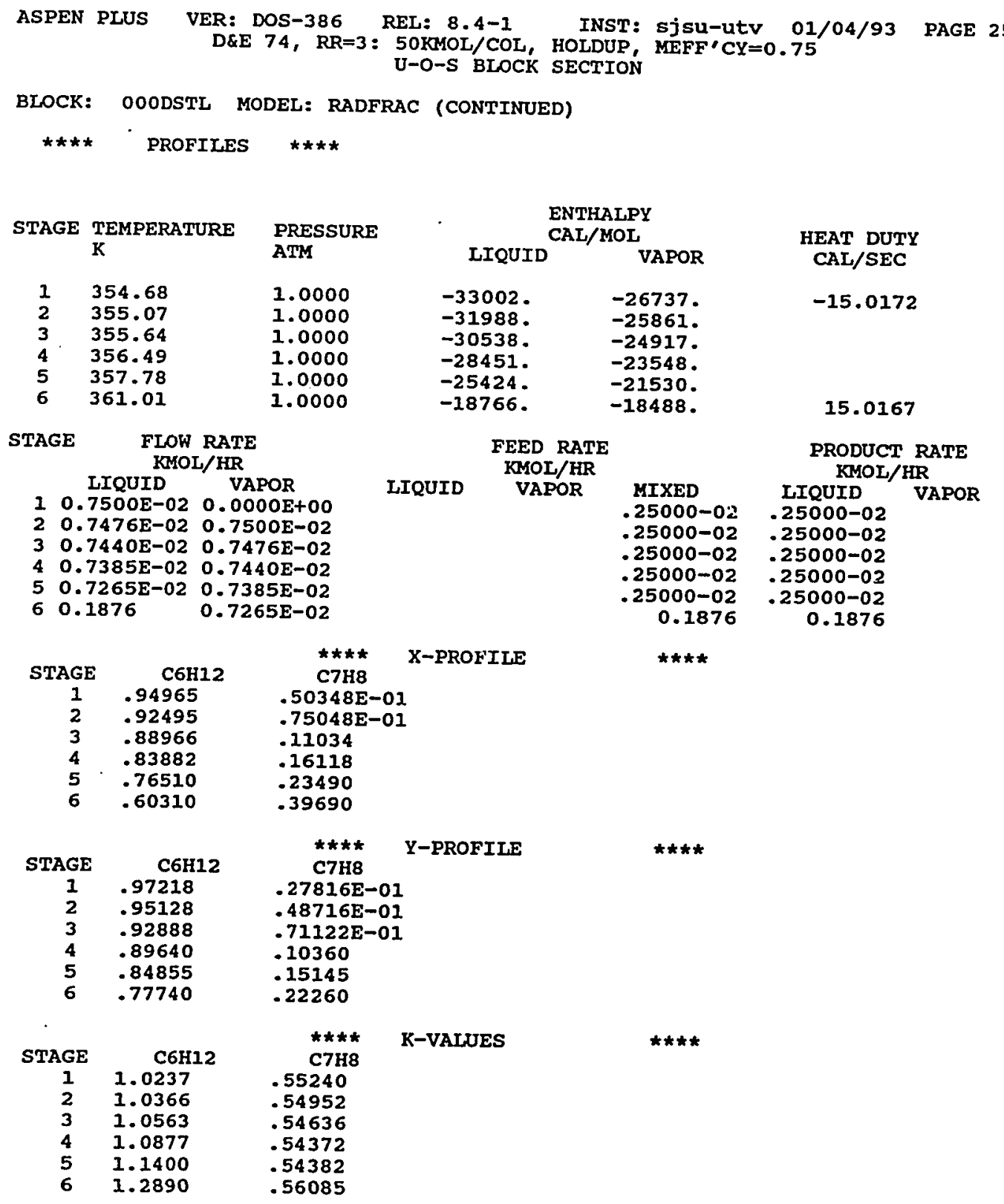




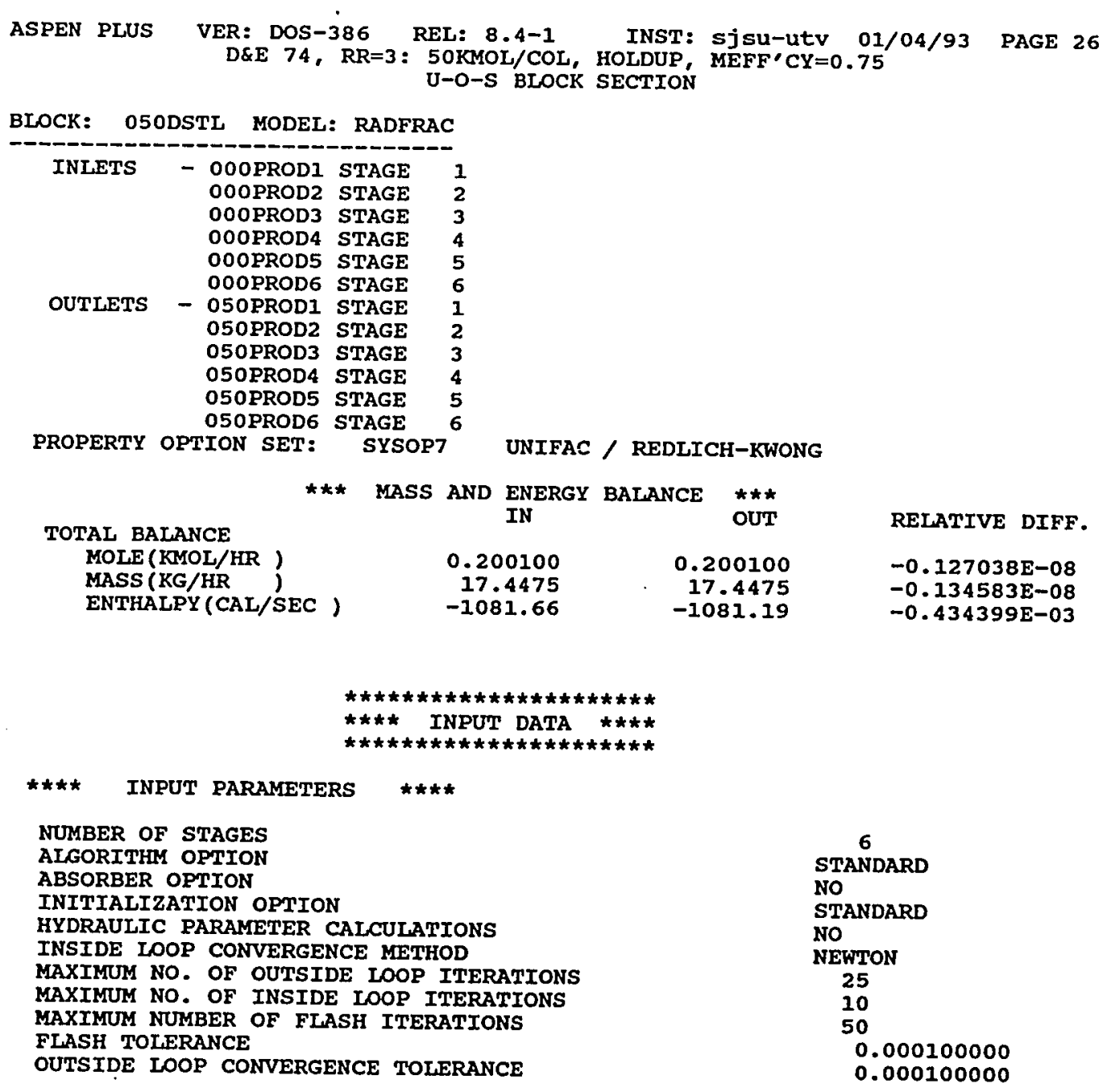




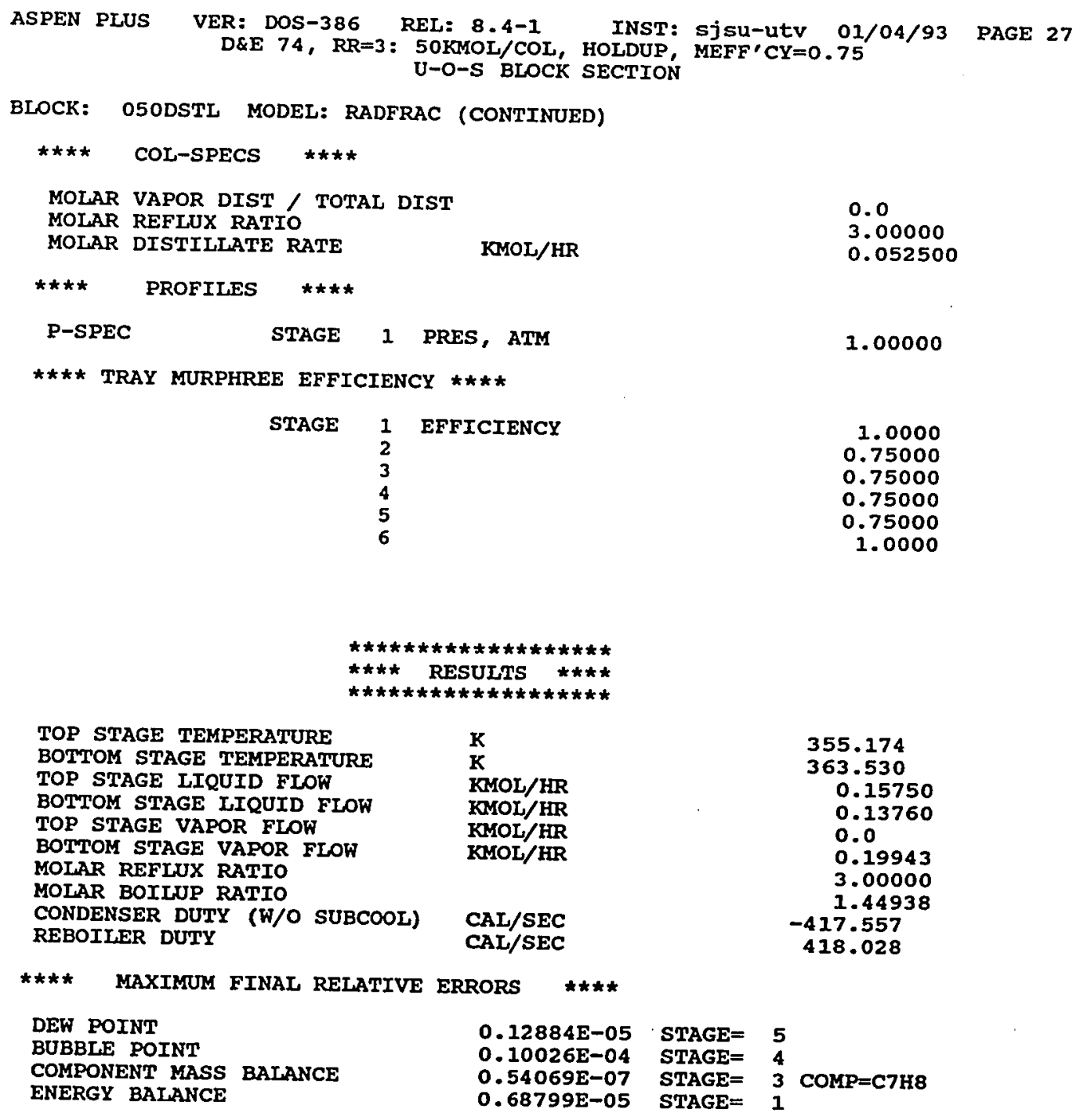


ASPEN PLUS

VER: DOS-386 REL: 8.4-1 $D \& E$ 74, RR=3: $50 \mathrm{KMOL} / \mathrm{COL}$, HOLDUP, MEFF' $\mathrm{CY}=0.75$

BLOCK: O5ODSTL MODEL: RADFRAC (CONTINUED)

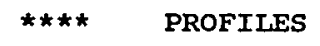

STAGE TEMPERATURE

$\mathrm{K}$

$\begin{array}{ll}1 & 355.17 \\ 2 & 355.94 \\ 3 & 356.97 \\ 4 & 358.36 \\ 5 & 360.23 \\ 6 & 363.53\end{array}$

STAGE

FLOW RATE

$\star \star \star$

PRESSURE
ATM
1.0000
1.0000
1.0000
1.0000
1.0000
1.0000

\begin{tabular}{cc}
\multicolumn{2}{c}{ ENTHALPY } \\
CAL/MOL \\
LIQUID & VAPOR \\
-31712. & -26016. \\
-29789. & -24452. \\
-27304. & -22926. \\
-24136. & -20955. \\
-20255. & -18452. \\
-14344. & -15387.
\end{tabular}

HEAT DUTY

CAL/SEC

$-417.5572$

418.0275

FEED RATE

KMOL/HR
LIQUID

10.1575

20.1563

30.1547

40.1527

50.1494

$0.0000 E+00$

0.2075

0.2063

0.2047

0.2027

60.1376

0.1994

$\begin{array}{cc}\text { STAGE } & \text { C6H12 } \\ 1 & .91822 \\ 2 & .87140 \\ 3 & .81088 \\ 4 & .73376 \\ 5 & .63931 \\ 6 & .49576\end{array}$

$\star \star \star \star \quad X-P R O F I L E$

KMOL/HR
VAPOR

LIQUID

PRODUCT RATE KMOL/HR

IIQUID

MIXED $.25000-02$

$.52500-01$

$.25000-02 \quad .25000-02$

$.25000-02.25000-02$

$.25000-02.25000-02$

$.25000-02.25000-02$

$\begin{array}{rr}0.1876 & .25000-1376\end{array}$

C7H8

$.81775 E-01$

.12860

.18912

.26624

.36069

.50424

\section{STAGE $\quad$ C6H12}

$\star \star * \star \quad Y$ YRROFILE

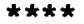

\section{C7H8}

.44880E-01

$.91785 \quad .82154 \mathrm{E}-01$

.88172

.83509

.77595

.70429

.11828

.16491

.22405

.29571

\begin{tabular}{|c|c|c|c|c|}
\hline STAGE & C6H12 & $\star \star * * *$ & K-VALUES & $\star \star \star \star \star$ \\
\hline $\begin{array}{c}\text { SIAL } \\
1\end{array}$ & 1.0402 & $\begin{array}{r}\text { C7H8 } \\
.54883\end{array}$ & & \\
\hline 2 & 1.0671 & .54515 & & \\
\hline 3 & 1.1065 & .54321 & & \\
\hline 4 & 1.1650 & .54529 & & \\
\hline 5 & 1.2511 & .55495 & & \\
\hline 6 & 1.4206 & .58645 & & \\
\hline
\end{tabular}




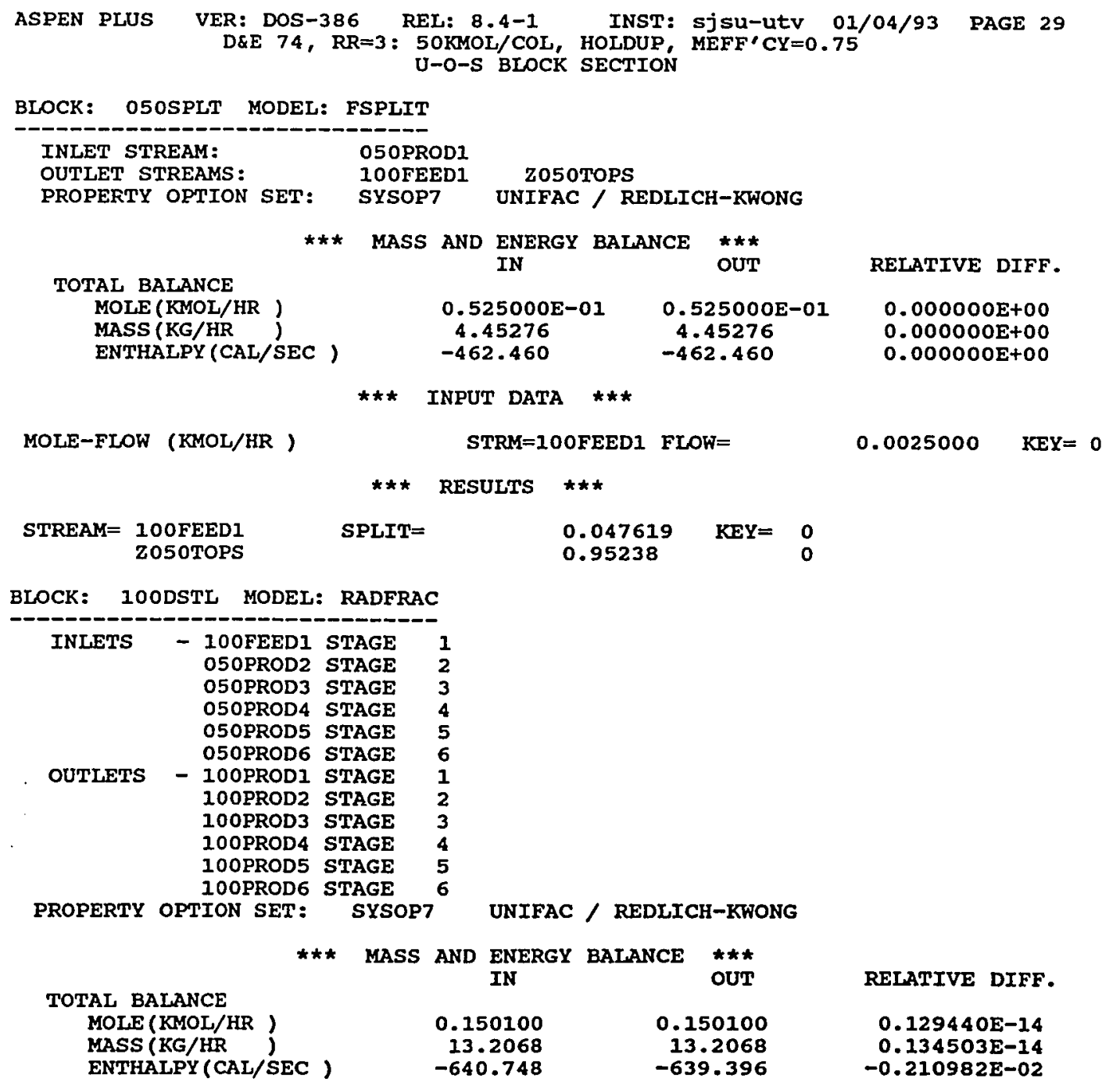




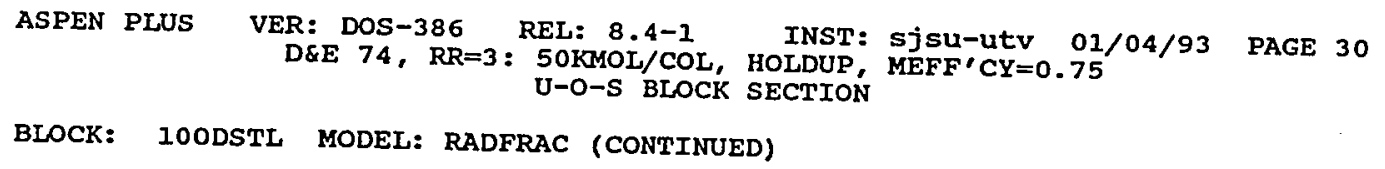

$\begin{array}{lll}\text { STAGE } & 1 & \text { EFFICIENCY } \\ & 2 & \\ 3 & \\ 4 & \\ 5 & \\ 6 & \end{array}$

6
STANDARD
NO
STANDARD
NO
NENTON
25
10
50
0.000100000
0.000100000

1.00000

1.0000
0.75000
0.75000
0.75000
0.75000
1.0000 
ASPEN PLUS VER: DOS-386 REL: 8.4-1 INST: sjsu-utV 01/04/93 PAGE 31 $\mathrm{D \& E} 74, \mathrm{RR}=3$ : 5OKMOL/COL, HOLDUP, MEFF' $\mathrm{CY}=0.75$

U-O-S BLOCK SECTION

BLOCK: 1OODSTL MODEL: RADFRAC (CONTINUED)

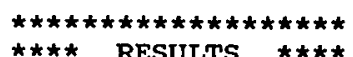

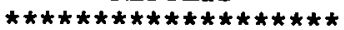

TOP STAGE TEMPERATURE BOTTOM STAGE TEMPERATURE TOP STAGE LIQUID FLOW BOTTOM STAGE LIQUID FLOW TOP STAGE VAPOR FIOW BOTTOM STAGE VAPOR FLOW MOLAR REFLUX RATIO MOLAR BOILUP RATIO CONDENSER DUTY (W/O SUBCOOL) REBOILER DUTY
$\mathbf{K}$

KMOL/HR

KMOL/HR

KMOL/HR

KMOL/HR

CAL/SEC

CAL/SEC

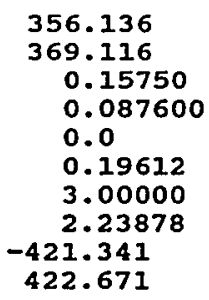

0.0

0.19612

3.00000

2.23878

$-421.341$

$422.67 I$

$\star \star \star \star$ MAXIMUM FINAL RELATIVE ERRORS $\star \star \star \star ~$

DEW POINT

BUBBLE POINT

COMPONENT MASS BALANCE

ENERGY BALANCE

$0.68669 E-04$

$0.34887 E-04$

$0.14701 \mathrm{E}-13$ STAGE $=1$ COMP $=\mathrm{C} 7 \mathrm{H} 8$

$0.40259 E-04$ STAGE $=1$

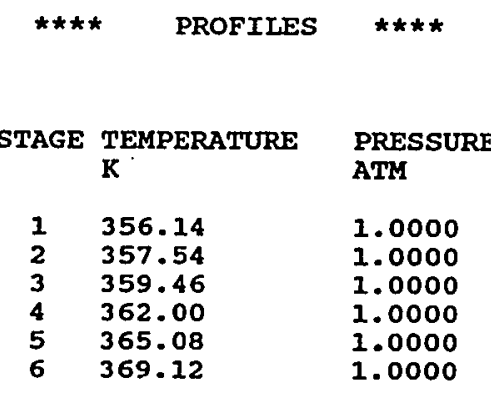

STAGE FLOW RATE

\begin{tabular}{lll} 
& \multicolumn{2}{c}{ KMOL/HR } \\
& \multicolumn{1}{c}{ LIQUID } & \multicolumn{1}{c}{ VAPOR } \\
1 & 0.1575 & $0.0000 E+00$ \\
2 & 0.1553 & 0.2075 \\
3 & 0.1526 & 0.2053 \\
4 & 0.1496 & 0.2026 \\
5 & 0.1461 & 0.1996 \\
6 & $0.8760 \mathrm{E}-01$ & 0.1961
\end{tabular}

\begin{tabular}{cccc} 
& FEED RATE & & \multicolumn{2}{c}{ PRODUCT RATE } \\
KMOL/HR & KMOL/HR \\
LIQUID & VAPOR & MIXED & LIQUID VID \\
& & $.25000-02$ & $.52500-01$ \\
& $.25000-02$ & $.25000-02$ \\
& $.25000-02$ & $.25000-02$ \\
$.25000-02$ & $.25000-02$ \\
& $.25000-02$ & $.25000-02$ \\
& 0.1376 & $.87600-01$
\end{tabular}


ASPEN PLUS VER: DOS-386 REL: 8.4-1 INST: Sjsu-utV 01/04/93 PAGE 32 $D \& E$ 74, RR=3: 5OKMOL/COL, HOLDUP, MEFF'CY=0.75

U-O-S BLOCK SECTION

BLOCK: 10ODSTL MODEL: RADFRAC (CONTINUED)

\begin{tabular}{|c|c|c|c|c|}
\hline $\begin{array}{c}\text { STAGE } \\
1 \\
2 \\
3 \\
4 \\
5 \\
6\end{array}$ & $\begin{array}{l}\quad \mathrm{C6H12} \\
.85950 \\
.77849 \\
.67705 \\
.55886 \\
.43742 \\
.30705\end{array}$ & $\begin{array}{r}\star \star \star \star \star \\
C 7 H 8 \\
.14050 \\
.22151 \\
.32295 \\
.44114 \\
.56258 \\
.69295\end{array}$ & X-PROFILE & $\star \star \star \star \star$ \\
\hline $\begin{array}{c}\text { STAGE } \\
1 \\
2 \\
3 \\
4 \\
5 \\
6\end{array}$ & $\begin{array}{c}\mathrm{C6H12} \\
.92349 \\
.85879 \\
.79637 \\
.71855 \\
.62841 \\
.53658\end{array}$ & 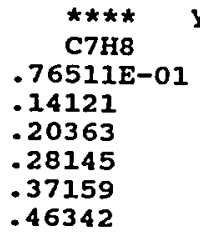 & Y-PROFILE & $\star \star \star \star \star *$ \\
\hline & & 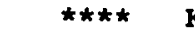 & K-VALUES & 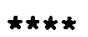 \\
\hline
\end{tabular}

\begin{tabular}{|c|c|}
\hline $\begin{array}{c}\text { STAGE } \\
1 \\
2 \\
3 \\
4 \\
5 \\
6\end{array}$ & $\begin{array}{l}\quad c 6 \mathrm{H} 12 \\
1.0745 \\
1.1299 \\
1.2146 \\
1.3395 \\
1.5065 \\
1.7475\end{array}$ \\
\hline
\end{tabular}

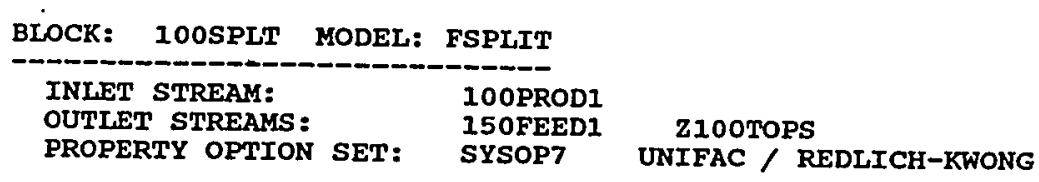

*** MASS AND ENERGY BALANCE $\star * \star$

TOTAL BALANCE MOLE (KMOL/HR ) MASS (KG/HR ENTHALPY (CAL/SEC)

MOLE-FLOW (KMOL/HR ) IN OUT

\section{$0.525000 E-01$ \\ 4.47736}

$-427.291$

$0.525000 \mathrm{E}-01$

4.47736

$-427.291$

** INPUT DATA $* \star \star$

$\begin{aligned} & \text { STREAM }= \text { 150FEED } 1 \\ & \text { Z100TOPS }\end{aligned}$

STRM=150FEED 1 FLOW=

$\star \star \star$ RESULTS

SPLIT $=$

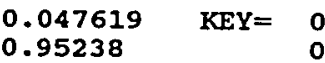

RELATIVE DIFF.

$0.000000 E+00$

$0.000000 \mathrm{E}+00$

$0.000000 E+00$

$0.0025000 \quad \mathrm{KEY}=0$ 


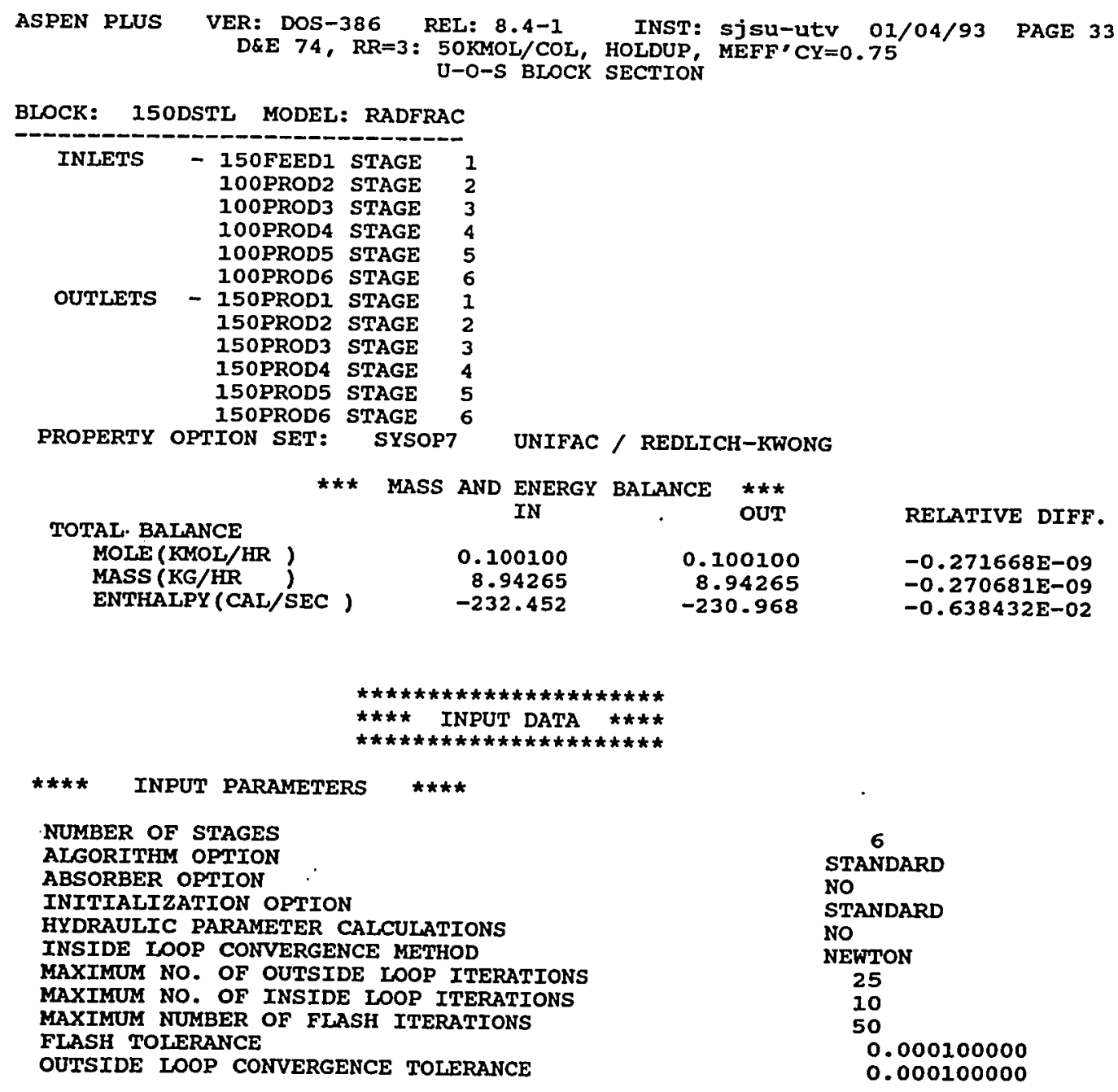




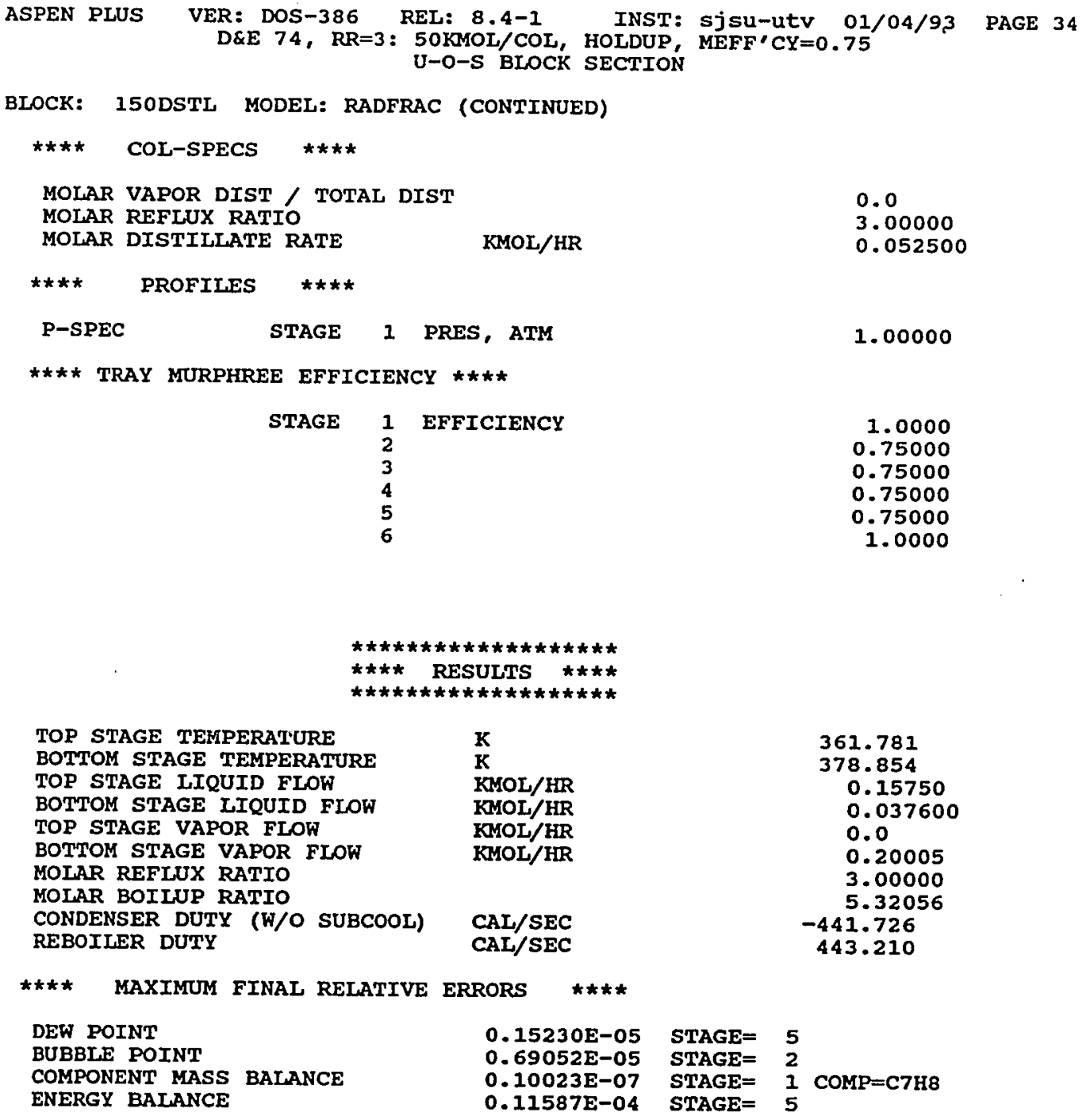




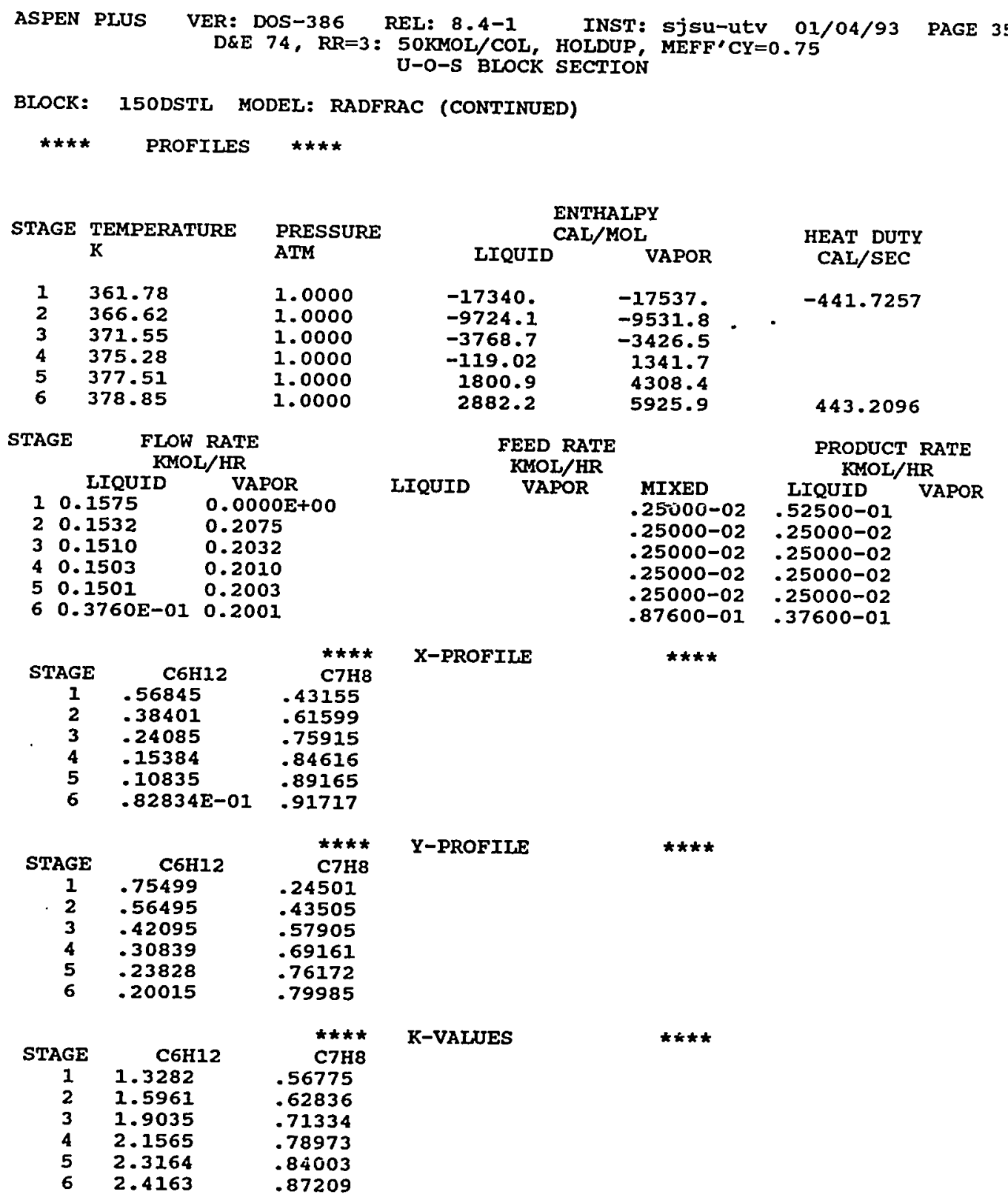




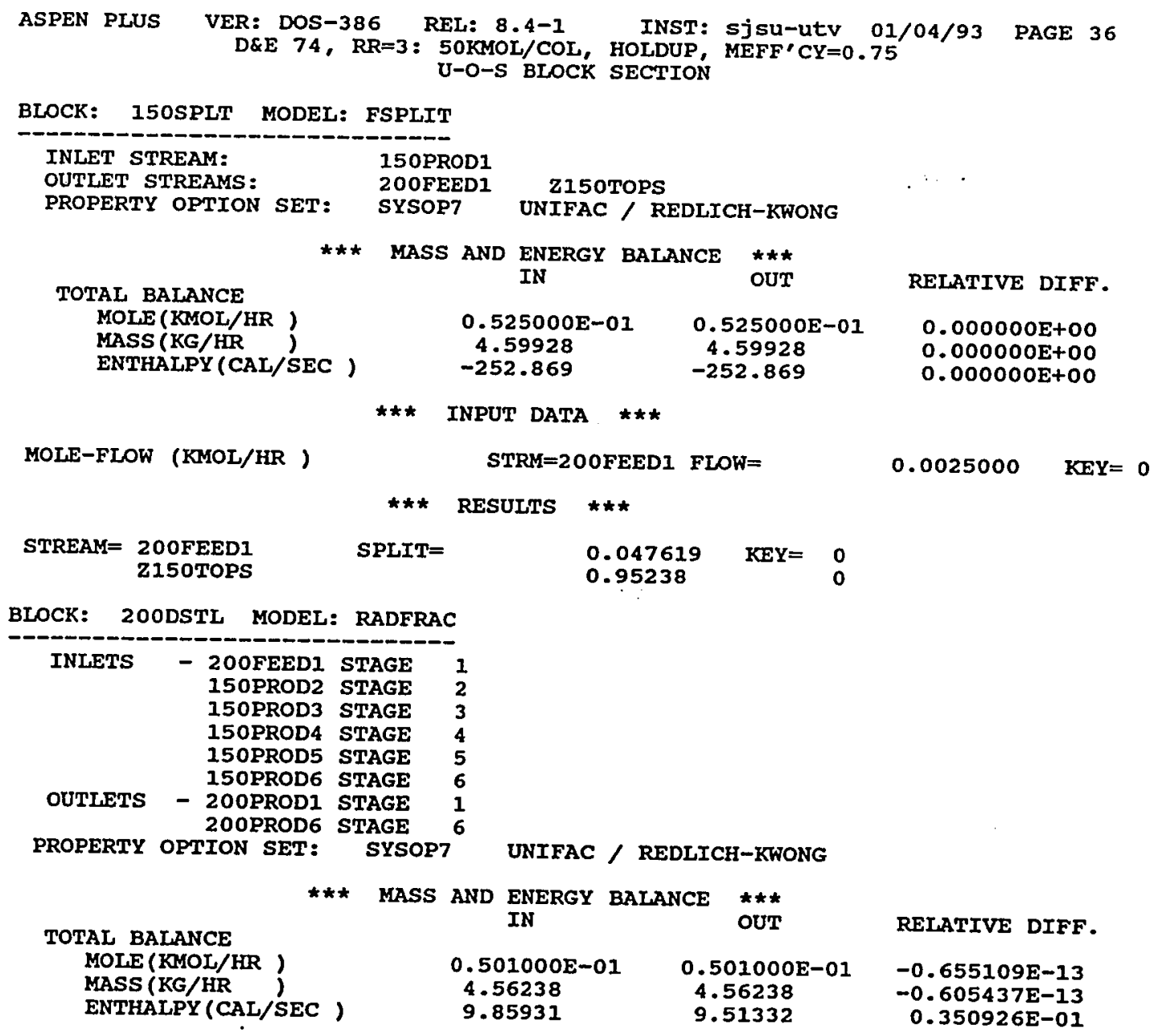


ASPEN PLUS VER: DOS-386 REL: 8.4-1 INST: sjsu-utv 01/04/93 PAGE 37 $\mathrm{D} \& E$ 74, $R R=3$ : 5OKMOL/COL, HOLDUP, $M E F F^{\prime} \mathrm{CY}=0.75$

U-O-S BLOCK SECTION

BLOCK: 20ODSTL MODEL: RADFRAC (CONTINUED)

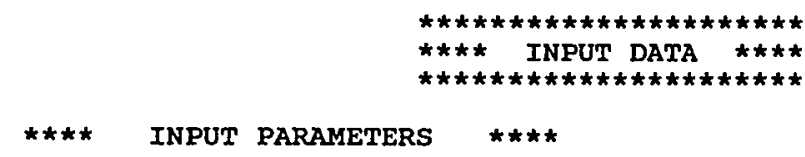

NUMBER OF STAGES

ALGORITHM OPTION

ABSORBER OPTION

INITIALIZATION OPTION

HYDRAULIC PARAMETER CALCULATIONS

INSIDE LOOP CONVERGENCE METHOD

MAXIMUM NO. OF OUTSIDE LOOP ITERATIONS

MAXIMUM NO. OF INSIDE LOOP ITERATIONS

MAXIMUM NUMBER OF FLASH ITERATIONS

FLASH TOLERANCE

OUTSIDE LOOP CONVERGENCE TOLERANCE

6
STANDARD
NO
STANDARD
NO
NEWTON
25
10
50
0.000100000
0.000100000

$\star * \star *$ COL-SPECS $\star * \star *$
MOLAR VAPOR DIST / TOTAL DIST
MOLAR REFLUX RATIO

MOLAR DISTILIATE RATE

KMOL/HR

0.0

3.00000

0.050000

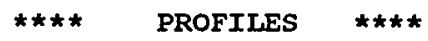
P-SPEC STAGE 1 PRES, ATM

1.00000

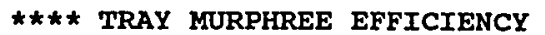

$\begin{array}{lll}\text { STAGE } & 1 & \text { EFFICIENCY } \\ & 2 & \\ 3 & \\ 4 & \\ 5 & \\ 6 & \end{array}$

1.0000
0.75000
0.75000
0.75000
0.75000
1.0000 


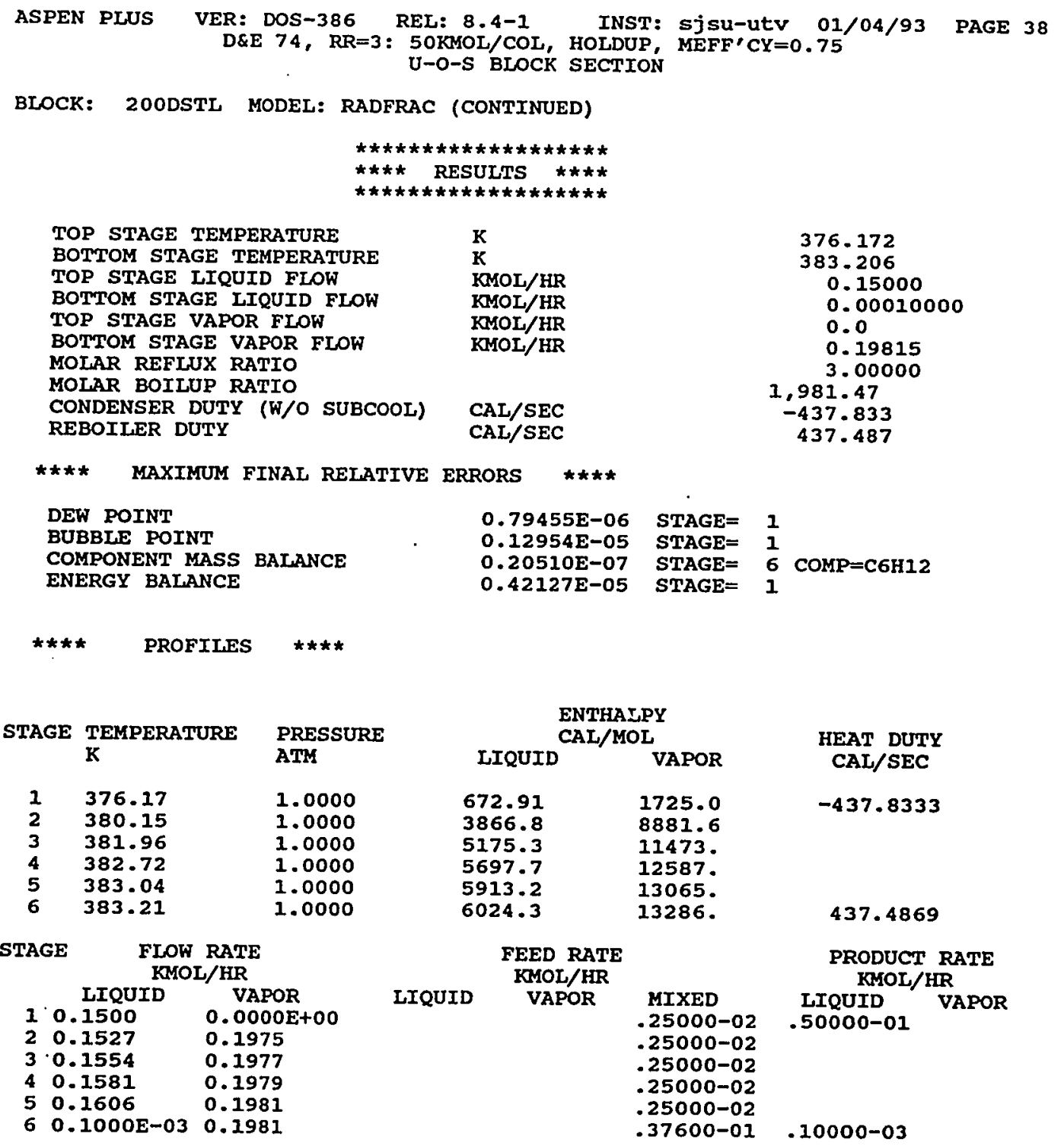


ASPEN PLUS VER: DOS-386 REL: $8.4-1$ INST: SjSU-UtV 01/04/93 PAGE 39 $D \& E$ 74, $R R=3$ : 50KMOL/COL, HOLDUP, MEFF' $C Y=0.75$

U-O-S BLOCK SECTION

BLOCK: 20ODSTL MODEL: RADFRAC (CONTINUED)

\begin{tabular}{|c|c|c|c|c|}
\hline \multirow{2}{*}{ STAGE } & & $\star \star \star * *$ & X-PROFILE & $\star \star \star \star *$ \\
\hline & C6H12 & С7H 8 & & \\
\hline 1 & .13505 & .86495 & & \\
\hline 2 & $.59669 \mathrm{E}-01$ & .94033 & & \\
\hline 3 & $.28994 E-01$ & .97101 & & \\
\hline 4 & $.16785 \mathrm{E}-01$ & .98321 & & \\
\hline $\begin{array}{l}5 \\
6\end{array}$ & -11755E-01 & .98824 & & \\
\hline & & & & \\
\hline & & $\star \star \star \star t$ & Y-PROFILE & $\approx \star \star \star$ \\
\hline
\end{tabular}

\begin{tabular}{|c|c|c|c|c|}
\hline $\begin{array}{c}\text { STAGE } \\
1 \\
2 \\
3 \\
4 \\
5 \\
6\end{array}$ & $\begin{array}{c}\quad \mathrm{C6H12} \\
.29980 \\
.12956 \\
.68199 \mathrm{E}-01 \\
.41811 \mathrm{E}-01 \\
.30482 \mathrm{E}-01 \\
.25245 \mathrm{E}-01\end{array}$ & $\begin{array}{c}\text { C7H8 } \\
.70020 \\
.87044 \\
.93180 \\
.95819 \\
.96952 \\
.97476\end{array}$ & & \\
\hline $\begin{array}{c}\text { STAGE } \\
1 \\
2 \\
3 \\
4 \\
5 \\
6\end{array}$ & $\begin{array}{l}\text { C6H12 } \\
2.2200 \\
2.5142 \\
2.6555 \\
2.7159 \\
2.7415 \\
2.7549\end{array}$ & $\begin{array}{r}\star \star \star \star \\
C 7 \mathrm{HB} \\
.80952 \\
.90392 \\
.95057 \\
.97071 \\
.97928 \\
.98377\end{array}$ & K-VALUES & $\star \star \star \star \star$ \\
\hline
\end{tabular}

BLOCK: 200SPLT MODEL: FSPLIT

$\begin{array}{lll}\text { INLET STREAM: } & \text { 200PRODI } & \\ \text { OUTLET STREAMS: } & \text { 250FEEDI } & \text { Z2OOTOPS } \\ \text { PROPERTY OPTION SET: } & \text { SYSOP7 } & \text { UNIFAC / REDLICH-KWONG }\end{array}$

*** MASS AND ENERGY BALANCE $\star * \star$

TOTAL BALANCE

$\begin{array}{lccc}\text { MOLE (KMOL/HR ) } & 0.500000 \mathrm{E}-01 & 0.500000 \mathrm{E}-01 & 0.000000 \mathrm{E}+00 \\ \text { MASS (KG/HR ) } & 4.55317 & 4.55317 & 0.000000 \mathrm{H}+00 \\ \text { ENTHALPY (CAL/SEC ) } & 9.34598 & 9.34598 & 0.000000 \mathrm{E}+00\end{array}$

ENTHALPY (CAL/SEC)

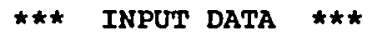

MOLE-FLOW (KMOL/HR )

STRM=250FEED1 FLOW=

0.0

$\mathrm{KEY}=0$

STREAM $=250 \mathrm{FEED} 1$

Z200TOPS

$\begin{array}{lll}\star \star \star & \text { RESULTS } & \star \star \star \\ \text { SPLIT }= & 0.0 & \\ & 1.00000\end{array} \quad \mathrm{KEY}=\begin{aligned} & 0 \\ & 0\end{aligned}$




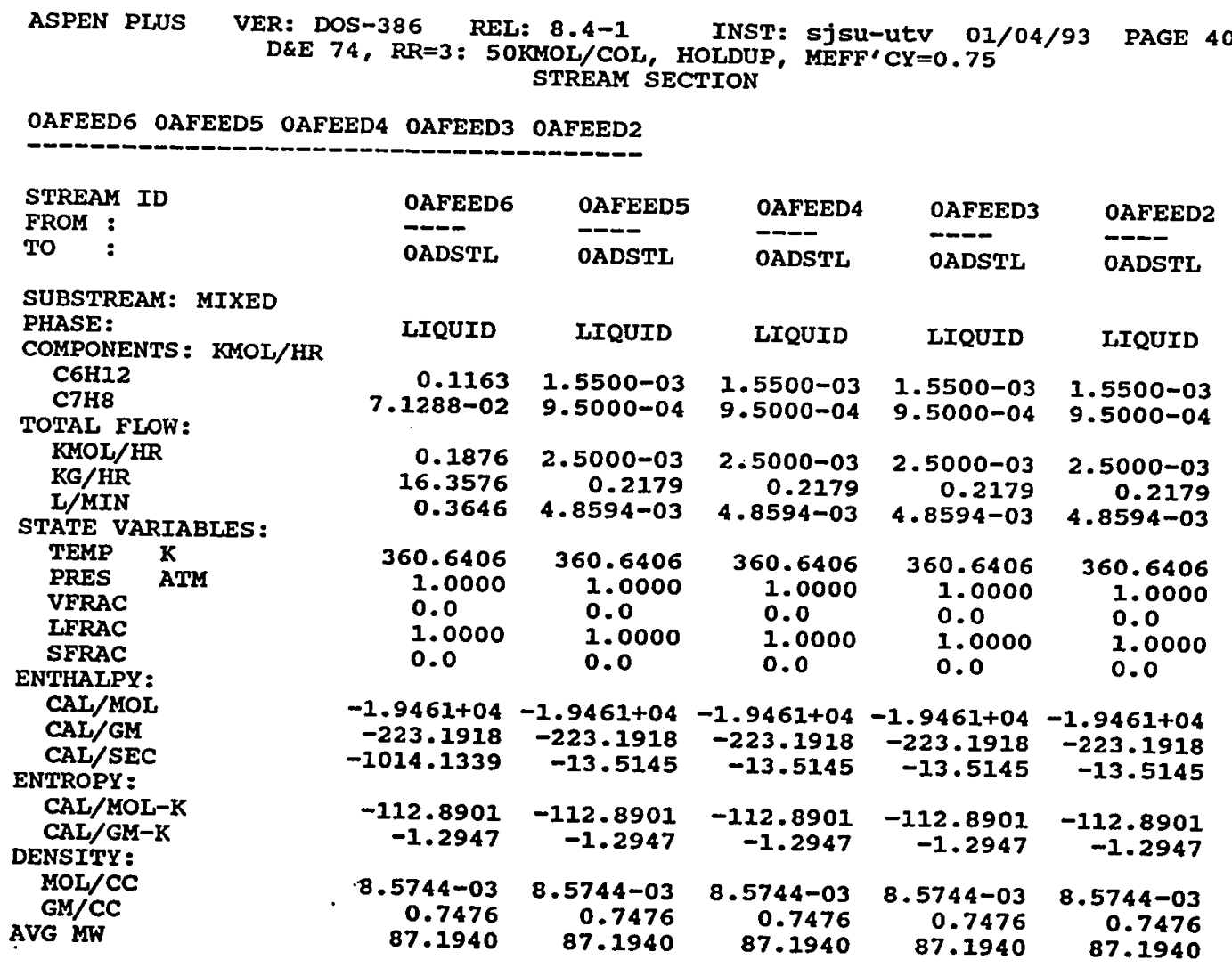




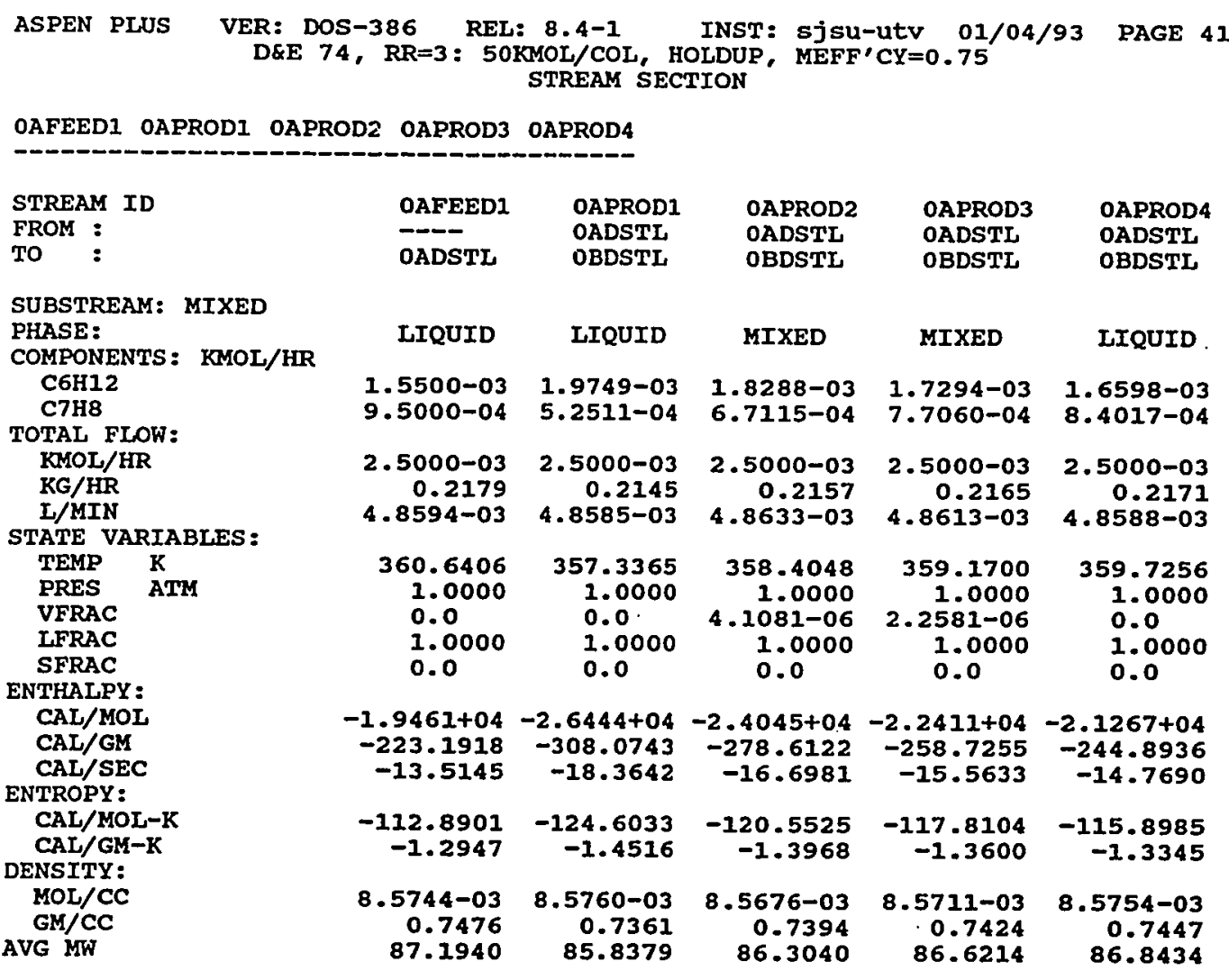




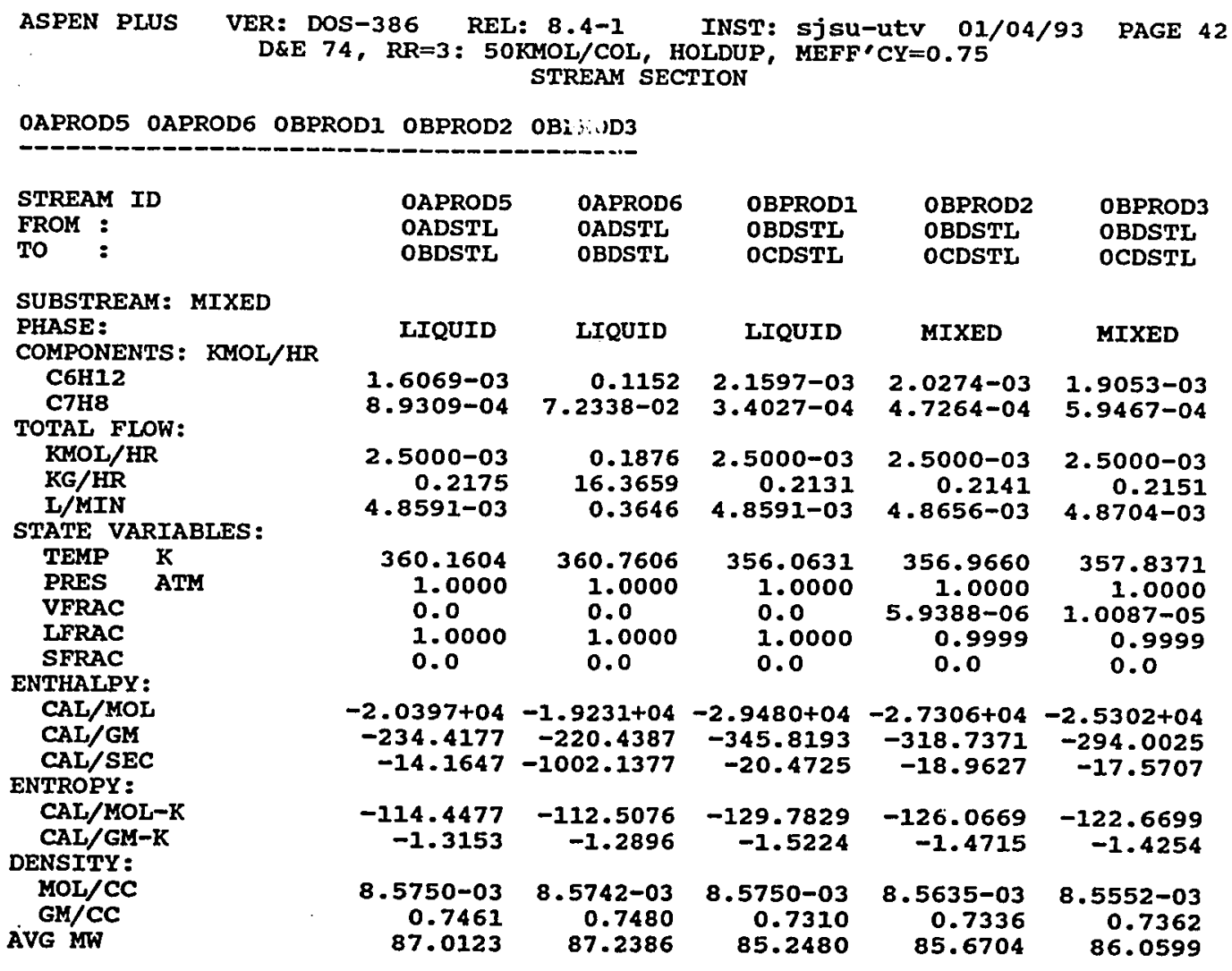




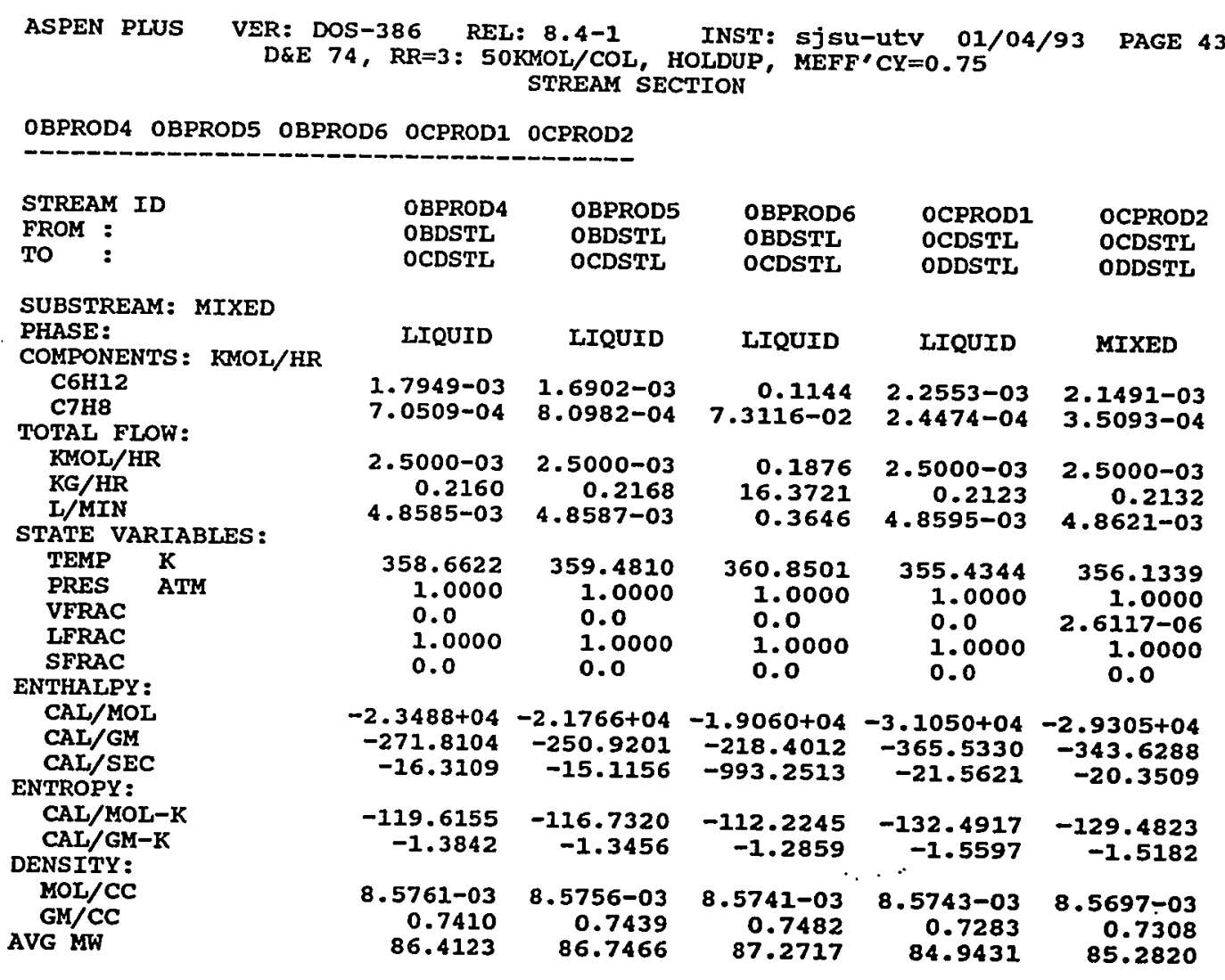




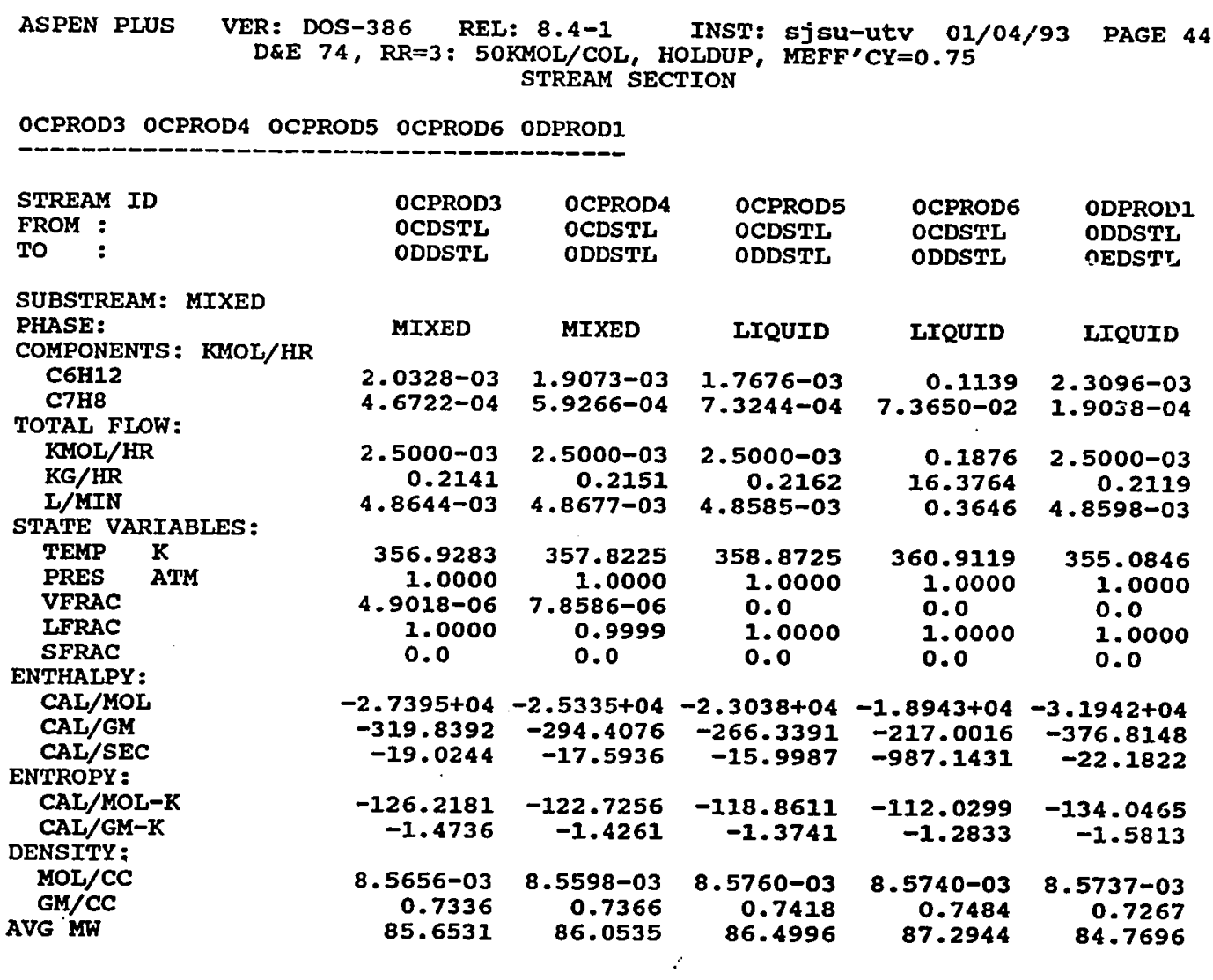




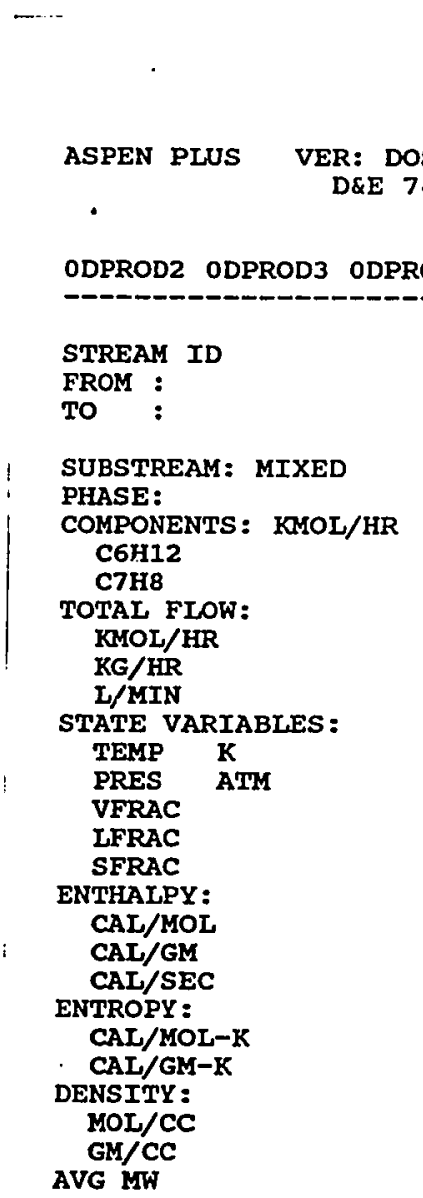

$\begin{array}{lllll}\text { ODPROD2 } & \text { ODPROD3 } & \text { ODPROD4 } & \text { ODPROD5 } & \text { ODPROD6 } \\ \text { ODDSTL } & \text { ODDSTL } & \text { ODDSTL } & \text { ODDSTL } & \text { ODDSTL } \\ \text { OEDSTL } & \text { OEDSTL } & \text { OEDSTL } & \text { OEDSTL } & \text { OEDSTL }\end{array}$

\begin{tabular}{rrrrr} 
MIXED & MIXED & MIXED & LIQUID & \multicolumn{1}{c}{ LIQUID } \\
$2.2227-03$ & $2.1166-03$ & $1.9876-03$ & $1.8269-03$ & 0.1136 \\
$2.7730-04$ & $3.8338-04$ & $5.1239-04$ & $6.7315-04$ & $\mathbf{7 . 4 0 0 1 - 0 2}$ \\
& & & & \\
$2.5000-03$ & $2.5000-03$ & $2.5000-03$ & $2.5000-03$ & 0.1876 \\
0.2126 & 0.2134 & 0.2144 & 0.2157 & 16.3792 \\
$4.8611-03$ & $4.8621-03$ & $4.8642-03$ & $4.8584-03$ & 0.3646 \\
& & & & \\
355.6463 & 356.3525 & 357.2455 & 358.4198 & 360.9527 \\
1.0000 & 1.0000 & 1.0000 & 1.0000 & 1.0000 \\
$1.5299-06$ & $2.7426-06$ & $4.8002-06$ & 0.0 & 0.0 \\
1.0000 & 1.0000 & 1.0000 & 1.0000 & 1.0000 \\
0.0 & 0.0 & 0.0 & 0.0 & 0.0 \\
$-3.0515+04$ & $-2.8772+04$ & $-2.6653+04$ & $-2.4013+04$ & $-1.8866+04$ \\
-358.7970 & -336.9690 & -310.6552 & -278.2125 & -216.0818 \\
-21.1907 & -19.9807 & -18.5093 & -16.6754 & -983.1271 \\
-131.5653 & -128.5684 & -124.9576 & -120.4975 & -111.9020 \\
-1.5469 & -1.5057 & -1.4564 & -1.3960 & -1.2816 \\
$8.5714-03$ & $8.5697-03$ & $8.5660-03$ & $8.5761-03$ & $8.5740-03$ \\
0.7289 & 0.7317 & 0.7349 & 0.7402 & 0.7485 \\
85.0470 & 85.3856 & 85.7973 & 86.3104 & 87.3094
\end{tabular}




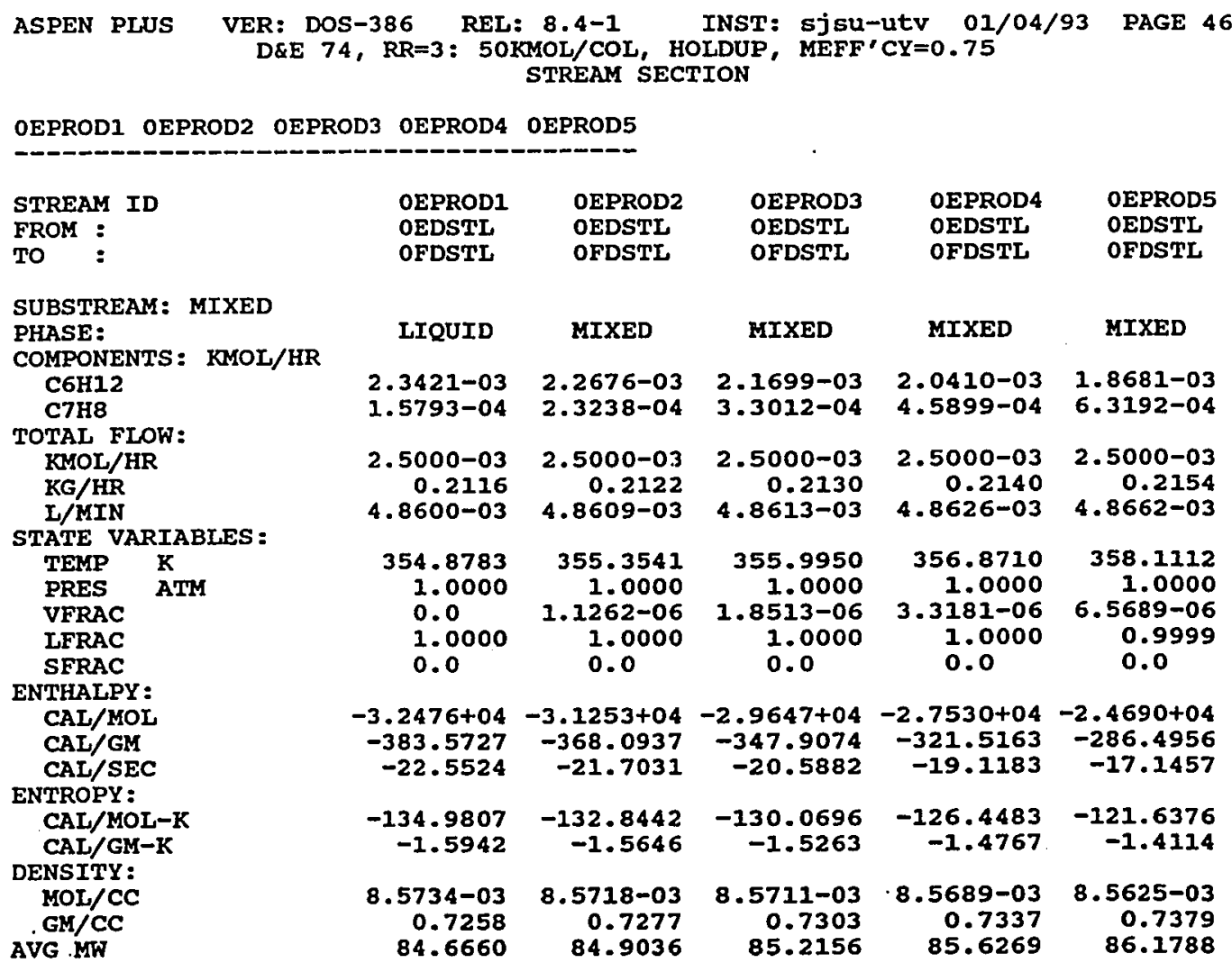




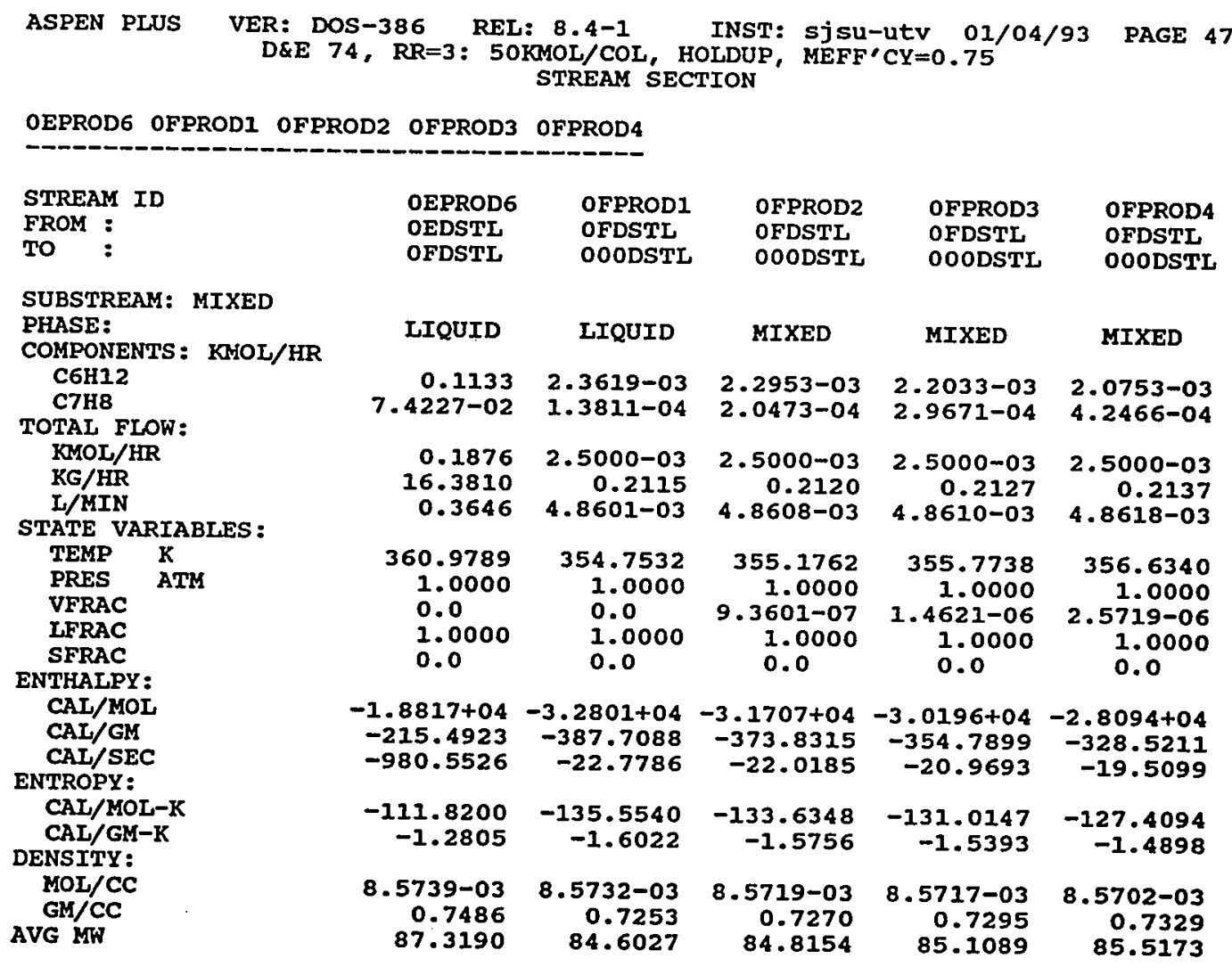


ASPEN PLUS VER: DOS-386 REL: 8.4-1 INST: sjsu-utV 01/04/93 PAGE 48 D\&E 74, RR=3: 5OKMOL/COL, HOLDUP, MEFF'CY $=0.75$ STREAM SECTION

OFPROD5 OFPROD6 DOOPROD1 OOOPROD2

\begin{tabular}{|c|c|c|c|c|c|}
\hline $\begin{array}{l}\text { STREAM ID } \\
\text { FROM : } \\
\text { TO : }\end{array}$ & $\begin{array}{l}\text { OFPROD5 } \\
\text { OFDSTL } \\
\text { OOODSTL }\end{array}$ & $\begin{array}{l}\text { OFPROD } 6 \\
\text { OFDSTL } \\
\text { OOODSTL }\end{array}$ & $\begin{array}{l}\text { OOOPRODI } \\
\text { OOODSTL } \\
\text { O5ODSTL }\end{array}$ & $\begin{array}{l}\text { OOOPROD: } \\
\text { OOODSTL } \\
\text { O5ODSTI }\end{array}$ & $\begin{array}{l}\text { OOOPROD3 } \\
\text { OOODSTI } \\
\text { O5ODSTL }\end{array}$ \\
\hline SUBSTREAM: MIXED & & & & & \\
\hline $\begin{array}{l}\text { PHASE: } \\
\text { COMPONENTS : KMOL/HR }\end{array}$ & MIXED & LIQUID & LIQUID & MIXED & MIXED \\
\hline $\begin{array}{l}\text { C6H12 } \\
\text { C7H8 } \\
\text { TOTAL FLOW: }\end{array}$ & $\begin{array}{l}1.8953-03 \\
6.0472-04\end{array}$ & $\begin{array}{r}0.1132 \\
7.4369-02\end{array}$ & $\begin{array}{l}2.3741-03 \\
1.2587-04\end{array}$ & $\begin{array}{l}2.3124-03 \\
1.8762-04\end{array}$ & $\begin{array}{l}2.2241-03 \\
2.7586-04\end{array}$ \\
\hline $\begin{array}{l}\text { KMOL/HR } \\
\text { KG/HR } \\
\text { L/MIN } \\
\text { STATE VARIABLES : }\end{array}$ & $\begin{array}{r}2.5000-03 \\
0.2152 \\
4.8648-03\end{array}$ & $\begin{array}{r}0.1876 \\
16.3821 \\
0.3646\end{array}$ & $\begin{array}{r}2.5000-03 \\
0.2114 \\
4.8602-03\end{array}$ & $\begin{array}{r}2.5000-03 \\
0.2129 \\
4.8608-03\end{array}$ & $\begin{array}{r}2.5000-03 \\
0.2126 \\
4.8608-03\end{array}$ \\
\hline $\begin{array}{ll}\text { TEMP } & \text { K } \\
\text { PRES } & \text { ATM } \\
\text { VFRAC } & \\
\text { IFRAC } \\
\text { SFRAC } \\
\text { ENTHALPY : }\end{array}$ & $\begin{array}{r}357.9106 \\
1.0000 \\
5.3647-06 \\
0.9999 \\
0.0\end{array}$ & $\begin{array}{l}360.9954 \\
1.0000 \\
0.0 \\
1.0000 \\
0.0\end{array}$ & $\begin{aligned} 354.6764 \\
1.0000 \\
0.0 \\
1.0000 \\
0.0\end{aligned}$ & $\begin{array}{r}355.0668 \\
1.0000 \\
8.3088-07 \\
1.0000 \\
0.0\end{array}$ & $\begin{array}{r}355.6369 \\
1.0000 \\
1.2753-06 \\
1.0000 \\
0.0\end{array}$ \\
\hline $\begin{array}{l}\text { CAL/MOL } \\
\text { CAL/GM } \\
\text { CAL/SEC } \\
\text { ENTROPY : }\end{array}$ & $\begin{array}{r}-2.5137+04 \\
-291.9763 \\
-17.4561\end{array}$ & $\begin{array}{r}-1.8785+04 \\
-215.1197 \\
-978.9250\end{array}$ & $\begin{array}{r}-3.3002+04 \\
-390.2654 \\
-22.9182\end{array}$ & $\begin{array}{r}-3.1988+04 \\
-377.3888 \\
-22.2137\end{array}$ & $\begin{array}{r}-3.0538+04 \\
-359.0948 \\
-21.2071\end{array}$ \\
\hline $\begin{array}{l}\text { CAL/MOL-K } \\
\text { CAL/GM-K } \\
\text { DENSITY : }\end{array}$ & $\begin{array}{r}-122.3914 \\
-1.4216\end{array}$ & $\begin{array}{r}-111.7682 \\
-1.2799\end{array}$ & $\begin{array}{r}-135.9091 \\
-1.6071\end{array}$ & $\begin{array}{r}-134.1258 \\
-1.5824\end{array}$ & $\begin{array}{r}-131.6062 \\
-1.5475\end{array}$ \\
\hline $\begin{array}{l}\text { MOL/CC } \\
\text { GH/CC } \\
\text { AVG MW }\end{array}$ & $\begin{array}{r}8.5650-03 \\
0.7373 \\
86.0920\end{array}$ & $\begin{array}{r}8.5739-03 \\
0.7487 \\
87.3250\end{array}$ & $\begin{array}{r}8.5731-03 \\
0.7249 \\
84.5637\end{array}$ & $\begin{array}{r}8.5720-03 \\
0.7265 \\
84.7608\end{array}$ & $\begin{array}{r}8.5719-03 \\
0.7289 \\
85.0424\end{array}$ \\
\hline
\end{tabular}




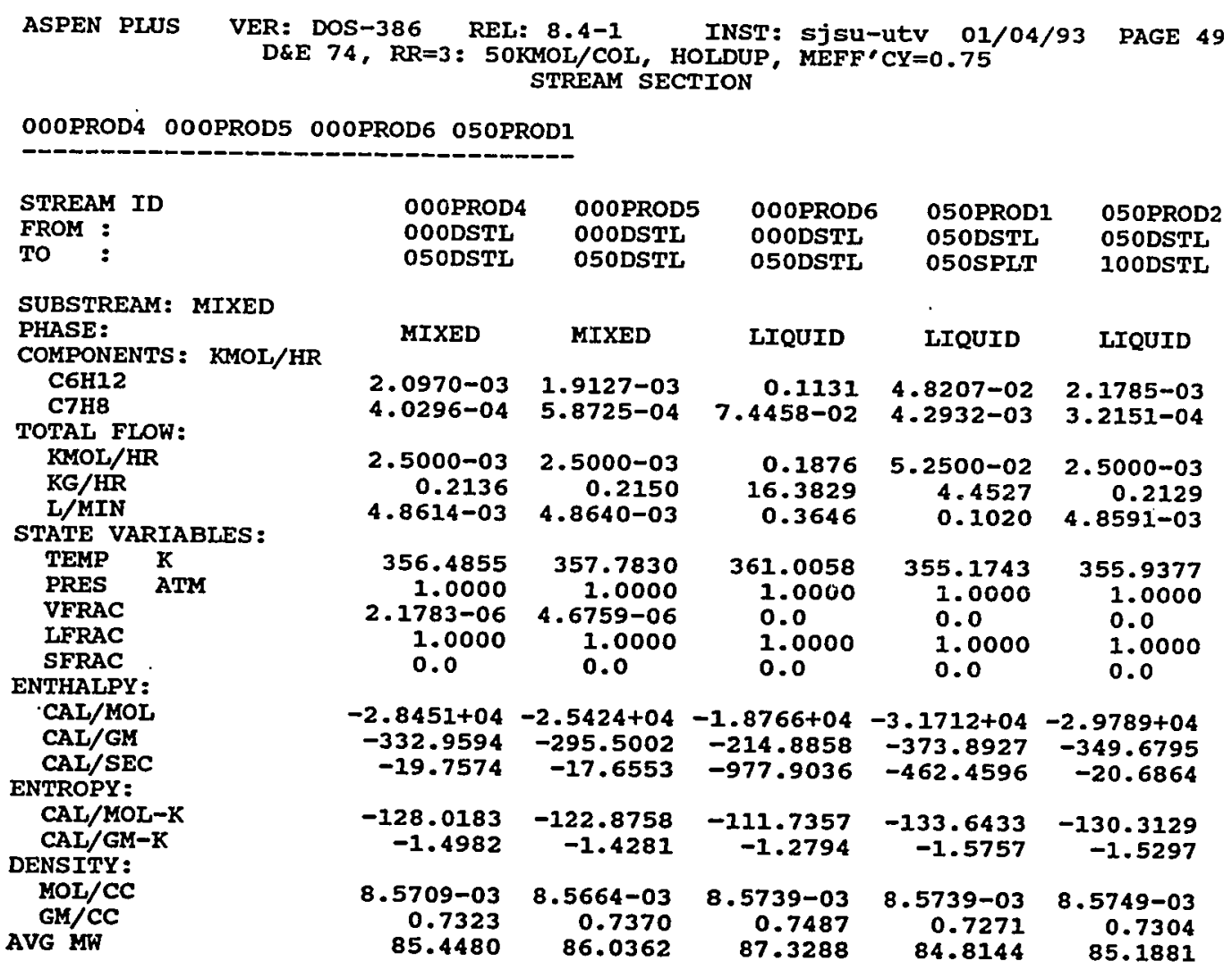




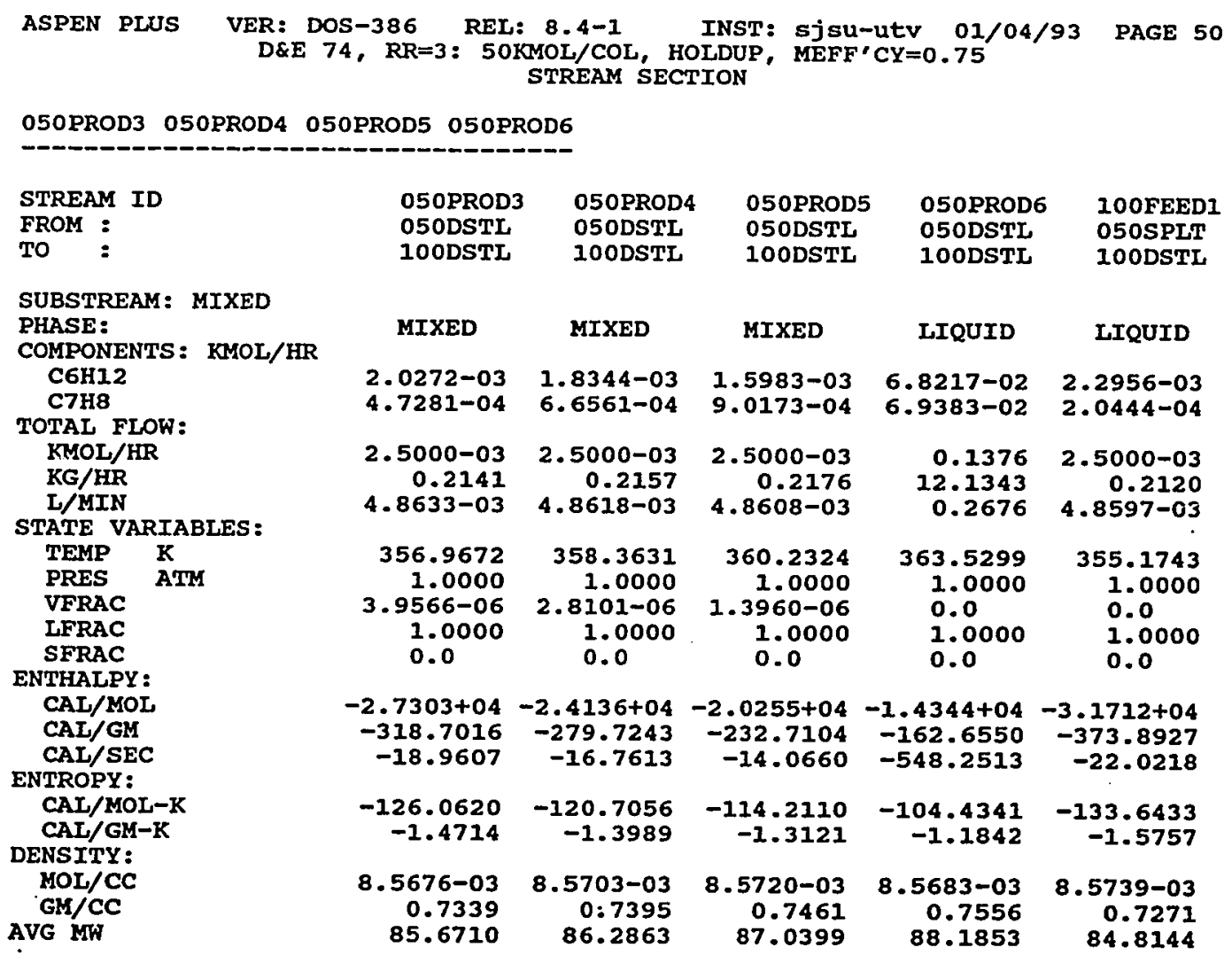




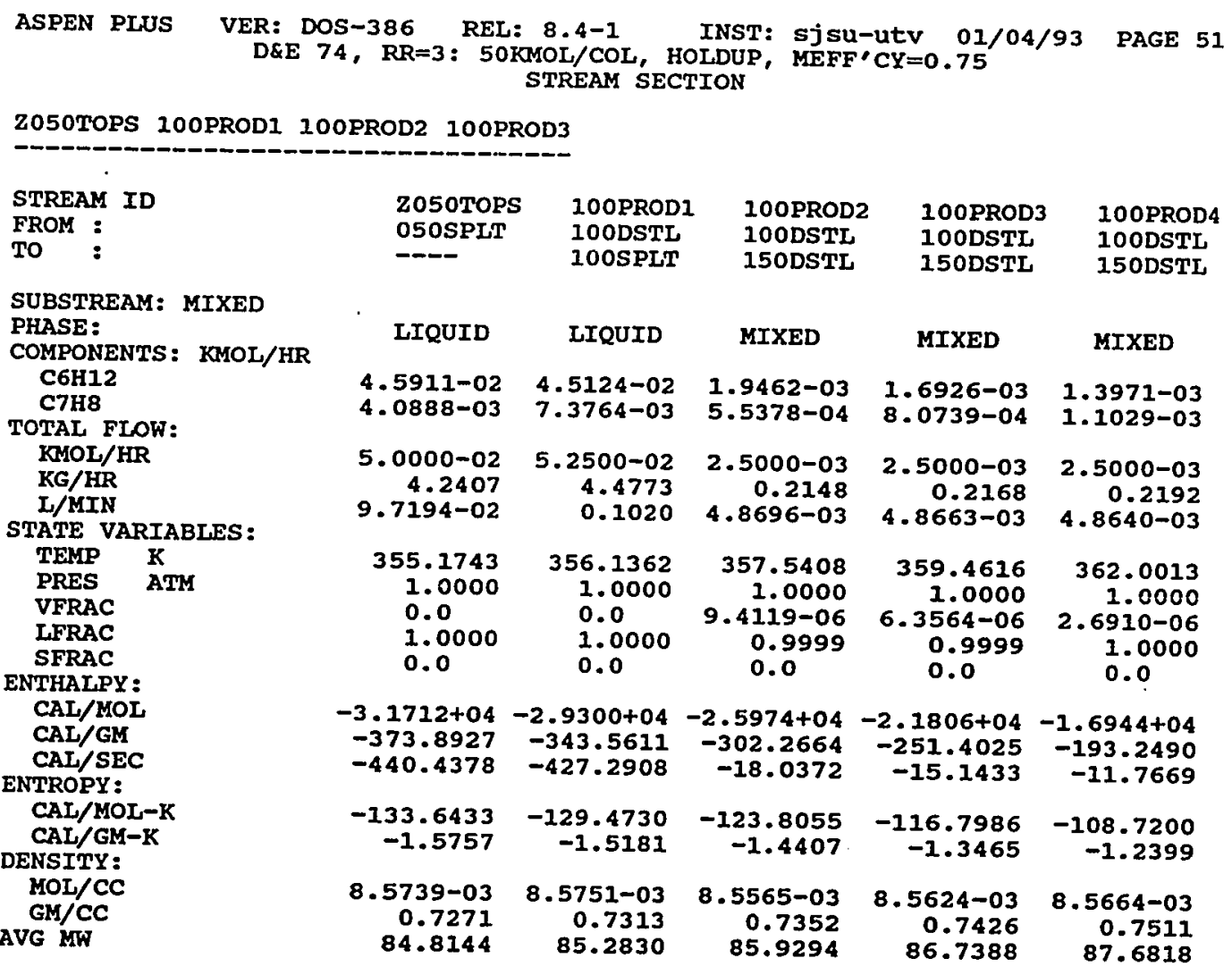




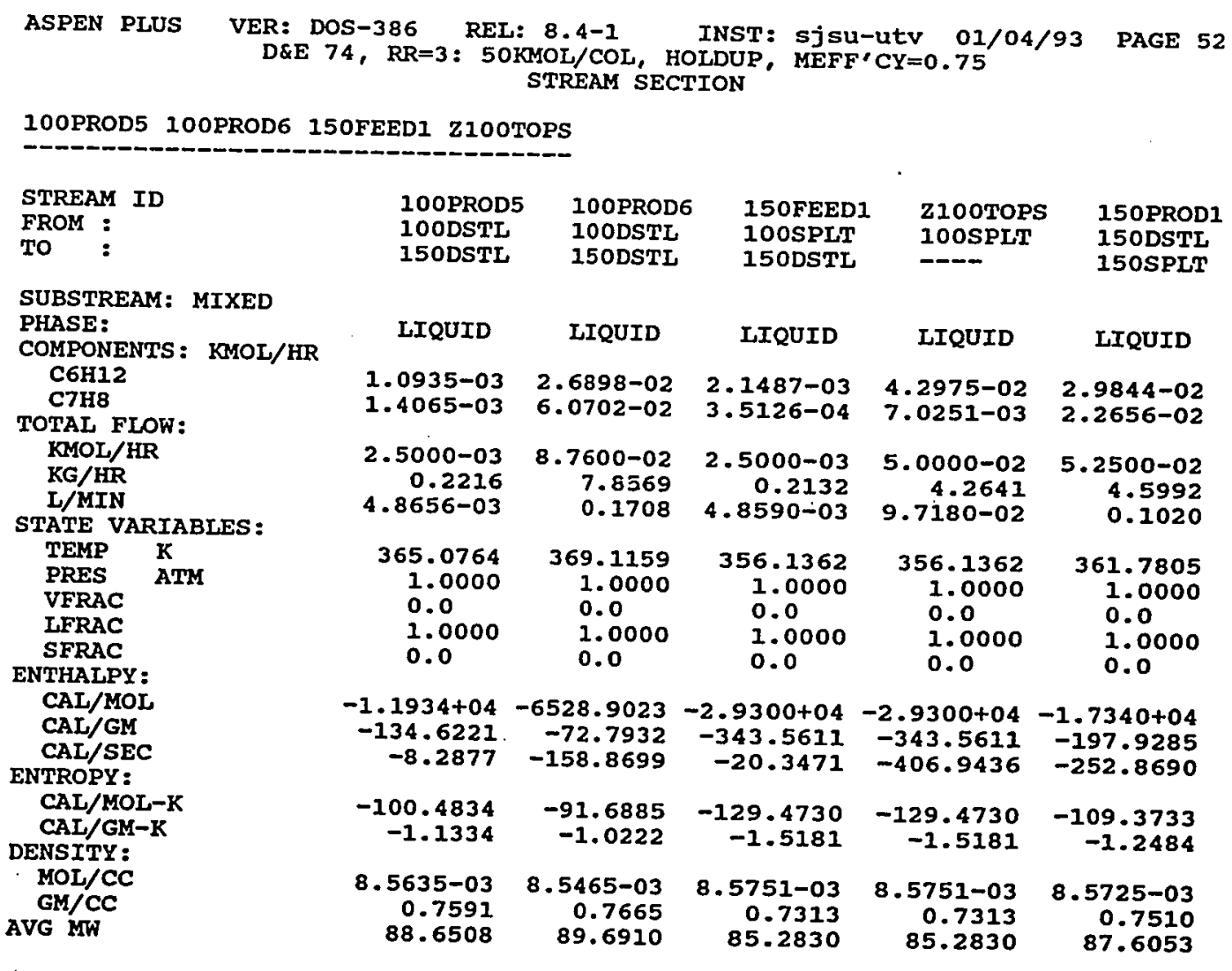




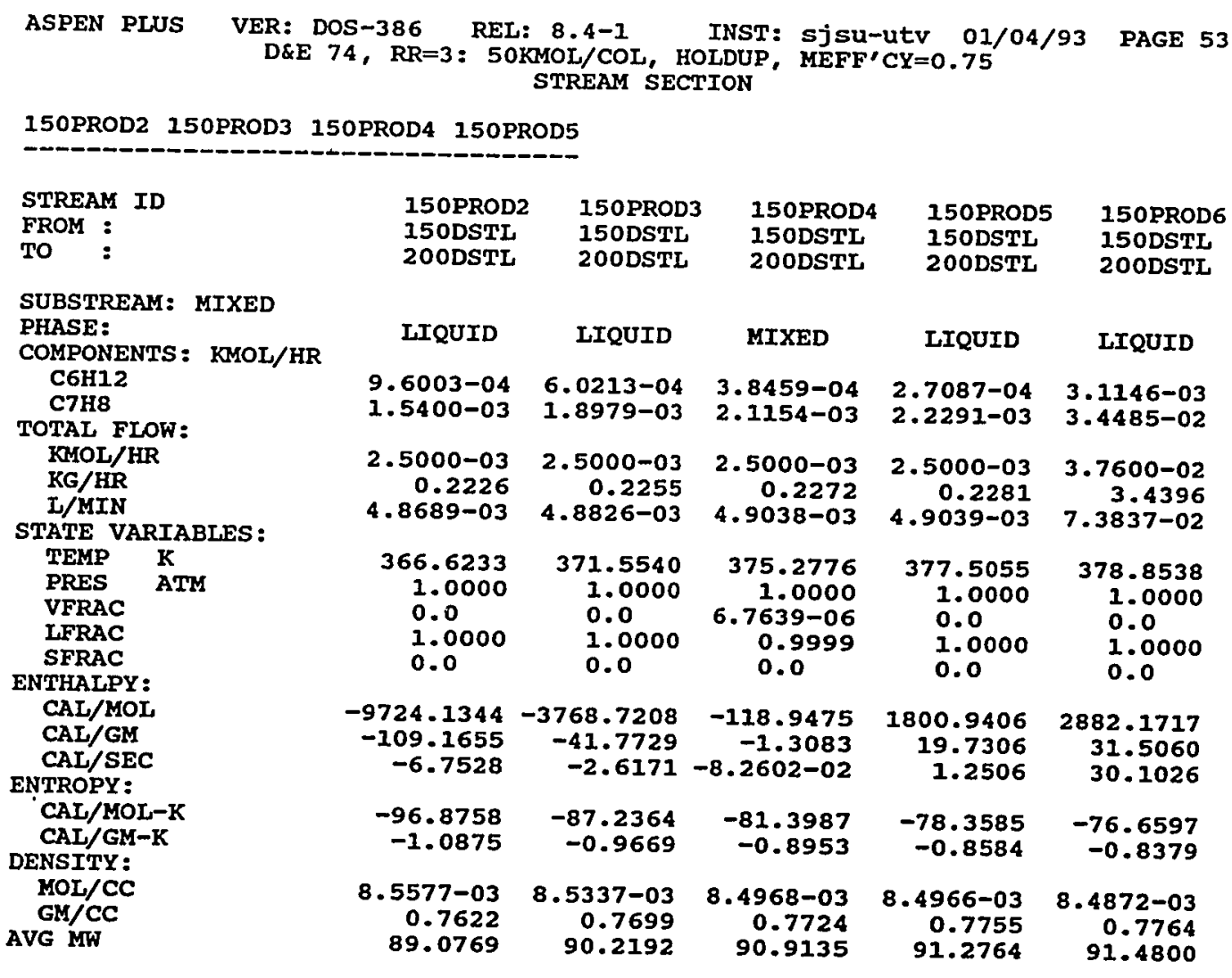




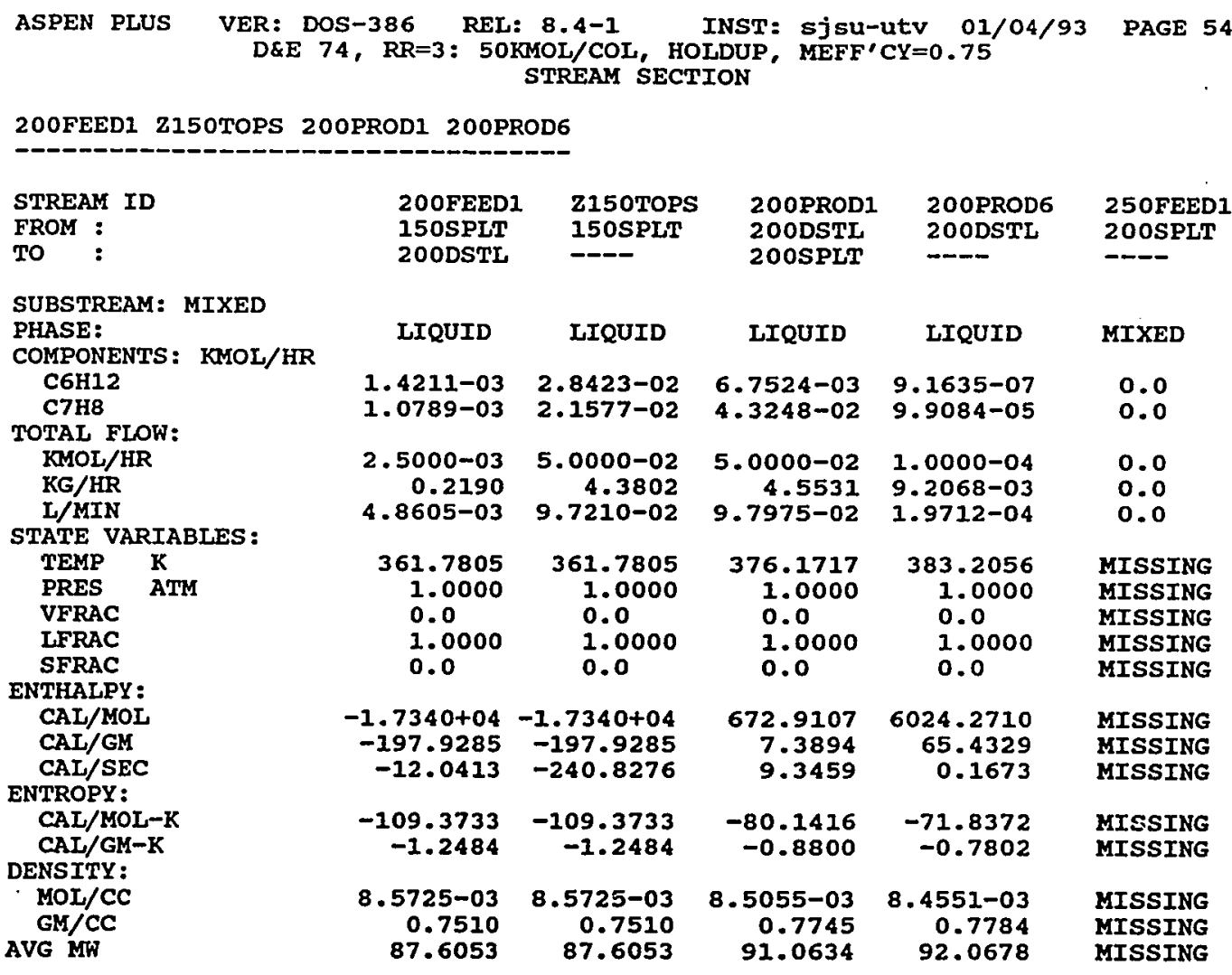




ASPEN PLUS VER: DOS
D\&E 74
Z2OOTOPS
STREAM ID
FROM :
TO :
SUBSTREAM: MIXED
PHASE:
COMPONENTS: KMOL/HR
C6HI2
C7H8
TOTAL FLOW:
KMOL/HR
KG/HR
L/MIN
STATE VARIABLES:
TEMP $\quad \mathrm{K}$
PRES ATM
VFRAC
LFRAC
SFRAC
ENTHALPY:
CAL/MOL
CAL/GM
CAL/SEC
ENTROPY:
CAL/MOL-K
CAL/GM-K
DENSITY:
MOL/CC
GM/CC
AVG MW

Z200TOPS

200SPLT

LIQUID

6. 7524-03

4. 3248-02

5. 0000-02

4.5531

9.7975-02

376.1717

1.0000

0.0

1.0000

0.0

672.9107

7.3894

9.3459

$-80.1416$

$-0.8800$

8.5055-03

0.7745

91.0634 


\section{APPENDIX B. COLLECTION OF BATCH DISTILLATION SIMULATIONS}

This appendix collects the data used to generate the plots in Chapters 3 and

4 and presents it in a standard format.

1. Published Simulations by Domenech \& Enjalbert, Galindez \& Fredenslund, Chiotti \& Scenna for Domenech \& Enjalbert's Case I: Reflux Ratio=3, Cyclohexane Feed Mol Fraction $=0.62$

2. Published Simulations by Domenech \& Enjalbert [D9, D11], Galindez \& Fredenslund [G2], Chiotti \& Scenna [C1], Diwekar \& Madhavan [D7] for Domenech \& Enjalber''s [D9, D11] Case II: Reflux Ratio=4, Cyclohexane Feed Mol Fraction $=0.55$

3. Published Simulations by Domenech \& Enjalbert, Galindez \& Fredenslund, Chiotti \& Scenna for Domenech \& Enjalbert's Case III: Reflux Ratio=6, Cyclohexane Feed Mol Fraction $=0.42$

4. Published Simulations by Domenech \& Enjalbert, Galindez \& Fredenslund for Domenech \& Enjalbert's Case IV: Reflux Ratio=5, Cyclohexane Feed Mol Fraction $=0.30$

5. Simulations using QSSCA, Plate-by-Plate Column Calculations and 2.5M/tray Holdup for Domenech \& Enjalbert's Case I: Reflux Ratio=3, Cyclohexane Feed Mol Fraction $=0.62$

6. Simulations using QSSCA, Plate-by-Plate Column Calculations and 2.5M/tray Holdup for Domenech \& Enjalbert's Case II: Reflux Ratio=4, Cyclohexane Feed Mol Fraction $=0.55$

7. Simulations using QSSCA, Plate-by-Plate Column Calculations and 2.5M/tray Holdup for Domenech \& Enjalbert's Case III: Reflux Ratio=6, Cyclohexane Feed Mol Fraction $=0.42$

8. Simulations using QSSCA, Plate-by-Plate Column Calculations and 2.5M/tray Holdup for Domenech \& Enjalbert's Case IV: Reflux Ratio=5, Cyclohexane Feed Mol Fraction=0.30 
9. Simulations using QSSCA, Plate-by-Plate Column Calculations and Neglecting Holdup for Domenech \& Enjalbert's Case I: Reflux Ratio=3, Cyclohexane Feed Mol Fraction $=0.62$

10. Simulations using QSSCA, Plate-by-Plate Column Calculations and Neglecting Holdup for Domenech \& Enjalbert's Case II: Reflux Ratio=4, Cyclohexane Feed Mol Fraction=0.55

11. Simulations using QSSCA, Plate-by-Plate Column Calculations and Neglecting Holdup for Domenech \& Enjalbert's Case III: Reflux Ratio=6, Cyclohexane Feed Mol Fraction $=0.42$

12. Simulations using QSSCA, Plate-by-Plate Column Calculations and Neglecting Holdup for Domenech \& Enjalbert's Case IV: Reflux Ratio=5, Cyclohexane Feed Mol Fraction=0.30

13. Simulations using QSSCA, Short-cut Column Calculations and Neglecting Holdup for Domenech \& Enjalbert's Case I: Reflux Ratio=3, Cyclohexane Feed Mol Fraction $=0.62$

14. Simulations using QSSCA, Short-cut Column Calculations and Neglecting Holdup for Domenech \& Enjalbert's Case II: Reflux Ratio=4, Cyclohexane Feed Mol Fraction $=0.55$

15. Simulations using QSSCA, Short-cut Column Calculations and Neglecting Holdup for Domenech \& Enjalbert's Case III: Reflux Ratio=6, Cyclohexane Feed Mol Fraction $=0.42$

16. Simulations using QSSCA, Short-cut Column Calculations and Neglecting Holdup for Domenech \& Enjalbert's Case IV: Reflux Ratio=5, Cyclohexane Feed Mol Fraction $=0.30$ 


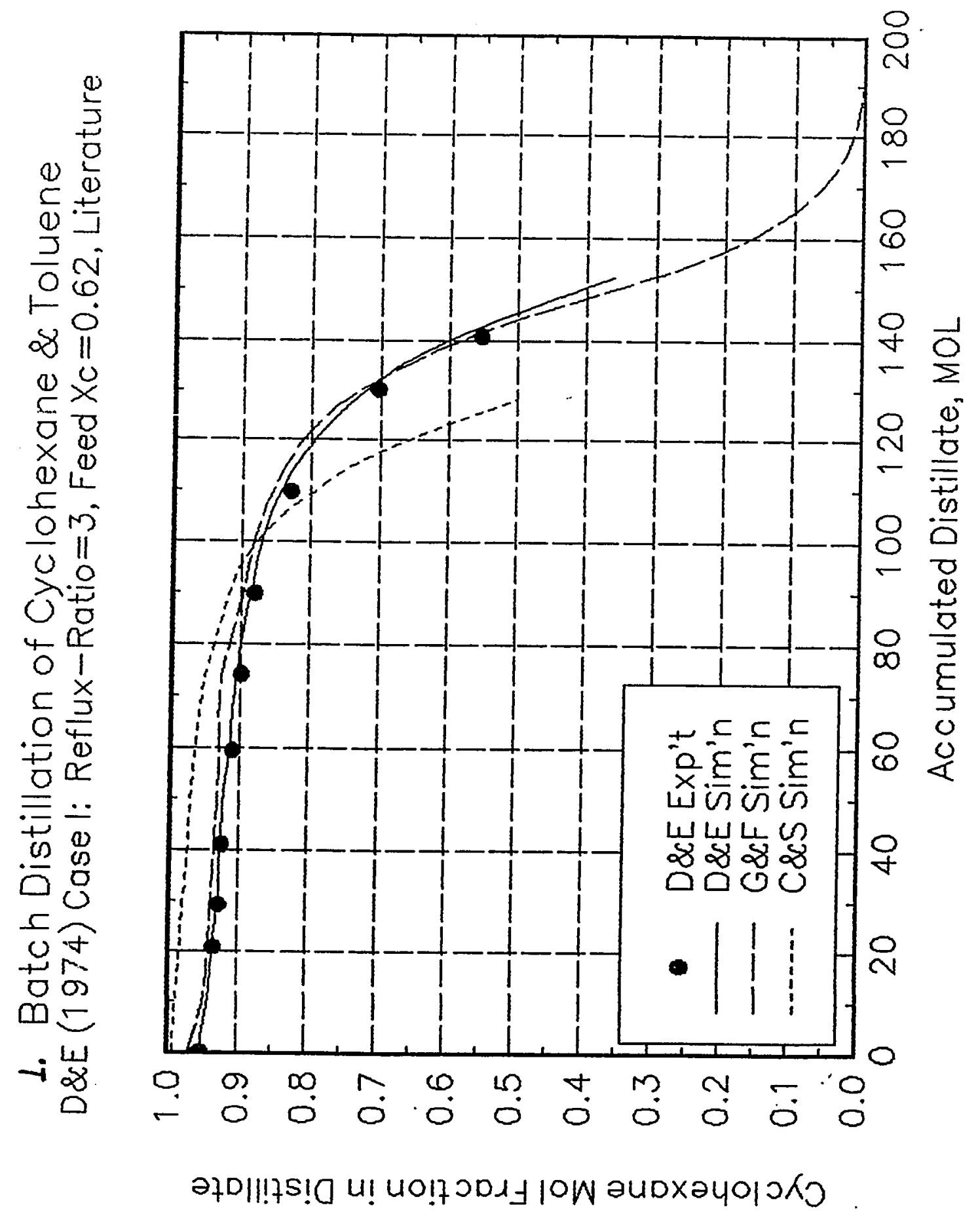




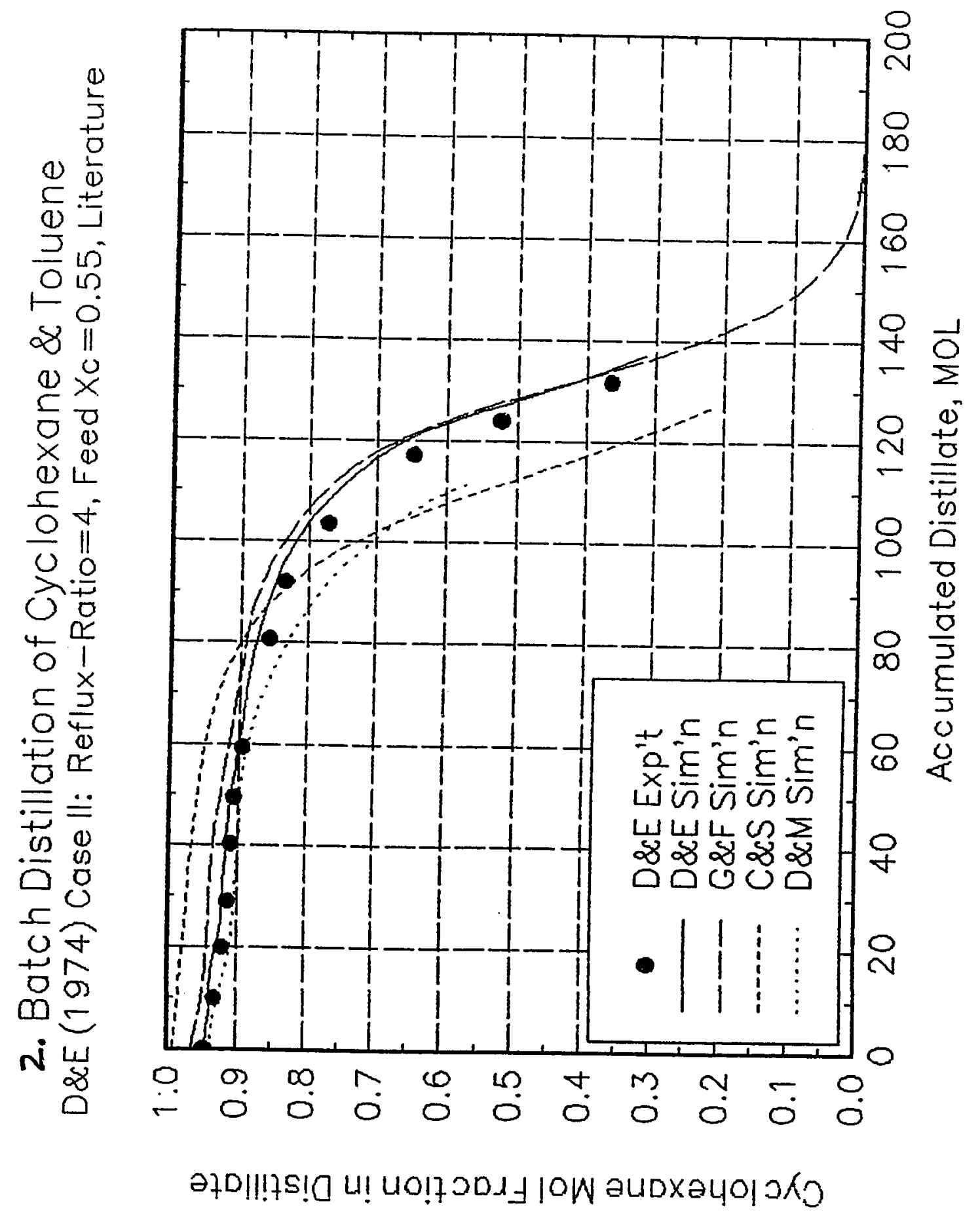




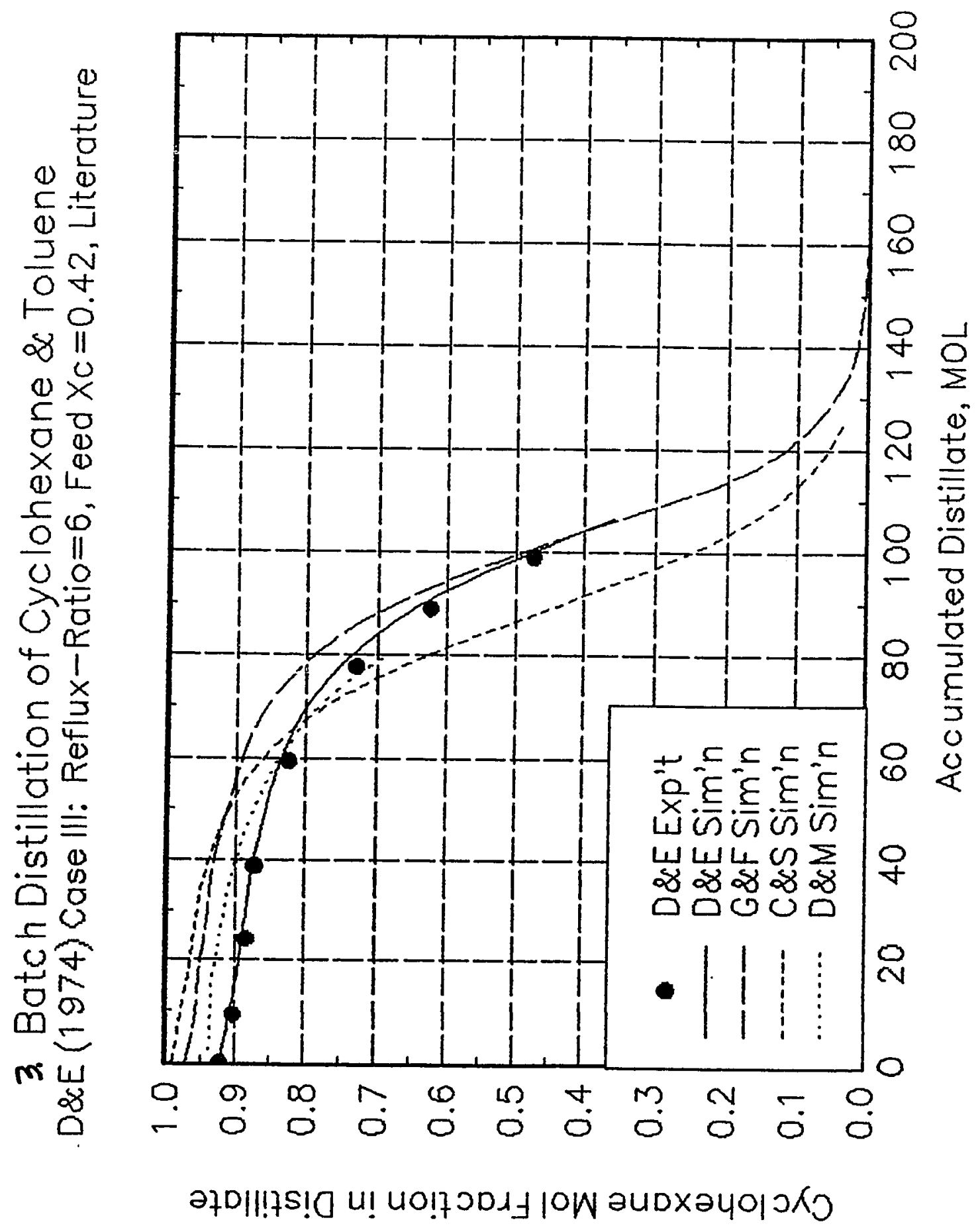




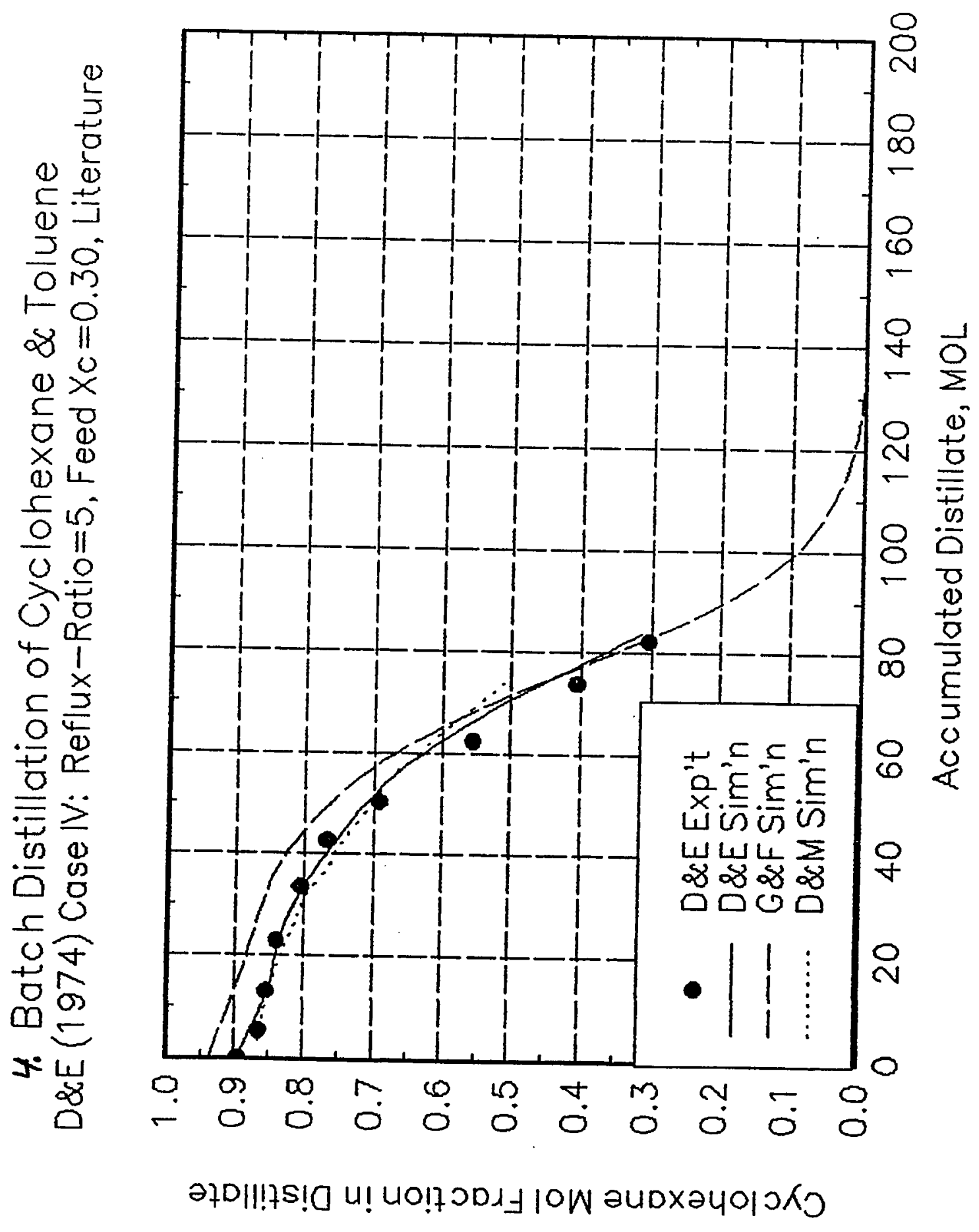




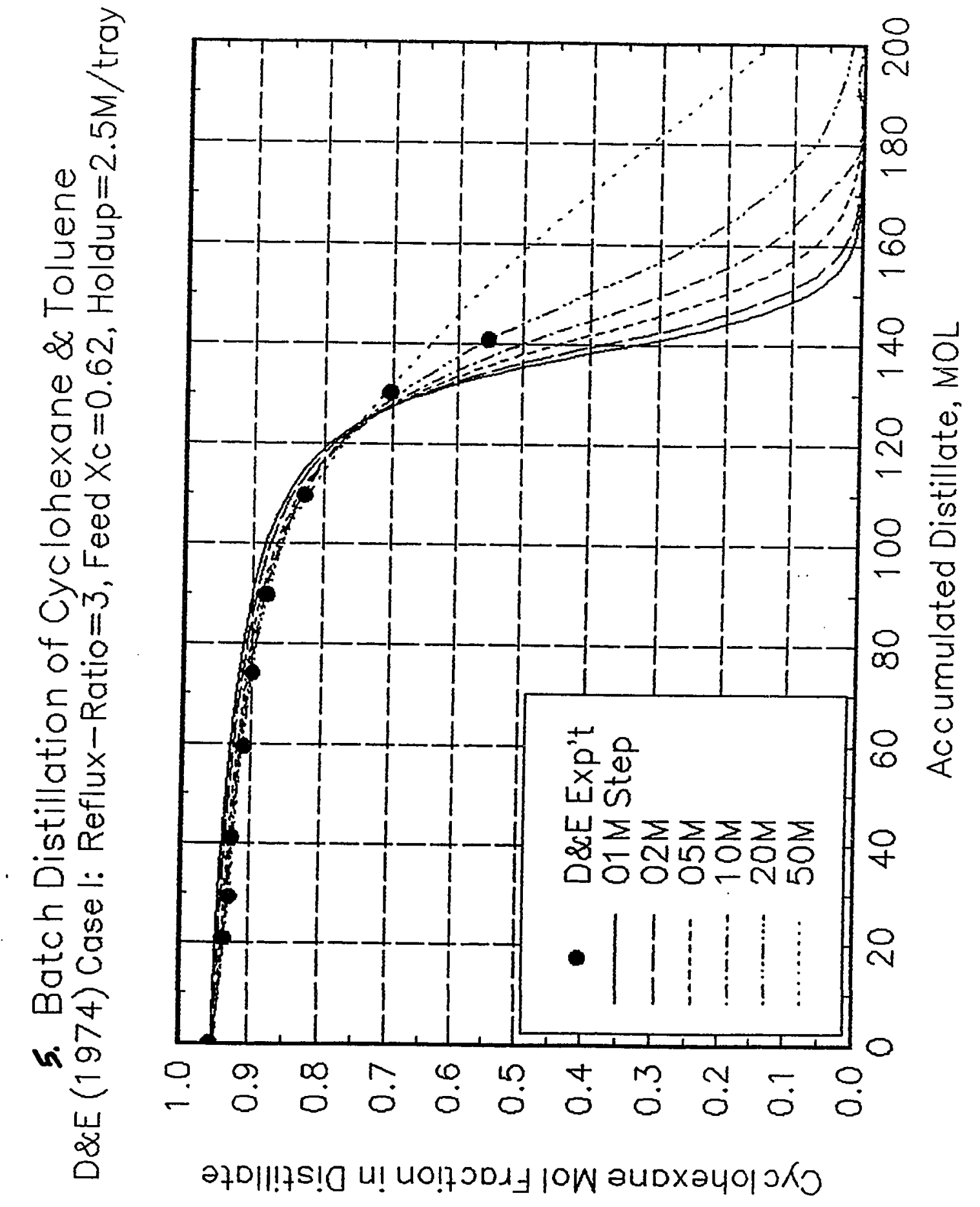




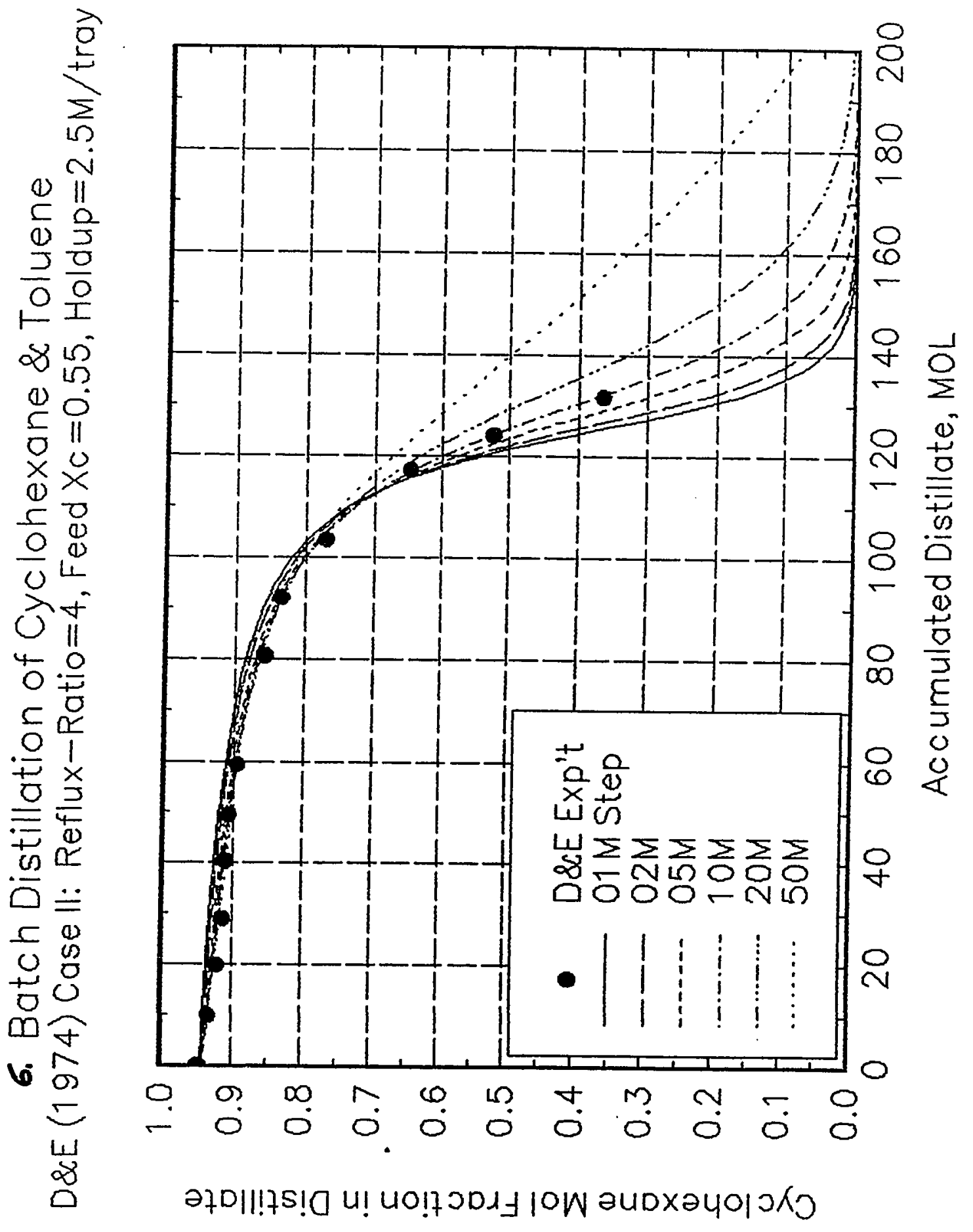




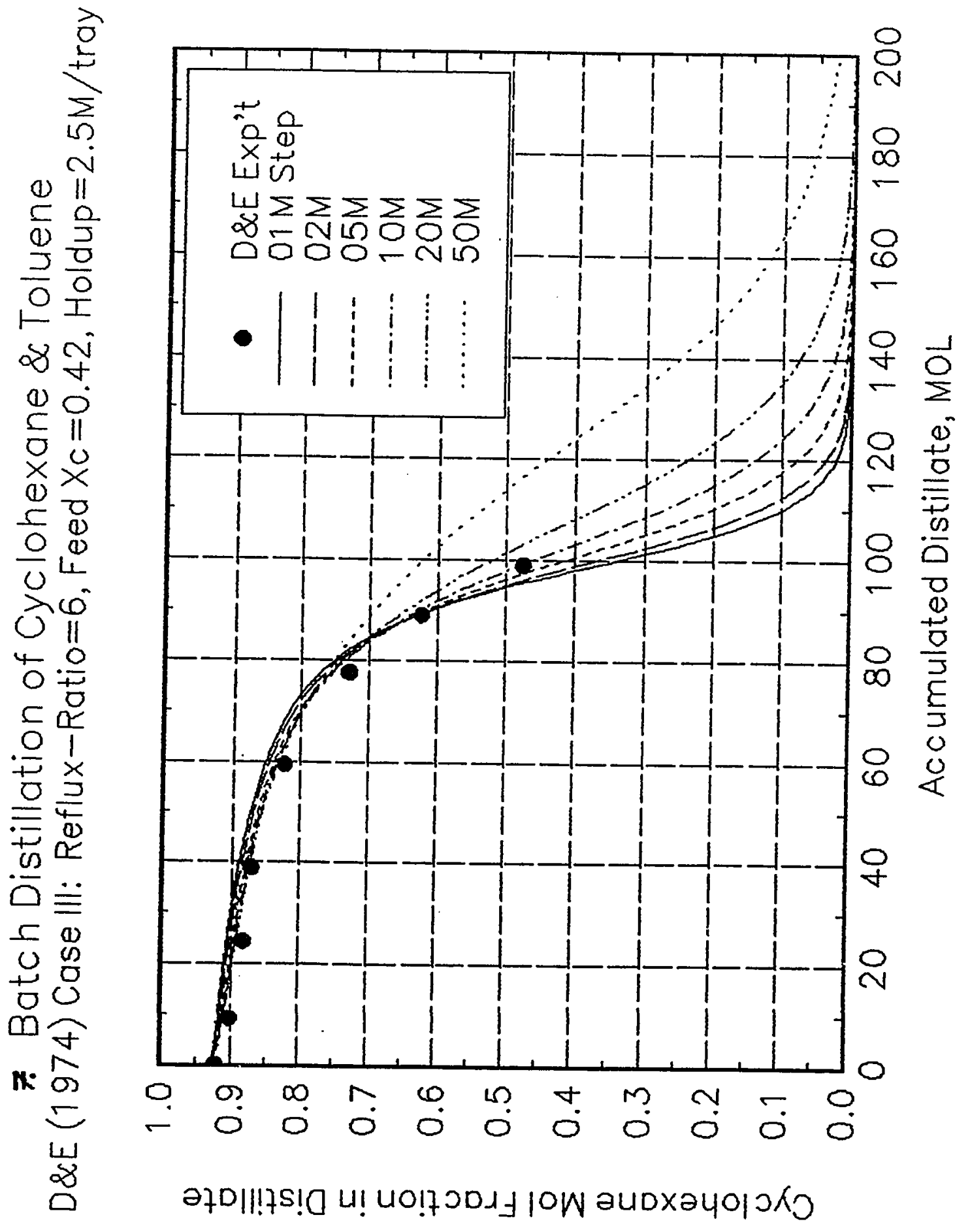




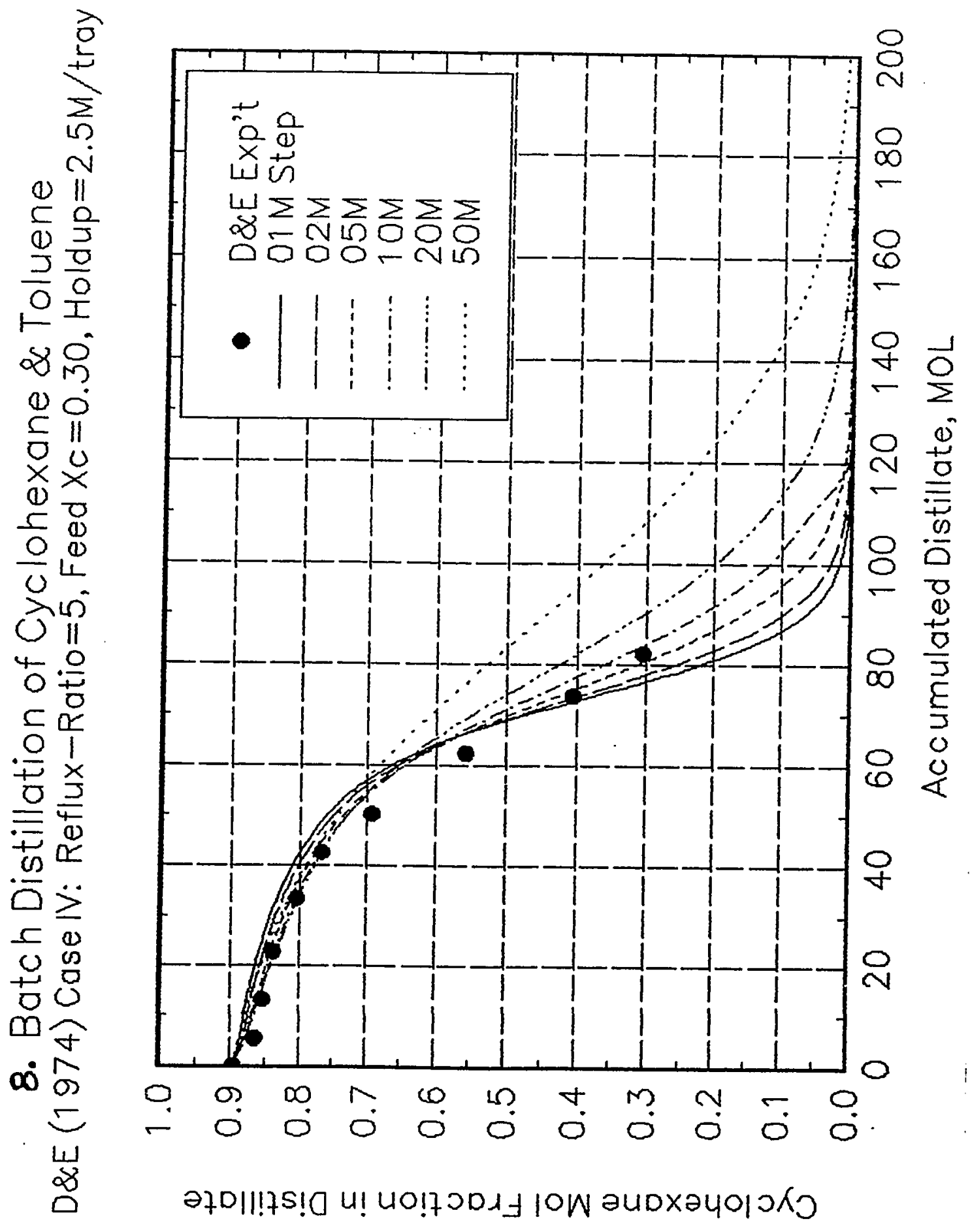




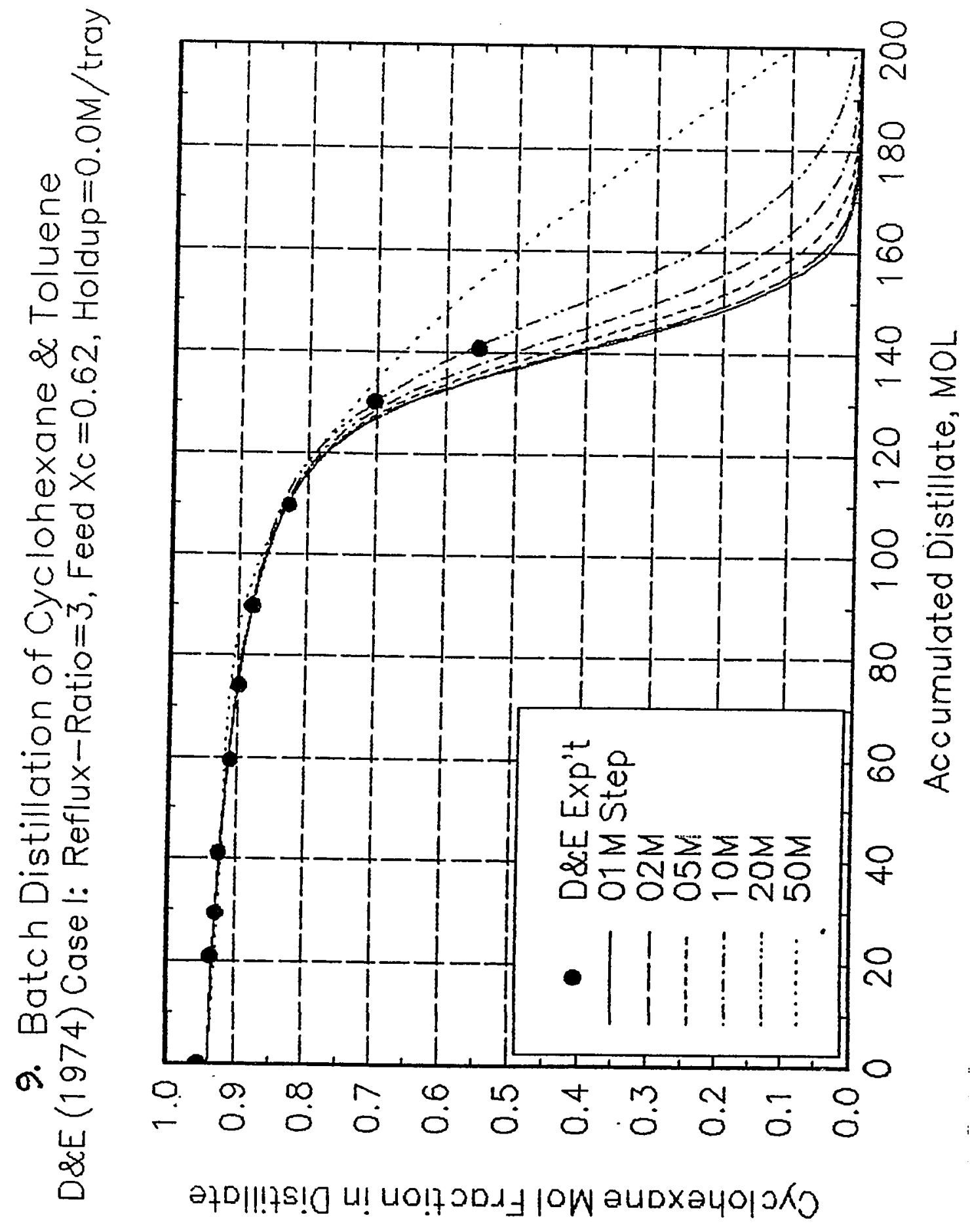




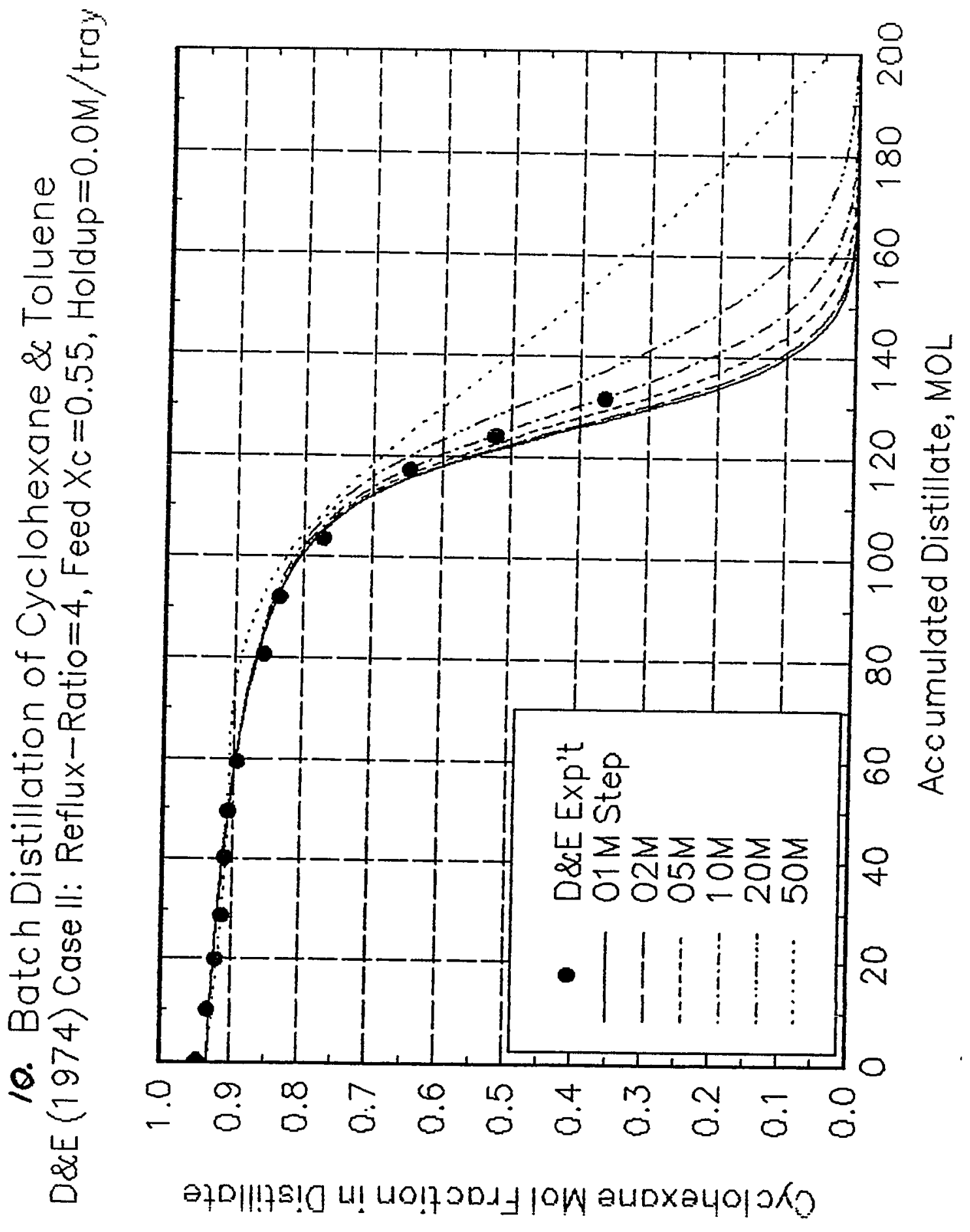




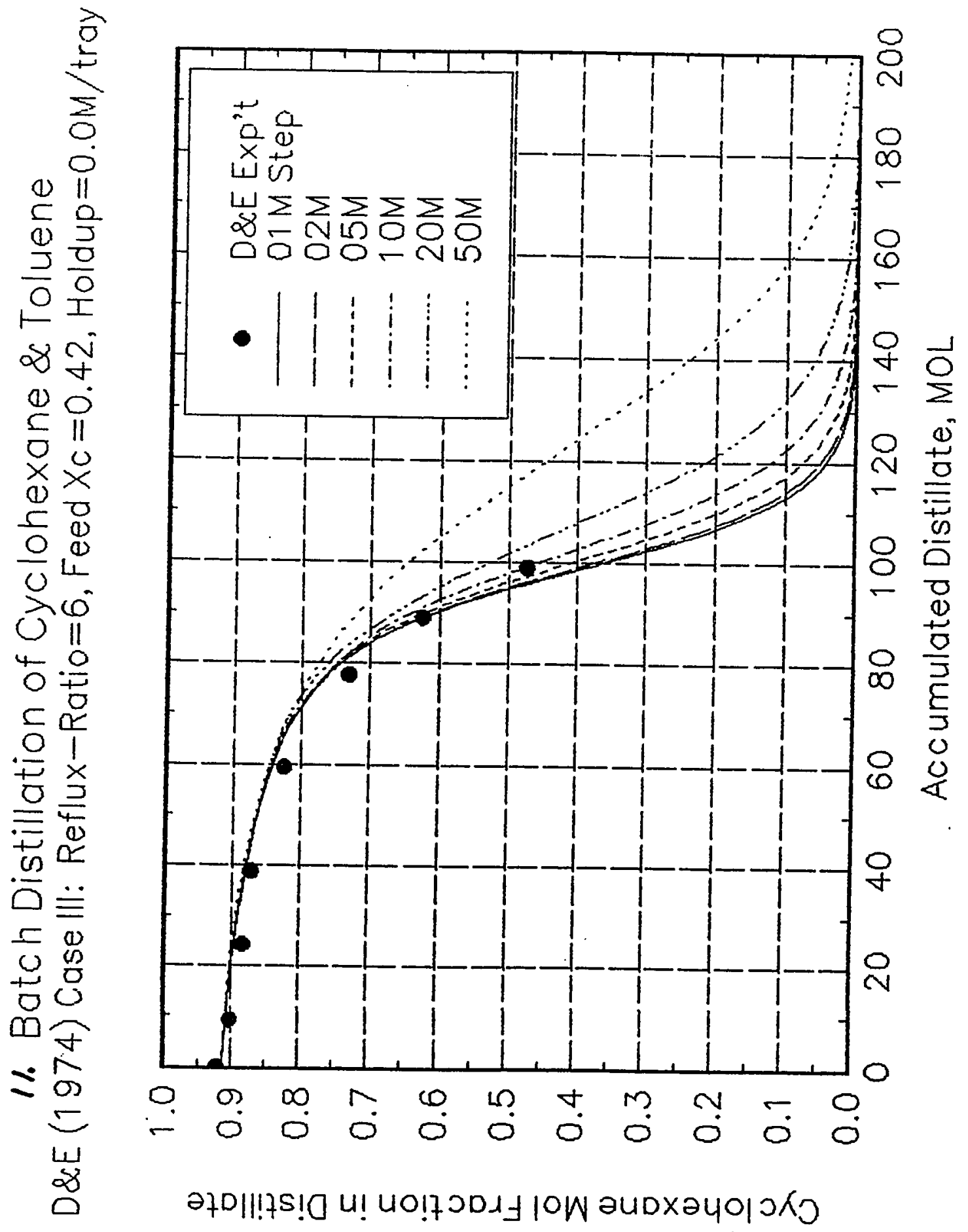




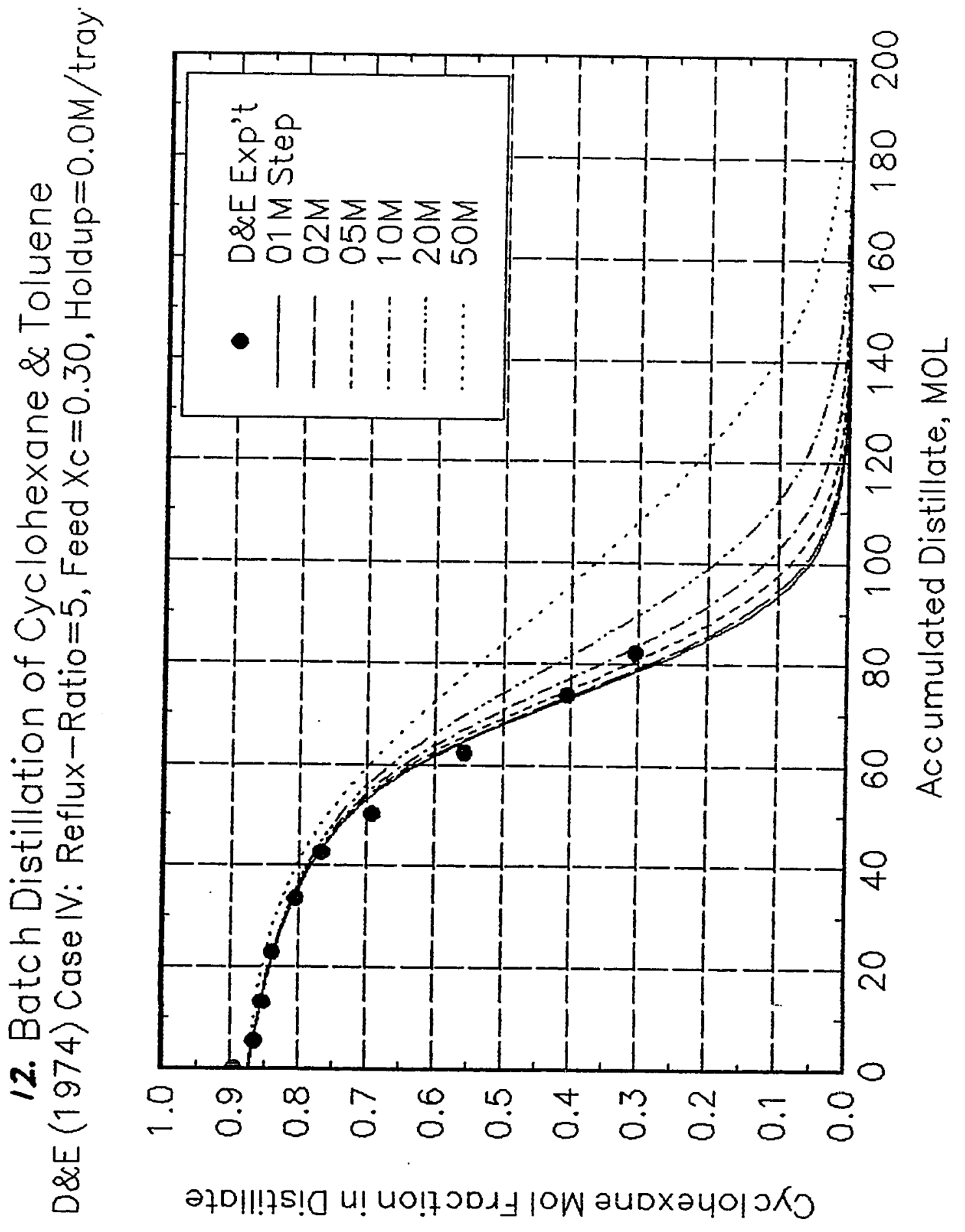




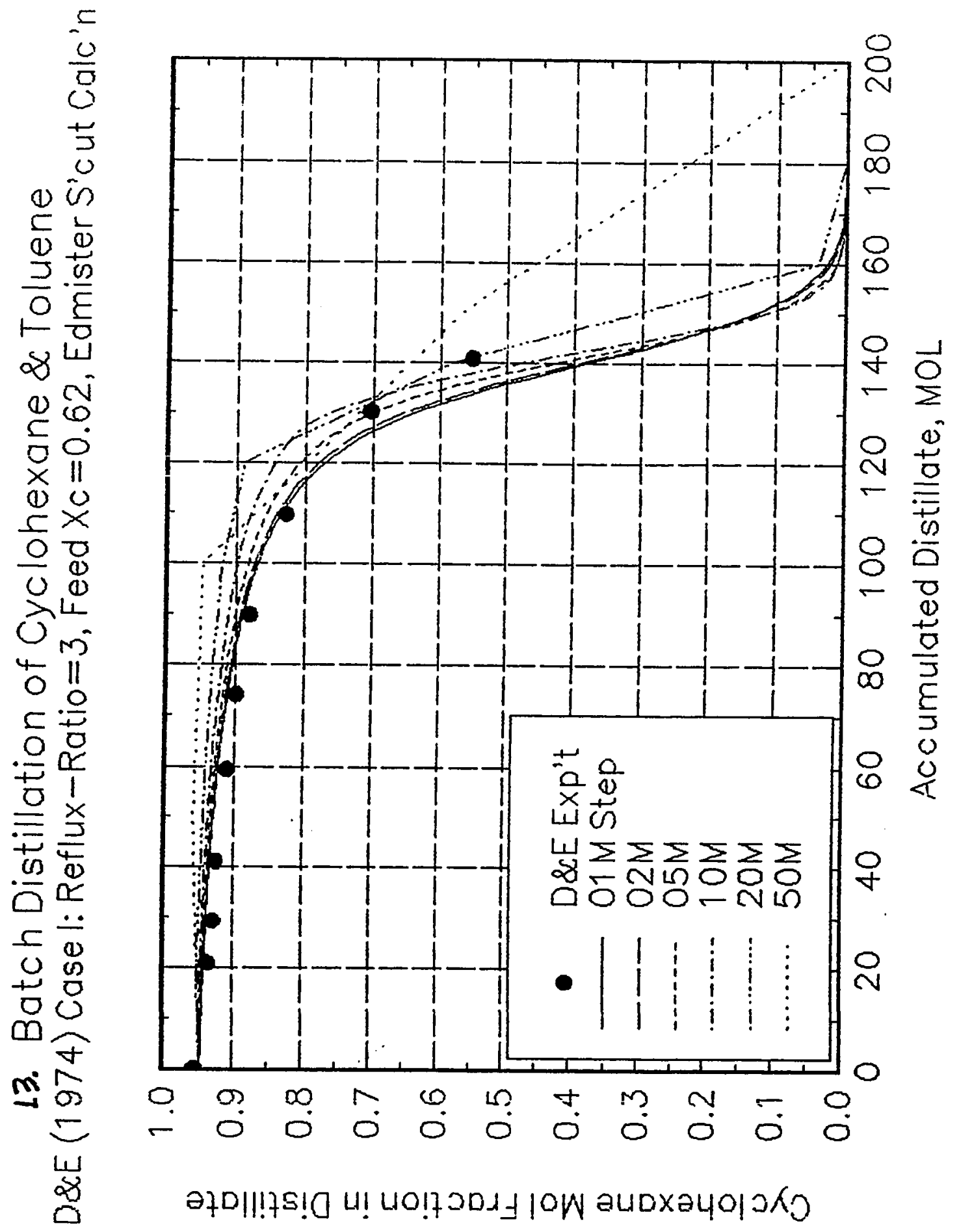




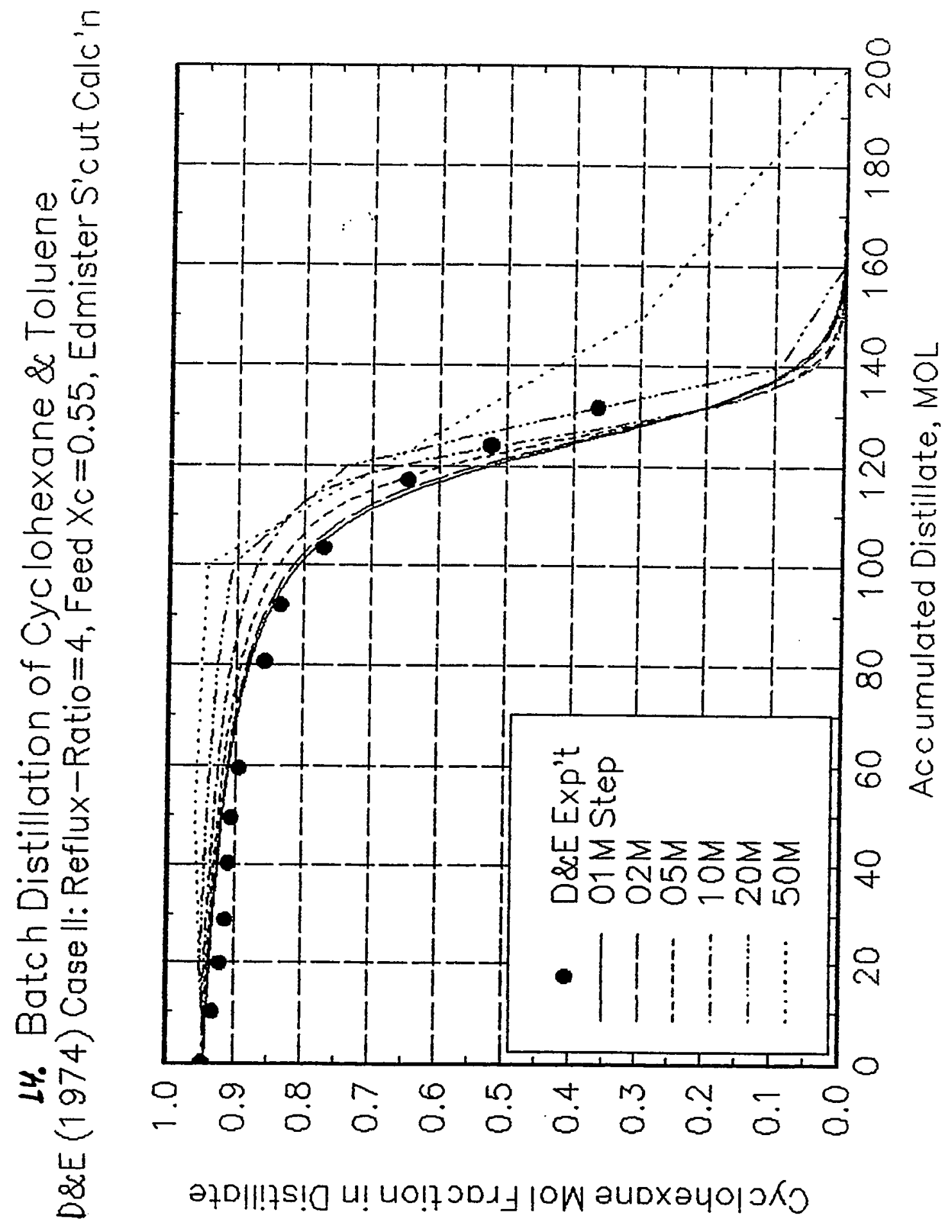




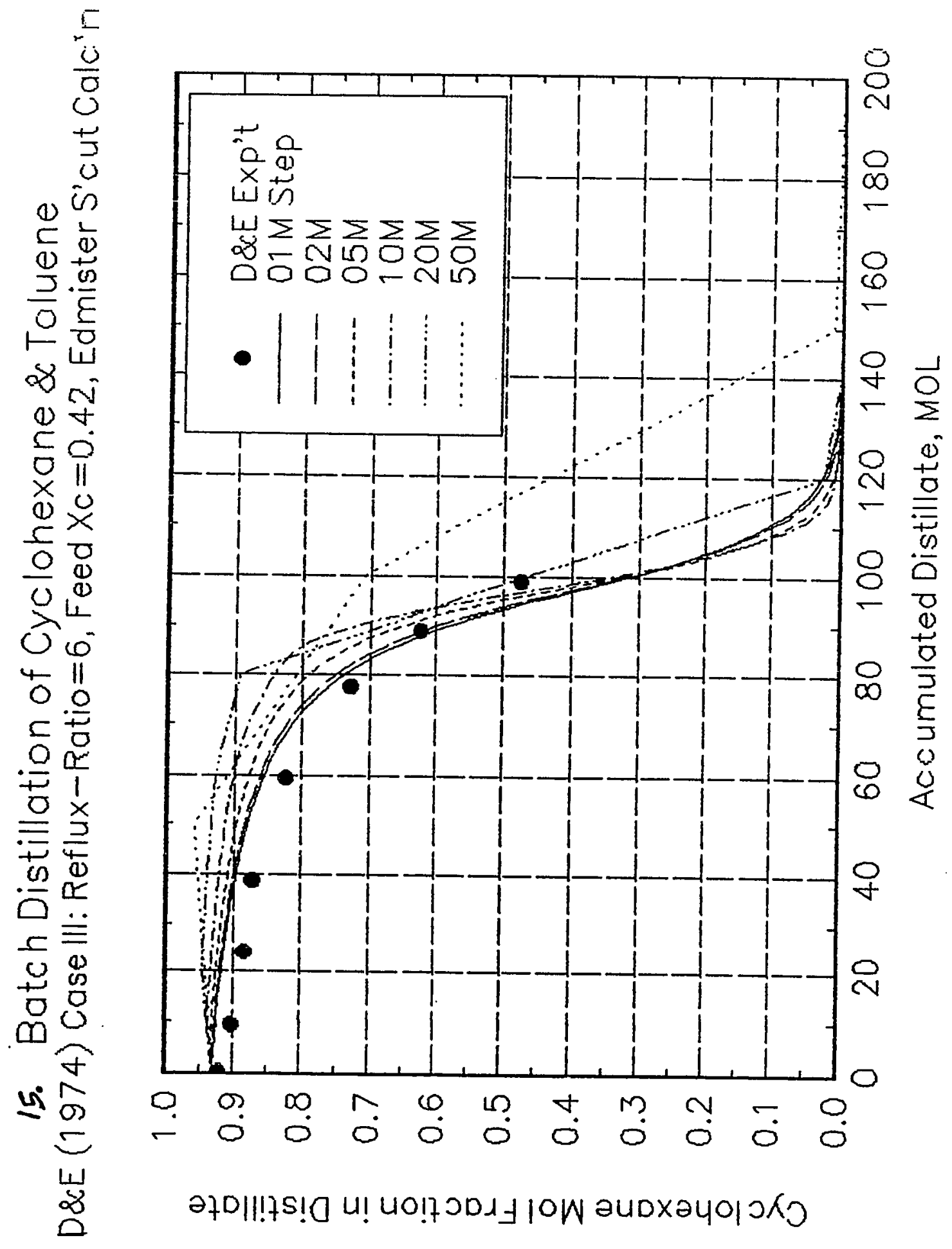




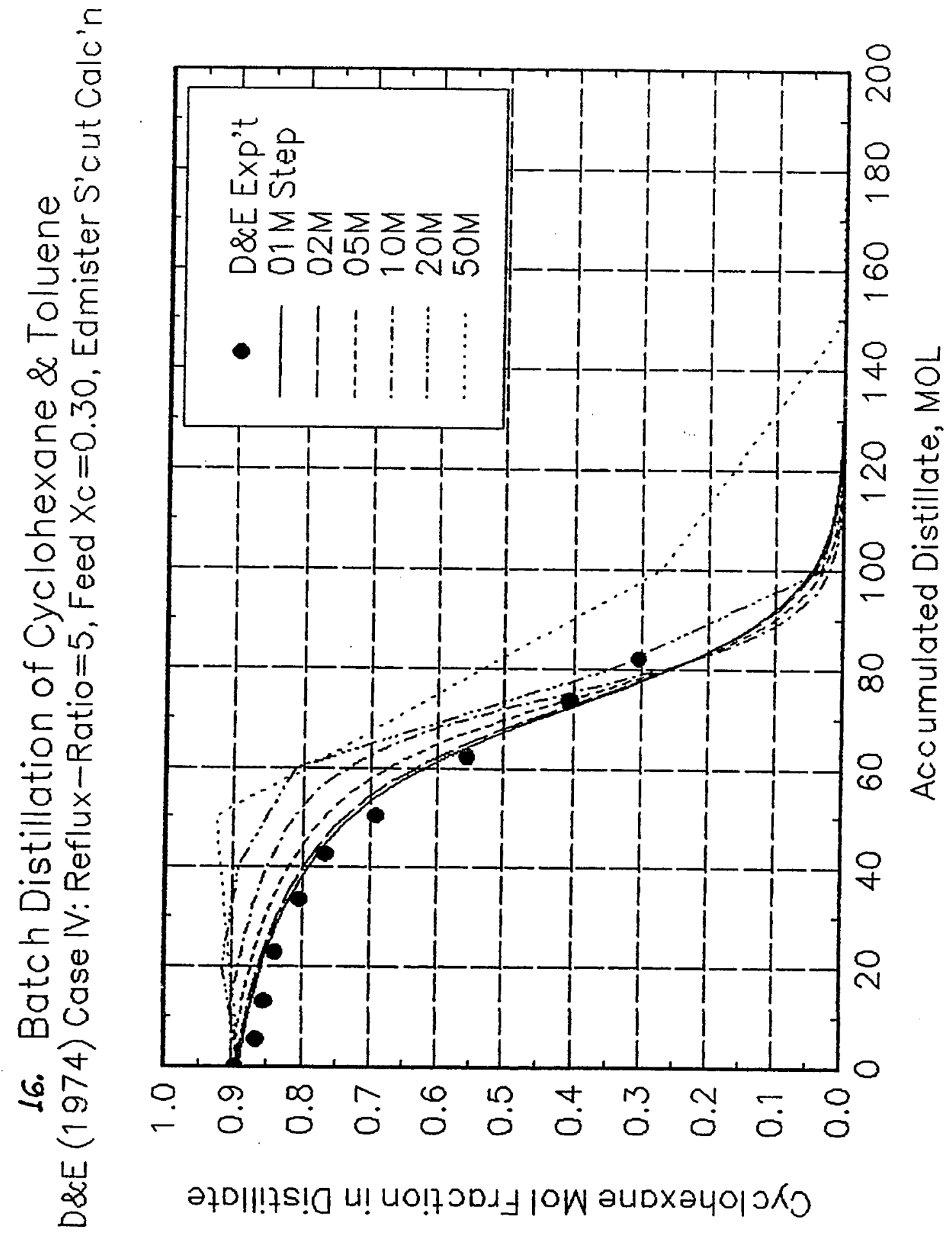




\section{REFERENCES}

Al-Tuwairn, M.S., and Luyben, W.L., "Multicomponent Batch Distillation. 3. Shortcut Design of Batch Distillation Columns", Ind. Eng. Chem. Res., Vol. 30, pp. 507-516, (1991).

Aly, S., Pibouleau, L., and Domenech, S., "Traitement par Une Methode d'Elements Finis de Modeles de Colonnes de Rectification Discontinue a Garnissage", Canadian J. of Chemical Engineering, Vol. 65, pp. 991-1003, (Dec. 1987).

Aly, S., Pibouleau, L., and Domenech, S., "Treatment of Batch, Packed Distillation by a Finite-Element Method. Part I. A Steady-State Model with Axial Dispersion", International Chemical Engineering, Vol. 30, No. 3, pp. 452-463, (July 1990a).

Aly, S., Pibouleau, L., and Domenech, S., "Treatment of Batch, Packed Distillation by a Finite-Element Method. Part II. A Steady-State Model with Axial and Radial Dispersion and a Dynamic Model", International Chemical Engineering, Vol. 30, No. 3, pp. 464-478, (July 1990b).

ASPEN PLUS Introductory Manual, Reiease 7.1, Aspen Technology Inc., Boston, MA, USA, pp. 1-1, 1-2, (1987).

Barb, D.K, and Holland, C.D., Seventh World Petroleum Congress Proc., Vol. 4, p. 31, (1967).

Barnette, D.T., and Sommerfeld, J.T., "Discrete-Event Simulation of a Sequence of Multicomponent Batch Distillation Columns", Computers Chem. Engng., Vol. 11 , No. 4, pp. 395-398, (1987).

Bernot, C., Doherty, M.F., and Malone, M.F., "Patterns of Composition Change in Multicomponent Batch Distillation", Chemical Engineering Science, Vol. 45, No. 5, pp. 1207-1221, (1990).

Bernot, C., Doherty, M.F., and Malone, M.F., "Feasibility and Separation Sequencing in Multicomponent Batch Distillation", Chemical Engineering Science, Vol. 46, No. 5/6, pp. 1311-1326, (1991).

Billet, R., Distillation Engineering, Chemical Publishing Co., New York USA, (1979). 
Bird, R.B., Stewart, W.E., and Lightfoot, E.N., Transport Phenomena, John Wiley \& Sons., New York USA, p.46, (1960).

Bogart, M.J.P., "The Design of Equipment for Fractional Batch Distillation", Trans. Am. Inst. Chem. Eng., Vol. 33, pp. 139-152, (1937).

Boston, J.F., "Inside-Out Algorithms for Multicomponent Separation Process Calculations", presented at the 178th National Meeting of the American Chemical Society, Washington D.C. USA, 1978.

Boston, J.F., Britt, H.I., Jirapongphan, S., and Shah, V.B., "An Advanced System for the Simulation of Batch Distillation Operations", in Mah, R.S.H. and Seider, W.D. (ed.), Foundation of Computer-Aided Chemical Process Design, Vol. 2 , Engineering Foundation, New York USA, pp. 203-237, (1981).

ChemCad Batch (product brochure), Chemstations Inc., Houston Texas USA, 1990.

Chiotti, O.J., and Scenna, N.J., "A Batch Distillation Module Integrated to the Process Simulator SIMBAD", Computers in Industry., Vol. 12, pp. 299-306, (1989).

Chiotti, O.J., and Iribarren, O.A., "Simplified Models for Binary Batch Distillation", Computers Chem. Engng., Vol. 15, No. 1, pp. 1-5, (1991).

Christiansen, L.J., Michelsen, M.L., and Fredenslund, Aa., "Naphtali-Sandholm Distillation for NGL Mixtures Near the Critical Region", Computers Chem. Engng., Vol. 3, pp. 535-542, (1979).

Colburn, A.P., and Stearns, R.F., "The Effect of Column Holdup on Batch Distillation", Trans. AlChE, Vol. 39, p. 291, (1941).

Cuille, P.E., and Reklaitis, G.V., "Dynamic Simulation of Multicomponent Batch Rectification with Chemical Reactions", Computers Chem. Engng., Vol. 10, pp. 389-398, (1986).

Davison, J., "Acid Reprocessing - Part I: Piranha or Sulfuric Acid Reprocessor", Solid Waste Technology., (Mar. 1992).

Distefano, G.P., "Mathematical Modeling and Numerical Integration of Multicomponent Batch Distillation Equations", AlChE J., Vol. 14, No. 1, pp. 190-199, (Jan. 1968a).

Disiefano; G.P.; "Stability of Numerical Integration Techniques", AlChE J., Vol. 14, No. 1, pp. 946-955, (Nov. 1968b). 
Diwekar, U.M., Malik, R.K., and Madhavan, K.P., "Optimal Reflux Rate Policy Determination for Multicomponent Batch Distillation Columns", Computers Chem. Engng., Vol. 11, No. 6, pp. 629-637, (1987).

Diwekar, U.M., Madhavan, K.P., and Swaney, R.E. "Optimization of Multicomponent Batch Distillation Columns", Ind. Eng. Chem. Res., Vol. 28, pp. 10111017, (1989).

Diwekar, U.M., "An Efficient Design Method For Binary, Azeotropic, Batch Distillation Columns", AlChE J., Vol. 37, No. 10, pp. 1571-1578, (Oct. 1991a).

Diwekar, U.M., and Madhavan, K.P., "Multicomponent Batch Distillation Column Design", Ind. Eng. Chem. Res., Vol. 30, pp. 713-721, (1991b).

Diwekar, U.M., and Madhavan, K.P., "BATCH-DIST: A Comprehensive Package for Simulation, Design, Optimization and Optimal Control of Multicomponent, Multifraction Batch Distillation Columns", Computers Chem. Engng., Vol. 15, No. 12, pp. 833-842, (1991c).

Diwekar, U.M., "Unified Approach to Solving Optimal Design-Control Problems in Batch Distillation", AlChE J., Vol. 38, No. 10, pp. 1551-1563, (Oct. 1992).

Domenech, S., and Enjalbert, M., "Modele Mathematique d'une Colonne de Rectification Discontinue-I. Etablissement du Modele", Chemical Engineering Science, Vol. 29, pp. 1519-1528, (1974a).

Domenech, S., Guiglion, C., and Enjalbert, M., "Modele Mathematique d'une Colonne de Rectification Discontinue-II. Exploitation Numerique", Chemical Engineering Science, Vol. 29, pp. 1529-1535, (1974b).

Domenech, S., and Enjalbert, M., "Program for Simulation of Batch Rectification as Unit Operation", Computers Chem. Engng., Vol. 5, pp. 181, (1981).

Egly, H., Ruby, V., and Seid, B., "Optimum Design and Operation of Batch Rectification Accompanied by Chemical Reaction", Computers Chem. Engng. Vol. 3, pp. 169, (1979).

"Company Cleans-up the Chips", San Francisco Examiner, pp. D1, D5, (27 Aug. 1990).

Farhat, S., Czernicki, M., Pibouleau, L., and Domenech, S., "Optimization of Multiple-Fraction Batch Distillation by Nonlinear Programming", AlChE J., Vol. 36, No. 9, pp. 1349-1360, (Sept. 1990).

Galindez, H.R., and Fredenslund, Aa., "Distillation Using Salt Effects", I.Chem.E. Symposium Series, No. 104, pp. A397-A411, (1988a). 
Galindez, H., and Fredenslund, Aa., "Simulation of Multicomponent Batch Distillation Processes", Computers Chem. Engng., Vol. 12, No. 4, pp. 281-288, (1988b).

Gallun, S.E., and Holland, C.D., "Gear's Procedure for the Simultaneous Solution of Differential and Algebraic Equations with Application to Unsteady State Distillation Problems", Computers Chem. Engng., Vol. 6, No. 3, pp. 231-244, (1982).

Gear, Numerical Initial Value Problems in Ordinary Differential Equations, Prentice-Hall, New Jersey USA, (1971).

Hitch, D.M., and Rousseau, R.W., "Simulation of Continuous-Contact Separation Processed: Multicomponent Batch Distillation", Ind. Eng. Chem. Res., Vol. 27, pp. 1466-1473, (1988).

Holland, C.D., and Liapis, A.I., Computer Methods for Solving Dynamic Separation Problems, McGraw-Hill, New York USA, (1983).

Huckaba, C.E., and Danly, D.E., "Calculation Procedures for Binary Batch Rectification", AlChE J., Vol. 6, No. 2, pp. 335-342, (1960).

Jahromi, M.F., Domenech, S., and Guiglion, C., "Modelisation d'une Colonne de Rectification Discontinue a Garnissage I. Etablissement des Modeles", The Chemical Engineering J., Vol. 25, pp. 125-135, (July 1982).

King, C.J., Separation Processes, McGraw-Hill, New York USA, p. 702, (1971).

Lapedes, D.N. (ed.), McGraw-Hill Dictionary of Scientific and Technical Terms, 2nd Ed., McGraw-Hill, New York USA, pp. 472, 637, (1978).

Lewis, W.K., J. Ind. Eng. Chem., Vol. 1, pp. 522, (1909).

Lewis, W.K., and Robinson, C.S, J. Ind. Eng. Chem., Vol. 14, pp. 481, (1922).

Logsdon, J.S., Diwekar, U.M., and Biegler, L.T., "On the Simultaneous Optimal Design and Operation of Batch Distillation Columns", Trans. IChemE, Vol. 68, Part A, pp. 434-444, (Sept. 1990).

Luyben, W.L., "Multicomponent Batch Distillation. 1. Ternary Systems with Slop Recycle", Ind. Eng. Chem. Res., Vol. 27, pp. 642-647, (1988).

Luyben, W.L., Process Modeling, Simulation, and Control for Chemical Engineers, 2nd Ed., McGraw-Hill, New York USA, (1990).

McCabe, W.L., and Thiele, E.W., "Graphical Design of Fractionating Columns", Ind. Eng. Chem., Vol. 17, No. 2, pp. 605-611, (1925). 
Meadows E.L., "Multicomponent Batch-Distillation Calculations on a Digital Computer", Chem. Eng. Prog. Symp. Ser., Vol. 59, No. 46, pp. 48-55, (1963).

Mish, F.C. (ed.), Webster's Ninth New Collegiate Dictionary, Mirriam-Webster, Mass. USA, p. 366, (1983).

Mujtaba, I.M., and Macchietto, S., "An Optimal Recycle Policy for Multicomponent Batch Distillation, European Symposium on Computer Aided Process Engineering-1", Computers Chem. Engng., Vol. 16, Suppl. T, pp. S273-S280, (1988).

Nad, M., and Spiegel, L., "Simulation of Batch Distillation by Computer and Comparison with Experiment", Proc. Use Comput. Chem. Eng. EFCE, p. 737, (1987).

Nowicki, L., and Gorak, A., "Methode zur Simulation der Periodischen Rektifikation mit Vollstandigem Rucklauf", Chem.-Ing.-Tech., Vol. 60, No. 7, pp. 555557, (1988).

Peters, W.A., J. Ind. Eng. Chem., Vol. 15, p. 402, (1923).

Pigford, R.L., Tepe, J.B., and Garrahan, C.J., "Effect of Column Holdup in Batch Distillation", Ind. Eng. Chem., Vol. 43, pp. 2592-2602, (1951).

Quintero-Marmol, E., and Luyben, W.L., "Multicomponent Batch Distillation. 2. Comparison of Alternative Slop Handling and Operating Strategies", Ind. Eng. Chem. Res., Vol. 29, pp. 1915-1921, (1990).

Quintero-Marmol, E., and Luyben, W.L., "Inferential Model-Based Control of Multicomponent Batch Distillation", Chemical Engineering Science, Vol. 40, No. 4, pp. 887-898, (1992).

Rayleigh, "On the Distillation of Binary Mixtures", Phil. Mag. IVl], Vol. 4, No. 23, pp. 521-537, (Nov. 1902).

Reuter, E., Wozny, G., and Jeromin, L., "Modeling of Multicomponent Batch Distillation Processes with Chemical Reaction and Their Control Systems", Computers Chem. Engng., Vol. 13, No. 4/5, pp. 499-510, (1989).

Riggs, J.B., An Introduction to Numerical Methods for Chemical Engineers, Texas Tech University Press, Lubbock Tx USA, pp. 144-147, (1988).

Rosanoff, M.A., Bacon, C.W., and Schulze, J.F.W., J. Am. Chem. Soc., Vol. 36, p. 2000, (1914).

Rose, A., and Welshans, L.M., "Sharpness of Separation in Batch Fractionation, Calculation of Maximum Sharpness of Separation When Holdup is Negligible", Ind. Eng. Chem., Vol. 32, No. 5, pp. 668-672, (1940a). 
Rose, A., Welshans, L.M., and Long, H.H., "Calculation of Maximum Sharpness of Separation When Holdup is Appreciable", Ind. Eng. Chem., Vol. 32, No. 5, pp. 673-675, (1940b).

Rose, A., "General Equation for a Batch Fractionation Curve", Ind. Eng. Chem., Vol. 32, No. 5, pp. 675-676, (1940c).

Rose, A., "Batch Fractionation", Ind. Eng. Chem., Vol. 33, No. 5, pp. 594-597, (1941).

Rose, A., Williams, T.J., and Prevost, C., "Holdup in Batch Distillation", Ind. Eng. Chem., Vol. 42, No. 9, pp. 1876-1879, (1950a).

Rose, A., Johnson, R.C., and Williams, T.J., "Batch Fractional Distillation", Ind. Eng. Chem., Vol. 42, No. 10, pp. 2145-2149, (1950b).

Rose, A., Johnson, R.C., and Williams, T.J., "Stepwise Plate-to-Plate Computation of Batch Distillation Curves", Ind. Eng. Chem., Vol. 43, No. 11, pp. 24592464, (1951).

Rose, A., Williams, T.J., and Kahn, H.A., "Theoretical Comparison of Laboratory Continuous and Batch Distillation", Ind. Eng. Chem., Vol. 43, No. 11, pp. 26082611, (1951).

Rose, A., and O'Brien, V.J., "Effect of Holdup-Charge Ratio in Laboratory Ternary Batch Distillation", Ind. Eng. Chem., Vol. 44, No. 6, p. 1480, (1952).

Rose, A., et al, Chem. Eng. Prog., Vol. 48, p. 549, (1952).

Rose, A., and Johnson, R.C., "The Theory of Unsteady-State Distillation", Chem. Eng. Prog., Vol. 49, No. 1, pp. 15-21, (1953).

Rose, L.M., "A Simulation Approach for the Design of Multicomponent Batch Distillation Equations", Chimia, Vol. 33, No. 2, pp. 59-65, (Feb. 1979).

Rose, L.M., Distillation Design in Practice, Elsevier Science Publishers B.V., Amsterdam Netherlands, (1985).

Ruby, V., Egly, H., and Seid, B., "Zeit-und Energieminimale Betriebsweise Diskontinuierlicher Prozesse", vt Verfahrenstechnik, Vol. 12, pp. 421-425, (1978).

Seader, J.D., and Kurtyka, Z.M., "Distillation", in Green, D.W. (ed.), Perry's Chemical Engineers' Handbook, 6th Ed., McGraw-Hill, New York USA, pp. 13-1 to $13-97,(1984)$. 
Seader, J.D., "Essential Features of a Model for Batch Distillation", Technology Seminar presented at ASPENWORLD 88 Conf. in Amsterdam Netherlands, (1318 Nov. 1988).

PRO/II BATCHSIM Users Guide, Version 3.01, Simulation Sciences Inc., Brea CA USA, (Dec. 1990).

Smoker, E.H., and Rose, A., "Graphic Determination of Batch Distillation Curves for Binary Mixtures", Trans. Am. Inst. Chem. Eng., Vol. 36, pp. 285-293, (1940).

Sundaram, S., and Evans, L.B., "Shortcut Procedure for Simulating Batch Distillation Operations", Ind. Eng. Chem. Res., Vol. 32, pp. 511-518, (1993).

van Winkle, M., Distillation, McGraw-Hill, New York USA, (1967).

Wozny, G., and Jeromin, L., "Dynamische Prozebsimulation in der Industriellen Praxis", Chem.-Ing.-Tech., Vol. 63, No. 4, 1991, pp. 313-326.

Young, S., Distillation Principles and Processes, Macmillan., London UK, (1922).

Zuiderweg, Chem. Ing. Tech., Vol. 25, p. 297, (1953). 